\title{
Westliche Moderne, Christentum und Islam. Gewalt als Anfrage an monotheistische Religionen
}

Wolfgang Palaver, Roman Siebenrock,

Dietmar Regensburger (Hg.)

The

innsbruck university press

in series 



\section{SERIES}

\section{Edition Weltordnung - Religion - Gewalt}

Editor-in-Chief: Wolfgang Palaver

Editorial Board:

Andreas Exenberger, Wilhelm Guggenberger, Peter Haider, Johann Holzner, Brigitte Mazohl, Dietmar Regensburger, Alan Scott, Roman Siebenrock, Kristina Stöckl, Claudia von Werlhof

Band 2

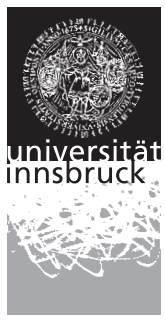


Gedruckt mit Unterstützung

der Österreichischen Forschungsgemeinschaft.

(C) 2008 innsbruck university press

1. Auflage

Alle Rechte vorbehalten.

\section{innsbruck university press}

Universität Innsbruck

ICT- Technologiepark

Technikerstraße 21 a

A-6020 Innsbruck

www.uibk.ac.at/iup

Herausgeber: Wolfgang Palaver, Roman Siebenrock, Dietmar Regensburger

Verlagsredaktion: Carmen Drolshagen, Gregor Sailer

Umschlaggestaltung: Alexander Eberharter

Lektorat: Alexander Eberharter

Satz: Dietmar Regensburger, Joseph Wang

Herstellung: Fred Steiner, Rinn

ISBN: 978-3-902571-59-5 


\section{Westliche Moderne, Christentum und Islam. Gewalt als Anfrage an monotheistische Religionen.}

Wolfgang Palaver, Roman Siebenrock, Dietmar Regensburger (Hg.)

Edition Weltordnung - Religion - Gewalt 2 



\section{Inhaltsverzeichnis}

7 Einleitung

Wolfgang Palaver, Roman A. Siebenrock

\section{Standortbestimmungen}

17 Zwischen Empire und Diaspora. Acht Fragen zum religionspolitischen Ort Europas

Otto Kallscheuer

29 Kränkung und Gewalt. Ehre und Blasphemie als Sicherheitsprobleme der Weltgesellschaft Thomas Scheffler

59 Monotheismus und Demokratie. Eine Standortbestimmung Jürgen Manemann

\section{Historische Orientierungen}

79 Heiliger Krieg und heiliger Frieden Arnold Angenendt

107 Nicolaus Cusanus, De pace fidei (1454)

Hanna-Barbara Gerl-Falkovitz.

127 Gewalt, Transzendenz und Vatergott. Patriarchatskritische Fragen zum „Anderl von Rinn“, einer Ritualmordlegende aus der Retorte Sibylle Auer 


\section{Systematische Perspektiven}

151 Im Zeichen des Opfers. Die apokalyptische Verschärfung der Weltlage als Folge des Monotheismus

Wolfgang Palaver

177 Religiöser Eifer und „reinigende“ Gewalt. Zur Dynamik kollektiver Passionen Andreas Oberprantacher

197 Das religiöse Denken und das Böse Werner W. Ernst

213 Allmacht und andere Mächte und Gewalten. Skizze eines systematisch-theologischen Projektes zum Verhältnis von Gott und politischem Diskurs in einer ,postsäkularen“ Zeit Roman A. Siebenrock

231 Legitimiert das Gottesbild des Korans Gewaltanwendung? Karl Prenner

\section{Problemfelder der Praxis}

253 Voraussetzungen und Stolpersteine für den interreligiösen Dialog. Eine Praxisbeobachtung aus christlicher Sicht in Österreich Elisabeth Dörler

257 Gewalterfahrungen muslimischer Kinder und Stellung der Gewalt im islamischen Religionsunterricht (IRU)

Ednan Aslan

267 Welchen Frieden schafft der Religionsunterricht? Schulische Gewalt und Friedensfähigkeit als Herausforderung des katholischen Religionsunterrichts an öffentlichen Schulen Matthias Scharer

289 Die Autorinnen und Autoren 


\section{Einleitung}

Wolfgang Palaver, Roman A. Siebenrock

Obwohl Religion schon als museales Studienobjekt der Vergangenheit abgeschrieben schien, dauerte es nur wenige Jahrzehnte, bis die entsprechende Säkularisierungsthese selbst obsolet und die Rückkehr von Religion in die Politik allgemein zur Kenntnis genommen wurde. Gewaltphänomene spielten für diese Perspektivenumkehr in der Öffentlichkeit eine besondere Rolle. Die Iranische Revolution im Jahre 1979 war ein erstes dramatisches Ereignis, das nicht mehr wirklich in die damals vorherrschenden Denkschemata passte. Kaum bemerkt wurde bei uns in diesen Jahren die wachsende Bedeutung der MoralMajority-Bewegung vornehmlich evangelikaler Gruppen in den USA, die seit der Präsidentschaft von Ronald Reagan eine bis heute bestimmende Bedeutung gewinnen konnten. ${ }^{1}$ Auch viele religiösnationale Konflikte in Europa, die nach dem Ende des Kalten Krieges offen ausbrachen, zeigten, dass auch in der moderne Welt mit Religion zu rechnen ist. ${ }^{2}$ Mit den Terroranschlägen des 11 . September 2001 wurde die - durchaus brisante - Rückkehr von Religion in die Politik Allgemeingut. Es wäre allerdings falsch, würden wir nur auf die negativen Phänomene wie Fundamentalismus und Terrorismus verweisen, wenn wir von der Rückkehr des Religiösen in die Politik sprechen. Parallel zum Erstarken des Islam in den 1970erJahren lässt sich beispielsweise auch in Europa eine Tendenz der 
„Rechristianisierung“ beobachten. ${ }^{3}$ So war der Zusammenbruch des real existierenden Sozialismus ganz wesentlich von religiösen Entwicklungen mitbestimmt. Mit der Wahl von Johannes Paul II. zum Papst im Jahre 1978 wurde beispielsweise eine religiös-politische Entwicklung in Polen gestärkt, die über den Aufbau der Gewerkschaftsbewegung Solidarnosc schließlich auch zum Sturz des Kommunismus beitrug.

Eine vertiefte und reflektierte Auseinandersetzung mit dem Verhältnis von Religion und Politik ist heute eine Notwendigkeit geworden. Diplomaten, Politiker und alle gesellschaftlich engagierten oder interessierten Menschen können ohne eine grundsätzliche Kenntnis religiöser Positionen und Haltungen die heutige Welt nicht wirklich verstehen. Der deutsche Religionspolitologe Claus Bärsch hat diesen Zusammenhang auf eine treffende Formel gebracht: „Wer Religion verkennt, erkennt Politik nicht. " ${ }^{4}$ Die ehemalige amerikanische Außenministerin Madeleine Albright hat diese Problematik verstanden und fordert in ihrem 2006 erschienenen Buch Der Mächtige und Allmächtige, dass Politiker und Diplomaten heute eine gründliche Einführung in religiöse und spirituelle Fragestellungen brauchen. Dabei ist hervorzuheben, dass Albright keine einseitige Sicht von Religion vertritt, sondern ausdrücklich und überzeugend auf die Ambivalenz des Religiösen hinweist. Religion ist ihrer Meinung nach einerseits ,,vermutlich die wichtigste Kraft bei der Ausgestaltung des menschlichen Gewissens“, andererseits aber zugleich auch „ein ewiger Quell von Hass und Konflikt“. 5

Im Herbst 2005 wurde auf Initiative der interfakultären Forschungsplattform der Universität Innsbruck „Weltordnung - Religion - Gewalt" von der Österreichischen Forschungsgemeinschaft eine österreichweite Arbeitsgemeinschaft zum Thema „Politik, Religion, Gewalt“ eingerichtet. $^{6}$ Ziel dieser Arbeitsgemeinschaft ist es, ein vertieftes Verständnis der Problematik von Politik, Religion und Gewalt zu erarbeiten und gleichzeitig zu klären, wie ein friedliches

3 Kepel (1991), 82.

4 Bärsch/Berghoff/Sonnenschmidt (2005).

5 Albright (2006), 84.

6 Dabei konnte auf mehrjährige Vorarbeiten des von Raymund Schwager initiierten theologischen Forschungsschwerpunktes „Religion - Gewalt - Kommunikation - Weltordnung“ zurückgegriffen werden. Siehe dazu Schwager/Niewiadomski (2003) und Siebenrock/Sandler (2005). 
Zusammenleben in unserer gegenwärtigen Welt gefördert werden kann. Eine erste Tagung im Frühjahr 2006 widmete sich diesem Thema am Beispiel des Films. Der Band des entsprechenden Symposiums ist gerade erschienen. ${ }^{7}$ Inzwischen wurde von den Mitgliedern der Arbeitsgemeinschaft ein Forschungsprogramm erarbeitet, das in den Jahren 2007 bis 2012 durchgeführt werden soll. Ziel dieses Forschungsprogramms ist die interdisziplinäre Diskussion und kritische Befragung verschiedener Rahmentheorien zum Verhältnis Politik, Religion und Gewalt, wobei die konkreten politischen und sozialen Fragen des weltanschaulich und religiös pluralen Zusammenlebens in der Europäischen Union - insbesondere auch in Österreich - besonders berücksichtigt werden sollen. Der besondere Fokus auf die europäische Situation lässt sich leicht erklären. Europa steht heute vor der dringenden Aufgabe, Millionen von Mitbürger(inne)n muslimischen Glaubens ein Leben in einem Europa zu ermöglichen, in dem sie sich als Glaubende heimisch fühlen können. Der britische Historiker Timothy Garton Ash spricht zu Recht davon, dass es diesbezüglich ,bereits fünf Minuten vor zwölf“" sei. $^{8}$ Gelingt Europa in diese Richtung ein guter Weg, so wird das wohl auch das Zusammenleben der Kulturen und Religionen auf weltweiter Ebene positiv beeinflussen. Scheitert Europa an dieser Herausforderung, so wird sich die gegenwärtige Krise unserer Welt verschärfen. Allzu leicht wird heute oft übersehen, dass gerade der dschihadistische Terrorismus wesentlich von Europa ausgegangen ist. Führende Attentäter des 11. September wurden während ihrer Zeit in Europa radikalisiert. Und während in den USA Ende 2007 nur 60 Menschen wegen terroristischer Aktivitäten inhaftiert waren, belief sich die entsprechende Zahl für Europa auf 2.300. ${ }^{9}$ Umgekehrt zeigt aber das Beispiel der Europäischen Union auch, wie gerade aus spirituellen Wurzeln Frieden entstehen kann. Nicht wenige von den politischen Vätern der Union - wie Robert Schuman, Alcide De Gasperi und Konrad Adenauer - waren gläubige Menschen und haben eines der interessantesten Friedensprojekte der Moderne auf den Weg gebracht. ${ }^{10}$ In den nächsten Jahren soll im Rahmen des Forschungsprogramms der Arbeitsgemeinschaft all diesen Fragen und Zusam-

\footnotetext{
7 Regensburger/Larcher (2008).

8 Ash (2007a), 53.

9 Ruthven (2008), 34.

10 Judt (2005), 157-158.
} 
menhängen aus der Sicht verschiedener Disziplinen, mit unterschiedlichen methodischen Zugängen und unter wechselnden weltanschaulichen Voraussetzungen nachgegangen werden.

Der erste Schritt dieses Forschungsprogramms erfolgte im Juni 2007, indem wir die aktuelle Debatte über den Monotheismus und dessen Verhältnis zur Gewalt zum Anlass unserer Gespräche und Diskussionen nahmen. Gerade der Monotheismus rückte im Zusammenhang mit den jüngsten Terroranschlägen ins Zentrum der Kritik. Richard Dawkins scharfer atheistischer Angriff auf die Offenbarungsreligionen verdankt sich beispielsweise ausdrücklich diesem Zusammenhang. ${ }^{11} \mathrm{Im}$ deutschen Sprachraum haben vor allem die Thesen des Ägyptologen Jan Assmann in den letzten Jahren die Diskussion über den Monotheismus geprägt. ${ }^{12}$ Der vorliegende Sammelband greift aber nicht direkt in diese von Assmann angestoBene Debatte ein - dazu liegen schon zahlreiche andere Publikationen vor $^{13}$-, sondern erörtert diese Frage im Rahmen der aktuellen religionspolitischen Herausforderung in Europa. Es geht in Europa heute darum, ein neues Verständnis von Säkularität zu entwickeln, das einerseits die Errungenschaften der Moderne - wie Religionsfreiheit oder die Trennung von Religion bzw. Kirche und Staat bewahrt und andererseits gläubigen Menschen die Möglichkeit gibt, ihren Glaubensüberzeugungen auch öffentlich treu zu bleiben. Insbesondere Muslime - aber nicht nur - müssen in Europa die Möglichkeit finden, öffentlichen Glauben und Säkularität miteinander verbinden zu können. Wir stimmen Timothy Garton Ash zu, dass es eine ganz unrealistische Politik wäre, von Muslimen die Absage an ihre Religion zu verlangen, um aus ihnen gute Europäer zu machen. „Wenn wir ihnen die Botschaft vermitteln, dass sie ihre Religion ablegen müssen, um Europäer zu werden, dann werden sie eben keine Europäer sein wollen."14 Im vorliegenden Band wird das Verhältnis von Monotheismus und Gewalt vor allem im Blick auf die Frage der Säkularisierung in Europa und unter besonderer Berücksichtung von Christentum und Islam diskutiert.

Die Beiträge in diesem Band gehen dieses Problemfeld unter vier verschiedenen Gesichtspunkten an. Im ersten Teil sind aktuelle 
Standortbestimmungen zu finden: mit großer historisch-politischer Perspektive bei Otto Kallscheuer, als Analyse des 2005 in Dänemark beginnenden Karikaturenstreits bei Thomas Scheffler, der seinen Beitrag unter dem Eindruck immer wieder ausbrechender Gewalt in Beirut geschrieben hat, und bei Jürgen Manemann, der das Verhältnis von Demokratie und Monotheismus aufgreift. Drei historische Orientierungen vertiefen die Fragestellung. Arnold Angenendt beleuchtet vornehmlich die christlich begründete Geschichte des Heiligen Krieges. Hannah-Barbara Gerl-Falkovitz, widmet sich der singulären Friedensvision des Nikolaus von Kues. Sibylle Auer nähert sich aus patriarchatskritischer Sicht der lokalen Ritualmordlegende des Anderle von Rinn und dem damit einhergehenden Antisemitismus. Auch die systematischen Perspektiven unterstreichen die Vielfalt möglicher Gesichtspunkte. Wolfgang Palaver weist unter dem Gesichtspunkt der apokalyptischen Verschärfung auf die ambivalente Wirkungsgeschichte des Christentums hin. Während Andreas Oberprantacher die vielfältige Präsenz des Religiösen in den Konfliktfeldern politischer Auseinandersetzungen nachweist, erörtert $W$ erner Ernst die anthropologischen und epistemologischen Voraussetzungen des Feldes von Politik und Religion. Roman Siebenrock skizziert ein systematisch-theologisches Projekt für den Forschungsprozess, der den verwickelten Verhältnissen von Allmacht Gottes und menschlichen Machtvorstellungen nachgeht. Karl Prenner bringt Klärungen in den Diskurs um die Gewaltfrage im islamischen Gottesbild.

Der Arbeitsprozess der Arbeitsgemeinschaft sieht in der Orientierung an verschiedenen Praxisfeldern nicht bloß eine Anwendung von Theorien, sondern vielmehr den primären Bezugspunkt der Analysen. So treten im Teil IV (,Problemfelder der Praxis“), wie im ersten Teil, aktuelle Situationsblitzlichter hervor. Elisabeth Dörler beleuchtet Problemzonen interkulturellen Zusammenlebens von Christen und Moslems am Beispiel des österreichischen Bundeslandes Vorarlberg. Fragen des Religionsunterrichts schließen diesen Band ab. Ednan Aslan analysiert das Thema Gewalt im islamischen Religionsunterricht auf dem Hintergrund unterschiedlicher Gewalterfahrungen von muslimischen Kindern und Jugendlichen. Matthias Scharer wiederum setzt sich sehr grundsätzlich mit den Themen Gewalt und Frieden im Kontext des Religionsunterrichts auseinander.

Unser Band diskutiert die hochbrisanten Zusammenhänge von Religion, Gewalt und Frieden exemplarisch. In den unterschiedli- 
chen Beiträgen und Perspektiven wird überaus deutlich, dass das Thema Religion aus dem öffentlich-politischen Diskurs nicht auszugrenzen ist. Wehe jenen, die es verdrängen! Andererseits skizzieren bereits im ersten Schritt unserer Forschungsentwicklung einige Autorinnen und Autoren auch jene Formen religiöser Präsenz, die als gefährlich eingestuft werden können. Bemerkenswerter aber scheint uns zu sein, dass sich auch Modelle und Beispiele abzeichnen, wie religiöse Traditionen in der tief greifenden Krise der Gegenwart große Bedeutung erlangen können.

Wir danken der Österreichischen Forschungsgemeinschaft für die hilfreiche Unterstützung dieses Forschungsprogramms und unserem Wiener Kollegen Rüdiger Loblker für die Hilfe bei der Suche nach geeigneten Referent(inn)en. Dank gebührt auch Alexander Eberbarter für das sorgfältige Lektorat sowie Dietmar Regensburger und Joseph Wang für den Satz und die redaktionelle Betreuung.

\section{Literatur}

Albright, Madeleine Korbel (2006): Der Mächtige und der Allmächtige. Gott, Amerika und die Weltpolitik. München: Droemer.

Ash, Timothy Garton (2007a): „Der Islam in Europa“, in: Chervel, Thierry/Seeliger, Anja, Hg.: Islam in Europa. Eine internationale Debatte. Frankfurt/M.: Suhrkamp, 30-54.

Ash, Timothy Garton (2007b): „Lieber Pascal als Pascal Bruckner“, in: Chervel, Thierry/Seeliger, Anja, Hg.: Islam in Europa. Eine internationale Debatte. Frankfurt/M.: Suhrkamp, 82-87.

Assmann, Jan (2002): Herrschaft und Heil. Politische Theologie in Altägypten, Israel und Europa. Frankfurt/M.: Fischer Taschenbuch Verlag.

Assmann, Jan (2003a): Die Mosaische Unterscheidung oder der Preis des Monotheismus. München: Carl Hanser Verlag.

Assmann, Jan (42003b): Moses der Ägypter. Entrifferung einer Gedächtnisspur. Frankfurt/M.: Fischer Taschenbuch Verlag.

Assmann, Jan (2006): Monotheismus und die Sprache der Gewalt. Wien: Picus Verlag.

Bärsch, Claus-Ekkehard/Berghoff, Peter/Sonnenschmidt, Reinhard, Hg. (2005): ,Wer Religion verkennt, erkennt Politik nicht.' Perspektiven der Religionspolitologie. Würzburg: Königshausen \& Neumann.

Dawkins, Richard (2006): The God Delusion. Boston: Houghton Mifflin Company.

Düringer, Hermann, Hg. (2004): Monotheismus. Eine Quelle der Gewalt? Frankfurt/M.: Haag und Herchen. 
Judt, Tony (2005): Postwar: A History of Europe since 1945. New York/NY: Penguin Press.

Kepel, Gilles (1991): Die Rache Gottes. Radikale Moslems, Christen und Juden auf dem Vormarsch. München: Piper.

Manemann, Jürgen, Hg. (2003): Monotheismus. Münster: LIT.

Palaver, Wolfgang (21988): „Amerikanischer Fundamentalismus: Zur Problematik der Vermischung von Religion und Politik", in: Niewiadomski, Józef, Hg.: Eindeutige Antworten? Fundamentalistische Versuchung in Religion und Gesellschaft. Thaur: Österreichischer Kulturverlag, 41-62.

Palaver, Wolfgang (1994): „Die religiöse Dimension des Nationalismus“, in: Theologisch-praktische Quartalschrift 142 (3), 225-233.

Regensburger, Dietmar/Larcher, Gerhard, Hg. (2008): Paradise now!?: Politik - Religion - Gewalt im Spiegel des Films. Marburg: Schüren Verlag.

Ruthven, Malise (2008): „The Rise of the Muslim Terrorists“, in: New York Review of Books 55 (9): 33-36.

Schwager, Raymund/Niewiadomski, Józef, Hg. (2003): Religion eræeugt Gewalt - Einspruch! Innsbrucker Forschungsprojekt „Religion - Gewalt - Kommunikation - Weltordnung". Münster: LIT.

Siebenrock, Roman/Sandler, Willibald, Hg. (2005): Kirche als universales Zeichen. In memoriam Raymund Schwager SJ. Wien: LIT.

Walter, Peter, Hg. (2005): Das Gewaltpotential des Monotheismus und der dreieine Gott. Freiburg: Herder. 



\section{Standortbestimmungen}





\section{Zwischen Empire und Diaspora. Acht Fragen zum religionspolitischen Ort Europas*}

Otto Kallscheuer

\section{Müssen monotheistische Religionen zivilisiert werden?}

Gewiss müssen sie das - aber nicht sie allein. Dass religiöse Wahrheiten einer institutionellen Zähmung bedürfen, galt bereits für die Stiftungsmythen göttlicher dike, die wir aus den großen griechischen Tragödien kennen. Vermutlich müssen alle kollektive Identität stiftenden Mythen im Wortsinne zivilisiert - sprich: in eine civitas eingebaut - werden, wenn sie zur Stabilisierung, Normierung oder Normalisierung (Michel Foucault) der Lebensformen eines Gemeinwesens taugen sollen.

Doch ist der Gegensatz von Herrschaft und Heil (Jan Assmann) keine transhistorische Konstante aller Religionen. Der Konflikt zwischen Gottesdienst und Polisverehrung ist vielmehr eine recht spezifische Konsequenz des Monotheismus: eine mögliche, zugespitzte, potentiell revolutionäre, konfliktträchtige Konsequenz neben anderen möglichen. Welche Möglichkeiten sich verwirklichten, das hängt natürlich nicht allein vom religiösen Code ab, sondern auch von den Formen seiner Institutionalisierung, von den sozialen Interessen und Gruppen, die sich mit ihm verbunden (oder identifiziert) haben, von den verfügbaren (und ,anschlussfähigen") Diskursen und Dispositi-

* Im folgenden Text, meinem Einleitungsvortrag zur Innsbrucker Tagung „Westliche Moderne, Christentum und Islam“, greife ich auf eigene Veröffentlichungen zurück, in denen sich weitere Literaturhinweise finden: Vgl. Kallscheuer (2003), Kallscheuer (2005), Kallscheuer (2006a) sowie die letzten Kapitel von Kallscheuer (2006b). Auf Fußnoten habe ich daher hier verzichtet. 
ven usw. All diese Fragen lassen sich nicht aus dem ,Wesen“ des Monotheismus deduzieren, sondern nur durch historische Sozialwissenschaft beantworten.

So setzte sich z.B. im Christentum etwa im dritten und vierten Jahrhundert eine keineswegs auf die biblische Offenbarung zurückgehende Reichstheologie durch (Eusebius, Orosius): Sie berief sich auf die Analogie der innerweltlichen Herrschaft des Imperators mit der kosmischen Alleinherrschaft des Schöpfergottes. Als sie dann allerdings mit der machtpolitischen Krise des Imperiums selbst in die Krise geriet, wurde sie im Westen durch ein anderes Paradigma ersetzt oder ergänzt (Augustins Lehre der beiden civitates, Gelasius' These von den beiden Schwertern).

Es ist ein vielleicht kontingentes historisches Faktum, dass diese monokratische Tradition nur für die Reiche des östlichen Mediterrans bestimmend blieb: sowohl für die byzantinische und postbyzantinische politische Kultur einer „Symphonie“ von Kaisertum und Reichskirche (bzw. dann später die orthodoxen Nationalkirchen) als auch für das osmanische Imperium - das sich in seiner Hochzeit durchaus als ordnungspolitischer Nachfolger des byzantinischen „Rom“ begriff. Allzu radikale Ansprüchlichkeiten des universalistischen Ein-Gott-Glaubens, die immer wieder in mystischen Mönchsoder Laienbewegungen aufbrachen, von russischen Altgläubigen bis $\mathrm{zu}$ anatolischen Sufi-Bruderschaften, wurden im Imperium durch machtpolitische Stabilitätsroutinen gezähmt und an soziale/ethnischpolitische Kompromisse angepasst.

Im lateinischen Westen hingegen kommt es im zweiten Jahrtausend zunächst zum strukturellen Dauerkonflikt zwischen Imperium und Sacerdotium sowie daher später zu Sphären- und Gewaltenteilungen der die beiden civitates vertretenden Institutionen. Und diese Geschichte ist auch nach der in der westlichen Christenheit ausgefochtenen Trennung von Kirche(n) und Staat(en) - einer im Westen entstandenen, aber international ausbaufähigen (und anpassungsbedürftigen) institutionellen Erfindung der Zivilisierung des Religiösen - noch keineswegs an ihr Ende gekommen.

\section{Gibt es ein politisches Spezifikum des Monotheismus?}

Ja - und dieses heißt: Mission. Der monotheistische Missionsimperativ ist transpolitisch (und wurde häufig antipolitisch verstanden); so stiftet er eine alle Poleis - alle Routinen und Institutionen politischer 
Herrschaft und Stabilität - übergreifende Geltungssphäre der Heilsbotschaft. Durch diese Globalisierung des ,Geistes‘ gehört der Monotheismus zur Geschichte des „Fortschritts im Bewußtsein der Freiheit" (Georg Wilhelm Friedrich Hegel).

Im universalistischen Monotheismus transzendiert das ad Deum finalisierte oder a Deo erhoffte (aus SEiner Rechtleitung fließende oder durch SEine Gnade geschenkte) Heil nicht nur diese oder jene Polis, sondern jede partikulare civitas. Im Gegensatz zu den Poliskulten der polytheistischen Antike - oder der ,zivilen“ oder BürgerReligionen des modernen Nationalismus (Jean-Jacques Rousseau) sind nämlich die monotheistischen Heilsbotschaften bereits ihrem Anspruch nach global: Sie betreffen alle gentes und nicht nur die eigene Polis oder Nation, ,außerhalb derer [für die Anhänger ihrer religion civile] alles ungläubig, fremd und barbarisch ist" (Rousseau). Darum müssen gerade missionarische, ihre Heilsbotschaft aktiv globalisierende Religionen zivilisiert werden. Besser: sie müssen sich selbst zivilisieren - dadurch, dass sie die Institutionen ihrer ureigenen, ,inneren“ oder ,geistigen“ civitas von den Mächten und Vormächten der Welt unterscheiden und sich ihnen gegenüber behaupten lernen. „Daheim“ wie in der Diaspora.

Die Frage nach künftigen Bewegungsformen universalistischer Religionen lässt sich zuspitzen auf die Alternative zwischen einer weitergehenden Politisierung des Religiösen und seiner erweiterten Zivilisierung; letztere erlaubt eine friedliche Entflechtung zwischen religiöser und politischer Macht.

\section{Wieso ist die Globalisierung ein monotheistisches Projekt?}

Die eine Welt ist die Schöpfung des Einen Gottes. Und unter SEiner Herrschaft wird sie am Ende der Zeiten vereinigt werden. Dies gilt ebenso für den Gott der Propheten, also die ethisch-politische Vereinigung der Welt unter dem einen „Königreich, das in Ewigkeit nicht untergeht" (Dan 2.44), wie für den Gott der Vernunft, der den Menschen eine rationale Weltbeherrschung ermöglicht: die wissenschaftlich-technische Durchdringung der Welt, die Mitarbeit des Menschen an Gottes Schöpfung, folgt ja der rationalen Kosmologie, welche der Eine Schöpfer SEiner Welt als SEinem Werk unterlegt hat (und dem Vernunftwesen Mensch als SEinem Bilde zugänglich macht). 
Der Polytheismus der Antike kannte so viele Welten, so viele Wissens- und Lebensweisen wie Städte, Kulte und Gottheiten. Der Polytheismus der Postmoderne kennt so viele Welten wie Sprachspiele. Nur für den Einen, allmächtigen Gott wird alles, was es gibt, zum Zeichen SEiner Allmacht, zur Konsequenz SEines Wollens. Der Gott der Philosophen thronte über einer einzigen Wirklichkeit; der Gott Mosis gab SEinem Volk nur ein Gesetz, das als Moralgesetz am Ende der Zeiten auch in aller Welt für Gerechtigkeit sorgen soll; der Vatergott Jesu Christi ist Vater aller Menschenkinder.

Jesu erste Aussendung ,Gehet hin in alle Welt!“ (Mk 16.15; Mt 28.19; Lk 24.47) war eine apokalyptische Botschaft. Bereits der Umstand, dass drei heidnische Weisen von der Geburt des Messias aus den Sternen wussten, während ER im Gottesvolk Israel noch verkannt ward, war Zeichen dafür, dass mit dieser Geburt das Ende der Geschichte begonnen hat. Denn bevor nicht „allen Völkern“ die Frohbotschaft verkündet ward, ist auch die prophetische Heilsgeschichte noch nicht zu Ende: ,Wer aber beharrt bis an das Ende, der wird selig" (Mk 13.13).

Und hier müssen wir die Monotheismen unterscheiden. Der spezifisch „paulinische“ Missionsauftrag bei der Übersetzung der Botschaft des Messias Jesus unterscheidet das Christentum vom etwa gleichzeitig entstehenden rabbinischen Judentum nach der Zerstörung des Zweiten Tempels. Auch dieses stellte zwar eine in ethischer Hinsicht universalistische Religion dar, aber sie entwickelte eben keine missionarische, propagandistische Dynamik, sondern breitete sich in Diaspora-Strukturen wie den „Netzwerken der Genisa“ aus. Im Gegensatz dazu ist es kein Zufall, dass heute die beiden quantitativ „stärksten“ Weltreligionen zugleich die Religionen mit einem expliziten Missionsauftrag sind: das Christentum und der Islam.

Die politische Etablierung monotheistischer Religionen kann, aber muss nicht revolutionäre (heute: fundamentalistische) Züge annehmen. Stabile Gestalt erhielt sie vielmehr in religiösen Reichen, in der Vergangenheit des Christentums (Byzanz, Spanien) ebenso wie des Islams (die wechselnden Kalifate). Nach ihrer expansiven Phase setzen Imperien häufig eher auf Stabilisierung und Arrondierung denn auf Expansion und Mission. Dann neigt die imperiale Staatsräson nicht nur außenpolitisch zu Formen des Appeasement (worin sich etwa die byzantinische Reichskirche vom revolutionären lateinischen Papsttum nach der gregorianischen „Reform“ unterschied), 
auch nach innen sucht sie nun eine flexiblere, „liberalere“ Form religiöser Ordnung.

Sieht man von der sozialen Privatisierung der Heilsbotschaft ab, einer der Hinsichten der „Säkularisierung“ des Religiösen im Westen seit einem Jahrhundert - so bestand bislang die Zivilisierung der universalistischen Heilsanstalt zumeist in ihrer (national)staatlichen Hegung. An erfolgreichen Institutionen für eine transnationale „Religionspolitik“ unter Bedingungen der internationalen Konkurrenz zwischen globalen Heilsanbietern fehlt es hingegen bis heute.

\section{Wann wird Mission imperialistisch?}

Das Imperium ist eine expansive Bewegungsform des Widerspruchs von expansiver Mission und politischer Stabilität - und es rationalisiert diese Tendenz durch den Universalismus von Recht und Macht. Mit der Konversion des Christentums zur römischen Staatsreligion wurde somit auch die Mission imperialistisch - und ihre Botschaft als Dogma verrechtlicht.

Christliche Mission begann zwar in der Diaspora, nach Konstantin und Theodosius aber wurde sie zur Staatsaufgabe der Reichsreligion, zum ,ideologischen Staatsapparat“ (Louis Althusser) des Imperiums. Als sich dann das Imperium spaltete, trennten sich auch die Christenheiten - in römisches Ost- und Westreich, eine Bewegung, die sich später im Osten fortsetzte in Gestalt des „Dritten Rom" und der (post)byzantinischen Nationalkirchen.

Nach islamischer Selbstdarstellung war die Ausbreitung der Botschaft des Gesandten Mohammed in erster Linie der Überzeugungskraft und Schönheit des Korans geschuldet (dessen vom Erzengel Gabriel dem Gesandten Gottes Mohammed diktierte Poesie unübersetzbar und in ihrer Schönheit unübertrefflich bleibt). Aus christlicher Sicht war dafür eher die mit Mohammeds militärischer Einung von Nomadenstämmen einsetzende machtpolitische Expansion des Kalifats verantwortlich. Die Geschichte des Islams kennt beide Gestalten der Mission: Im Mittelmeer überwog wohl die imperiale Expansion; im Pazifischen Ozean waren wohl - wie für die frühe Christenheit im Mediterran - Handel und Diaspora das Medium der Botschaft des Propheten. In der Vergangenheit hatte die islamische Mission durchaus imperialistische Züge - aber heute blüht sie in der Diaspora. Zu Beginn des 21. Jahrhunderts kommunizieren die „Neofundamentalisten“ (Olivier Roy) in der Diaspora über das Me- 
dium einer elektronisch vernetzten ,virtuellen Umma“ (Gemeinschaft der Rechtgläubigen) - während die politisch Radikalen (oder „Islamisten“) wieder vom verlorenen Imperium, vom Kalifat als Weltherrschaft, träumen.

\section{Prägt Missionsgeschichte das weltpolitische Gedächtnis?}

Wichtige geopolitische Spannungsbögen der Gegenwart sind durch die Gedächtnisgeschichte der Weltmissionen imprägniert. Für Europa sei an erster Stelle der religiöse und politische Kontrast zwischen Westen und Osten genannt: zwischen orthodoxer, von Byzanz aus missionierter, und lateinischer Christenheit. Dieser ekklesiale „Kalte Krieg“" ist weit älter als der Kalte Krieg in der zweiten Hälfte des 20. Jahrhunderts (der kapitalistisch-kommunistische Systemgegensatz) und wird diesen daher vermutlich noch recht lange überleben.

Im Westen gelingt der Religionsfrieden erst am Beginn der Neuzeit, durch verschiedene Weisen der „Neutralisierung“ des religiösen Konflikts (Carl Schmitt): der feindlichen Trennung (laizistisches Modell), der völligen Separation durch eine Trennmauer (nordamerikanisches Modell) oder den freundschaftlichen (partiellen) Trennungen von Kirche(n) und Staat in Europa. In Nordamerika entsteht der staatsfreie (aber sozial mächtige) Markt der Religionen, in Westeuropa werden die Religionskonflikte zunächst durch die Konfessionalisierung der Staaten gezähmt, dann durch die Säkularisierung des Staats.

Die östliche, byzantinische Christenheit hat diese Erfahrung ebenso wenig gemacht wie der Islam. An den Grenzen zwischen lateinischer und orthodoxer Christenheit (Litauen, Polen, Weißrussland, Ukraine, Rumänien, Balkan) missverstehen bis heute orthodoxe Reichs- oder Nationalkirchen die katholische Seelsorge und theologische Lehre ebenso wie protestantische Evangelisierungserfolge von Sekten und Freikirchen als westliche Eroberungsfeldzüge. Jüngste Tendenzen zur Internationalisierung der russischen Orthodoxie durch die Vereinigung von metropolitaner und russischer Diaspora-Kirche des ehemaligen antikommunistischen Exils sind auch unter diesem Gesichtswinkel von Interesse.

Gewiss gingen also in der Geschichte der Christenheit die Mission der Seelen und die Eroberung der Territorien (zu) häufig Hand in Hand. Freilich fällt es der islamischen politischen Tradition bis heute schwer, beides überhaupt auseinanderzuhalten. 
Der zweite Gegensatz kontrastierender Missionserfahrungen und Erinnerungen ist der mit der Geschichte der europäischen Imperien verbundene Nord-Süd-Konflikt. Einer der Gründe für die frühe Expansion des Katholizismus nach Lateinamerika (und Lateinasien: Philippinen) waren schließlich die iberischen Kolonialreiche. Im Gegensatz dazu fand die weltweite protestantische Mission zunächst ihre Stütze in Gestalt von Handelskompanien, und erst im 19. Jahrhundert wird sie massiv auch staatlich, staatskirchlich gestützt. Heute ist freilich der in Latein- und Mittelamerika bis zum 20. Jahrhundert vorherrschende Katholizismus gegenüber der charismatischen Konkurrenz evangelikaler Freikirchen (Assembleas de Dio, Pfingstler, Baptisten) in die Defensive geraten. Derweil erobern katholische „Hispano“-Einwanderer den bisher vorwiegend protestantischen religiösen Markt in Nordamerika.

Die Globalisierung der Märkte, Migrationen und elektronische Kommunikation verallgemeinern auch die Mission: Der universale Heilsanspruch konkurrierender Monotheismen wird virtuell allgegenwärtig. Nach dem Desaster der kommunistischen Karikatur des christlichen Universalismus bleiben Islam und Christentum weltweit die erfolgreichsten Konkurrenten. Aber auch innerhalb der großen Religionen hat der globalisierte Markt der Bekenntnisse die Pluralität möglicher Optionen erhöht: In den verschiedenen Ausprägungen des Islams ebenso wie in den Christenheiten findet nicht nur eine ,konfessionelle Konkurrenz statt (zwischen Shiiten und Sunniten, Protestanten und Katholiken ...), sondern auch ein Gestalt-Konflikt zwischen eher dogmatisch normierten (dogmatisch-rechtlich kodifizierten) und eher mystisch oder erfahrungsorientierten Formen und Traditionen persönlicher Identität und kollektiver Zugehörigkeit (charismatische Bewegungen, Sufi-Bruderschaften).

\section{Worin besteht der europäische Sonderweg?}

In Europa geschah die Zivilisierung des Religiösen durch den Staat auf im Einzelnen durchaus verschiedenen Wegen, die in der klassischen Säkularisierungstheorie nicht hinreichend unterschieden werden. Im Gegensatz zum katholischen Europa - aber auch zum sektenprotestantisch besiedelten und beseelten Nordamerika - war es im protestantischen Norden Europas der konfessionelle Staat, der die machtpolitisch „vollendete Reformation“ (Carl Schmitt) verwirklichte. Damit aber bereitete die verstaatlichte, volks- oder landes- 
kirchliche Gestalt des Christentums seine Verweltlichung bereits vor, bis am Ende (in den Worten Sören Kierkegaards) „das Christentum durch seine Verbreitung abgeschafft worden ist".

Die beste Formulierung dieses protestantisch-landeskirchlichen Weges zur Säkularisierung findet man immer noch bei Hegel: Die Entmachtung eines eigenen kirchlichen Herrschaftsapparats durch Luthers Eintreten für das „Priestertum aller Gläubigen“ bereitete auch die religiöse „Durchbildung und Durchdringung des weltlichen Zustandes" durch das Prinzip der christlichen Freiheit vor. Die Freiheit des Christenmenschen verwirklicht sich durch die „Innenleitung“ (David Riesman) des Gott-unmittelbar gestellten Individuums; die buchhalterische Verrechnung von guten Werken mit jenseitigen Strafen wird damit überflüssig; stattdessen verinnerlicht die protestantische Moral die Glaubens- und Gewissenskontrolle; und diese sedimentiert sich dann als Sittlichkeit.

Der Verfassungsstaat ließ sich damit als Verwirklichung des „,christlichen Prinzips, des Selbstbewußtseins der Freiheit“ deuten. Darin besteht - schematisch vereinfacht - Hegels Theorie der Säkularisierung als einer ,guten“, d.h. protestantischen Verweltlichung des christlichen Prinzips (im Gegensatz natürlich zur „schlechten“, bloß äußerlichen „Verweltlichung“ von Theologie und Philosophie in der katholischen Scholastik und Kasuistik). Die Verweltlichung des Christentums in diesem positiven Sinne ist dann das Wirken des Heiligen Geistes in der Welt; dessen universalistisches Freiheitsprinzip führt uns an das „letzte Stadium der Geschichte“. Die Verallgemeinerung der christlichen Innerlichkeit der Freiheit mündet somit ein in den weltlichen Fortschritt. Während freilich in Frankreich, einem Lande katholischer Hitzköpfe, schon die Aufklärung antiklerikal ausfiel und mit den Septembermassakern die Revolution zum Terror entartete, konnte im protestantisch vernünftigen Deutschland die einmal eingerichtete konstitutionelle Monarchie die legitime Staatsreform einleiten.

\section{Warum gibt es im erweiterten Europa noch keine transnationale Religionspolitik?}

Das hat viele Gründe, aber es ist auch ein Versäumnis der christlichen Kirchen. Bislang beschränkten sich diese vorwiegend auf den symbolischen Kampf um eine „christliche“ oder religiöse Präambel der künftigen EU-Verfassung. Damit wählten sie de facto einen 
Nebenkriegsschauplatz; sie blieben möglichen Auseinandersetzungen um die Konstituierung einer europäischen Öffentlichkeit fern.

Brüsseler Religionslobbyisten und kirchliche Entscheidungsträger waren sich nämlich darin einig, dass die diversen nationalen Staatskirchenrechte auf keinen Fall anzutasten seien. Das Verhältnis von Staat und Kirche(n) prägte das kulturelle Gesicht und die politischen Traditionen jeder europäischen Nation anders. National privilegierte Kirchen (in Deutschland, England, Italien) mussten in „Europa“ den Verlust von Vorrechten aus ihren Konkordaten und Staatsverträgen fürchten: Autonomien, öffentliche Hoheit und (Steuer)gelder. Also scheuten katholische Bischofskonferenzen in Deutschland, Österreich oder Italien ebenso wie die lutheranischen Nationalkirchen Skandinaviens eine europaweite Trennung von Kirche(n) und Staat.

Somit befestigt heute das institutionelle „Europa“ die Kirchen in ihrer Identität, ihrer Macht und ihrem Einfluss gerade als nationale Größen: „nur“ als gesellschaftliche Großanbieter für Transzendenz oder gar (wie im Vereinigten Königreich, in Griechenland, in Polen) als offizielle Nationalkirchen. „Europa“ tut dies ausgerechnet zu einem Zeitpunkt, wo die religiöse Kommunikation, ihre spirituellen Dialekte und auch die Konversionen (zu dieser oder jener Religionsgemeinschaft) immer transnationaler werden. So sind die Ursachen für das Anwachsen der islamischen Bevölkerung in den verschiedenen Staaten Westeuropas weitgehend dieselben: die Immigration und ihre Folgen - gebrochen durch unterschiedliche koloniale Traditionen und Erinnerungen. Zwar gibt es in manchen Ländern mittlerweile erste Schritte auf dem Weg hin zu einer offiziellen Institutionalisierung von islamischen Religionsgemeinschaften (am weitesten in Österreich, das hier auf legale Ansätze aus der KuKMonarchie zurückgreifen kann) - aber noch geschieht dies mit konträren Modellen und Erwartungen (etwa in Frankreich und Deutschland).

Für die geografischen „Ränder“ der Europäischen Union, gen Osten und Südosten, gibt diese weiterhin ausschließlich nationale Verantwortung der Religionspolitik das exakt falsche Signal. Die in den osmanischen wie byzantinischen Reichstraditionen tradierte Vermischung von nationalen und religiösen Identitäten wird damit scheinbar auch im Westen befestigt. Längst ist zwar der Anglikanismus auch als (absterbende) Staatsreligion Großbritanniens keine Bedrohung für Muslime oder Hindus in Greater London mehr. Doch 
in Ländern wie Russland oder Kasachstan ist das nationale Vorrecht der ethnisch-religiösen Mehrheit, auch die Mitgliedschaft in religiösen Minderheiten zu regulieren, zu kontrollieren und - durch fragwürdige Registrierungsverfahren - einzuschränken, bis heute ungebrochen.

\section{Warum ist die Diaspora die Religionsgestalt der Zukunft?}

Die (post)moderne Situation verallgemeinert die Diaspora - und zwar auch die spirituelle. Noch nie war die Mobilität von Gütern, Informationen und Menschen derart allgemein - heute ist sie Signum der condition bumaine. Dies erinnert an die Entstehung des Christentums in der spätantiken „Postmoderne“. Auch die paulinische Mission war Predigt in der Diaspora, auf der Agora, vor dem Areopag, vor Heiden und Juden, zwischen Händlern, Gurus und Therapeuten - und ihr Ziel war kein Staatskult, kein christliches Reich, sondern der universelle Ruf zur Umkehr: metanoia.

Seit dem Ende des Kalten Krieges - seitdem es „nach auBen“ politisch, ökonomisch, informatisch immer schwieriger wird, Nationen, Territorien, Staaten durch „Eiserne Vorhänge“ gegeneinander abzuschotten - ist eine protektionistische Haltung auch kulturell und spirituell reaktionär. Jeder Versuch, politische (nationale) Territorien zu theologischen Erbhöfen zu erklären, verwechselt das Reich Cäsars mit dem Reich Gottes. Der Heilige Geist weht, wann er will, wo er will, in welcher Sprache er will - und in welcher Konfession er will.

Dies gilt freilich auch „nach innen“: Es gibt keine „Erbhöfe" selbstverständlicher Religiosität mehr - die Formen des Gottesdienstes und der Gemeindebildung werden selber polymorph. Zum Werte-Polytheismus der Moderne, zum Religionspluralismus als normalem Umfeld der Mission tritt zunehmend auch eine Polymorphie der Weisen des Gottesdienstes intra muros ecclesiae bzw. in der binnen- und zwischenkirchlichen Konkurrenz.

\section{Literatur}

Kallscheuer, Otto (2003): „Ein Gott - eine Welt - viele Missionen“, in: Voegele, Wolfgang/Wegner, Gerhard, Hg.: Religion und Globalisierung. Schriften der Evangelischen Akademie. Rehburg-Loccum: Evangelische Akademie, 131-142. 
Kallscheuer, Otto (2005): „Kreuz des Südens“, in: Universitas 60(713), 11601168.

Kallscheuer, Otto (2006a): „Macht Religion Politik?“, in: Mörschel, Tobias, Hg.: Macht Glaube Politik? Religion und Politik in Europa und Amerika. Göttingen: Vandenhoeck \& Ruprecht, 89-107.

Kallscheuer, Otto (2006b): Die Wissenschaft vom Lieben Gott. Frankfurt/M.: Eichborn. 



\section{Kränkung und Gewalt. Ehre und Blasphemie als Sicherheitsprobleme der Weltgesellschaft}

Thomas Scheffler

\section{Vom Wortwechsel zur Gewalt}

Dass gegenseitige Beleidigungen leicht zu Tätlichkeiten führen können, ist nicht nur aus antiken Heldenepen und den Duellritualen des europäischen Adels bekannt. Polizisten, Sozialarbeiter und die Pausenaufsicht auf unseren Schulhöfen wissen ebenfalls ein Lied davon zu singen. Die Eskalation der dänischen Karikaturenkrise hingegen stellte für viele zeitgenössische Beobachter, jedenfalls in Dänemark, eine Überraschung dar. Für die wenigsten schien es nachvollziehbar, dass zwölf den Propheten Muhammad karikierende Zeichnungen, die die dänische Tageszeitung Jyllands Posten am 30. September 2005 veröffentlicht hatte, eine Krise heraufbeschwören würden, in der Gewalt gegen Sachen und Personen eine so große Rolle spielte.

„Aber das waren doch nur Zeichnungen!" war eine Bemerkung, die ich in Dänemark häufig zu hören bekam, wenn die Bilanz des Karikaturenstreits zur Sprache kam: 139 Tote und 823 Verletzte in insgesamt sieben Ländern; ${ }^{1}$ Brandangriffe auf diplomatische Vertretungen Dänemarks und anderer westlicher Staaten; Massenverbrennungen von westlichen Nationalflaggen und Bildern westlicher Politiker; Ausschreitungen gegen Kulturzentren und Entwicklungshilfeeinrichtungen westlicher Länder, gegen internationale Organisationen, unbeteiligte orientalische Christen und deren Kirchen; ein Boykott dä-

1 Daten nach Angaben der anonymen, inzwischen geschlossenen Website Cartoon Body Count: Death by Drawing. Die Aufstellung umfasst Tote und Verletzte im Umfeld des dänischen Karikaturenstreits zwischen 5. Februar und 25. März 2006. Vgl. Anonym (2006). 
nischer Produkte in mehreren islamischen Staaten sowie ein beschleunigter individueller Radikalisierungsprozess bei einigen jungen Muslimen: Zwei Libanesen, die im Juli 2006 selbstgebaute Kofferbomben in zwei deutschen Regionalzügen deponiert hatten, gaben 2007 vor Gericht an, sie hätten aus Zorn über die dänischen Muhammad-Karikaturen gehandelt. Im Februar 2008 nahm die dänische Polizei zwei Tunesier und einen Dänen marokkanischer Abkunft fest, die beschuldigt wurden, die Ermordung Kurt Westergaards geplant zu haben, jenes Zeichners, der den Propheten 2005 mit einer Bombe im Turban dargestellt hatte.

Aus der Perspektive internationaler Sicherheitspolitik demonstrierte der Karikaturenstreit, wie leicht gewaltträchtige internationale Krisen heute durch symbolische Aggressionen ausgelöst werden können, d.h. durch Handlungen, die in sich selbst zwar noch keine physische Gewalt darstellen, aber von anderen als schwerwiegend genug eingestuft werden, um eine gewaltsame Antwort zu rechtfertigen. Die Krise zeigte ferner, dass Symbole sich im Zeitalter globaler Medienpräsenz als veritable Langstreckenwaffen erweisen können: Eine Provokation, die anfangs wohl primär die kleine muslimische Minderheit in Dänemark im Visier gehabt hatte, trug dazu bei, Unruhen in Ländern wie Nigeria, Pakistan, Libanon oder dem Gazastreifen anzuheizen. Firmen und Entwicklungsagenturen verschiedenster westlicher Länder mussten ohnmächtig erfahren, wie sehr ihre Arbeit vor Ort von der unberechenbaren Eskalationsdynamik symbolischer Scharmützel in ganz anderen Teilen der Welt beeinflusst werden kann.

Die Krise dokumentierte zugleich eine ungeahnte Zunahme potentiell sicherheitsrelevanter Störfaktoren: Wenn Zeichnungen und Worte in einem derartigen Ausmaß weltweit Gewalt auslösen oder eskalieren können, dann beschränkt sich der Kreis der potentiellen Akteure von Gewaltkonflikten nicht mehr nur auf diejenigen, die die Mittel physischer Gewaltausübung kontrollieren. Vielmehr sind zusätzlich auch all jene Akteure einzurechnen, die in der Lage sind, (a) die kollektiven Symbole anderer Gruppen öffentlich herabzusetzen und (b) die Medien darüber berichten zu lassen.

Obwohl die dänische Karikaturenkrise viele Beobachter überraschte, war sie weder die erste noch die letzte ihrer Art:

- 1988 hatte die Veröffentlichung von Salman Rushdies Roman Die Satanischen Verse weltweit eine Welle von Demonstrationen und Buchverbrennungen ausgelöst, die am 14. Februar 1989 
von Ayatollah Khomeinis berühmter „Fatwa“ gekrönt wurde, die zur Tötung Rushdies aufrief und damit den vorübergehenden Abbruch der diplomatischen Beziehungen zwischen Großbritannien und dem Iran provozierte. Nicht nur Rushdie selbst, sondern auch seine Übersetzer, Drucker, Verleger sowie die Vertreiber des Buches wurden mit dem Tode bedroht. In der Folgezeit wurde 1991 ein Übersetzer ermordet und ein weiterer schwer verletzt; der Verleger der norwegischen Ausgabe überlebte 1993 einen Mordanschlag.

- Die Ausstrahlung des Films Submission im niederländischen Fernsehen am 29. August 2004 provozierte einen Islamisten marokkanischer Abkunft dazu, den Regisseur des Films, Theo van Gogh, am 2. November 2004 in Amsterdam auf offener Straße zu ermorden.

- Als das amerikanische Nachrichtenmagazin Newsweek im Mai 2005 berichtete, in Guantanamo würden amerikanische Sicherheitskräfte den Koran entweihen, um muslimische Gefangene zu erniedrigen, kam es zu weltweiten muslimischen Protesten, in deren Verlauf in Afghanistan 17 Menschen getötet wurden.

- Eine weitere muslimische Protestwelle wurde ausgelöst, als Papst Benedikt XVI. in seiner Regensburger Rede vom 12. September 2006 aus einem byzantinischen Dialog des späten 14 . Jahrhunderts zitierte, in dem es unter anderem hieß: ,Zeig mir doch, was Mohammed Neues gebracht hat, und da wirst du nur Schlechtes und Inhumanes finden wie dies, dass er vorgeschrieben hat, den Glauben, den er predigte, durch das Schwert zu verbreiten“. ${ }^{2}$ Die Reaktionen auf diese Rede umfassten nicht nur Todesdrohungen gegen den Papst, sondern auch Anschläge gegen christliche Kirchen im Gazastreifen und in der Westbank, die Ermordung einer Nonne in Somalia sowie die Enthauptung eines chaldäischen Priesters im Irak.

In all diesen Fällen speiste sich der darauf einsetzende Effekt ungläubiger Überraschung in der westlichen Öffentlichkeit aus der scheinbaren Asymmetrie zwischen verbaler Kränkung und Gewalt. Viele Beobachter missbilligten zwar die Verspottung religiöser Sym- 
bole, lehnten es aber ab, Gewalt als angemessene Antwort darauf zu akzeptieren.

\section{Zur Logik der „Überreaktion“}

\subsection{Populäre theoretische Ansätze}

Unter den Theorien, die in westlichen Kommentaren bemüht wurden, um die schwer verständliche Inkongruenz zwischen gewaltlosen Kränkungen und gewaltsamer „Überreaktion“ darauf zu erklären, waren die folgenden drei besonders häufig anzutreffen:

1. Dem Einfluss sozialpsychologischer Frustrations-AggressionsTheorien ist vor allem die von Bernard Lewis popularisierte Vorstellung verpflichtet, Muslime im Allgemeinen und Araber im Besonderen besäßen gegenwärtig ein besonders hohes Aggressionspotential, weil sie an einem historischen Minderwertigkeitskomplex litten, der sich aus der Spannung zwischen der Erinnerung an ihre einstige historische Größe und ihrer jetzigen Unterlegenheit gegenüber dem Westen speise. ${ }^{3}$

2. Eher ideologietheoretisch orientierte Ansätze hingegen gehen von der Annahme aus, das Verhalten von Muslimen werde von den Doktrinen ihrer Religion regiert. Und da Gewalt im Koran und in der Sunna eine erhebliche Rolle spiele, sei es nur folgerichtig, zu erwarten, dass Muslime auf vieles, was ihnen nicht gefalle, erst recht aber auf Beleidigungen ihres Glaubens gewaltsam reagierten.

3. Im Gegensatz zu den beiden vorgenannten Deutungsmustern gehen instrumentalisierungstheoretische Ansätze von der Annahme aus, dass es nicht Religion, religiöse Gefühle oder theologische Dogmen „an sich“ seien, die zur Gewalt drängten, sondern deren Instrumentalisierung durch politische Akteure. ${ }^{4}$ Die Eskalation des Karikaturenstreits im Frühjahr 2006 wäre demnach nicht primär als Reaktion auf die Verletzung theologischer Gebote zu erklären, etwa des angeblichen „Bilderverbots“ im Islam. Die Karikaturen hätten lediglich einigen Regierungen und radikalen Islamisten einen Vorwand mehr geliefert, um das zu 
tun, was sie ohnedies hätten tun wollen, z.B. mit gewalttätigen Aktionen auf sich aufmerksam zu machen, für eine Politik der Konfrontation zu werben oder ihre Anhänger Dampf ablassen zu lassen.

Alle drei Ansätze weisen meines Erachtens Defizite auf:

Der Erklärungswert sozialpsychologischer Frustrations-AggressionsTheorien ist schon deshalb beschränkt, weil individuelle Gefühle sich nicht umstandslos in organisierte kollektive Handlungen übersetzen lassen. Psychische Dispositionen wie „Frustration“, „Angst“, „Ärger", „Verzweiflung“, „Wut“ oder „Hass“ werden aus den verschiedensten Ursachen gespeist und sind entsprechend weit verbreitet, müssen aber nicht notwendig vom Auftauchen sozialer Bewegungen begleitet sein. ${ }^{5}$ Entstehung, Dynamik, Selbstbehauptung und Erfolg kollektiver Protestbewegungen hängen von vielen zusätzlichen Umständen $\mathrm{ab}$, so z.B. von den personellen, finanziellen und militärischen Ressourcen, auf die sie vor Ort zugreifen können; von ihrer organisatorischen Kapazität, diese Ressourcen für sich zu mobilisieren; von den Freiräumen, die ihre Gegner ihnen überlassen; vom Einfluss ihrer Verbündeten; von der Plausibilität und Breitenwirkung der ideologischen Rahmenkonzepte, mit denen sie ihre Anhänger werben und motivieren. ${ }^{6}$

Die ideologietheoretische Erwartung, dass das empirische Verhalten von Muslimen primär von den Dogmen islamischer Theologie angetrieben werde, unterschätzt die multiplen Identitäten der meisten Menschen und den prägenden Einfluss sozialer Beziehungen auf ihr religiöses Bewusstsein: Die Identifizierung mit einer Religion hängt nicht zwangsläufig mit einer genaueren Kenntnis ihrer Dogmen zusammen. Weit wichtiger sind die Attraktivität ihrer sozialen Netzwerke $^{7}$ und ggf. auch deren Opposition zu anderen Religionsgemeinschaften. In ihrem Alltagsleben folgen viele Gläubige erwiesenermaBen nur sehr eingeschränkt den normativen Geboten ihrer Religion bzw. gehen mit diesen höchst kreativ und selektiv um. Im Falle des dänischen Karikaturenstreits können ideologietheoretische Deutungen darüber hinaus kaum erklären, warum öffentliche Gewaltausbrü-

5 Wiktorowicz (2004), 8-9.

6 McAdam/McCarthy/Zald (1996), della Porta/Diani (2006) und Wiktorowicz (2004).

7 Stark (1996), 14-21. 
che gegen die Muhammad-Karikaturen sich nur auf relativ wenige Länder beschränkten. Wie widersprüchlich die Lage selbst dort war, zeigten die Ausschreitungen gegen das dänische Konsulat in Beirut am 5. Februar 2006, wo sunnitische Geistliche, die zu einer Protestkundgebung vor dem Konsulat aufgerufen hatten, sich (vergeblich) bemühten, das Entgleisen ,ihrer" Kundgebung in eine Gewaltorgie zu verhindern. Vollends unerklärlich bleibt im Rahmen eines rein ideologietheoretischen Ansatzes, warum die weitaus meisten Toten (107 von 139) und Verletzten (510 von 823) im Rahmen des Karikaturenstreits ausgerechnet in Nigeria zu verzeichnen waren. ${ }^{8}$

Instrumentalisierungstheorien konzentrieren sich auf politische „Unternehmer", die genügend Ressourcen und Organisationskapazitäten besitzen, um ihre Agenda durch publikumswirksame Aktionen zu fördern. Im Gegensatz zu den beiden vorgenannten Ansätzen können Instrumentalisierungstheorien relativ gut den Übergang von der subjektiven Empörung zum organisierten Massenprotest erklären, einschließlich der Frage, warum z.B. im Falle der Karikaturenkrise Gewalt nur in relativ wenigen Ländern auftrat - vor allem in Nigeria, Afghanistan, Libyen, Pakistan, Libanon, Kenia, Somalia, Syrien, Iran und den israelisch besetzten Gebieten, also in Ländern mit jeweils spezifischen und langen Konfliktvorgeschichten, in denen radikale Gruppen, zum Teil aber auch die Regierungen selbst ihre eigenen Gründe hatten, um bereits vorhandene Konflikte zu eskalieren. Die Schwäche von Instrumentalisierungstheorien hingegen wird vor allem dort sichtbar, wo sie erklären sollen, warum es in intensiven Konflikten immer wieder religiöse Symbole sind - und nicht z.B. ökonomische Interessen -, die sich dafür eignen, von Politikern massenwirksam zum Aufputschen der Emotionen instrumentalisiert zu werden.

\subsection{Die Macht der Symbole}

Um gewaltsame Reaktionen auf die Verhöhnung von Symbolen besser zu verstehen, schlage ich vor, einen etwas komplexeren Ansatz zu entwerfen und zunächst das Problem der Macht von Symbolen zu durchdenken. Warum und wann werden kränkende Worte und Zeichnungen für so wichtig und gefährlich gehalten, dass sie den Schritt zur Gewalt rechtfertigen? 


\subsubsection{Symbole und soziale Wirklichkeit}

Die allgemeinste Erklärung lautet: Worte sind nicht nur Worte und Zeichnungen nicht nur Zeichnungen. Sie sind Symbole und als solche Komponenten sozialen Handelns und sozialer Wirklichkeit. Der Mensch ist ein auf Kooperation angewiesenes Gruppenwesen (zoón politikón). Menschliche Kooperation wiederum wird mittels Kommunikation hergestellt, d.h. durch Sprache und entsprechende symbolische Codes. In diesem Kontext sind Worte und Bilder ein Mittel, Macht über die Dinge, Menschen und Ereignisse zu gewinnen, die sie bezeichnen sollen. Auch wenn man Worten keine magische Macht zuschreibt, ${ }^{9}$ sind sie doch ein Vorspiel zu physischen Handlungen, ein Versuch, Wirklichkeit zu ordnen und bearbeitungsfähig zu machen. Je mehr Macht man dabei Symbolen zuschreibt, desto ernster wird man Beleidigungen gegen sie nehmen.

\subsubsection{Symbole, Identität und kollektive Repräsentation}

Dies gilt vor allem dort, wo Symbole kollektive Identitäten repräsentieren sollen. Insbesondere komplexe Gesellschaften, deren Beziehungsgeflecht über bloße face-to-face-Kommunikation hinausgeht, können ihre Einheit nur in dem Maße herstellen, wie sie sich als „imaginierte Gemeinschaften" ${ }^{10}$ konstituieren, d.h. über den gemeinsamen Bezug auf Symbole ihrer Einheit. Emile Durkheim hat hierin die zentrale Funktion des Religiösen und der ihm zugrunde liegenden Trennung von Sakralem und Profanem gesehen. Die Kollektivsymbole werden mit der Aura des „Sakralen“ zu einer unverfügbaren, dem „profanen“ Zugriff entzogenen Tabuzone stilisiert und damit geschützt. ${ }^{11}$

Je schwächer, fragiler und lückenhafter die ökonomische und institutionelle Integration einer komplexen Gesellschaft, desto gröBer die Bedeutung ihrer symbolischen und ideologischen Integration. ${ }^{12}$ Wer die Kollektivsymbole imaginierter Gemeinschaften angreift, untergräbt den Zusammenhalt der letzteren und muss mit Gegenreaktionen derer rechnen, die von der Achtung, Verbreitung und Verteidigung dieser Symbole am meisten zu profitieren glauben,

9 Hierzu: Frazer (1989), 15-65.

10 Anderson (1991).

11 Zur Unterscheidung von „sakral“ und „profan“ vgl. Durkheim (1981), 62-68, 75.

12 Webster (1975). 
gleichgültig ob es sich dabei um die reichstragenden Eliten eines „,von oben“ integrierten Imperiums handelt oder um Mitglieder einer „,von unten“ integrierten transnationalen Bewegung, die auf internationale Solidarität angewiesen sind.

Die Gleichgültigkeit, mit der viele westliche Gesellschaften heute die öffentliche Herabsetzung einiger ihrer Kollektivsymbole hinnehmen, etwa das Verbrennen ihrer Nationalflaggen, muss nicht unbedingt bedeuten, dass der Zusammenhalt dieser Gesellschaften schwächer geworden ist. Ebenso gut lässt sich vermuten, dass diese Gesellschaften inzwischen alternative, nichtideologische Integrationsmechanismen herausgebildet haben oder dass sich die Zusammensetzung ihrer symbolischen Repertoires gewandelt hat. Auf allgemeinster Ebene wäre hier auf die bereits von Walter Benjamin 1921 angedeutete Rolle des Kapitals als Religionsersatz in der Moderne zu denken. ${ }^{13}$ Und falls das „Religiöse“, durkheimianisch gedacht, in einer Gesellschaft primär dort zu suchen ist, wo sich ihre wirksamsten Tabus befinden, dann ließe sich im Anschluss an Luca Di Blasi vermuten, dass es in vielen westlichen Gesellschaften heute die Erinnerung an den Holocaust ist, die das Zentrum ihrer Zivilreligiosität prägt. ${ }^{14}$

\subsubsection{Symbolisches Kapital, Ehre und Abschreckung}

In innergesellschaftlichen Transaktionen ist die Macht von Symbolen umso größer, je mehr sie das „symbolische Kapital“ einer Person oder Gruppe betreffen, d.h., je mehr die „Ehre“, der „gute Ruf“, das „Prestige“ eine direkte Ressource sozialer, ökonomischer und politischer Macht darstellen. ${ }^{15}$

Dies gilt vor allem in schwach integrierten Gesellschaften mit einer schwachen oder gar keiner staatlichen Zentralinstanz. In solchen Gesellschaften beruht die Sicherheit des eigenen Lebens und Eigentums auf der Fähigkeit von substaatlichen Solidargemeinschaften (Familie, Clan, Stamm o.Ä.), sich selbst zu schützen und - wichtiger noch - potentielle Gegner von Angriffen abzuschrecken. Eine Gruppe, die im Ruf steht, selbst den geringfügigsten Angriff auf ihre Ehre wütend zu rächen, wird größere Chancen haben, unbehelligt zu

13 Benjamin (1985) und Palaver (2002).

14 Vgl. Di Blasi (2000), 381-386.

15 Zum Begriff des „symbolischen Kapitals“ vgl. vor allem Bourdieu (1979), 335-377 und Bourdieu (1990), 112-121. 
leben, als eine Gruppe, von der man glaubt, sie nehme Erniedrigungen lethargisch hin. ${ }^{16}$ Individuen, die in solchen schwach integrierten Gesellschaften leben, müssen schon aus Gründen der Selbsterhaltung nicht nur an ihrer persönlichen Ehre interessiert sein, sondern auch an der ihrer jeweiligen Solidargemeinschaft(en). Der Zustand der individuellen bzw. kollektiven „Ehre“ stellt hier einen Seismografen bzw. ein Frühwarnsystem dar, das dazu dient, Leib, Leben und Eigentum zu schützen. Versuche, die Reputation einer Person oder Gruppe durch Spott, üble Nachrede oder offene Beleidigungen zu untergraben, können in diesem Kontext leicht als Angriff auf diesen moralischen Sicherheitsgürtel bzw. als verbales Vorspiel zu physischen Angriffen angesehen werden.

In unübersichtlichen Situationen, in denen keine feste, übergeordnete Rang- und Rollenverteilung zu erkennen ist oder Informationen über Macht und Verhalten anderer nicht verlässlich scheinen, können übrigens auch „Überreaktionen“ auf vermutete Ehrverletzungen strategisch sinnvoll sein: Ähnlich wie bei dem von Thorstein Veblen (1857-1929) analysierten übertriebenen Luxuskonsum von Neureichen ${ }^{17}$ oder bei der von Marcel Mauss (1872-1950) beschriebenen legendären Geschenkfreudigkeit archaischer Stammesgesellschaften ${ }^{18}$ macht es unter Umständen durchaus Sinn, „dick aufzutragen“" und starke, kostenintensive Signale auszusenden, um potentiellen Gegnern, aber auch möglichen „Geschäftspartnern“, die eigene Macht drastisch vor Augen zu führen. ${ }^{19}$

Wohin umgekehrt die systematische Rufschädigung von Gruppen führen kann, zeigt die Konstruktion innergesellschaftlicher Sündenböcke, voran das Beispiel des Antisemitismus. Die Konstruktion von Sündenböcken ist neben dem Aufbau externer Freund-FeindBilder einer der historisch wichtigsten Mechanismen, um innergesellschaftliche Spannungen mittels Aggressionsverschiebung zu dämpfen. ${ }^{20} \mathrm{Als}$ potentielle Opfer solcher Ausgrenzungsstrategien bieten sich vor allem Personen und Gruppen an, die bereits Zeichen des „Anderen“ bzw. der Abweichung von der jeweiligen „Normalität “ an sich tragen, etwa Fremde, Angehörige ethnischer, religiöser, 
sozialer und sexueller Minderheiten, aber auch Kranke oder geistig und körperlich Behinderte. ${ }^{21}$

Die Rufschädigung von Minderheiten durch herabwürdigende Witze, negative Gerüchte oder polemische Literatur muss zwar nicht direkt zu Pogromen gegen sie führen, aber sie trägt zur allmählichen Verdichtung von negativen Stereotypen bei, die sich für die Betroffenen spätestens dann verhängnisvoll auswirken können, wenn im Innern einer Gesellschaft, aus welchen Gründen auch immer, der Anpassungs- bzw. Normalisierungsdruck steigt. Wie Rodney Stark am Beispiel antijüdischer Ausschreitungen von Christen und Muslimen während der Kreuzzüge gezeigt hat, steigt in Zeiten großer politischer Konflikte bei den Hauptprotagonisten nicht nur die Abneigung gegen die feindlichen „Anderen“, sondern auch die Empfindlichkeit gegenüber kleineren Normabweichungen im eigenen Lager. Die Verschärfung des externen Konflikts geht mit sinkender Toleranz gegenüber nichtkonformen Minderheiten im eigenen Machtbereich einher - und zwar selbst dann, wenn diese Minderheiten kein militärisches Sicherheitsrisiko darstellen. ${ }^{22}$

\subsubsection{Symbole, Monotheismus und Ethik}

Worte und Bilder ernst zu nehmen, ist auch ein konstitutives Element der drei monotheistischen Religionen mit ihrer dramatischen Unterscheidung von ,wahr" und „falsch“.23 Die Bereitschaft, in einer Gesellschaft solche radikalen Unterscheidungen sozial zu akzeptieren und anzuwenden, wird vor allem durch akute Krisenstimmungen begünstigt - durch das Gefühl, dass normale, ,,horizontale“ Transaktionen von Mensch zu Mensch nicht mehr ausreichen, um die eigene Sicherheit zu garantieren.

Judentum, Christentum und Islam sind Offenbarungsreligionen, d.h., sie beruhen auf göttlich ,geoffenbarten" heiligen Botschaften, die die Gläubigen auf eine bestimmte ethische Lebensführung verpflichten wollen. Die ernste Art des Umgangs mit diesen göttlichen Botschaften wird durch deren errettenden Charakter bestimmt, d.h. durch die Wahrnehmung der Krise, aus der sie herausführen sollen: Wer Katastrophen auf Erden verhindern will, darf mit Gottes Wort 
nicht spielen. Die Botschaften Gottes müssen korrekt verstanden, rezitiert, ehrfurchtsvoll behandelt und erinnert werden - und dies bedeutet, sie auch gegen Entstellungen, Scherze, Parodien und Ironie zu verteidigen, weil andernfalls Zweifel an der absoluten Wahrheit und Ernsthaftigkeit der Offenbarung begünstigt werden könnten.

Da dramatische Unterscheidungen zwischen Wahrheit und Lüge sich andererseits gut dazu eignen, soziale Barrieren zwischen Gläubigen und Ungläubigen aufzurichten, können sie indirekt auch die Entwicklung religiöser Ethnien begünstigen, d.h. von Gruppen, die auf soziale Distanz zu Trägern anderer religiöser Überzeugungen achten und ihr Heirats- und Kontaktverhalten entsprechend ausrichten. Gottes Wort und die religiösen Kollektivsymbole, die ihm entsprechen, werden hier allmählich in Symbole der ethnischen Abgrenzung gegenüber anderen Gruppen verwandelt und ihre Verteidigung erfolgt nicht primär um ihres ethisch-normativen Gehalts willen, sondern um die eigene kollektive Identität bzw. die Gruppenehre zu betonen.

\subsubsection{Ethnizität, Säkularisierung und Ehrverletzung}

Es ist diese letztere, „ethnisierende“, Funktion religiöser Symbole, entlang derer sich der Charakter einer Kränkung von der Blasphemie zur weltlichen Ehrverletzung verschiebt. Das aus dem Griechischen stammende Wort Blasphemie (zusammengesetzt aus blaptein, ,schädigen“, und pheme, „Ruf“") bedeutet an und für sich nur „Rufschädigung"; de facto hat es sich jedoch als technischer Begriff für einen ganz bestimmten Typ von Beleidigungen durchgesetzt, nämlich für Beleidigungen Gottes, Seiner Offenbarung und der Symbole, die sie auf Erden repräsentieren. In einer theokratischen Ordnung oder in einer gesellschaftlichen Gruppe, die einzig und allein nach Maßgabe ihres jeweiligen göttlichen Gesetzes leben will, stellt die Blasphemie ein Kardinalverbrechen dar, das im Prinzip schwerste körperliche Strafen verdient. In einer säkularisierten politischen Ordnung hingegen, in der der Staat sich einerseits für weltanschaulich neutral erklärt, andererseits aber das Monopol körperlicher Bestrafungen für sich in Anspruch nimmt, können Delikte wie Blasphemie und Häresie weder von Staats wegen verfolgt noch mit körperlichen Strafen geahndet werden.

Die einzigen Formen, in denen die Verspottung religiöser Kollektivsymbole auch im Rahmen einer säkularisierten Gesellschafts- 
ordnung juristisch verfolgt werden kann, sind diejenigen, die der Schutz der allgemeinen bürgerlichen Rechte eröffnet, vor allem der Schutz vor rassischer, ethnischer oder weltanschaulicher Diskriminierung, der Respekt vor den „,religiösen Gefühlen“ anderer Menschen, der Schutz der menschlichen Würde, der Schutz des öffentlichen Friedens etc.

Es bedarf nur geringer Phantasie, um vorauszusagen, dass in einem Zeitalter globaler Säkularisierung ethnische Konflikte einer der wichtigsten Transmissionsriemen sind, um das politische und juristische Interesse an religiösen Symbolen wachzuhalten. Ethnische Konflikte sind häufig eine Begleiterscheinung des kulturellen Homogenisierungsdrucks, der mit dem Kampf um die Herausbildung moderner Territorialstaaten und insbesondere mit ihrer Demokratisierung einhergeht. ${ }^{24}$ In einer bemerkenswert großen Zahl von Konfliktherden der heutigen Welt sind ethnische mit religiösen Spannungslinien vermischt, z.B. in Afghanistan, Bosnien, Indien, Irak, Iran, Israel/Palästina, Kaschmir, dem Kosovo, dem Libanon, Nigeria, Nordirland, Pakistan, den Philippinen, Sri Lanka, dem Sudan, Thailand, Tibet und Timor. Darüber hinaus nimmt im Zuge globaler Migration auch die ethnoreligiöse Heterogenität vormals relativ homogener Gesellschaften zu. Und schließlich macht es der globale Charakter der modernen audiovisuellen Kommunikationsmedien möglich, sich emotional mit erlittenen Kränkungen imaginierter Leidensgenossen in anderen Teilen der Welt zu identifizieren und diese Projektionen in die eigene lokale Politikagenda einzuspeisen.

\section{Prophetenbeleidigung und Klagereligiosität im Islam}

\subsection{Theologische und geschichtliche Grundlagen}

Als Zwischenergebnis der bisherigen Darlegungen lässt sich festhalten, dass die Bereitschaft, auf Ehrverletzungen mit Gewalt zu reagieren, vor allem in relativ schwach integrierten Gesellschaften mit stark entwickeltem Krisenbewusstsein Sinn macht. Diese beiden Kriterien treffen auch auf weite Teile der vormodernen islamischen Welt $\mathrm{zu}$ - sie galten dort, lange bevor der westliche Imperialismus die muslimischen Staaten in die Defensive drängte. 
Die von Bernard Lewis popularisierte These, dass die Muslime der Neuzeit an einem historischen Minderwertigkeitskomplex litten, betont in der Regel gerne die frühen politischen Erfolge des Islam und den Glanz der Kalifatszeit - eine Periode imposanter staatlicher Machtentfaltung, vor deren Hintergrund sich dann der spätere Machtverlust als um so schmerzlicheres Trauma hervorheben lässt. Dieser stark säkularistisch gefärbte Blick auf fünfzehn Jahrhunderte muslimischer Geschichte unterschätzt aber drei weitere Gründe für innermuslimische Empfindlichkeiten gegenüber einer Verspottung des Islam:

Erstens war die frühe islamische Gemeinde auch in den mekkanischen Jahren der Offenbarung (ca. 613-622), d.h. in ihrer vorstaatlichen Phase, Verfolgungen ausgesetzt. Zweitens entwickelte sich die Theologie des Islam im Bezugsrahmen einer langen monotheistischen Klagetradition, in der die Verspottung und Verfolgung gottesfürchtiger Gläubiger einen wichtigen Platz einnahm. Die Zusammenstöße zwischen jüdischen Propheten und Königen im Alten Testament gehören ebenso hierher wie die Ansätze einer Martyriumstradition bei den Makkabäern, die Passionsgeschichte Christi sowie der Märtyrerkult im Christentum. Drittens schließlich waren selbst die großen Kalifatsimperien des Mittelalters, allem Glanz ihrer Hauptstädte zum Trotz, politisch-militärisch nie stark genug integriert gewesen, um heterodoxe Oppositionsbewegungen völlig unterdrücken zu können. Im Gegenteil, mit zunehmender Entwicklung muslimischer Staatlichkeit stiegen auch die inneren religiösen Konflikte, in deren Rahmen bald Charidschiten, Schiiten und Sunniten einander verspotteten, verfluchten und verfolgten.

Was den Propheten Muhammad selbst betrifft, so enthalten sowohl der Koran als auch die sira (die biografischen Berichte über sein Leben) Hinweise, dass der Prophet in Mekka häufig verspottet wurde - und dass er unter diesem Spott litt. Sein erster Biograf, Ibn Isḥāq (ca. 704-768), überliefert, der Prophet sei in Mekka bisweilen so verzweifelt gewesen, dass schließlich sogar der Erzengel Gabriel eingreifen musste und fünf der unangenehmsten Spötter (mustabzi'ün) umkommen ließ. ${ }^{25}$ Dieser Bericht gehört zugegebenermaßen ins Reich der Legende, aber mehrere andere Quellen berichten auch, 
dass der Prophet, nachdem er in Medina begonnen hatte, selber politische Macht auszuüben, die Tötung mehrerer Personen anordnete oder erlaubte, die ihn in Gedichten verspottet hatten oder seine Kenntnis der jüdischen und christlichen heiligen Schriften in Zweifel zogen. ${ }^{26}$

Die Härte, die der Prophet gegen diese Spötter und Besserwisser an den Tag legte, kontrastiert in bemerkenswerter Weise mit der Milde, die er häufig gegenüber Gegnern zeigte, die ihn gewaltsam bekämpft hatten. Laut Ibn Ishạa hatte z.B. Hind b. 'Utba, die Gattin seines Hauptfeindes Abū Sufyān, nach der von den Muslimen verlorenen Schlacht von Uhud (625) gemeinsam mit anderen mekkanischen Frauen den Leichen getöteter Prophetengefährten Ohren und Nasen abgeschnitten, um Schmuckanhänger daraus zu machen. Hamza, dem Onkel des Propheten, hatte sie sogar die Leber aus dem Bauch gerissen und sie zu verschlingen versucht. ${ }^{27}$ Dennoch nahm der Prophet sie und ihren Gatten nach der Eroberung Mekkas (630) in die Gemeinschaft der Muslime auf.

Diese ungleiche Behandlung von Gewalt- und Zungentätern mag auf den ersten Blick paradox erscheinen, muss aber vor dem Hintergrund der damaligen Freund-Feind-Konstellationen auf der Arabischen Halbinsel gesehen werden: Hind war nicht nur die Gattin des damals einflussreichsten Notabeln der Mekkaner, den $\mathrm{Mu}-$ hammad für die Sache des Islam gewinnen wollte. Ihr damaliges Handeln repräsentierte auch eine archaische Form der Feindschaft, die für den Propheten weit weniger gefährlich war als die der „Spötter“". Getötete Gegner rituell zu verstümmeln und bestimmte Körperteile zu verzehren war noch Bestandteil der alten Kultur der jähiliyya, des Zustands der vormonotheistischen „Unwissenheit“ bzw. „Barbarei“.

Hind zu vergeben und das endgültige Urteil über ihr Verhalten Gott zu überlassen, trug dazu bei, den überlegenen Tugendkanon islamischer Zivilisiertheit öffentlich zu unterstreichen. Die „Spötter" hingegen gaben mit ihrer Ironie und arroganten Besserwisserei $z u$ verstehen, sie stünden auf einem höheren intellektuellen Niveau als der Prophet, und untergruben dadurch die Glaubwürdigkeit seiner Botschaft bei Monotheisten oder solchen, die es werden wollten. 
Gerade an dieser Stelle aber musste der Prophet besonders empfindlich sein. Denn die eigentliche Bewährungsprobe der jungen islamischen Gemeinschaft lag, wie Gerald Hawting gezeigt hat, schon damals weniger in der Auseinandersetzung mit primitiven Polytheisten alten Stils, sondern in einer großen innermonotheistischen Kontroverse zwischen dem neuen Gottesvolk der Muslime und den auf der Arabischen Halbinsel bereits etablierten Juden und Christen. ${ }^{28}$

Die Jahrhunderte nach dem Tod des Propheten erlebten in dieser Hinsicht eine janusköpfige Entwicklung, nämlich einerseits eine ungeahnte territoriale Expansion staatlicher muslimischer Macht, andererseits aber auch eine (für viele Muslime bestürzende) Zunahme innerislamischer Konflikte - Konflikte, die den inneren Zusammenhalt der islamischen Großreiche gefährdeten und tatsächlich immer wieder auch zu territorialen Spaltungen des Där al-Isläm führten. Der Glanz der Kalifate der Ummayaden und Abbassiden und deren gewaltige räumliche Ausdehnung können nicht den Blick auf deren innere Heterogenität versperren und auf die Tatsache, dass die reichstragenden Eliten sich von den frühesten Tagen des muslimischen Kalifats an sich einer nicht enden wollenden Kette von Stammesrevolten, Sektenaufständen, Thronfolgedisputen und messianischen Erhebungen gegenübersahen.

Diese Konflikte wurden meist militärisch ausgetragen, hatten aber auch ihre „verbalen“ Komponenten, denn die streitenden Parteien sprachen sich gegenseitig die religiöse Legitimität ab und bemühten sich, die Identifikationsfiguren der Gegenparteien sowie die von ihnen reklamierten religiösen Traditionen teils intellektuell in Zweifel zu ziehen, teils subtil lächerlich zu machen, teils grob zu beschimpfen. Unter Schiiten gehörte es z.B. lange zur Tradition, die ersten drei Kalifen der islamischen Gemeinschaft, Abū Bakr (632634), 'Umar b. al-Khațțāb (634-644) und 'Uthmān b. al- 'Affān (644656), zu verfluchen - ein Vergehen, das von sunnitischer Seite unter Umständen mit der Todesstrafe geahndet werden konnte.

Spott, Ironie und Zweifel in religiösen Fragen konnten in einem solchen Umfeld schwer als Ausdruck eines unschuldigen intellektuellen Spieltriebs wahrgenommen werden. Je nach politischer Lage lag es näher, in ihnen eine verborgene politische Stellungnahme oder die subversive Wühlarbeit einer neuen, theologisch verkleideten oder ir- 
regeleiteten Oppositionsströmung zu wittern. Entsprechend strenger, unnachsichtiger und inquisitorischer wurde im Lauf der Jahrhunderte der Umgang mit Apostaten; ${ }^{29}$ und selbst nichtmuslimische Untertanen verwirkten nach Meinung vieler Rechtsgelehrter den Schutz der dhimma, des Schutzvertrags für unterworfene Anhänger anderer Schriftreligionen, wenn sie Gott, den Koran, den Propheten oder die islamische Religion lästerten. ${ }^{30}$

Alles in allem lässt sich im Islam - ebenso wie in den anderen monotheistischen Religionen - eine Empfindlichkeit gegenüber Gottes- und Prophetenlästerungen beobachten, die weit älter und theologisch tiefer verwurzelt ist, als es die säkularistische Annahme eines historischen Minderwertigkeitskomplexes der Muslime im 19. und 20. Jahrhundert vermuten lassen würde. Der Kampf gegen mächtige religiös-politische Oppositionsströmungen im eigenen Lager, der die Gemeinschaft der Muslime seit frühester Zeit begleitete, hielt auch das Bewusstsein wach, dass die eigene Ordnung, trotz aller irdischen Erfolge, fragil war und stets aufs Neue energisch verteidigt werden musste, einschließlich ihrer religiösen Symbole.

„Ihr seid die beste aller Gemeinschaften, die unter den Menschen entstanden ist: Ihr gebietet das Rechte, verbietet das Verwerfliche und glaubt an Gott", heißt es im Koran (3.110). Doch diese Passage zeigt, dass die Gnade Gottes an die aktive Erfüllung einer wichtigen Bedingung geknüpft ist, nämlich das Rechte zu gebieten und das Verwerfliche zu verbieten. Geschieht dies nicht, dann könnte auch die Gemeinschaft der Muslime ihren Heilsstatus als Volk Gottes verlieren, so wie es, nach muslimischer Überzeugung, zuvor schon den Juden und Christen geschah. Das vieldeutige Wort Muhammads, seine Gemeinschaft werde dereinst in 73 Gruppen (firaq) zerfallen, von denen 72 zur Hölle verdammt seien, ${ }^{31}$ zeigt, dass auch in der Glanzzeit des Islam das Bewusstsein der Heterogenität und Fragilität der eigenen Heilsgemeinschaft fortbestand.

\subsection{Religiöse Symbolik im modernen Islamismus}

In der heutigen muslimischen Welt ist die Sphäre religiöser Symbole sowohl zentrales Schlachtfeld als auch Ersatz für politische und so- 
ziale Konflikte. Diese Entwicklung kann nicht erstaunen. Wie bereits oben dargelegt, sind symbolische Ressourcen für die Integration einer Gesellschaft oder eines sozialen Netzwerks umso wichtiger, je schwächer ihre ökonomischen und politisch-institutionellen Integrationsmechanismen sind. Der Wert religiöser symbolischer Ressourcen ist dabei umso größer, je ausgeprägter das Krisen- und Gefährdungsbewusstsein in der betreffenden Gesellschaft ist. Faktoren, die in diesem Sinne die Bedeutung religiöser Symbolik steigern, sind in der heutigen muslimischen Welt in Fülle gegeben:

Das Krisenbewusstsein speist sich auf allgemeinster Ebene aus dem kumulierten Druck tiefgreifender und schneller gesellschaftlicher Wandlungsprozesse, denen die muslimischen Gesellschaften der Gegenwart ebenso ausgesetzt sind wie vor ihnen andere Gesellschaften der Welt auch: die Unterwerfung unter die Zwänge des Weltmarkts, der Übergang von der Agrar- zur Industrie- und Dienstleistungswirtschaft, Überbevölkerung, Urbanisierung, nationale und internationale Migrationströme, die Auflösung traditioneller Arbeits-, Autoritäts-, Solidaritäts-, Familien- und Geschlechterverhältnisse, der politische Partizipationsdruck neuer sozialer Schichten etc.

In der Modernisierungsgeschichte Westeuropas konnte ein groBer Teil dieses Drucks durch die sukzessive Entwicklung wirtschaftlich starker National- und Wohlfahrtsstaaten aufgefangen werden. In vielen Ländern der muslimischen Welt vollzog sich der Wandel aber lange Zeit unter dem zusätzlichen Druck demütigender Kriegsniederlagen, großer Gebietsverluste, kolonialer Fremdherrschaft und wirtschaftlicher Abhängigkeit. Nachhaltige Legitimation durch einen gewonnen Krieg blieb den meisten muslimischen Regierungen des 20. Jahrhunderts, mit Ausnahme der kemalistischen Türkei, versagt. Zeitweilige Legitimation durch Wohlfahrt war bisher nur in den reichen, bevölkerungsarmen Ölmonarchien wirklich möglich. In den bevölkerungsreichen und wirtschaftlich schwachen Staaten hingegen blieb sie trotz aller Bemühungen populistischer Reformer bis heute ein Wunschtraum. Die Vision eines starken panarabischen Staates, wie sie zeitweise vom Nasserismus und der Baath-Partei propagiert worden war, blieb mehr Rhetorik als Realität, behinderte aber jahrzehntelang den Aufbau stabiler nationalstaatlicher Institutionen.

Umso wichtiger wurden die transnationalen Solidaritätsnetzwerke islamistischer Verbände, die sich in der Regel in Opposition zu den herrschenden politischen Regimes ihrer Region entwickelten, im Widerstand gegen nichtmuslimische Fremdherrschaft wuchsen 
und überall dort wohlfahrtsstaatliche, karitative und erzieherische Funktionen übernahmen, wo der Staat versagte.

Organisationen wie die Muslimbruderschaft, Hizballah, Hamas, die pakistanische Jamaat-e Islami, Hizb ut-Tahrir, die irakische Mahdi-Armee und viele andere sind in hohem Maße symbolisch integrierte Verbände. Selbstverständlich verfügen sie über organisatorische Strukturen und gewähren ihren Anhängern und Sympathisanten auch diverse materielle Vorteile. Aber ihr Aufstieg in einem Umfeld autoritärer und mehr oder minder feindlicher Regime beruht in erster Linie auf der Einsatz- und Opferbereitschaft ihrer Anhänger, und diese wiederum hängt von der Intensität ihrer mentalen und kulturellen Motivierung ab.

Symbolische Figuren wie der Prophet Muhammad - und im schiitischen Islam auch sein 680 bei Karbalā' gefallener Enkel Husayn - sind, abgesehen von ihrem theologischen Stellenwert, für die Mobilisierungsstrategien islamistischer Bewegungen schon deshalb wichtig, weil sie vorbildliche Lebensläufe im Schnittpunkt von conditio bumana und göttlicher Offenbarung darstellen. Sie stehen erstens für die reale Möglichkeit eines Menschen, durch Hinwendung zum Transzendenten seine eigene Situation und die Situation anderer grundlegend zu verändern. Und zweitens stehen sie für die (im Zeitalter der Imperialismusdiskussion polemisch besonders wichtige) Differenz zu Juden und Christen - eine Funktion, die die biblischkoranisch belegte Figur Abrahams nicht zu erfüllen vermag.

„Vertreibe den Feind aus Deinem Herzen und er wird Dein Land verlassen“"32 - dieser berühmte, zur Zeit der britischen Kolonialherrschaft in Ägypten geprägte Slogan des Gründers der Muslimbruderschaft, Hasan al-Banā (1906-1949), artikuliert im Kern die Verbindung zwischen persönlicher, kultureller und politischer Wandlung im Transformationsprojekt islamistischer Bewegungen: Menschen, denen die Macht fehlt, ihre Herrscher zu wechseln, können zumindest sich selbst verändern - ihren Körper, ihr Denken, ihr Erscheinungsbild -, indem sie z.B. die äußerlichen Unterschiede betonen, die sie von ihren Unterdrückern trennen. Einen Schleier tragen, sich einen Bart wachsen lassen, seine Ess- und Trinkgewohnheiten ändern, seinen Tagesthythmus dem Rhythmus der Gebete anpassen, religiöse Rituale streng beobachten, seine Freunde und Be- 
kannten wechseln, bei jeder Gelegenheit den Koran und die Sunna rezitieren: all dies kann dazu dienen, ein „Nein“ zum Status quo auszudrücken und damit selbst in Situationen politischer Ohnmacht eine Quelle subjektiven Machtgewinns werden.

Die Kehrseite dieser normativ-kulturellen Rückbesinnung auf die eigenen religiösen Symbole bestand nicht zuletzt darin, diejenigen Minderheiten in der eigenen Gesellschaft anzugreifen und einzuschüchtern, die diesen Symbolen nicht zu respektieren schienen und damit als Einfallstore westlichen Gedankenguts ausgemacht werden konnten. Schien es auch lange Zeit unmöglich, die westlichen Kolonialmächte militärisch zu besiegen, so war es doch immerhin möglich, deren kulturelle Vormachtstellung dadurch herauszufordern, dass man die „Apostaten“, „Häretiker“, verwerflichen „Neuerer“ und „Verräter“ unter den Muslimen selbst verfolgte.

Schon lange vor der Rushdie-Affäre gab es in der arabischislamischen Welt große öffentliche Kampagnen gegen nonkonformistische Denker, etwa gegen 'Alī 'Abd al-Rāziqs Buch Der Islam und die Grundlagen der Herrschaft (al-islām wa-ușūl al-ḥukm, 1925), Taha Husayns Studie Über die vorislamische Poesie (Fi al-šír al-ğăbili, 1926); Nağīb Maḥfūẓs Roman Die Kinder unserer Straße (Auläd haritnā, 1959) oder Șādiq Ğalāl al-'Aẓms Kritik des religiösen Denkens (Naqd al-fiker aldini, 1969). In allen diesen Kampagnen konzentrierte sich die Kritik auf vermeintliche Abweichungen vom Islam, d.h. auf eine häretische bzw. blasphemische Dimension, die ihre Autoren zu Apostaten mache. Die Liste muslimischer Freidenker, die ähnlichen Kampagnen ausgesetzt waren, ließe sich beliebig erweitern. Zu den bekanntesten neueren Fällen gehören die des Journalisten Farağ Fūda (ermordet 1992), des Literaturnobelpreisträgers Nağīb Mạ̣fūz (1994 durch Mordanschlag schwer verletzt), des Koran-Hermeneutikers Naṣr Hāmid Abū Zayd (1995 Zwangsscheidung wegen Apostasie, seither Exil) und des Schriftstellers und Islamhistorikers Sayyid al-Qimnī (Widerruf und Schreibverzicht nach Morddrohungen 2005).

In der Rushdie-Affäre 1988-1989 begannen sich noch vier weitere Dimensionen solcher Kampagnen abzuzeichnen. Erstens deuten viele Indikatoren - der satirische Inhalt des Romans und die Reaktionen - darauf hin, dass es in der Rushdie-Affäre nicht nur um Fragen der Häresie und Apostasie ging, sondern auch um Probleme der Be- 
leidigung und damit der Ehre der muslimischen Gemeinschaft in einem multireligiösen weltgesellschaftlichen Umfeld. ${ }^{33}$ Zweitens richteten sich die Proteste und Morddrohungen diesmal nicht mehr „,nur“ gegen muslimische Autoren in muslimischen Ländern, sondern direkt gegen einen im Westen lebenden Autor, westliche Verlagshäuser und westliche Politiker. Drittens profilierten sich erstmals Teile der muslimischen Diaspora Europas als Speerspitze des Gesinnungsdrucks: Bücherverbrennungen - eine Praxis, die man in Europa zuvor primär mit der Erinnerung an die Inquisition und den Faschismus verbunden hatte - wurden jetzt öffentlich von muslimischen Einwanderern in Großbritannien zelebriert. Und viertens instrumentalisierte am 14. Februar 1989 - knapp fünf Monate nach Erscheinen der Satanischen Verse - ein ausländischer Staatsführer und Theologe, Ayatollah Khomeini (1902-1989), die Affäre, um mit seinem berühmten „Todesurteil“ gegen den britischen Staatsbürger Salman Rushdie das Recht auf weltweite Jurisdiktion für sich zu reklamieren und damit von seiner, Khomeinis, desaströsen Außenpolitik im Krieg gegen den Irak (1980-1988) abzulenken sowie zugleich eine neue ökumenische Brücke zu sunnitischen Muslimen zu schlagen.

Es war kein Zufall, dass gerade ein symbolbewusster Politiker und Theologe wie Khomeini bestrebt war, die Rushdie-Affäre aufzugreifen und sie durch sein Todesurteil sowie die auf Rushdies Ermordung ausgesetzte Kopfprämie so lange wie möglich zu verlängern. ${ }^{34}$ Die iranische Revolution von 1978-79, die ihm zum Sieg verholfen hatte, war ein revolutionäres, welthistorisches Ereignis gewesen, in dem religiöse Symbole, voran die Erinnerung an das Martyrium Husayn ibn 'Alīs bei Karbalā', eine zentrale Rolle bei der Mobilisierung der Bevölkerung gespielt hatten. Aus der Sicht der islamischen Revolutionäre war die Revolution ein Sieg des Geistes über die Materie, des Glaubens über die Technik gewesen. Gegen alle irdische Wahrscheinlichkeit hatte der Glaube im Iran Berge versetzt. Millionen zuvor scheinbar machtloser Menschen hatten ein übermächtiges, vom Westen militärisch hochgerüstetes Regime zu Fall

33 Vgl. Slaughter (1993), 155, 161-168, 170, 172-173, 193-200.

34 Khomeinis Todesurteil gegen den Verfasser der Satanischen Verse ist bis heute in Kraft und von der iranischen Staatsführung wiederholt bestätigt worden. Die 1989 ausgesetzte Kopfprämie für Rushdies Ermordung wurde von einer Million Dollar (1989) auf 2,8 Millionen (2006) erhöht. Siehe Wikipedia (2008). 
gebracht, indem sie sich ihrer Religion zugewandt, ihre Todesfurcht überwunden hatten und dadurch unüberwindbar geworden waren. Im irakisch-iranischen Krieg, in dem die iranische Führung ab Herbst 1982 Tausende Jugendliche mit Paradiesschlüsseln um den Hals in die irakischen Minenfelder geschickt hatte, war dieser $\mathrm{Zu}$ sammenhang von Transzendenzbezug, Todesverachtung und irdischer Macht vorübergehend sogar Teil der offiziellen Militärstrategie geworden. Langfristig noch folgenreicher waren die im November 1982 mit iranischer Hilfe einsetzenden „Märtyrer-Operationen“ schiitischer Islamisten im Libanon gegen amerikanische, französische und israelische Ziele. Sie führten zum Rückzug der amerikanischen, französischen und später auch der israelischen Truppen und motivierten damit auch sunnitische Gruppen, diese Kampftechnik aufzunehmen.

Der Glaube, dass technische und militärische Unterlegenheit durch die Intensität symbolisch vermittelter religiöser Motivation wettgemacht werden könnten, schien auch durch mehrere spätere Ereignisse bestätigt zu werden: den sowjetischen Rückzug aus Afghanistan 1989, den Rückzug Israels aus dem Südlibanon 2000, die Anschläge vom 11. September 2001, den Fehlschlag der 2003 begonnenen angloamerikanischen Invasion Iraks, der Wiederaufstieg der Taliban in Afghanistan nach 2001 sowie den Fehlschlag des israelischen 33-Tage-Kriegs gegen die libanesische Hizballah im Juli/August 2006. Nichtmuslimische Mächte, die von vielen Muslimen lange für unbesiegbar gehalten worden waren, schienen nun zunehmend als „Papiertiger“ entzaubert zu werden. ${ }^{35}$ Es ist kein Wunder, dass islamistische Aktivisten kaum eine Gelegenheit ausließen, den Wert ihrer religiösen Symbole öffentlich zu demonstrieren - und heftige Reaktionen auf deren Verspottungen durch westliche Säkularisten waren stets eine besonders medienwirksame Gelegenheit dazu.

\subsection{Politische Emotionen in Zeiten des Furchtverlusts}

Als der britische Journalist Robert Fisk im Herbst 2005 in Beirut sein Buch The Great War for Civilization vorstellte, bemerkte er, die wichtigste Veränderung, die er in nahezu dreißigjähriger Berufstätigkeit im Nahen Osten festgestellt habe, bestünde darin, dass die Ara- 
ber ihre Furcht verloren hätten. ${ }^{36}$ Diese bemerkenswerte Beobachtung verdient tiefes Nachdenken. Thomas Hobbes (1588-1679) zufolge ist die Furcht einer der wichtigsten Mechanismen, Menschen zu befrieden. ${ }^{37}$ Wo die Furcht erodiert, zerfallen auch die Sicherheitsstrukturen, die auf ihr beruhen.

In modernen Massenrevolutionen, etwa der Französischen Revolution, ist häufig beobachtet worden, dass die „Wut“ der Massen auf das jeweilige Ancien Régime in dem Maße wuchs, in dem sie ihre Furcht vor den Herrschenden verloren. Kleinigkeiten, die zuvor wenig Aufmerksamkeit erregt hätten, wurden nun als unerträgliche Symbole einer nicht mehr hinnehmbaren Unterdrückung wahrgenommen und mit öffentlichen Wutausbrüchen beantwortet. Diese Empörung, die gerade schwachen oder nachgiebigen Repräsentanten des Ancien Régime in revolutionären Situationen entgegenschlägt, scheint sich zum Teil aus dem Selbsthass derjenigen zu speisen, denen schlagartig bewusst wird, dass sie viel zu lange einen „Gott auf tönernen Füßen“ gefürchtet haben und nun vor der Möglichkeit stehen, ihn mit geringem Risiko für sich selbst in Scherben zu schlagen.

Eine andere radikalisierende Komponente des Furchtverlusts besteht allerdings darin, dass der Zerfall des Ancien Régime auch neue, ungeahnte Möglichkeitsräume des politischen Handelns und des zwischenmenschlichen Umgangs zu eröffnen scheint - Möglichkeitsräume, deren Grenzen erst noch experimentell auszutesten sind. Je größer der Kreis derjenigen, die aus der Streitkultur des Ancien Régime ausgeschlossen waren, desto größer das Risiko radikaler und utopischer Experimente. Gerade für Mitglieder primär ideologisch integrierter Oppositionsbewegungen ist die Versuchung groß, im Erfolgsrausch die eigenen „Prinzipien“ $z u$ verabsolutieren und bis in die letzten extremen Konsequenzen zu treiben. Erst dort, wo sich zeigt, dass auch die neuen Möglichkeitsräume nicht grenzenlos sind und dass sie, wenn überhaupt, nur auf der Basis gegenseitigen Respekts und gemeinsamer Kompromisse mit anderen genutzt werden können, kann sich eine neue öffentliche Streitkultur herausbilden.

Gerade Konflikte um die Ehre, d.h. um den Wert des „symbolischen Kapitals“ alter und neuer Akteure, ${ }^{38}$ sind ein wichtiger Testfall solcher Partizipationskonflikte. Wer die Reputation neuer Gruppen 
pauschal verächtlich macht, indem er ihre Kollektivsymbole verspottet, verringert ihr symbolisches Kapital und damit ihre Chancen, sich auf gleicher Augenhöhe an der Entscheidung öffentlicher Angelegenheiten zu beteiligen. Umgekehrt können leidenschaftliche öffentliche Reaktionen auf Beleidigungen der eigenen Kollektivsymbole auch zur Schaffung von partizipatorischer Zivilmacht seitens der Beleidigten beitragen. In dem sie ihre „Ehre“ in öffentlichen Kampagnen verteidigen, machen die Beleidigten darauf aufmerksam, dass sie Ehre besitzen und bereit sind, auf der Basis gegenseitigen Respekts an der Gesellschaft, in der sie leben, mehr teilzuhaben als zuvor.

\subsection{Vom Streit zur Streitkeultur}

Der dänische Karikaturenstreit, d.h. der Streit um die Darstellung des Propheten Muhammad in westlichen Massenmedien, kann in dieser Hinsicht als ein Experimentierfeld gegensätzlicher Tendenzen bei der Entstehung einer neuen Streitkultur in der Weltgesellschaft gesehen werden.

Zwischen der ursprünglichen Provokation, der Veröffentlichung der beleidigenden Karikaturen am 30. September 2005, und den darauf bezogenen internationalen Gewaltausbrüchen im Februar/März 2006 lagen mehrere Monate. In der Erforschung sozialer Unruhen ist dieses Phänomen als lull period, d.h. als Periode der Ruhe vor dem Sturm, bekannt. ${ }^{39}$ Es handelt sich hier natürlich um keine wirkliche Ruheperiode, sondern um eine Zeit gespannten Abwartens, hektischer Verhandlungen und logistischer Vorbereitungen auf die nächsten zu erwartenden Ereignisse. Solche Perioden können kurz sein, manchmal nur wenige Stunden umfassen, oder lang. Sie können für Verhandlungen und Vermittlungsinitiativen benutzt werden oder auch nicht. ${ }^{40}$ In jedem Fall entscheidet sich in dieser Ruheperiode, ob die Krise unkontrolliert eskaliert oder durch neue vertrauensbildende Maßnahmen im Zaum gehalten werden kann.

Im Falle der dänischen Karikaturenkrise wurde diese Chance nur unzureichend genutzt. Bezeichnenderweise bestand die erste muslimische Antwort auf die Karikaturen in einem höflichen Schreiben von elf Botschaftern muslimischer Länder an den dänischen 
Premierminister Anders Fogh Rasmussen. ${ }^{41}$ Das Schreiben erhob nicht den Vorwurf der Blasphemie, sondern den der Diskriminierung und sprach von einer Verleumdungskampagne gegen den Islam und Muslime, die dem Geist dänischer Toleranz und der Achtung der Menschenrechte zuwiderlaufe. Die Botschafter baten den Premierminister dringend um ein Treffen und forderten ihn auf, die Verantwortlichen nach Maßgabe dänischen (!) Rechts zur Verantwortung zu ziehen. Erst als der Premierminister dieses Treffen verweigerte und stattdessen öffentlich das Recht der dänischen Medien auf unzensierte freie Meinungsäußerung hervorhob, eskalierte die Krise weiter.

Auch jetzt kamen die wichtigsten Folgeschritte noch überwiegend von Muslimen, die keinen Bruch mit westlichen Regierungen wünschten und daher bestrebt waren, die Proteste auf der Ebene zivilgesellschaftlichen gewaltlosen Protests zu halten. Die Forderung nach einem Boykott dänischer Produkte wurde z.B. in Kuwait und Saudi-Arabien lanciert, d.h. in mit dem Westen politisch verbündeten Ländern, die ihr ramponiertes Image als Verteidiger muslimischer Interessen aufbessern wollten. Aus dieser Perspektive war die Karikaturenkrise eine Gelegenheit, öffentlich zu demonstrieren, dass Muslime ihre Interessen in der Weltgesellschaft auch auf gewaltlosem Wege wahrnehmen könnten, z.B. durch zivilgesellschaftliche Aufklärungs-, Missions-, und Boykottkampagnen, das Ausschöpfen aller vorhandenen Rechtsmittel sowie durch den Versuch, neues Recht zu schaffen und die Vereinten Nationen für ein stärkeres Engagement zum Schutz der Weltreligionen vor Diskriminierung und Verspottung zu gewinnen.

Erst relativ spät sprangen radikalere Kräfte auf den rollenden Zug auf, um ihn durch medienwirksame Gewaltaktionen in Richtung ihrer eigenen Agenden zu lenken. Die Tötung vieler Unschuldiger und Unbeteiligter, die dabei in Kauf genommen wurde, diskreditierte die Urheber dieser Aktionen auch in den Augen vieler Muslime, zumal sie offensichtlich Wasser auf die Mühlen islamophober und ausländerfeindlicher Kreise in Europa goss und im Widerspruch zum erklärten Ziel vieler muslimischer Organisationen stand, den Islam

41 Das vom 12. Oktober 2005 datierte Schreiben trug die Unterschriften der Botschafter bzw. Geschäftsträger Ägyptens, Algeriens, Bosniens, Indonesiens, des Iran, Libyens, Marokkos, Pakistans, Saudi-Arabiens, der Türkei sowie der Palästinensischen Delegation. Text abrufbar über Wikipedia (2007), Anmerkung 17. 
gegen den Vorwurf in Schutz zu nehmen, er sei eine Religion der Gewalt.

Alles in allem bot der dänische Karikaturenstreit das Bild einer Krise, deren Auswüchse hätten vermieden werden können, wenn gemäßigte Autoritäten auf beiden Seiten früher und entschiedener eingegriffen hätten, um die Zeit der „Windstille“ nach der ersten Veröffentlichung der Zeichnungen zu deeskalierenden Schritten zu nutzen.

Wie sich in den folgenden Monaten und Jahren zeigte, haben inzwischen viele Seiten aus dem dänischen Karikaturenstreit gelernt. Obwohl es auch danach an Anlässen nicht fehlte, bei denen Muslime zu Recht oder zu Unrecht annahmen, absichtlich provoziert und gekränkt worden zu sein, gab es keine vergleichbaren öffentlichen Ausschreitungen mehr, nicht zuletzt deshalb, weil die Bemühungen um Schadensbegrenzung früher einsetzten.

- Als z.B. nach Papst Benedikts XVI. Regensburger Rede vom 12. September 2006 erste Todesdrohungen und Ausschreitungen wegen der darin verklausuliert enthaltenen Kritik des Islam bekannt wurden, bemühte sich nicht nur der Papst persönlich um eine schnelle Entschärfung der Krise, sondern es antworteten ihm am 13. Oktober 2006 auch 38 sunnitische und schiitische Würdenträger in einem offenen Brief, in dem sie die Rede des Papstes zwar kritisierten, aber vor allem dafür eintraten, die Auseinandersetzung auf der Ebene des Dialogs zu führen - getreu der Aufforderung des Korans an die Angehörigen der Schriftreligionen, miteinander in guten Taten zu wetteifern (Koran, al-Mä́ida, 5.48). Ein Jahr später, am 13. Oktober 2007, folgte ein weiterer Brief, der von 138 Gelehrten aus 43 Ländern unterzeichnet war. ${ }^{42}$ Anfang 2008 war die Zahl der muslimischen Unterzeichner auf 216 gestiegen. ${ }^{43}$

- Als der niederländische Politiker Geert Wilders (*1963) im Februar 2007 erklärte, er würde den Propheten Muhammad als Extremisten aus dem Land jagen, falls dieser noch lebte, bedauerte die niederländische Regierung offiziell seine Äußerungen. Und als Wilders, der am 8. August 2007 ein Verbot des Korans in den Niederlanden verlangt hatte, ab Ende November 2007 
wiederholt andeutete, er arbeite an einem kritischen Film über den Koran und werde ihn demnächst ins Internet stellen, distanzierten sich die niederländische Regierung und die katholischen und protestantischen Kirchen der Niederlande schon im Vorfeld davon.

- Als zahlreiche dänische Zeitungen im Februar 2008 die umstrittenen Muhammad-Karikaturen erneut veröffentlichten (diesmal mit dem Argument, ein Zeichen gegen die Mordpläne dreier Islamisten gegen den Zeichner Kurt Westergaard setzen zu wollen), distanzierten sich der Päpstliche Rat für den Interreligiösen Dialog und die analoge Kommission der Kairoer AzharUniversität gemeinsam von diesem Schritt. ${ }^{44}$

- Als Papst Benedikt XVI. im März 2008 einen Muslim, den ägyptisch-italienischen Journalisten Magdi Allam (*1952), in der Osternacht mit großem Zeremoniell öffentlich im Petersdom taufte, stieß dies zwar auf Kritik islamischer Intellektueller, führte aber bisher nicht zu öffentlichen gewaltsamen Ausschreitungen. Der Vatikan konnte vielmehr im gleichen Monat auf bemerkenswerte Erfolge im christlich-muslimischen Dialog verweisen, etwa auf die Eröffnung der ersten christlichen Kirche in Qatar und auf Verhandlungen mit Saudi-Arabien, um auch dort die Genehmigung zum Bau von Kirchen zu erlangen.

Alles in allem zeigen die unterschiedlichen Reaktionen auf die geschilderten symbolträchtigen Ereignisse, dass symbolische Provokationen nicht zwangsläufig mit Gewalt beantwortet werden müssen. Sicher, die Bereitschaft, auf die Kränkung von Kollektivsymbolen mit Wut und gegebenenfalls Gewalt zu antworten, steigt mit der Bedeutung, die diesen Symbolen für das vitale Wohl und Wehe, die Ehre und Identität der eigenen Gemeinschaft zugeschrieben wird, sowie mit dem Grad der sozialen und emotionalen Abhängigkeit der Individuen von dieser symbolisch integrierten Gemeinschaft. Dennoch gibt es, wie die Erforschung sozialer Bewegungen inzwischen zur Genüge gezeigt hat, keinen automatischen Zusammenhang zwischen individueller und kollektiver Wut einerseits und der Form, sie öffentlich auszudrücken, andererseits. Zahlreiche zusätzliche Variablen spielen hier ebenso eine Rolle, z.B. das Krisenmanagement ge- 
mäßigter politischer und religiöser Autoritäten einschließlich der Wahl des richtigen Zeitpunkts, die Palette der objektiv zur Verfügung stehenden Mittel des Protests, die Vorsichtsmaßnahmen und der Grad der Repression durch die lokalen Ordnungskräfte, die Haltung der jeweiligen Regierung, die Intervention auswärtiger Mächte, die Einschätzung der globalen politischen Rahmenbedingungen durch die beteiligten Akteure sowie nicht zuletzt die frische Erinnerung an bereits gemachte gute oder schlechte Erfahrungen mit solchen Protestaktionen. Leidenschaftliche Proteste gegen vermutete Kollektivbeleidigungen können in eine Spirale von Gewalt und Gegengewalt münden und damit gewaltorientierten Gruppen neue Anhänger zuführen. Sie können aber, wenn sie gewaltlos bleiben, auch ein Weg sein, um zivile Alternativen zur sterilen Gewalt dschihadistischer Gruppen zu testen. Vom Kampf dieser beiden Tendenzen wird es abhängen, ob und in welchem Maße symbolische Aggressionen künftig zum Vorspiel von Gewaltausbrüchen werden oder ob sie zur Entwicklung einer demokratisch-pluralistischen Streit- und Partizipationskultur beitragen, die das Recht auf freie Meinungsäußerung ebenso respektiert wie die Würde und religiösen Gefühle anderer.

\section{Literatur}

Anderson, Benedict (1991): Imagined Communities: Reflections on the Origin and Spread of Nationalism, revised edition. London: Verso.

Anonym (2006): „Cartoon Body Count: Death by Drawing“, online unter: http:/ / www.cartoonbodycount.com (Zugriff am 27.3.2006).

Assmann, Jan (2003): Die Mosaische Unterscheidung oder Der Preis des Monotheismus. München: Hanser.

Benedikt XVI. (2006): Glaube, Vernunft und Universalität. Erinnerungen und Reflexionen. Ansprache von Benedikt XVI. Aula Magna der Universität Regensburg, Dienstag, 12. September 2006, online unter: http://www.vatican. va/holy_father/benedict_xvi/speeches/2006/september/documents/ hf_ben-xvi_spe_20060912_university-regensburg_ge.html (Zugriff am 18.5.2008).

Benjamin, Walter (1985): „Kapitalismus als Religion“, in: Benjamin, Walter: Gesammelte Schriften. Band 6. Frankfurt/M.: Suhrkamp, 100-103.

Bliege Bird, Rebecca/Smith, Eric Alden (2005): „Signaling Theory, Strategic Interaction, and Symbolic Capital“", in: Current Anthropology 46 (2), 221 238. 
Bock, Joseph G./McCauley, Clark (2003): „A Call to Lateral Mission: Mobilizing Religious Authority against Ethnic Violence“, in: Mission Studies 20 (2), 9-34.

Bourdieu, Pierre (1979): Entwurf einer Theorie der Praxis auf der ethnologischen Grundlage der kabylischen Gesellschaft. Frankfurt/M.: Suhrkamp.

Bourdieu, Pierre (1990): The Logic of Practice. Cambridge, UK: Polity Press.

della Porta, Donatella/Diani, Mario (2006): Social Movements: An Introduction. London: Blackwell.

Di Blasi, Luca (2000): „Zivilreligion und antifaschistischer Grundkonsens“, in: Zeitschrift für Politik 47 (4), 369-387.

Durkheim, Emile (1981): Die elementaren Formen des religiösen Lebens. Frankfurt/M.: Suhrkamp.

Fisk, Robert (2005a): The Great War for Civilisation: The Conquest of the Middle East. New York: Knopf.

Fisk, Robert (2005b): „Fisk: Aujourd'hui, les Arabes n'ont plus peur, tel est le seul véritable changement régional. Propos recueillis par Emilie Sueur", in: L'Orient-Le Jour, 7. November.

Frazer, James George (1989): Der Goldene Zweig. Das Geheimnis von Glauben und Sitten der Völker. Hamburg: Rowohlt.

Girard, René (1992): Ausstoßung und Verfolgung: Eine historische Theorie des Sündenbocks. Frankfurt/M.: Fischer.

Goldziher, Ignaz (1968): „Le dénombrement des sectes mahométanes“, in: Goldziher, Ignaz: Gesammelte Schriften. Band 2. Hildesheim: Olm, 406414.

Griffel, Frank (2001): „Toleration and Exclusion: al-Shāfíī and al-Ghazālī on the Treatment of Apostates", in: Bulletin of the School of Oriental and African Studies 64 (3), 339-354.

Harrison, Simon (1995): „Four Types of Symbolic Conflict“, in: The Journal of the Royal Anthropological Institute 1 (2), 255-272.

Hasenclever, Andreas/Rittberger, Volker (2000): „Does Religion Make a Difference? Theoretical Approaches to the Impact of Faith on Political Conflict", in: Millenium 29 (3), 641-674.

Hawting, Gerald R. (1997): „Širk and 'Idolatry' in Monotheist Polemic“, in: Israel Oriental Studies 17, 107-126.

Hobbes, Thomas (1976): Leviathan oder Stoff, Form und Gewalt eines bürgerlichen und kircblichen Staates. Frankfurt/M.: Ullstein.

Horowitz, Donald L. (2001): The Deadly Ethnic Riot. Berkeley: University of California Press.

Ibn Ishāà, Muhammad (172004): The Life of Mubammad: A Translation of Ișāqq's Sirat Rasūl Alläh. Karachi: Oxford University Press.

Ibn Kathīr (2000): Tafsir Ibn Kathir (Abridged). Zehn Bände. Riyadh: Darussalam Publishers.

Lewis, Bernard (1990): „The Roots of Muslim Rage“, in: The Atlantic Monthly 266 (3), 47-60. 
Lewis, Bernard (2002): What Went Wrong? Western Impact and Middle Eastern Response. New York: Oxford University Press.

Mauss, Marcel (1968): Die Gabe: Form und Funktion des Austauschs in archaischen Gesellschaften. Frankfurt/M.: Suhrkamp.

McAdam, Doug/McCarthy, John D./Zald, Mayer N., Hg. (1996): Comparative Perspectives on Social Movements: Political Opportunities, Mobilizing Structures, and Cultural Framings. New York: Cambridge University Press.

Mitchell, Richard P. (1993): The Society of the Muslim Brothers. New York: Oxford University Press.

Muller, Jerry Z. (2008): „Us and Them: The Enduring Power of Ethnic Nationalism", in: Foreign Affairs 87 (2), 18-35.

Orient (2008): „Les caricatures de Mohammad condamnés d'une seule voix par le Vatican et al-Azhar", in : L'Orient-Le Jour, 28. Februar, 10.

Palaver, Wolfgang (2002): „Kapitalismus als Religion“, online unter http:// theol.uibk.ac.at/leseraum/artikel/283.html (Zugriff am 6.5.2008).

Palaver, Wolfgang (2003): René Girards mimetische Theorie im Kontext kulturtheoretischer und gesellschaftspolitischer Fragen. Münster: LIT.

Rodinson, Maxime (1971): Mohammed. New York: Pantheon Books.

As-Safadi, Muhammad Ibn 'Abd ar-Rahman (2004): The Mercy in the Difference of the Four Sunni Schools of Islamic Law. London: Dar al-Taqwa.

Samir, Samir Khalil, SJ (2007): „The Letter of 138 Scholars to the Pope“, in: Asia News, 17 October, online unter: http://www.asianews.it/ index.php? $1=$ en\&art $=10577 \&$ geo $=\&$ theme $=\&$ size $=$ A (Zugriff am 5.5. 2008).

Samir, Samir Khalil, SJ (2008): „Benedict XVI’s Improbable Dialogue with 138 Muslim Scholars", in: Asia News, 9 January, online unter: http:/ / www.asianews.it/index.php?l=en\&art=11201\&size=A (Zugriff am 5.5.2008).

Scheffler, Thomas (1996): „Worte, Taten, Bilder: Gewaltkult und Realpolitik im palästinensischen Nationalismus", in: Orywal, Erwin/Rao, Aparna/Bollig, Michael, Hg.: Krieg und Kampf: Die Gewalt in unseren Köpfen. Berlin: Reimer, 121-133.

Scheffler, Thomas (2002): „Allahu akbar‘: Zur Theologie des Widerstandsgeistes im Islam“, in: Stanisavljević, André/Zwengel, Ralf, Hg.: Religion und Gewalt: Der Islam nach dem 11. September 2001. Potsdam: Mostar Friedensprojekt, 21-46.

Scheffler, Thomas (2004): „Zeitenwende und Befreiungskampf: Zur Gegenwartsdiagnose Bin Lādins“, in: Kippenberg, Hans G./Seidensticker, Tilman, Hg.: Terror im Dienste Gottes: Die „Geistliche Anleitung“ der Attentäter des 11. September 2001, Frankfurt/M.: Campus, 87-105.

Slaughter, Marty M. (1993): „The Salman Rushdie Affair: Apostasy, Honor, and Freedom of Speech“, in: Virginia Law Review 79 (1), 153-204.

Stark, Rodney (1996): The Rise of Christianity: A Sociologist Reconsiders History. Princeton/NJ: Princeton University Press. 
Stark, Rodney (2001): One True God: Historical Consequences of Monotheism. Princeton/NJ: Princeton University Press.

Veblen, Thorstein (1981): Theorie der feinen Leute: Eine ökonomische Untersuchung der Institutionen. München: Deutscher Taschenbuch Verlag.

Watt, William M. (1971): „The Great Community and the Sects”, in: Grunebaum, Gustave E. von, Hg.: Theology and Law in Islam. Wiesbaden: Harrassowitz, 25-36.

Webster, David L., 1976: „On Theocracies“, in: American Anthropologist 78 (4), 812-828.

Wikipedia (2007): „Jyllands-Posten Muhammad cartoons controversy“, online unter: http://en.wikipedia.org/wiki/Jyllands-Posten_Muham mad_cartoons_controversy (Zugriff am 27.12.2007).

Wikipedia (2008): „The Satanic Verses controversy“, online unter: http://en. wikipedia.org/wiki/The_Satanic_Verses_controversy (Zugriff am 5.5. 2008).

Wiktorowicz, Quintan (2004): „Introduction: Islamic Activism and Social Movement Theory“, in: Wiktorowicz, Quintan, Hg.: Islamic Activism: A Social Movement Theory Approach. Bloomington: Indiana University Press, $1-33$. 


\section{Monotheismus und Demokratie. Eine Standortbestimmung}

Jürgen Manemann

\section{Zwischen Neopolitisierung und Entpolitisierung der Religion}

\subsection{Entsäkularisierung: Die Wiederkehr der Religionen}

Wir leben in einer krisengeschüttelten Weltrisikogesellschaft. ${ }^{1}$ Das Wort „Krise“ avanciert mehr und mehr zum Schlüsselwort der gesellschaftspolitischen und geistigen Signatur unserer Zeit: Es ist nicht nur die Rede von der Beschäftigungskrise, der Krise des Moralischen, der Krise des Politischen, der ökologischen Krise, sondern auch von der Kirchen-, ja sogar von der Gotteskrise. Nur von der Religionskrise ist nicht die Rede. Religion boomt. Soziologen sprechen sogar von einer Religionsproduktivität.

Die Wiederkehr der Religionen irritiert und erschreckt: Zum einen, weil sie alle harmonischen Visionen vom „Ende der Geschichte" zerstört, die im Zusammenhang mit den Umbruchsprozessen im Jahre 1989 ausgerufen worden sind. ${ }^{2}$ Mit den Religionen kehrt die Geschichte wieder. Zum anderen, weil es sich nicht um die Wiederkehr eines schon Bekannten handelt: „Alles, was geschieht, geschieht nur einmal, und ,Religion heute“ ist nicht ,Religion gestern"“.3 Geschichte kennt bekanntlich keine Renaissancen. Von Religionsproduktivität sprechen Religionssoziologen hierzulande primär im Hin- 
blick auf neue religiöse Bewegungen, deren Trägerin in erster Linie eine von Midlifekrisen bedrohte Mittelschicht ist. So werden denn auch diese Phänomene unter den Begriff „City Religion“ subsumiert. ${ }^{4}$ Des Weiteren dient der Begriff dazu, auf einen Aggregatwechsel des Religiösen im Zeitalter reflexiver Modernisierung zu verweisen, der in Prozessen der De-Institutionaliserung wurzelt. ${ }^{5}$ Neben diesen eher privaten und unsichtbaren Formen von Religiosität gibt es aber auch eine Wiederkehr sogenannter ,,public religions“. Damit meint der US-amerikanische Religionssoziologe José Casanova ,the revitalization and the assumption of public roles by precisely those religious traditions which [...] theories of secularization [...] had assumed were becoming ever more marginal and irrelevant in the modern world". ${ }^{6}$ Es ist in erster Linie dieses Phänomen einer Entprivatisierung, das heutzutage eine radikale Herausforderung darstellt.

Mit dem gegenwärtigen Vormarsch öffentlicher Religionen brechen Konflikte auf, die mit einer Bedrohung fundamentaler Voraussetzungen demokratischen Zusammenlebens einhergehen. Zunehmend werden Stimmen laut, die die Überwindung einer gescheiterten Moderne fordern, in deren Gottesferne die Ursache aller Misserfolge und Ausweglosigkeiten gesehen wird. Zukunftsfähig sei die Gesellschaft nur, so ihre Kritiker, wenn sie wieder auf eine sakrale Grundlage gestellt werden würde. Dieser Trend zur Entsäkularisierung geht auf breiter Front vonstatten, insbesondere in den monotheistischen Religionen. ${ }^{7}$ Im Zuge dieser Prozesse erhält Religion als ein Identitäts- und Unterscheidungskriterium neue Valenz.

Entsäkularisierungsprozesse sind keineswegs nur in nichtdemokratischen „Angstgesellschaften“ aufweisbar, sondern auch in demokratischen „Freiheitsgesellschaften“, 8 wie ein Blick auf die USA, insbesondere auf die neokonservative Politik von George W. Bush, verdeutlicht. Wenn Bush den Amerikaner(inne)n und ihrer Führung die Aufgabe zuweist, ,die Gunst der Stunde zu nutzen, um die Vorzüge der Freiheit in der ganzen Welt zu verbreiten", ${ }^{\text {( }) ~ w e n n ~ e r ~ s i c h ~}$

4 Vgl. Höhn (1994), 118-138.

5 Vgl. Gabriel (2000).

6 Casanova (1994), 5.

7 Kepel (1991), 14.

$8 \mathrm{Zu}$ dieser Terminologie siehe Sharansky/Dermer (2004).

9 George W. Bush verkündete am 28. Januar 2003: „,[...] freedom is not America's gift to the world, it is God's gift to humanity." Dass damit ein Sendungsauftrag verbunden ist, wurde bereits in seiner Eröffnungsrede der nationalen Sicherheitsstrategie vom 17. Sep- 
dabei als Instrument Gottes begreift und in seinen Reden den Gedanken des Gerichts, das über Gut und Böse entscheidet, mit einer realen politischen Instanz verbindet, dann droht erneut die Gefahr, dass eine politische Instanz sich zum Subjekt der Geschichte ermächtigt und diejenigen, die in ihrem Namen handeln, zu Vollstreckern der als Weltgericht gedachten Geschichte macht. ${ }^{10}$

Es droht also gegenwärtig eine Neopolitisierung von Religionen, in deren Verlauf diese als Waffe im Kampf um kollektive Identitäten missbraucht werden.

\subsection{Säkularisierung: Die Forderung der Entpolitisierung Gottes}

Wie kann diesen Herausforderungen standgehalten werden? Angesichts islamischer und christlicher Verschärfungen sind Forderungen nach einer forcierten Säkularisierung, nach einem strikten Laizismus nur allzu verständlich. Ihre Vertreter geben sich nicht mehr mit der Trennung von Staat und Kirche zufrieden, sondern zielen auf eine generelle Trennung von Religion und Politik, wollen die Religionen auf den ihnen zustehenden Platz verweisen - die Moschee, die Kirche, die Synagoge und den Privatbereich. Im Zuge dieser Forderungen wird die Frage aufgeworfen, ob denn nicht grundsätzlich alle auf Absolutheitsansprüche basierenden Religionen demokratieunverträglich seien. Müsse nicht spätestens nach den Terroranschlägen vom 11. September 2001 die Hoffnung aufgegeben werden, die in den monotheistischen Religionen enthaltene Gewalt rationalisieren zu können? Seien die Terrorattacken nicht der Beweis, dass mit Gott alles erlaubt und möglich sei, sogar die Vernichtung Tausender Menschen? Folglich hätte also nicht die Moral ihr Fundament in Gott, sondern der Glaube an den einzigen Gott wäre der Grund für die Unmoral. Demgemäß müsste Dostojewskijs Ausspruch „Ohne Gott ist alles erlaubt“ heute umformuliert werden: „Mit Gott ist alles erlaubt!" An der Zeit wäre also eine strikte Depolitisierung der Religion im Allgemeinen und des Christentums im Besonderen. Dem biblischen Gott könne allenfalls noch im privaten Bereich ein Duldungsrecht zugesprochen werden.

tember 2002 deutlich: „Schließlich werden die Vereinigten Staaten die Gunst der Stunde nutzen, um die Vorzüge der Freiheit in der ganzen Welt zu verbreiten.“; vgl. dazu Junker (2005), 217.

10 Vgl. dazu Liebsch (2005). 


\section{Politik als das Totale}

Die Frage nach dem Verhältnis der Religionen zur Neuzeit und zur Moderne, zum säkularen Staat und zur pluralistischen Gesellschaft überhaupt spitzt sich immer mehr zu. Wie ist das Verhältnis von Monotheismus und Demokratie im Spannungsfeld zwischen der Politisierung der Religion auf der einen und der Depolitisierung der Religion auf der anderen Seite zu bestimmen?

Die Politisierung der Religion geht mit einer polemischen, einer auf einer Freund-Feind-Unterscheidung basierenden Politik einher, in der bereits eine radikale Feindschaft präformiert ist. ${ }^{11}$ Im Zuge dieser Politisierungen wird unter Rekurs auf politische Philosophien und politische Theologien eine Politik der Feindschaft entwickelt. ${ }^{12}$ Es war insbesondere der politische Theologe und Katholik Carl Schmitt - der „Kronjurist des III. Reiches“ (Waldemar Gurian) -, der die Einsicht in die Notwendigkeit eines Feinddenkens schärfte, indem er darauf insistierte, dass niemand seine Identität retten könne, ohne sich zu klassifizieren, d.h. ohne sich durch einen Feind zu klassifizieren. ${ }^{13}$ In diesem Sinne gibt es also kein eigentlich politisches Handeln ohne die Unterscheidung von Freund und Feind. Ein Kollektiv - sei es ein Volk oder eine Nation -, das zu dieser Unterscheidung nicht mehr fähig ist, ist nach Schmitt zum Untergang verdammt.

Die religionspolitisch folgenreiche Kulturkampftheorie des USamerikanischen Politologen Samuel Huntington, sein Szenario vom Clash of Civilizations, ist eine translatio hostilitatis auf die neuen geopolitischen Konstellationen im ausgehenden 20. und am Beginn des 21. Jahrhunderts. Huntington zufolge kann kein Staatsmann und Wissenschaftler von der fundamentalen Bedeutung der Feindschaft absehen, denn: „Für Menschen, die ihre Identität suchen und ihre Ethnizität neu erfinden, sind Feinde unabdingbar, und die potentiell gefährlichsten Feindschaften begegnen uns an den Bruchlinien zwischen den großen Kulturen der Welt." "14 Huntington geht sogar so weit, dass er seine Aussagen auch noch anthropologisch abzusichern versucht: „Hassen ist menschlich. Die Menschen brauchen Feinde

$12 \mathrm{Zu}$ dieser Terminologie siehe Sharansky/Dermer (2004).

13 Schmitt (1991), 36.

14 Huntington (1998), 18. 
zu ihrer Selbstdefinition $[\ldots]^{\natural .} .15$ Wer also wissen möchte, wer er ist, der muss wissen, wer er nicht ist und gegen wen er ist. ${ }^{16}$

Für Schmitt war das Politische - die Unterscheidung von Freund und Feind - das Totale. Auch bei Huntington droht das Politische wieder das Totale zu werden. In der Art und Weise, wie er das Politische in die Kultur einschreibt, tritt es an die Stelle der Kultur: das Politische wird zum neuen Namen für Kultur. Kulturelle Identität wird antagonistisch angeschärft. Dadurch wird das Kulturelle transformiert, denn die kulturelle Differenz ist eigentlich nicht die zwischen Freund und Feind, sondern die zwischen Eigenem und Anderem, dem Hiesigen und dem Fremden. ${ }^{17}$

Nun beinhalten Kulturen zwar selbst die Gefahr, Nährboden für ein polemisches Identitäts- und Politikverständnis zu sein, sind sie doch aufgrund ihrer Identität-Differenz-Funktion zutiefst ambivalent. ${ }^{18}$ Die Artikulation einer kulturellen Differenz erzeugt ja erst so etwas wie kulturelle Identität. Diese Differenz kann durchaus in antagonistische Strukturen umkippen: Wir - die Anderen, Zivilisierter - Barbar, Freund - Feind. Kulturelle Kategorien sind jedoch nicht per se antagonistisch konturiert. Die kulturelle Kategorie der Fremdheit ist beispielsweise im eigentlichen Verständnis ein Begriff ohne Gegenbegriff, mithin kein Begriff sozialer Ordnung im Sinne von Reinhard Koselleck. ${ }^{19}$ Dennoch kann Fremdheit zu Feindschaft mutieren, dagegen wurde in Kulturen bekanntlich das Institut der Gastlichkeit entwickelt. Um allerdings derartige Dualismen aufzubrechen, bedarf es eines Kulturverständnisses, das Kultur nicht als Besitz betrachtet: Meine Kultur ist niemals nur meine Kultur - das beinhaltet auch die Einsicht, dass Kultur originär interkulturell ist. ${ }^{20}$

\section{Monotheismus als partikularisierender Universalismus}

Die Politiken der Feindschaft, die in demokratisch verfassten Gesellschaften $\mathrm{zu}$ entstehen beginnen, sind nicht ein endogenes Virus, sondern das Produkt eines gnostischen Verständnisses des Christen- 
tums, das dualistisch grundiert ist und die Welt in Jenseits und Diesseits, Gut und Böse, Licht und Finsternis, guter Gott und schlechter Gott einzuteilen weiß. Die Anziehungskraft solcher Stereotypen resultiert aus der Einfachheit, mit der die Welt durch sie aufgeteilt wird. Ein gnostischer Dualismus ist nicht mit dem biblischen Monotheismus vereinbar. Deshalb sind auch die dualistisch grundierten Politiken kein monotheistischer Reflex. Im Gegenteil! Der Monotheismus ist durch und durch antidualistisch. Seine fundamentale kulturelle Funktion besteht in dem Bekenntnis zu einem einzigen Gott, das den Grund dafür legt, „die Wirklichkeit als Einheit zu begreifen und für die Menschheit mit einer universalen Geschichte zu rechnen“. Der Sinn des Monotheismus liegt demnach nicht in der bloßen Behauptung, ,daß es nur einen Gott gebe statt vieler, sondern in seiner Bestimmung der menschlichen Welt: daß sie nicht gespalten sein soll im Widerstreit göttlicher Mächte und in der Verteilung unterschiedlicher Herrschaftsregionen, nicht zerrissen in einem unüberwindbaren Dualismus von Licht und Finsternis, von gutem und bösem Sein, nicht endgültig pluralisiert in der antagonistischen Selbstbehauptung der Völker". ${ }^{21}$

Der strikt anti-dualistische Affekt des Monotheismus resultiert aus seinem Universalismus. Gerade dieser Nexus wird jedoch heute als Beweis für das konstitutive Gewaltpotential des Monotheismus herangezogen. Im Rahmen dieser Herleitungen wird exemplarisch immer wieder auf Reden des US-amerikanischen Präsidenten rekurriert. Dessen Reden sind allerdings von einem Sendungsbewusstsein durchdrungen, das daraufhin zu befragen ist, ob sich in ihm das Bemühen um einen Universalismus um der Anderen willen artikuliert oder ein Universalismus, der aus einem Ermächtigungsstreben hervorgeht.

Aufgrund seiner Leidempfindlichkeit kämpft der reflexive Monotheismus immer wieder gegen seine eigenen usurpatorischen Momente an. Aus den biblischen Texten lassen sich vor allem zwei Formen des Universalismus herausfiltern: ein covering law-Universalismus, der material in dem Sinne ist, dass er den Glauben an einen Gott konsequent deutet als ein Gesetz, eine Gerechtigkeit, eine Erlösung, eine Vorstellung vom guten Leben etc.; bei der zweiten Form 
handelt es sich dagegen um einen (re)iterativen Universalismus ${ }^{22}$, der paradigmatisch von Amos artikuliert wird: „Seid ihr für mich mehr als die Kuschiter, ihr Israeliten? - Spruch des Herrn. Wohl habe ich Israel aus Ägypten heraufgeführt, aber ebenso die Philister aus Kaftor und die Aramäer aus Kir“، (Am 9.7) Aus dieser Perspektive betrachtet, gibt es also nicht nur einen Auszug, eine göttliche Erlösung, einen Zeitpunkt der Befreiung für die ganze Menschheit. „Befreiung ist eine besondere, von jedem unterdrückten Volk wiederholte Erfahrung. Gleichzeitig ist sie in jedem Einzelfall eine gute Erfahrung, denn Gott ist der allgemeine Befreier. Jedes Volk erfährt seine eigene Befreiung durch die Hand eines einzigen, in allen Fällen identischen Gottes, dem vermutlich jegliche Unterdrückung verhasst ist" ${ }^{\text {“ }}{ }^{23}$

Von großer Bedeutung für das biblische Verständnis des Universalismus ist der Bund, den Gott vor dem Bund mit dem Volk Israel und vor dem Bund mit Abraham mit allen Menschen und Tieren geschlossen hat: der Bund mit Noah (Gen 9.8-17). Die Erinnerung an diesen Bund ist Ausdruck des Widerstandes gegen alle Versuche, Gott als Besitz einer bestimmten Religion zu reklamieren. Und so wird Johann Baptist Metz nicht müde zu betonen, dass Gott ein Menschheitsthema ist oder überhaupt kein Thema. Im Lichte einer solchen Perspektivierung wird auch die Erwählungskategorie, die immer wieder religiös zu politischen Machtzwecken benutzt worden ist, in ihrem Antielitismus einsichtig. ${ }^{24}$ Erwählung stellt eben kein Privileg dar, sondern weit mehr eine Bürde, denn wer auserwählt ist, muss sich mit strengeren Maßstäben messen lassen als die Anderen. Der biblische Monotheismus steht für eine „Dignity of difference“: ,a unity in heaven creates diversity on earth“ ". ${ }^{25}$ Ein solcher Universalismus partikularisiert, und Partikularität ist Ausdruck der Liebe. Liebe drückt sich nämlich nicht in einer generalisierten Affektion zu Personen aus; Liebe ist eine partikulare Beziehung zu einer Person in ihrer/seiner Einzigartigkeit. Ein solcher Universalismus kann als Fundament von Differenz ausgelegt werden. ${ }^{26}$

22 Vgl. Walzer (1996) und Rottländer (1993).

23 Walzer (1996), 144.

24 Vgl. Werbick (2000), 696-701.

25 Sacks (2003), 54.

26 Vgl. Walzer (1996). 


\section{Kultur der Anerkennung der Anderen in ihrem Anderssein}

Der biblische Monotheismus zielt auf eine Kultur der Anerkennung der Anderen in ihrem Anderssein. Eine solche Kultur beinhaltet neben der Verpflichtung zur Anerkennung anderer Kulturen eine Verpflichtung auf eine in die Kultur eingeschriebene Differenz, die eine „Anderheit“"27 in der Andersheit des Anderen markiert. So wird der Andere nicht in seiner Andersartigkeit bzw. Andersheit eingesperrt, sondern in seinem Antlitz wahrgenommen. Die Herausforderung des Anderen darf nämlich nicht auf den Kontext reduziert, der Kontext nicht zum alleinigen Identitätsmarker erklärt werden. Dadurch wird auch die Hermeneutik verändert. Verstehen ist mehr als das Verstehen eines Kontextes; es ist Anruf und Anspruch. Der Andere lässt sich nie einfach aus dem jeweiligen kulturellen Horizont ableiten; „Anderheit“ steht quer zu allen Festlegungen. Mit ihr ist die Weigerung bezeichnet, den Anderen auf seine Kultur zu reduzieren, ihn seiner unvergleichbaren Singularität zu berauben. Keine Kultur kann die Würde einer Person beanspruchen. ${ }^{28}$ Ein solches Kulturverständnis widersteht somit Versuchen, Kulturen als geschlossene Einheiten zu zementieren. ${ }^{29}$

Diese intrakulturellen Bruchlinien mit ihren Konflikten sind das Lebenselixier der Kulturen. Eine Kultur der Anerkennung der Anderen in ihrem Anderssein ist das Fundament einer Differenz, die das Gegenteil eines gleichgültigen Relativismus ist, handelt es sich doch um eine Differenz im Verhältnis zum Anderen als Nicht-Indifferenz. Diese Nicht-Indifferenz ist eine Heraus-Forderung, in der das Ich zum Anderen steht, insofern der Andere der Nächste ist. Sie zielt auf eine Gesellschaft, in der man „ohne Angst verschieden sein“30 kann. Demokratische Gesellschaften sind der Humus, auf dem eine Kultur der Anerkennung der Anderen in ihrem Anderssein sich entwickelt. Die kulturelle Herausforderung für die Gesellschaft wird jedoch unterlaufen, wenn Politiker sich in einem behaglichen Antagonismus einrichten, indem sie Anderheit und Andersheit, welche Vergesellschaftungen aufbrechen, durch die Kategorie des Feindes zu substituieren versuchen. Solche Versuche dienen dazu, die Herausforderung durch den Anderen zu unterlaufen. 


\section{Demokratie: Leben mit Ungewissheit}

Die Zementierung einer Einheit, auf die Politiken der Feindschaft abzielen, ist zutiefst antidemokratisch, da ein Volk reklamiert wird, das eine Einheit, Eines darstellt. Das empirische Volk setzt sich jedoch aus Vielen zusammen. Es ist „das Volk aus Fleisch und Blut mit seinen Individuen“. 31 Aus diesem Grund hat Demokratie ihren Lebensnerv nicht im Konsens, sondern im Dissens. Der Dissens ist der Motor der Demokratie. Der Dissens ist Garant der Freiheit aller Bürger: der Freiheiten des Dissidenten gegenüber dem Souverän und der Mehrheit gegenüber sich selbst. Die Demokratie ist in dem Sinne zukünftig, da in ihr das Versprechen grundgelegt ist, das wirkliche Volk als „das Ensemble der streitenden Individuen“ ernst zu nehmen. ${ }^{32}$ Darin besteht die demokratische Herausforderung. Im Aushalten des Dissenses kann so etwas wie eine „erweiterte Denkungs-

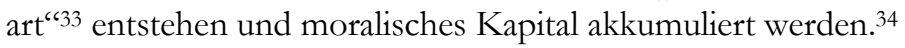

Demokratie zielt nicht auf Volkwerdung, sondern auf Subjektwerdung. Demokratie ist die ,institutionalisierte Form des öffentlichen Umgangs mit Ungewissheit". 35 An der Zeit ist ein erweitertes Demokratieverständnis, das Demokratie nicht einfach gleichsetzt mit einer bestimmten Regierungsform, sondern mit einer bestimmten Art zu sein. Gefordert ist ein Verständnis von Demokratie, das Demokratie als eine Lebensform versteht, die den Menschen viel abverlangt. Demokratie heißt, mit Ungewissheiten leben zu können, sie als produktive Herausforderungen zu verstehen. Aber mit Ungewissheiten zu leben ist ein Risiko. Die Zerrissenheit in Permanenz kann scheitern. Sie macht Angst. Ungewissheit kann aber auch neue Handlungsspielräume entstehen lassen. Von diesem Wissen zeugt der biblische Monotheismus. Er dient deshalb nicht dazu, dieser Ungewissheit Herr zu werden. Im Gegenteil! Er radikalisiert die Ungewissheit. Der biblische Monotheismus ist ein einziger Aufruf gegen Verwurzelungen, ein Aufruf zu produktiver Heimatlosigkeit. ${ }^{36}$ Abraham wird von Gott auf den Weg gerufen, und es wird ihm ge- 
sagt, er solle nie wieder an den Ursprung zurückkehren. Ungewissheit ist das Fundament der Subjektwerdung.

Der Ort der Subjektwerdung in der Demokratie ist die Zivilgesellschaft. Sie ist der Ort, an dem die Mobilisierung der moralischen Kräfte stattfindet. Die Zivilgesellschaft ist der eigentliche Motor der Demokratie. Sie ist Quelle von Widerstand, Innovation und Veränderungen - mit einem anderen Wort: Ort der Subpolitik. Subpolitik unterscheidet sich von Politik dadurch, dass sie nicht regelgeleitet ist, sondern regelverändernd wirkt. ${ }^{37}$ Die Zivilgesellschaft ist auch der öffentliche Raum, in dem Religionsgemeinschaften als soziale Akteure wirken. Monotheistische Religionen können eine Quelle regelverändernder Politik sein. Der Glaube an den einen, einzigen Gott begründet eine Moralität, die auf einem negativen Universalismus basiert, der das Axiom enthält, ,dass es kein Leid gibt, das uns nicht angeht" (Peter Rottländer). Das Buch Ijob, das dem Schrei eines Einzelnen Ausdruck verleiht, zeigt, dass der pathische Monotheismus auf die Dignität des Menschen in seiner Singularität zielt. Daraus entsteht ein Veränderungspotential, das nicht nur die Religionen, sondern auch demokratische Gesellschaften dazu nötigt, nicht bei sich zu bleiben.

\section{Die Politik und das Politische}

Diese Entgrenzung macht es Gesellschaften schwer, sich gleichgültig gegenüber dem Anspruch des Fremden zu verhalten. Sogar angesichts des Feindes wird der Anspruch auf Gerechtigkeit eingefordert. An dieser Stelle ist man mit der wohl radikalsten Gegenidee zu den Politiken der Feindschaft konfrontiert, nämlich mit der Aufforderung „Liebe deinen Feind!“‘ Das heißt, dass es im Feind immer auch den Anderen mitzuentdecken gilt, „für den man noch im Exzess kollektiver Verfeindung eine nicht abzuwerfende Mit-Verantwortung trägt". ${ }^{38}$ Eine auf einer dualistischen Rhetorik basierende Politik der Feindschaft kündet deshalb auch nicht die Verschärfung des Politischen an, sondern dessen Liquidierung. Der Bereich des Politischen wird nämlich verlassen, wenn jemandem der Anspruch zu existieren, 
abgesprochen wird. ${ }^{39}$ Die Verfechter einer dualistischen Politik sind deshalb auf dem Weg ins Antipolitische.

Das Politische beruht auf der Tatsache der Verschiedenheit der Menschen. ${ }^{40}$ Es handelt nicht nur „,von dem Zusammen- und Miteinandersein der Menschen“, sondern es entsteht überhaupt erst dann, wenn die Beziehung zwischen dem Ich und dem Anderen durch den Dritten erschüttert wird; das Politische ist dieses Zwischenden-Menschen.$^{41}$ Es ist die soziale Frage - die Gerechtigkeitsfrage -, die den Raum des Politischen konstituiert. Aus diesem Grund ist das Politische von der Politik, die ein Sachgebiet bezeichnet, zu unterscheiden. Anders als die Politik, also die Gesamtheit der Diskurse, Institutionen und Praktiken, ,deren Ziel es ist, eine Ordnung herzustellen und menschliches Zusammenleben in einem Kontext zu organisieren, der aufgrund des ,Politischen“ immer konfliktuell ist", ${ }^{4}$ ist das Politische nicht ein ,abgrenzbarer Gegenstand, nicht [...] ein bestimmtes Ziel, sondern [...] ein Aggregatzustand der Interaktion zwischen Personen und Personengruppen". 43 Nach diesem Zustand bemisst sich der Ort des Politischen, der dann auch Felder einbeziehen kann, die vormals nicht als Felder des Politischen im Blick waren.

\section{Individuelles Gerechtwerden}

Im Zeitalter der Entpolitisierungen ist die demokratische Gesellschaft gut beraten, auf das in den biblischen Traditionen enthaltene Veränderungspotential zu achten. In der Bibel findet sich zwar nicht das Wort „Demokratie“ - Israel hat das Wort nicht erfunden -, aber Israel hat das, was die liberale Demokratie fordert, nämlich das Recht des Individuums zu schützen, als das Recht des Anderen in seiner Anderheit immer wieder eingeklagt.

Die politische Debatte muss auf die Grenzen der Gerechtigkeit reflektieren, nur so wird offenbar, wo die realisierte Gerechtigkeit sowohl ihre Zielneutralität verletzt, indem sie partikulare Lehren begünstigt, als auch ihrer Auswirkungsneutralität nicht gerecht wird,

39 Liebsch (2005), 167.

40 Vgl. zum Begriff des Politischen ausführlich Manemann (2008b).

41 Arendt (1993), 9-12.

42 Mouffe (2002), 105.

43 So Böckenförde im Rekurs auf Carl Schmitt: Böckenförde (2000), 4. 
indem sie partikulare Lehren schwächt. Eine derart grundierte selbstreflexive Politik führt zur Anerkennung der Differenz von Idee und Realität und zur Anerkennung der Differenz zwischen politischer Gleichheit und dem Guten. Diese Selbstreflexivität gilt es zu übersteigern, bis dahin, dass die Gleichheit sich im Blick auf diese Begrenzungen selbst begrenzt. ${ }^{44}$ Moralität entsteht nämlich nicht, und darauf macht die Bibel aufmerksam, in der Gleichheit, sondern dadurch, dass man den Armen, den Waisen und den Witwen dient. ${ }^{45}$ Durch den darin erhobenen Imperativ der Anerkennung fremden Leids wird die Theorie und Praxis von der Gerechtigkeit bzw. Gleichheit in der liberalen Gesellschaft immer wieder neu im Blick auf die konkreten Menschen in ihrer unendlichen Würde befragt. ${ }^{46}$ Von dieser Würde aus ergeht die Forderung, die Eigenperspektive der Individuen zu brücksichtigen. Eine liberale Demokratie, die Gerechtigkeit als Gleichheit versteht, muss in der Verantwortung gegenüber dem Anderen gründen, denn diese ist der Motor der Gerechtigkeit. Gerechtigkeit ist auf diese Solidarität angewiesen, da ihr Medium immer auch Ungerechtigkeit ist. ${ }^{47}$ Das Hörbarwerden der Klagen der Einzelnen, mit denen sie auf eine eingewöhnte Gleichheitspraxis reagieren, ist das Fundament der Selbstreflexivität. ${ }^{48}$ Die egalitäre Einstellung der Mitglieder demokratisch verfasster Gesellschaften wird durch dieses individuelle Gerechtwerden vervollständigt. „Individuelles Gerechtwerden heißt hier, mit dem anderen gegen das zu reagieren, wogegen er leidend und klagend reagiert" ${ }_{4} 9$ Die Idee der Moralität, die sich darin ausdrückt, gründet in Nähe. Dagegen drückt sich in Politiken der Feindschaft eine Ideologie aus, mit der man seinen Menschenhass sittlich zu rechtfertigen sucht. Dieser Hass auf den anderen Menschen ist wohl weniger Ausdruck der Zurückweisung der Vielheit; „,er verrät vielmehr die Zurückweisung der dem Ich zugefallenen Verantwortung “"50.

Die monotheistischen Religionen indizieren bestimmte Phänomenbereiche, die Gemeinsamkeiten zwischen verschiedenen Men- 
schen erkennen und fühlen lassen. Zu nennen ist die analogia passionis $^{51}$, die aus einer zweifachen Verwundbarkeit resultiert: Jedem Menschen kann Leid zugefügt werden und ein jeder wird vom Leid des Anderen betroffen. Insofern kann als gemeinsame, wenn auch jeweils unterschiedliche Erfahrung aller die Leiderfahrung festgehalten werden. ${ }^{52}$ Der hier hineingelesene ethische Anspruch der analogia passionis besteht nun darin, nicht bei der Wahrnehmung und Erinnerung „des eigenen Leids stehenzubleiben“, sondern zur Wahrnehmung und „Erinnerung des fremden Leids vorzustoßen. Das Zusammenspiel von Binnen- und Außenperspektive, von Zeugnis und Empathie eröffnet dann Möglichkeiten tendenziell universaler Verständigung“".53 Eine solche Verständigung auf der Basis der analogia passionis motiviert dazu, das individuelle Leiden der Menschen in der Gesellschaft nicht auf ein partikulares Leiden zu reduzieren, sondern es so mit dem Ganzen der Gesellschaft zu korrelieren, dass es in zweifacher Weise die Gesellschaft betrifft: Erstens kann der Leidende unterstellen, dass jeder Andere seinen Schmerz, sein Leiden auch nicht erfahren möchte und ablehnt; zweitens zielt die damit einhergehende Veränderung auf das Ganze, weil es das Ganze neu orientiert. Erst dann wäre von „eigentlicher Politik“ (Slavoj Žižek) zu sprechen. Hingegen steht zurzeit das hoch im Kurs, was „PostPolitik“ (Slavoj Zižek) genannt wird, eine Politik, die den ganzen Apparat von Experten, Sozialarbeitern usw. mobilisiert, um die Gesamtforderung einer partikularen Gruppe auf Partikulartität zu reduzieren. $^{54}$

Die Maxime des individuellen Gerechtwerdens ist der Grund gesellschaftlicher Reflexivität. Von hier aus wird einsichtig, dass der neue Name für Politik Kultur ist - genauer: eine Kultur der Anerkennung der Anderen in ihrem Anderssein, die sich weigert, die Probleme von Menschen ins Partikulare abzudrängen, statt sie in neuer Weise mit dem Ganzen zu korrelieren. Wie heißt es bei Paulus im Blick auf den einen Leib und die vielen Glieder: „Wenn darum ein Glied leidet, leiden alle Glieder mit; wenn ein Glied geehrt wird, freuen sich alle anderen mit ihm" (1Kor 12.26). In den Religionen sind diese Einsichten aufgehoben, etwa in dem Gedanken, dass der- 
jenige, der einen Menschen rettet, die ganze Welt rettet. Eine demokratische Gesellschaft, der es nicht gelingt, das Schicksal des Einzelnen mit dem Ganzen zu verbinden, ist auf dem Weg ins Antidemokratische. Wer einen Menschen rettet, rettet die ganze Gesellschaft. Nur wenn dieser Satz eine Bedeutung hätte, könnten wir von Demokratie sprechen, deren Zentrum die Anerkennung des Anderen in seiner Anderheit ist und nicht seine Nichtbeachtung.

Der Monotheismus durchbricht Postpolitiken, die den Einfluss konkreter politischer Forderungen auf das System verhindern, und fordert zu echter Politik heraus. Echte Politik würde an der Veränderung der Parameter arbeiten, die als ,möglich“ und ,real“ charakterisiert sind, wäre also die Kunst des Unmöglichen, mithin messianische, unterbrechende Politik. ${ }^{55}$ Eine solche Politik würde sich nicht mit Realitätssinn begnügen, sondern Möglichkeitssinn evozieren. Sie erst wäre der Beginn des Endes von Verfeindungen. ${ }^{56}$

\section{Säkulare Demokratie}

Religionen können zwar - und wir erleben es ja heute - für die demokratische Gesellschaft und die Politik eine Versuchung darstellen, die Öffnungen, die das Lebenselixier der Demokratie sind, zu schlieBen; sie haben freilich auch das Potential, diese zu garantieren, indem sie dafür Sorge tragen, dass die Politik sich nicht auf die Erhaltung der vorgegebenen Ordnung begrenzt. ${ }^{57}$ Gefordert ist eine Permanenz des Theologisch-Politischen in der modernen Demokratie; $\mathrm{zu}$ widerstehen ist hingegen einer Restauration eines PolitischTheologischen. ${ }^{58}$ Religionen sollen keine Politik machen; sie können helfen, Politik möglich zu machen, indem sie eine Scharnierfunktion zwischen der privaten und der öffentlichen Sphäre wahrnehmen. Sie repolitisieren das Private und renormativieren die Öffentlichkeit, indem sie die persönliche Moral mit öffentlichen Problemen und die Öffentlichkeit mit Fragen der privaten Moral konfrontieren.

Gesellschaften, die den Konflikt eliminieren, erlahmen. Ihnen geht der Atem aus. Sie werden uniform und anonym. Religionen sprengen Eindimensionalitäten auf. Durch religiöse Herausforde- 
rungen erfährt die Gesellschaft eine Konfrontation mit etwas, das sie nicht selbst produziert. Die Konfrontation mit etwas, das die Gesellschaft nicht selbst hervorgebracht hat, ist die conditio sine qua non von Selbstreflexivität, die immer eine gewisse Exterritorialität voraussetzt. „Daß die menschliche Gesellschaft nur eine Öffnung auf sich selbst hat, indem sie in eine Öffnung hineingenommen wird, die sie nicht erzeugt, genau das sagt jede Religion, jede auf ihre Weise, genau so wie die Philosophie und noch vor dieser, wenngleich in einer Sprache, die letztere nicht zu der ihren machen kann".59

Wenn kulturelle Lebensformen von Menschen entwickelt werden, um einander davon zu überzeugen, dass das eigene Leben und das des Anderen lebenswert sind, dann zeigen gegenwärtige eruptive Gewaltexzesse und das Einwandern der Feindschaft in die Kultur, dass mit den kulturellen Lebensformen etwas zutiefst nicht mehr stimmt. ${ }^{60}$ Die avancierten nachmodernen Gesellschaften ,haben längst damit begonnen [...], die kulturellen Bedingungen ihrer Existenz selbst zu produzieren". ${ }^{61}$ Solche Gesellschaften zerstören die Fähigkeit zur Toleranz, neutralisieren, reduzieren Kultur auf das nur noch Selbstproduzierte, dulden keine Differenz mehr. Sie produzieren einen Immanentismus, durch den alles Nichtidentische wenn nicht aufgelöst, so doch unwirksam gemacht und in die Privatsphäre verbannt wird. Der Versuch jedoch, sich gegen alles, was anders ist und somit als bedrohlich angesehen wird, zu immunisieren, gegen das Nichthergestellte, das Andere, die Natur, die Religion, beinhaltet die Gefahr, Autoimmunreaktionen auszulösen - Autoaggressionen und Heterophobien sind dann die Folgen.

Wird Religion aus der Öffentlichkeit verdrängt, Kultur auf Hergestelltes reduziert, wird der Konflikt abgeschafft, Anderheit und Andersheit durch Feindschaft ersetzt, so verschwindet die transformierende Wirkung in der Gesellschaft. In einer Gesellschaft ohne Konflikt breitet sich schließlich eine nihilistische Gestimmtheit aus, die in Zynismus, Resignation und Ressentiment zu münden droht. Am Ende bleiben nur noch Einsamkeit, Kälte und Tod. ${ }^{62}$ 
74 Monotheismus und Demokratie

\section{Literatur}

Adorno, Theodor W. (1987): Minima Moralia. Reflexionen aus dem beschädigten Leben. Frankfurt/M.: Suhrkamp.

Arendt, Hannah (1993): Was ist Politik? Fragmente aus dem Nachlaß. München: Piper.

Beck, Ulrich (1993): Die Erfindung des Politischen. Zu einer Theorie reflexiver Modernisierung. Frankfurt/M.: Suhrkamp.

Beck, Ulrich (1995): Die feindlose Demokratie. Ausgewählte Aufsätž. Stuttgart: Reclam.

Beck, Ulrich (2007): Weltrisikogesellschaft. Auf der Suche nach der verlorenen Sicherbeit. Frankfurt/M.: Suhrkamp.

Böckenförde, Ernst-Wolfgang (22000): „Was heißt heute eigentlich ,politisch?", in: Manemann, Jürgen, Hg.: Jahrbuch Politische Theologie. Band 1. Demokratiefähigkeit. Münster: LIT, 2-5.

Brague, Remi (1993): Europa. Eine exzentrische Identität. Frankfurt/M.: Campus.

Casanova, José (1994): Public Religions in the Modern World. Chicago: Chicago University Press.

Dubiel, Helmut (1994): Ungewißheit und Politik. Frankfurt/M.: Suhrkamp.

Finkielkraut, Alain (1989): Die Weisheit der Liebe. Reinbek/H.: Rowohlt.

Flores d'Arcais, Paolo (2005): „Ist Amerika noch eine Demokratie?“, in: Die Zeit 4.

Fukuyama, Francis (1992): The End of History and the Last Man. New York: The Free Press.

Gabriel, Karl (72000): Christentum zwischen Tradition und Postmoderne. Freiburg/B.: Herder.

Höhn, Hans-Joachim (1994): GegenMythen. Religionsproduktive Tendenzen der Gegenwart. Freiburg/B.: Herder.

Honneth, Axel (1995): „Das Andere der Gerechtigkeit“, in: Fischer, Peter, Hg.: Freibeit oder Gerechtigkeit. Perspektiven Politischer Philosophie. Leipzig: Reclam, 194-240.

Huntington, Samuel P. (61998): Kampf der Kulturen. Die Neugestaltung der Weltpolitik im 21. Jahrhundert. München: Siedler.

Junker, Detlef (2005): „Auf dem Weg zur imperialen Hypermacht? Die manichäische Falle ist besetzt. U.S.-Außenpolitk nach dem 11. September", in: Brocker, Manfred, Hg.: God bless America. Politik und Religion in den US A. Darmstadt: Wissenschaftliche Buchgesellschaft, 208-224.

Kant, Immanuel (21996): Kritik der Urteilskraft. Frankfurt/M.: Suhrkamp.

Kepel, Gilles (1991): Die Rache Gottes. Radikale Moslems, Christen und Juden auf dem Vormarsch. München: Piper.

Lefort, Claude (1999): Fortdauer des Theologisch-Politischen. Wien: Passagen.

Lévinas, Emmanuel (1987): Totalität und Unendlichkeit. Versuch über die Exteriorität. Freiburg/B.: Alber. 
Lévinas, Emmanuel (1995): Zwischen uns. Versuche über das Denken an den Anderen. Freiburg/B.: Alber.

Liebsch, Burkhard (2005): Gastlichkeit und Freiheit. Polemische Konturen europäischer Kultur. Weilerswist: Velbrück.

Manemann, Jürgen (1998): „Kritik als zentrales Moment des Glaubens. Zur gesellschaftskritischen Dimension der Fundamentaltheologie", in: Müller, Klaus, Hg.: Fundamentaltheologie - Fluchtlinien und gegenwärtige Herausforderungen. Regensburg: Pustet, 217-241.

Manemann, Jürgen (2002): Carl Schmitt und die Politische Theologie. Politischer Anti-Monotheismus. Münster: Aschendorff.

Manemann, Jürgen (2005): Rettende Erinnerung an die Zukunft. Essay über die christliche Verschärfung. Mainz: Matthias-Grünewald.

Manemann, Jürgen (2006): „Theologie als Kulturwissenschaft - Ein Plädoyer", in: Orientierung 4, 38-43.

Manemann, Jürgen (2007a): „Nachbarschaft und Feindschaft“, in: Theologie der Gegenwart 3, 186-195.

Manemann, Jürgen (2007b): „Vom Eingang des Nichts in die Zeit“, in: SitLiver, Beat, Hg.: Utopie. München: Kohlhammer, 55-78.

Manemann, Jürgen (2008a): Über Freunde und Feinde. Brüderlichkeit Gottes. Kevelaer: Topos-Taschenbuch.

Manemann, Jürgen (2008b): „Das Politische in der Neuen Politischen Theologie“, in: Manemann, Jürgen/Wacker, Bernd, Hg.: Jahrbuch Politische Theologie. Band 5. Politische Theologie - gegengelesen. Münster: LIT, (im Druck).

Menke, Christoph (2000): Spiegelungen der Gleichheit. Berlin: Akademie.

Menke, Christoph (2002): „Grenzen der Gleichheit. Neutralität und Politik im Politischen Liberalismus“, in: Deutsche Zeitschrift für Philosophie 6, 897-906.

Mouffe, Chantal (2002): „Für eine antagonistische Öffentlichkeit“, in: Enwezor, Okwui/Basualdo, Carlos/Ghez, Susanne/Bauer, Ute M., Hg.: Demokratie als unvollendeter Prozess. Documenta 11-Plattform 1. Ostfildern: Hatje Cantz, 101-112.

Polednitschek, Thomas (2003): Diagnose Politikmüdigkeit. Die Psychologie des nicht-vermissten Gottes. Berlin: Wichern.

Rottländer, Peter (1993): „Ethik in der Politischen Theologie. Johann Baptist Metz zum 65. Geburtstag“", in: Orientierung 13/14, 152-158.

Rottländer, Peter (2000): „Alterität versus anamnetische Ethik?““, in: Manemann, Jürgen, Hg.: Jabrbuch Politische Theologie. Band 1. Demokratiefähigkeit. Münster: LIT, 238-249.

Sacks, Jonathan (2003): The Dignity of Difference. How to avoid the Clash of Civilizations. London-New York: continuum.

Schmitt, Carl (1991): Glossarium. Aufzeichnungen der Jahre 1947-1951. Berlin: Duncker \& Humblot. 
Sharansky, Natan/Dermer, Ron (2004): The Case for Democracy: The Power of Freedom to Overcome Tyranny and Terror. New York: Public Affairs.

Walzer, Michael (1996): Lokale Kritik - globale Standards. Hamburg: Rotbuch.

Werbick, Jürgen (2000): Den Glauben verantworten. Eine Fundamentaltheologie. Freiburg/B.: Herder.

Zimmerli, Walther (1984): „Wie neu ist die neue Religiosität? Von Konsistenz und Widerspruch in der Suche nach Unmittelbarkeit", in: Oelmüller, Willi, Hg.: Kolloquien zur Gegenwartsphilosophie. Religion und Philosophie. Band 1: Wiederkehr von Religion? Paderborn: Schöningh, 9-24.

Zirker, Hans (1995): „Monotheismus und Intoleranz“, in: Hilpert, Konrad/Werbick, Jürgen, Hg.: Mit den Anderen leben. Wege zur Toleran₹: Düsseldorf: Patmos, 95-117.

Žižek, Slavoj (2001): Die Tücke des Subjekts. Frankfurt/M.: Suhrkamp. 


\section{Historische Orientierungen}





\section{Heiliger Krieg und heiliger Frieden*}

Arnold Angenendt

Krieg ist ein Kampf mit Waffen, geführt zu dem Zweck, dem Gegner den Willen des eigenen Gemeinwesens oder der eigenen Klasse oder Partei aufzuzwingen - so lautet die gängige Definition, die auf den Sozialisten Karl Kautsky (†1938) zurückgeht und sich auch im derzeitigen Lexikon für Theologie und Kirche findet. ${ }^{1}$ Nicht erwähnt ist allerdings das eigentlich Bösartige: „Im Krieg wird getötet“. ${ }^{2}$ Und das auch aus Gründen der Religion, die dadurch ins Zwielicht gerät. Ist Religion - so fragt Joseph Ratzinger - „,eine heilende und rettende, oder nicht eher eine archaische und gefährliche Macht"? ${ }^{3}$ Das Neue Testament preist die Gewaltlosigkeit und die Friedfertigkeit. Die Friedensfähigkeit entscheidet heute über den Fortbestand der Welt.

\section{Krieg in der Christenheit}

Die europäische Geschichte erscheint wie eine ununterbrochene Kriegsgeschichte. Für die erste Hälfte des Mittelalters bis zum 11. Jahrhundert ergibt sich für die Kriegs- und Friedensjahre eine Relation von $5 \mathrm{zu} \mathrm{1;}$ im 17. Jahrhundert blieben ganze sieben Jahre

* Der folgende Beitrag bietet eine gekürzte Version der entsprechenden Kapitel aus Angenendt (42008).

1 Beestermöller (1997).

2 Burkert (1995), 179.

3 Ratzinger (2005), 46. 
kriegsfrei und im 18. Jahrhundert sechzehn. Krieg erscheint so als „der europäische Normalzustand“.4 Allerdings wütete nicht immer schon der moderne Krieg. Karls des Großen Kriegerscharen werden auf 5.000 bis 10.000 geschätzt, die auch nur für wenige Monate mobilisiert wurden. Die mittelalterliche Ritterschaft beschränkte sich auf ein bis drei Prozent Berufskrieger, die freilich überproportional an Herrschaft und Ökonomie beteiligt waren. Bemessen nach den Dimensionen moderner Kriege könnte man demnach für das Mittelalter kaum von Krieg sprechen. Das änderte sich mit der zunehmenden Zentralisierung der Staatsmacht und ihrem Gewaltmonopol; dadurch schränkten sich zwar die inneren Clan-Kämpfe und Fehden ein, wurden aber andererseits die Kriege nach außen umso geballter. Mit den spätmittelalterlichen Massenheeren der Söldner und Landsknechte erreichte der Krieg eine neue Dimension und ließ auch die Zahl der Getöteten ansteigen. Hatte schon das Zweite Laterankonzil von 1139 „die todbringende und gottverhaßte Kriegstechnik der Armbrust- und Bogenschützen" verurteilt, ${ }^{5}$ so äußerte Erasmus von Rotterdam (†1536) pures Entsetzen über die neuen Kanonen mit ihren 20.000 Toten in der Schlacht bei Marignano (1515): Dort hätten Christen Höllenmaschinen angewandt, raffinierter und schrecklicher noch als alles von Barbaren und Heiden jemals Ersonnene. ${ }^{6}$ Luther zufolge wäre Adam - hätte er die neuen Geschütze sehen können „für Leide gestorben“.7 Am Ende der europäischen Kriegsentwicklung stehen die Vernichtungsschlachten der beiden Weltkriege des 20. Jahrhunderts, mit zuletzt noch der Atombombe.

Die europäisch-christlichen Kriege könnten auf den ersten Blick noch wüster erscheinen als die der Antike. Gleichwohl steht fest - so der Berliner Mediävist Dietrich Kurze -, dass das Mittelalter zwar von der Pax Romana nur habe träumen können, aber dennoch ,erheblich weniger militant gewesen ist als etwa das republikanische Rom oder die Masse der neuzeitlichen Staaten. "8 In der Tat, die Kriege der Antike, wie sie die Griechen und Römer führten - so die heutige Forschung - bezeugen eine unvorstellbare Grausamkeit. Der Althistoriker Egon Flaig schreibt zu Art und Vorgehen des alt-

4 Repgen (1988), 69.

5 Zweites Laterankonzil (2000), 203.

6 Christ-von Wedel (2003), 217.

7 Luther (1914), Nr. 3552, 403-404.

8 Kurze (1991), 3. 
griechischen Kriegeradels: „Der erhöhte Druck, dauernd seine Ehre zu verteidigen, fördert eine Disposition, dies auf aggressive oder maßlose Weise zu tun“, wobei sich zeigt, „wie gering die Chancen sind, zu gerechtem Verhalten und zu einer den minimalen Anforderungen von Gerechtigkeit entsprechenden Konfliktregelung zu gelangen, solange Ruhm und Ehre die zentralen Werte sind und es den einzelnen obliegt, ihre Ehrwahrung nach eigenem Ermessen in die Hand zu nehmen. ${ }^{\text {"9 }}$ Platon hielt Krieg für eine Krankheit. Aristoteles indes erachtete Krieg ,als Teil der Erwerbskunst“, „nämlich als Jagd auf Menschen, die von Natur zum Dienen bestimmt sind [...], so daß ein solcher Krieg dem Naturrecht entspricht."10 Cicero gebührt das Verdienst, erstmals eine von Recht und Ethik bestimmte Kriegs- und Friedenslehre entwickelt zu haben. ${ }^{11}$

Eine besondere Dimension erreicht der Heilige Krieg. Selbstverständlich wurden bei Krieg und Kampf immer Gott/Götter angerufen. Aber nicht nur wurde im Auftrag der Götter, sondern auch für sie gekämpft. Das ist „heiliger Krieg“, wobei der Feind wegen seiner anderen Religion bekämpft wird. Eine Art Gottesdienst vollziehen die heiligen Krieger und können des göttlichen Lohnes sicher sein. Klassisch findet sich der Heilige Krieg im Alten Testament, zumal bei der Landnahme Israels. Es ist „der von Jahwe ausgelöste, geführte und gewonnene Krieg gegen die Feinde Israels, welche eo ipso als seine Feinde betrachtet werden“; dieser Krieg bildete „einen wichtigen Bestandteil des Glaubens“,12 denn ,die Auffassung von der Heiligkeit des Landes Israel und der Verpflichtung, Götzendiener in ihm nicht zu dulden, [gab] Anlaß zu Pflichtkrieg. "13 Jahwe ist hier der Stammesgott, dessen Feinde „dem Tod geweiht sind“ (Num 21.3). Das Judentum hat diesen Heiligen Krieg noch bis zum BarKochba-Aufstand (132-135 n.Chr.) weitergeführt.

\section{Der christliche Frieden und der gerechte Krieg}

Das Neue Testament kennt keinen Heiligen Krieg. Von Jahwe-Krieg oder Kriegsbegeisterung wird nirgends gesprochen. Im Gegenteil; 
aufgerufen wird zum Verzicht auf Gewalt, statt Gegengewalt die Feindesliebe geboten (Mt 5.43-48). „Falls überhaupt, dann kann das Führen eines Krieges nur erlaubt sein, wenn es der unbedingten Liebesforderung nicht widerspricht." 14 Die alte Christenheit sah sich zu einem Totalpazifismus verpflichtet. Erst in der Spätantike entfaltete sich die Idee vom gerechten Krieg, wofür Augustinus (†430) die Grundlage schuf: Erlaubt sei Krieg nur bei feindlichen Angriffen bzw. zur Abwehr von Unrecht und niemals zur Unterjochung oder Eroberung; verantwortbar nur bei Verhältnismäßigkeit und nicht übermäßiger Schadenswirkung; rechtfertigbar nur bei ethisch einwandfreier Intention und niemals aus schierer Kampfeslust oder Beutegier; durchführbar allein seitens der legitimen Obrigkeit und nicht auf eigene Faust. Bei solcherart gerechter Kriegsführung schuldeten die Soldaten der Obrigkeit Gehorsam. ${ }^{15}$ Allein die Gerechtigkeit soll also einen Krieg legitimieren, und zwar „zwingend und nachdrücklich“. ${ }^{16}$ Verwehrt ist „die Identifikation eines (National-)Volkes und eines irdischen Landes als von Gott besonders erwähltes Volk und/oder Land“, ${ }^{17}$ ebenso „die Legitimation eines jeden Heiligen Krieges zur Erlangung des eigenen Heils“. ${ }^{18}$ Strikt also begrenzt Augustinus die staatliche Gewaltanwendung auf ,die Einhaltung genau bestimmter Obergrenzen der Gewaltanwendung; die physische Gewalt darf ihm zufolge Stockschläge nicht überschreiten; Folter und Todesstrafe lehnt er vehement ab." 19 Das Postulat des gerechten Krieges wurde christliches Gemeingut: Der Krieg ist nur erlaubt zur Abwehr von Unrecht und Willkürgewalt; er wird für die Gerechtigkeit geführt, aber nicht für Gott.

Die erste tief greifende Veränderung der christlichen Kriegsbzw. Friedenslehre erfolgte in der Spätantike. Das römische Reich war christlich geworden, und Theodosius I. (†395) hatte das Heidentum verboten. Hiermit begann der Staatszwang zugunsten des Christenglaubens. Gleichwohl kann die Christianisierung des Imperiums nicht generell als Zwangsaktion gedeutet werden: „Der Niedergang des Heidentums und seine Verdrängung durch das Christentum“ -

14 Beestermöller ( $\left.{ }^{3} 1997\right), 476$.

15 Gerlings (2001); Rief (1981), 16-26.

16 Janssen (1982), 571.

17 Weissenberg (2005), 519.

18 Weissenberg (2005), 519.

19 Weissenberg (2005), 521. 
so der Münsteraner Althistoriker Johannes Hahn - „erfolgt in der Regel auf weit weniger spektakuläre, friedliche Weise“.20 Anders allerdings, nämlich zwanghaft, verlief die Außenpolitik. Sobald ein Volk dem nunmehr christlichen Imperium zugeschlagen wurde, musste es, ob freiwillig oder gezwungen, christlich werden. Hier entstanden die Zwangsmission und von Neuem der Religionskrieg. Doch begegnet die gewaltsame Bekehrung ,,nicht vor dem 5. Jahrhundert und bildet vor Justinian I. (†565) die Ausnahme“. ${ }^{21}$ Mit der politischen Zwangsverpflichtung zum Christentum aber entstand die in Wahrheit unchristliche Alternative „Taufe oder Tod“. Karl der Große (†814) befolgte sie bei der Eroberung des Sachsenlandes; bei Taufverweigerung drohte die Hinrichtung. ${ }^{22}$ Die Zeitgenossen sprachen bereits von einer Mission „mit eiserner Zunge“, nämlich Karls „Abschaffung des Heidentums und Einführung des Christentums unter Todesstrafe".${ }^{23}$ Die ottonische Mission ging östlich der Elbe nicht anders vor. So beschrieben der Mönch Widukind von Corvey $(† 973)$ und der Bischof Thietmar von Merseburg (†1018) die Unterwerfung der Slawen als Heiligen Krieg; ebenso betrieben die Deutschordensritter im Baltikum Heiligen Krieg. ${ }^{24}$

Wir haben hier einzurechnen, dass mit der Spätantike sowohl der kulturelle Überbau wie ebenso die Theologie zusammenbrachen. Die altkirchliche Lehre vom gerechten Krieg tat keine Wirkung mehr. In Europa herrschte wieder der ,natürliche Krieg“, wie Georges Duby gesagt hat: „Die natürliche Feindschaft zwischen den Volksstämmen indes wurde nicht nur in Raubzügen freigesetzt. Sie hatte auch einen regelmäßigen und friedlichen Transfer von Reichtümern zur Folge. Der jährliche Tribut war nämlich nichts anderes, als das gesetzlich geregelte Beutemachen zugunsten eines Volksstammes, der seinen Nachbarn so bedrohlich erschien, daß sie es in ihrem eigenen Interesse für besser hielten, ihn zu diesem Preis von Plünderungen abzuhalten. " 25 Ganz allerdings ging die christliche Komponente nicht verloren. Karl der Große hat aus christlicher Internatio- 
nalität sein Großreich geschaffen. ${ }^{26}$ Dass er ganz unterschiedliche Populationen, die zuvor miteinander im Krieg lagen, zusammenführte und zu einem Vielvölker-Reich zu vereinen vermochte, konnte nur dank übergentiler Bewusstseinskategorien gelingen, und die eben lieferte das Christentum. Die karolingischen Reichstheoretiker wandten die paulinische Forderung: „nicht Juden und nicht Griechen“, „,nicht Sklaven und nicht Fremde“ (1 Kor 12.13, Kol 3.11, Gal 3.28), auf ihre eigene Situation an: „nicht mehr Aquitanier und Langobarden, Burgunder oder Alemannen“. ${ }^{27}$ Der Fuldaer Abt und Mainzer Erzbischof Hrabanus Maurus (†856) konnte schreiben, es dürfe keinen Unterschied unter den verschiedenen Nationen geben, denn die katholische Kirche existiere als Einheit mit Verbreitung über den ganzen Erdkreis. ${ }^{28}$ Dem Karlsreich ist es zu verdanken, dass Europa - trotz aller weiteren Kriege - dennoch ein gemeinsames Fundament behielt: die christianitas. Der Austausch der „gentilreligiösen“" gegen „universalreligiöse“ Grundstrukturen ist als jene epochale Leistung bezeichnet worden, die Europa erst hervorgebracht hat ein Vorgang von ,wahrhaft weltgeschichtlichem Rang““. ${ }^{29}$ Nicht die militärische Imperialität, sondern die Christianisierung ist am wichtigsten gewesen.

Das große Erwachen kam mit der Renaissance des 12. Jahrhunderts, als die westliche Christenheit erneut in der Lage war, sich der eigenen Grundhaltung zu vergewissern. Die im 11. und 12. Jahrhundert wieder belebte Kanonistik hatte dabei auch über den ,gerechten“ wie „heiligen“ Krieg zu befinden. Die große Rechtssammlung des Gratian († Mitte 11. Jahrhundert) wiederholte die augustinische Verteidigungslehre: „Gerecht ist der Krieg, wenn er auf [herrscherliche] Erklärung hin geführt wird, um Verluste wiederzugewinnen oder um Angreifer abzuwehren." ${ }^{30}$ Thomas von Aquin (†1274) zitierte nur wieder Augustinus: ${ }^{31}$ „Zu einem gerechten Krieg sind drei Dinge erforderlich: Erstens die Vollmacht des Fürsten [...] Zweitens ist ein gerechter Grund verlangt [...] Drittens wird verlangt, daß die

26 Fleckenstein (1989a); Fleckenstein(1989b).

27 Agobard, Adversus Legem Gundobaldi 3; CChr.CM 52, $20^{9}$.

28 Epistularum Fuldensium Fragmenta 11; MGH.Ep.5, $520^{\circ}$.

29 Kahl (1989), 37-38.

30 Gratian, „Decretum“ (pars II, c. 23, q. 2 c. 1), in: Friedberg, Hg. (1879), 894.

31 Rief (1981), 27-34. 
Kriegführenden die rechte Absicht haben. “32 Insgesamt sind Kriege „nur so weit erlaubt und gerecht, als sie die Armen und den ganzen Staat vor den Anschlägen der Feinde schützen." 33 Wer in dieser Weise „für die Wahrheit des Glaubens oder die Rettung des Vaterlandes und zur Verteidigung der Christenheit sein Leben läßt, wird von Gott himmlischen Lohn erlangen. “"34

Diese Auffassung verstärkte sich noch durch die Rezeption der aristotelischen Staatslehre, der zufolge der Staat als „natürlich“ galt. Nicht länger wurde die Staatsgemeinschaft als von Gottes Gnaden begründete und geheiligte Herrschaft angesehen, sondern verstand sich aus der allgemeinen menschlichen Natur und musste darum auch Nichtchristen zugebilligt werden. Ein heidnischer Staat hatte demnach ein ebenbürtiges Recht auf Leben, Besitz, Herrschaft und Eigendasein; folglich verbot sich ein Angriff aus Religionsgründen. Nicht allein das Christlichsein war für vollmenschlich zu nehmen, sondern auch die Menschennatur, und darum stand auch dem heidnischen Staat, weil menschlich, Eigenständigkeit und Existenzrecht zu. Der Engländer Radulf Niger († um 1200), Student in Paris und zum Kreis um Erzbischof Thomas Becket (†1170) gehörend, mahnte angesichts des dritten Kreuzzugs, dass die Heiden „Menschen sind, wenn auch ungläubige" ("homines enim sunt licet infideles"), wie auch die Sarazenen ,von derselben Natur-Beschaffenheit sind wie wir" ("ejusdem conditionis naturae cujus et nos sumus"). ${ }^{35}$ Die gemeinsame Menschennatur erscheint hier als das Übergreifende, das über die Christlichkeit hinaus alle verbindet. In Wolfram von Eschenbachs Willehalm gewinnt der Heide - so der Germanist Joachim Bumke - eine neue Qualität: Er ist „genau so Gottesgeschöpf und Gotteskind, nicht von vornherein verdammt und darum zu schonen“.36 Somit eröffneten Naturrecht und Geschöpflichkeit neue Friedensperspektiven.

Die theologische Konsequenz zog Thomas von Aquin (†1274): Ein Krieg könne nicht wegen purer Nichtchristlichkeit eröffnet wer-

32 Thomas von Aquin, Summa theologica II-II, qu. 40, a. 1 (Die deutsche Thomas-Ausgabe Band 17B, 83-85).

33 Thomas von Aquin, Summa theologica II-II, qu. 40, a. 2, 1 (Die deutsche Thomas-Ausgabe Band 17B, 87-88.).

34 Thomas von Aquin, Summa theologica II-II, qu. 40, a. 2, 4 (Die deutsche Thomas-Ausgabe 17B, 89).

35 Radulfus Niger (1977), 196, 205 (III,90 und IV,12).

36 Bumke (1999), 1403. 
den, wie obendrein immer Bekehrungsfreiheit zu respektieren sei. Nur dort und dann sah er eine Möglichkeit von „Nötigung“, wenn Heiden sich in bewusstem Falschglauben kriegerisch verteidigten, darin böswillig verharrten oder unerleuchtet dorthin zurückkehrten; zudem durften sie die Christgläubigen weder provozieren noch ihre Ehre schmähen, sollten überdies ehemals christliche Territorien herausgeben. 37

\section{Die Kreuzzüge}

Eine besondere Herausforderung stellten die Kreuzzüge dar, militärtechnisch und mehr noch ideell. Trotz der Rückkehr der hochmittelalterlichen Kanonistik zum altchristlichen Konzept des gerechten und nicht des heiligen Krieges waren die Kreuzzüge ein Heiliger Krieg. Der Engländer Riley-Smith, der zurzeit die Kreuzzugsforschung dominiert, definiert: „Ein Kreuzzug war ein heiliger Krieg, der zur Wiedererlangung christlicher Besitzrechte oder zum Schutze der Kirche oder der Christen gegen diejenigen ausgetragen wurde, die als äußere oder innere Feinde der Christenheit angesehen wurden. Er galt als Anliegen der Christenheit insgesamt [...] Man glaubte, daß der Krieg, den ein solches Heer austrug, unmittelbar von Christus selbst durch den Papst als sein Sprachrohr gebilligt worden sei. Unter den Teilnehmern gab es zumindest einige, die ein aus dem der Wallfahrer sich herleitendes Gelübde ablegten, und man belegte sie und ihre Feldzüge oft mit Begriffen aus dem Wallfahrtswesen; ebenso wurde ihnen Ablaß gewährt [...] Kreuzzüge wurden im Nahen Osten, in Spanien, in Nordafrika, im Baltikum, in Osteuropa sowie auch innerhalb Westeuropas unternommen. Unter den Feinden waren Moslems, heidnische Slawen, Mongolen, orthodoxe Christen (Griechen und Russen), Häretiker (Katharer, Bogomilen, Hussiten) sowie politische Gegner des Papsttums. “38

Zumal gegenüber den Sarazenen schien der Griff zum Schwert gerechtfertigt. Hatten sie nicht den Christen das Heilige Land mitsamt Jerusalem weggenommen, das doch die „Braut Christi“ war (vgl. Offb 21.2)? Musste man nicht diesen entfremdeten und sogar entheiligten Urboden der Christenheit zurückgewinnen? Die Kano- 
nistik aber blieb eher ablehnend. Wohl verkündete Gratians Dekret: „Wir dürfen nicht die Juden, wohl aber die Sarazenen verfolgen“; denn ,gegen letztere wird zurecht gekämpft, weil sie die Christen verfolgen und von ihren Sitzen vertreiben." ${ }^{39}$ Wurde hier zur Rechtfertigung der Verteidigungsfall unterstellt, so hielten andere dafür, „daß, wenn die Sarazenen mit den Christen in Frieden leben, sie nicht angegriffen oder getötet werden dürfen." 40

Dabei konnte sogar aus dem Kreuzzugsaufruf Papst Urbans II. „Gott will es“ ("Deus vult”) bei den Kanonisten ein „Gott will es nicht" ("Deus non vult") werden. ${ }^{41}$ Der schon erwähnte Radulfus Niger schrieb 1187 einen Anti-Kreuzzugstraktat: Gott bedürfe nicht einer von Menschen ausgeführten Rache; wenn er eine solche wirklich wolle, solle er doch zwölf Legionen Engel schicken; wenn weiter der Papst als Stellvertreter Gottes zur Sündentilgung die Pilgerfahrt nach Jerusalem empfehle - gemeint ist evident der KreuzfahrerAblass -, müssten gleichwohl Besonnenheit und Billigkeit gewahrt bleiben; kein irgendwie geartetes Blutvergießen könne eine Genugtuung für Sünden darstellen. ${ }^{42}$ Solche Kritik musste die KreuzfahrerMentalität im Kern treffen ${ }^{43}$. Zu Recht kann heute eigens betont werden, man dürfe der Christen-Seite nicht einen generellen Hass gegen den Islam unterstellen. ${ }^{44}$

Zur Legitimierung der Kreuzzüge berief man sich auf die alttestamentlichen Makkabäer, ${ }^{45}$ die das Heilige Land Israel vom Schmutz der hellenistischen Heiden gereinigt hatten. Für die Kreuzzugspredigt ergab sich daraus eine Art Kompromiss: „Die Rechtfertigung für den Kreuzzug lieferte mithin die Rückeroberung christlichen Territoriums und vor allem auch Christi eigenen Erbes, das die Muslime sich widerrechtlich angeeignet hatten." 46 Tatsächlich führten die Kreuzritter im Heiligen Land einen veritablen Heiligen Krieg, wie Kaspar Elm betont: Es war „kein gewöhnlicher Krieg, kein Ge-

39 Gratian, „Decretum“ (pars II, c. 23, q. 8, c. 11), in: Friedberg, Hg. (1879), 955.

40 Herde (1967), 365: "If the Saracens lived in peace with the Christians, they were not to be attacked or killed, but tolerated."

41 Flahiff (1947).

42 Radulfus Niger (1977), 196-197.

43 Radulfus Niger (1977), 62.

44 Kedar (1984), 57-74.

45 Schreiner (2000), 30-37; Cowdrey (1992); Gilchrist (1988).

46 Riley-Smith (2003), 29. 
rechter Krieg“. ${ }^{47}$ Vielmehr wurde dieser Krieg direkt für Gott geführt, näherhin für das Erbe des Gottessohnes und dessen irdische Berührungspunkte: den Stall, in dem er geboren worden war, den See, an dem er gepredigt, und den Brunnen, aus dem er getrunken hatte, den Berg, auf dem er verklärt worden war, das Kreuz, an dem er gehangen hatte, das Grab, in das er gelegt worden war, und das Tal, in dem er zum Letzten Gericht wiedererscheinen wird. Diese Orte der Gnade und Garanten der Hoffnung sah man zur Schande der Christenheit in die Hände der unreinen Heiden und Gotteslästerer gefallen und dadurch besudelt und entehrt. „Ein Heiliger Krieg war es also zur Ehrung und Reinigung der heiligen Orte Jesu Christi“.48

In keiner Darstellung der Kreuzzüge fehlt das „Waten in Blut“. Die von Steven Runciman (†2000) in seinem Klassiker Geschichte der Kreuzzüge vorgegebene Deutung beruht auf direkter Quellenwiedergabe: „Die Kreuzfahrer, nach so viel Leiden und Entbehrungen völlig von Sinnen über einen so großen Sieg, rasten wie Besessene [...] Früh am nächsten Morgen erzwang sich eine Rotte der Kreuzfahrer Eintritt in die Moschee und erschlug sie [die Muslime] samt und sonders [...] Die Juden Jerusalems hatten sich geschlossen in ihre Hauptsynagoge geflüchtet; [...] das Gebäude wurde in Brand gesteckt; in seinem Innern fanden sie alle den Feuertod. Das Blutbad von Jerusalem machte auf die ganze Welt einen tiefen Eindruck. “49

Aber war das die Wirklichkeit? Die heutige Forschung nennt die Eroberung Jerusalems „kriegsüblich“. Sofern aber die Reinigung des Heiligen Landes von heidnischer Besudelung hervorgehoben werden sollte, bedurfte es einer besonderen „Blutsprache“ .50 Eine neue französische Untersuchung zum Volkskreuzzügler Peter von Amiens ( um 1115) interpretiert die Eroberung Jerusalems „im Sinne einer Rückgewinnung und einer Reinigung der Heiligen Stätten“. ${ }^{51}$ Das Modell dafür lieferten die schon erwähnten Makkabäer-Bücher. Judas Makkabäus etwa „erschlug ihre gesamte männliche Bevölkerung mit scharfem Schwert, zerstörte die Stadt völlig und ließ sie plündern. Dann marschierte er über die Leichen der Erschlagenen

47 Elm (2001), 46.

48 Elm (1998), 23-24.

49 Runciman (1995), 273-274.

50 Elm (2001), 46-53.

51 Flori (1999), 420: „dans le sens d'une recenquête et d'une purification des Lieux saints“. 
hinweg durch die Stadt“ (1 Makk 5.51); oder: „Sie richteten in ihr [der Stadt Kaspin] ein unbeschreibliches Blutbad an, so daß ein zwei Stadien breiter See, der neben der Stadt lag, von dem Blut, das in ihn geflossen war, angefüllt zu sein schien" (2 Makk 12.16). In diesem Sinne dürften urtümliche Reinigungsvorstellungen bei der Eroberung Jerusalems bestimmend gewesen sein: die heilige Stadt als verunreinigte Braut Christi, die durch das gerächte Blut zu entsühnen war. ${ }^{52}$ Wilhelm von Tyrus, einer der wichtigen Kreuzzugschronisten und ob seiner Toleranz heute besonders gefeiert, bestätigt: „Mit Bestimmtheit ist das nach gerechtem Urteil Gottes geschehen, daß diejenigen, die mit abergläubischen Riten das Heiligtum des Herrn entweiht und den gläubigen [Christen-]Völkern entfremdet hatten, dies mit der Vergießung ihres eigenen Blutes reinigten und mit dem Tod ihre strafwürdige Schandtat sühnten. “53

Innozenz III. (†1216) erklärte die Kreuznahme zum umfassenden Programm für alle Gläubigen. Der Papst handelte als Stellvertreter Christi mit Blickrichtung auf Jerusalem wie zugleich gegen den Islam, dazu im Kampf für den von seiner heiligen Stätte vertriebenen König der Könige Jesus Christus. Der Kreuzzug wurde so zur religiösen Heilshandlung, gestützt durch tägliche Messen und noch durch Sondersteuern. ${ }^{54}$ Das Vierte Laterankonzil legitimierte 1215 den Kreuzzug gesamtkirchlich: „Die Befreiung des Heiligen Landes aus den Händen der Ungläubigen ist unser brennender Wunsch. “55 Bald richtete sich die Kreuznahme auch gegen innerkirchliche Abweichler. Wiederum das Vierte Laterankonzil erklärte: „Die Katholiken, die sich, angetan mit dem Zeichen des Kreuzes, zur Verteidigung der Häretiker gürten, erhalten [...] Ablaß. “56

So dauerte die religiöse Motivkraft fort, ermöglichte sowohl die direkte Kampfbereitschaft wie weiter die Etablierung der Ritterorden. Die Kreuzfahrer-Päpste - so der englische Historiker John Gilchrist - , hatten kein Verständnis für Pazifismus“. ${ }^{57}$ Michael Mitterauer spricht vom „Krieg des Papstes“; 58 Hans E. Mayer nennt

53 Wilhelm von Tyrus, Chronicon 8,20; Corpus Christianorum, Hg., Cont. Med. 63, $412^{14}$.

54 Menzel (2000).

55 Viertes Laterankonzil 71, in: Wohlmuth, Hg. (2000), 267-271.

56 Viertes Laterankonzil 71, in: Wohlmuth, Hg. (2000), 267-271.

57 Gilchrist (1988), 193.

58 Mitterauer (2003), 201. 
speziell die päpstlich abgesegneten Ketzer-Kreuzzüge eine „Pervertierung der ursprünglichen Kreuzzugsidee“; 59 Bernard Lewis bezeichnet die Kreuzzüge als „eine radikale Abkehr von den in der Heiligen Schrift formulierten christlichen Grundwerten“. ${ }^{60}$ Vor dem Hintergrund der altchristlichen Gewaltlosigkeit können alle diese Urteile nur als Verurteilungen gelten.

\section{Die Humanisten und der Frieden}

War den Mittelalterlichen der Krieg weithin etwas Normales, so stellten die Humanisten den Frieden obenan, sogar um den Preis von Rechts- und Landesverzichten. Der bekannteste Vertreter hierfür ist Erasmus von Rotterdam (†1536). Den Krieg nannte er einen „Ozean allen Unheils“ und forderte einen christlichen Pazifismus: „Wer immer Christus verkündet, verkündet den Frieden“; denn „kannst du mit dem Munde den gemeinsamen Vater anrufen, wenn du das Schwert in das Herz deines Bruders stößt?“ Im Krieg geistlichen Beistand zu leisten, erklärt er für absurd: „In beiden Heerlagern [...] werden Gottesdienste gefeiert. Ist das nicht etwas Ungeheuerliches? Das Kreuz kämpft mit dem Kreuz, Christus führt mit Christus Krieg [...] Die gottgeweihten Priester können nur dort anwesend sein, wo man den Krieg abwehrt."61 Auch berechtigte Ansprüche sollten nicht mit Krieg durchgesetzt werden; gegebenenfalls hätten die Untertanen den hierfür eingeforderten Waffendienst zu verweigern. Aber angesichts der Türken-Gefahr, zumal der Schlacht von Mohacs von 1526 und der Belagerung Wiens von 1529, wollte Erasmus doch keinen absoluten Pazifismus gepredigt haben. ${ }^{62}$ Auch Luther dachte nur an gerechten Krieg, konnte dabei predigen, wer Krieg anfange, sei ein Unrechter; insbesondere verurteilte er jede Art von Kreuzzug oder Religionskrieg. ${ }^{63}$

Lange ist vergessen geblieben der entschiedenste Vertreter eines christlichen Friedenskonzeptes, nämlich Juan Luis Vives (†1540), ein konvertierter spanischer Jude, der seine Eltern als Opfer der Inquisition verloren hatte, dann in Paris studierte, die weiteren Lebensjahre

59 Mayer (2005), 252.

60 Lewis (2003), 58.

61 Erasmus von Rotterdam (1995), 361, 383, 389, 413.

62 Christ-von Wedel (2003), 215-225.

63 Maron (1996), 32-33. 
in den habsburgischen Niederlanden zubrachte und seine Friedenshoffnungen auf Karl V. richtete. Zum höchsten Gut erklärte er den Frieden; Krieg sei durch nichts zu rechtfertigen, nicht einmal zur gerechten Verteidigung; denn zuviel zerstöre der Krieg, erzeuge nur Not, weswegen dem Krieg immer noch ein ungerechter Frieden vorzuziehen sei. Alle Versuche, mit Gewalt Verbesserungen herbeizuführen, verdammte Vives und schrieb darum auch gegen die Täufer von Münster. Sogar gegenüber den bedrohlichen Türken, gegen die er ausnahmsweise eine Verteidigung guthieß, wollte er letztlich das Liebesgebot angewandt wissen: „Die Türken sind zu lieben, da sie ja Menschen sind, zu lieben von denen, die jener Weisung folgen wollen: ,Liebet eure Feinde'. Wir werden ihnen, was Zeichen der wahren Liebe ist, Gutes wünschen, und zwar für sie das einzige und wahre Gut wünschen, nämlich die Erkenntnis der Wahrheit, was wir aber niemals mit Schmähungen und Verwünschungen erreichen, sondern nur auf jene Weise, wie wir selbst sie durch die Hilfe und Wohltat der Apostel erlangten: nämlich in Übereinstimmung mit den natürlichen und menschlichen Einsichten durch reine Lebensführung mit Bescheidenheit, Mäßigung, Unbescholtenheit und untadelige Lebensführung, damit wir zuerst durch die Tat erweisen, was wir glauben und zu glauben heißen, so daß die Türken nicht unser so abweichendes Leben davon abhält, unseren Worten Glauben zu schenken. " 64

Solche Appelle blieben insofern nicht ohne Wirkung, als z.B. Karl V. den Schmalkaldischen Krieg gegen die protestantischen Fürsten 1546/47 „mit peinlicher Sorgfalt als einen Krieg gegen friedensbrüchige Reichsfürsten deklarierte“, also zur Verteidigung von Gerechtigkeit und nicht als „Kreuzzug gegen Ketzer“. ${ }^{65}$

\section{Die Anfänge des Völkerrechts}

Es gehört zu den Glanzpunkten der spanischen Geschichte, dass die Kolonialisierung Südamerikas eine so neuartige Diskussion in Gang brachte, dass daraus wesentliche Elemente des modernen Völkerrechts hervorgingen. Zu nennen ist allen voran Francisco de Vitoria $(† 1546)$. Anknüpfend an Thomas von Aquin formulierte er zwei 
Grundelemente: der weltliche Staat und die Freiheit des Taufentscheides.

Zum Staat heißt es: „Ungläubigkeit verhindert nicht, daß jemand ein echter Herr ist“, wie ebenso gilt, „daß man wegen Ketzerei vom Standpunkt des göttlichen Rechts her seiner Güter nicht verlustig geht. "66 So haben Ungläubige wie auch Ketzer eigene unantastbare Rechte; selbst der Papst besitzt keinerlei zeitliche Vollmacht über die Barbaren oder über Ungläubige ${ }^{67}$ Für die Kolonisation stellt Vitoria ganz neue Überlegungen über Einwanderungs- und Ansiedlungsrecht an. Denn es durfte am Anfang der Welt, als allen alles gemeinsam war - so mit Blick auf die christliche Urgemeinde (vgl. Apg 4.32) -, ,,jeder in jedes Gebiet ziehen und reisen, in das er reisen wollte“.68 Daraus leitete Vitoria ab, „daß die Barbaren den Spaniern Unrecht zufügen würden, falls sie diese von ihren Gebieten fernhielten." 69 Umgekehrt gebietet sich für die einwandernden Spanier strenge Friedenspflicht, „daß sie nicht kommen, um den Barbaren zu schaden, sondern daß sie sich in friedfertiger Weise als Gäste aufhalten und in der Fremde weilen wollen, ohne daß dies mit irgendeinem Nachteil für die Barbaren verbunden wäre. " ${ }^{\text {"70 }}$ So weit zunächst einmal Vitorias ,völkerrechtliche“ Argumentation.

Es folgt die „missionarische“ Argumentation, steht doch über seinem ganzen Traktat der Taufbefehl: „Lehrt alle Völker und tauft

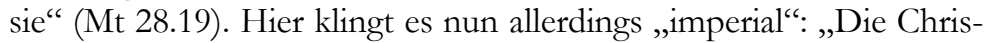
ten haben das Recht, das Evangelium in den Provinzen der Barbaren zu predigen und zu verkündigen." 71 Demzufolge sind die Indios verpflichtet, den Glauben an Christus anzunehmen; denn ,wer glaubt und sich taufen läßt, wird gerettet; wer aber nicht glaubt, wird verdammt werden" $\left(\mathrm{Mk}\right.$ 16.16).$^{72}$ Gemeint ist indes alles andere als eine Zwangsmission. Denn als Voraussetzung und Mittel der Bekehrung wird gefordert, den Barbaren den christlichen Glauben ,in glaubwürdiger Weise darzulegen, d.h. mit glaubwürdigen und vernünftigen Argumenten und mit einem ehrenwerten, im Sinne des 
Naturgesetzes ernsthaften Leben, und wenn dies nicht nur einmal und oberflächlich, sondern sorgfältig und ernsthaft geschieht, dann sind die Barbaren bei Todsünde dazu verpflichtet, den Christusglauben anzunehmen. “73 Dabei ist Krieg „,kein Argument für die Wahrheit des christlichen Glaubens“. ${ }^{74}$ Nur dann kann Krieg gerechtfertigt sein, wenn die freie Predigt in böswilliger Weise unterbunden wird: „Falls die Barbaren [...] die Spanier daran hindern, das Evangelium frei zu verkündigen, können die Spanier [...] auch gegen den Willen der Barbaren predigen und sich um die Bekehrung jenes Volkes bemühen sowie [...] einen Krieg in Angriff nehmen bzw. beginnen, bis sich Gelegenheit und Sicherheit zur Verkündigung des Evangeliums einstellen. "75 Im Ganzen bringt Vitoria einen zunächst traditionellen und dann doch neuartigen Gedankengang: Vom Taufbefehl her und aus Gründen der freien Taufannahme wird hier das „Völkerrecht“ auf freie Predigt - oder modern: auf freie Meinungsäußerung - proklamiert; dieses Recht, aber nicht die Taufe darf erzwungen werden.

Die positiven Beurteilungen und Argumente, wie sie hier bevorzugt zur Sprache gebracht sind, bezeugen ein Sozialdenken, das sich im Verlauf der Neuzeit zum Völker- und Menschenrecht weiterentwickelt hat. Anzuerkennen bleibt, wie Wolfgang Reinhard schreibt, „daß keine andere Kolonialmacht so früh so viel Selbstkritik geübt hat, wie die spanische Gesetzgebung 1542-1573 und die spanische theologische Diskussion der zweiten Hälfte des 16. Jahrhunderts zeigt." "76 Ebenso richtig ist aber auch, dass dadurch die schwere Katastrophe bei der Kolonialisierung Südamerikas nicht verhindert werden konnte, denn - so ebenfalls Reinhard - ,insgesamt ist eine Tendenz zur „Ausbeutung“ und „Verelendung“ der indianischen Unterschichten nicht zu verkennen."77

\section{Die Konfessionskriege}

In Deutschland konnte, als im übrigen Europa die Konfessionskämpfe ihren Höhepunkt erreichten, der Krieg zunächst gestoppt 
werden. Der Augsburger Religionsfrieden von 1555 sicherte für mehr als ein halbes Jahrhundert den Frieden. Zur Katastrophe wurde der Dreißigjährige Krieg. Ob hier ein Religionskrieg tobte, wird bis heute diskutiert. Außer Zweifel steht, dass der geistliche Appell an die Fürsten, den wahren Glauben zu schützen, kämpferisch anheizte. Es entstand ein staatliches Sendungsbewusstsein zur Ausrottung der Ketzerei, was zur religiösen Überhöhung des Krieges führte. Der Faktor Konfession spielte in der Propaganda „eine zentrale Rol$1 e^{\text {“. }}{ }^{78}$ Für den Anführer der katholischen Liga, Maximilian I. von Bayern (†1651), war „das Seelenheil der Menschen in Wahrheit der wichtigste Aspekt des Gemeinwohls“. ${ }^{79}$ Auf evangelischer Seite stachelte das Luther-Jubiläum von 1617 den Kampfesgeist an: von Neuem Hetze in Pamphleten und Predigten, dazu militante Flugblätter mit derben Bildmotiven, letztendlich der Triumph der Reformation als heilsgeschichtliche Gottestat. ${ }^{80}$ Der Papst antwortete dagegen mit dem Bild einer Ecclesia, die mit ihrem Fuß alle Neuerer zertritt, und verordnete ein Jubeljahr mit Ablässen zur Austilgung aller Ketzereien. Kämpferisch wirkte weiter das Jubiläum der Confessio Augustana im Jahre 1630, als zeitgleich der Schweden-König Gustav Adolf (†1632) zur Rettung der Reformation in Stralsund an Land ging. Die in politische Lager gespaltenen Konfessionen steigerten sich - so der Wiener Neuzeit-Historiker Heinrich Lutz - „zu unerhörten innerchristlichen Kriegsmotivationen" " 81 Aber zuletzt verlor der Krieg seinen deutschen und damit auch konfessionellen Charakter, wurde ,zum internationalen Mächtekrieg““ ${ }^{82}$ Ins allgemeine Bewusstsein ist er als der große schreckliche Krieg eingegangen und hat „das Kriegsbild in Deutschland bis hin zum Ersten Weltkrieg entscheidend beeinflußt" .83

In der Langzeitwirkung blieb gleichwohl das neutestamentliche Friedensgebot keineswegs wirkungslos, schuf aber keinen Dauerfrieden. Ließ der „natürliche Krieg“, wie er im Mittelalter zunächst wieder vorherrschte, „das Bedürfnis nach einer Rechtfertigungstheorie des Krieges gar nicht erst aufkommen, so erfordert das Christentum

78 Burkhardt (1992), 133.

79 Bireley (1975), 224.

80 Burkhardt (1992), 133.

81 Lutz (1984), 41.

82 Schindling (2002), 29, 36.

83 Schindling (2002), 14. 
[...] eine solche zwingend und nachdrücklich. "84 Was dabei als Erstes geschah, war ein Nachdenken über Krieg und Frieden, sodass „die Friedens- und Kriegsproblematik ein Dauer- und Zentralthema der mittelalterlichen Gesellschaft" ${ }^{\text {"85 }}$ wurde. Für die Neuzeit konstatiert Anton Schindling, federführend in einem Tübinger Sonderforschungsbereich Krieg und Gesellschaft in der Neuzeit. „Das Konzept des gerechten Krieges hatte als Fundament eine Aussage über den anzustrebenden gerechten Frieden und war deshalb in seiner theologischscholastischen ebenso wie in seiner modernen säkular-völkerrechtlichen Form stets in erster Linie eine Lehre zur Verhinderung, Eindämmung und Begrenzung von Kriegen. Dabei spannt sich der Bogen von Thomas von Aquin bis zur Begründung des Krieges gegen Serbien durch die Nato. “86

\section{Die Weltkriege}

Mit der Globalisierung ist auch der Krieg global geworden: zum „Weltkrieg“. Die im 19. und 20. Jahrhundert von den europäischen Nationen ausgefochtenen Kriege weiteten sich global aus, schon im Ersten und vor allem im Zweiten Weltkrieg. Europa verbreitete mit seiner Technik, Zivilisation, Kultur und Religion auch seinen Krieg in alle Welt. Es ist ein bedrückendes Fazit: Die Friedensreligion Christentum hat weder den europäischen Krieg zu beseitigen noch die weltweite Ausbreitung des eigenen Kriegs zu verhindern vermocht.

Das 19. Jahrhundert hat die Nation zum politischen Idol erhoben. Der Nationalismus wurde „Ersatzreligion“: „In der Sprache des politischen Glaubens gewinnt Nation so einen religiösen Zug. [...] Das Religiöse wird im Nationalen säkularisiert, das Säkulare sakralisiert. "87 Der nationale Volksraum galt als heiliges Vaterland, und der Krieg wurde zum religiösen Blutopfer erhoben, dargebracht auf dem Altar der Nation. ${ }^{88}$ Ein im Jahre 2000 unter dem Titel Gott mit uns publizierter Sammelband bringt gleich als ersten Satz: „Der Zusammenhang von Nation, Religion und Gewalt bezeichnet ein zentrales

84 Janssen (1998), 571.

85 Kurze (1991), 9.

86 Schindling (2002), 19.

87 Nipperdey (1983), 300.

88 Angenendt (1994), 323-329. 
Element europäischer Staatswirklichkeit der Neuzeit, insbesondere aber im langen 19. Jahrhundert, der Zeit von 1789 bis 1914. " 89 Evangelischerseits hat man von einem „Pastorennationalismus“ 90 gesprochen, der von 1815 bis zu den Weltkriegen im 20. Jahrhundert angedauert habe, mit dem „Opfertod für die Nation als höchstem Wert", mit klarer Scheidung auch von ,nationaler ,InGroup“ und ,Out-Group“".91 Die Katholiken, die wegen der Internationalität ihrer römisch-päpstlichen Kirche eher zurückstanden, wurden nach 1900 gleichfalls national. Immerhin warnte der damals als katholischer Sprecher auftretende Münsteraner Moraltheologe Joseph Mausbach (†1930) 1912 vor Chauvinismus und Hochrüstung: „Nicht nur die äußere Wehr und Rüstung der Völker wird schwerer und drückender; auch eine innere Entfremdung und Härte legt sich wie dreifaches Erz um ihre Brust und nimmt den zahlreichen Friedensversicherungen der Staatslenker den warmen, eindringenden Ton der Wahrheit. Der alte Humanitätsgedanke wird heute belächelt als eine schöne Utopie der Aufklärungszeit; die neue Friedensbewegung faßt in den maßgebenden, den Gang der Ereignisse beeinflussenden Kreisen, nur schwer Wurzel; die Deputationen von Geistlichen, Schriftstellern, Arbeitern, die zur Förderung der gegenseitigen Beziehungen ins Ausland gehen, richten gegen jene elementaren Mächte wenig aus, und das Schiedsgericht in Haag wird mit Fragen, die das Nationalgefühl stärker erregen, kaum behelligt. Weil die Kirche als katholische, das heißt allgemeine Kirche alle Völker mit gleicher Liebe umfaßt, weil sie jede nationale Einschränkung des christlichen Gedankens und jede Verletzung der allumfassenden christlichen Liebe verbietet, [...] dürfen wir als Christen das Emporwuchern eines überspannten, völkertrennenden Nationalismus und einer noch inhumaneren, naturalistischen Rassentheorie als eine Gefahr für die Menschheit bezeichnen." "92

Dass 1914 der Erste Weltkrieg ausbrach, war nicht nur Großreichswahn. Antreibend wirkte auch ein ästhetischer Bellizismus. Die Epoche des schönheitsseligen Jugendstils verherrlichte gerade auch Gewalt; man denke an Hugo von Hoffmannsthals Elektra, Gustave Flauberts Hérodias, Oscar Wildes Salome, Gabriele d'Anunzios Marty-

89 Krumeich/Lehmann (2000), 1.

90 Kuhlemann (2001).

91 Hübinger (2000), 233.

92 Mausbach (1912), 401-402. 
rium des beiligen Sebastian. In Literatur, Theater und Malerei geschah eine „weltanschauliche und politische Aktivierung mythischer Opfermodelle“, und am Vorabend des Ersten Weltkrieges waren sich rechts und links nirgends „so nahe wie in ihrer euphorischen Zustimmung zum Krieg“.93 Das viel beredete „Hineinschlittern“ in den Ersten Weltkrieg übersieht diese ästhetisch-archaische Gewaltverherrlichung.

Im August 1914 erschien die Sache Deutschlands so absolut gerecht, dass die Zustimmung allgemein war, auch vonseiten der Katholiken einschließlich Mausbach. Wegen der plötzlich wieder gefüllten Kirchen erhoffte man sich, „die christliche Botschaft gleichsam auf dem Rücken der nationalen Gesinnung zu neuer Geltung zu bringen". ${ }^{94}$ Angesichts des Stellungskrieges und der Vernichtungsschlachten ermutigten sich auch die Katholiken zu trotzigem Kampf; in nationaler Solidarität wollten sie durchhalten, „obschon sie [...] gegenüber dem nationalen Staat eine größere Distanz wahrten“. 95 Klaus Schreiner hat aufgezeigt, wie der Krieg auf die Frömmigkeit einwirkte und umgekehrt die Frömmigkeit auf das Durchhaltevermögen. ${ }^{96}$

Nationaler agierten die Protestanten. Wohl keine gesellschaftliche Gruppe hat - so der Düsseldorfer Zeithistoriker Wolfgang J. Mommsen - „die Kriegsanstrengungen des deutschen Reiches von August 1914 bis zum bitteren Ende im November 1918 mit größerer Entschiedenheit unterstützt als die protestantischen Landeskirchen. “97 Seit 1917 griff Ernüchterung um sich. Für einen Verständigungsfrieden taten sich im Berliner Reichstag Sozialdemokratie und Zentrum zusammen. Papst Benedikt XV. legte einen Friedensvorschlag vor, der aber in Deutschland an „machiavellistischer Hintertreibung“" scheiterte. ${ }^{98}$ Zentrumspolitiker warben für Zustimmung, dabei Joseph Mausbach auch um Verständnis für Frankreich: „Vergleichen wir, um nur eins zu nennen, Deutschlands blühende, unversehrte Fluren mit dem zerklüfteten, verödeten, blutgetränkten Boden Nordfrankreichs, und erwägen wir, was alles dieser Ausgang des 
Krieges - ohne Elsaß! - für Frankreichs Volksseele bedeutet!'“99 Für einen Verständigungsfrieden setzte sich auch der große Adolf von Harnack ein. ${ }^{100}$ Doch neigte der Protestantismus mehr zu der auf Sieg setzenden Vaterlandspartei. Der Kirchenhistoriker Karl Holl $(† 1926)$, grundsätzlich gegen alles Schwächliche und Weibische eingestellt und für das Lebensrecht der Stärkeren eintretend, feierte die Anfangserfolge der deutschen Frühjahrsoffensive von 1918 noch als „wunderbare Wendung“, vernahm Gottes Stimme „durch allen Geschützdonner hindurch" .101

Mehrfach untersucht ist inzwischen die Kriegspredigt, die heute bestürzend wirkt. ${ }^{102}$ Gerd Krumeich resümiert die folgenden Punkte: das Motiv des gerechten und deshalb von Gott gesegneten Krieges, weiter der Krieg als Missionar gegen die Entsittlichung und den Materialismus, dazu die Kriegszeit als Bußzeit. Trotz Steigerung vom gerechten zum heiligen Krieg schränkt Krumeich ein: „Der Haß wird kaum einmal zum Prinzip erkoren“; die Predigt ,gerinnt selten zum Religionskrieg“, will vielmehr ,Zuchtmeister Christi“ sein, sieht zuletzt statt eines Kreuzzugs einen „Kreuzweg“" „Mit moderner Mobilmachung der Geister hat das noch nicht wirklich zu tun“. ${ }^{103}$ Tatsächlich war nach dem katholischen Feldgesangbuch von 1914 zu beten: „Bewahre mich vor jedem unnützen Blutvergießen, vor jeder unmenschlichen Behandlung des verwundeten oder gefangenen Feindes. Die Erinnerung an grausame Mißhandlung oder Tötung des Wehrlosen würde mir meine Todesstunde verbittern und das Sterben schwer machen. Laß mich nie vergessen, daß nur die im Felde mir gegenüberstehenden Krieger meine Feinde, daß dagegen die unbewaffneten Einwohner des Landes, die Verwundeten und Wehrlosen meine leidenden Mitbrüder sind, denen ich Schonung und Mitleid schuldig bin“; den Abschluss des Gebetes bildet die Bitte für die Regierenden: „Flöße ihnen friedfertige Gesinnungen ein, verkürze durch sie das Elend des Krieges, und gib uns in nicht ferner Zeit die große Wohltat eines gesegneten Friedens wieder." ${ }^{\text {"104 Hier vereinten }}$

99 Mausbach (1917), 92.

100 Harnack (1996a), 353 und Harnack (1996b).

101 Hamm (2002), 293.

102 Missalla (1968) und Hammer (1971).

103 Krumeich/Lehmann (2000), 280.

104 Feldgesangbuch für die katholischen Mannschaften des Heeres (o.J.), 41. 
sich - auf eine kurze Formel gebracht - „Legitimation und Konsolation". 105

Bei Kriegsausbruch 1939 war bei Katholiken „,von Begeisterung [...] nichts zu spüren“. ${ }^{106}$ Gleichwohl blieb die Vaterlandspflicht, verbunden durchaus mit der Aufforderung zum Kämpferischen. So postulierte das vom Freiburger Erzbischof Gröber (†1948) herausgegebene Handbuch für Gegenwartsfragen ,die Erziehung zum deutschen Menschen mit seinen Grundeigenschaften des Heldischen, des Kämpferischen, der Aufgeschlossenheit für Ehre und vor allem der opferfrohen Einsatzbereitschaft für die Gemeinschaft. Sie stellt sich damit freudig in den Dienst der nationalpolitischen Erziehung. "107 Die Hirtenbriefe riefen bei Kriegsbeginn zum gerechten Frieden auf, und „von ,Sieg“ ist nicht die Rede“. 108 Gleichwohl wurde die Kampfbereitschaft religiös überhöht: „Deutschland muß leben, auch wenn wir sterben müssen“. ${ }^{109}$ Das für die Frontkämpfer neu belebte Opfer-Motiv konnte sich im Kampf gegen den gottlosen Kommunismus zunächst noch verstärken; der münstersche Bischof von Galen bezeichnete die Gefallenen als den Märtyrern ähnlich. Direkte Gegenstimmen blieben in der Minderheit, wie etwa der Essayist und Konvertit Theodor Haecker (†1945): „Der deutsche Soldat wird funktionieren, ungleich besser als seine Maschinen, die auch schon gut funktionieren. “110 Fast erstaunlich wirkt, dass „bislang weder aus der Zeit des Ersten noch des Zweiten Weltkriegs ein Fall von Waffensegnung nachgewiesen" ist. ${ }^{111}$ Zuletzt aber wurde der Zweite Weltkrieg zur Wende. Die Gestapo registrierte bei Katholiken immer wieder das Predigtthema, „daß der gegenwärtige Krieg eine Strafe Gottes für die Gottlosigkeit und Sittenlosigkeit der nationalsozialistischen Führung sei“. ${ }^{112}$ Die evangelische Kirche hat - wie gesagt worden ist - „die Entfesselung des Krieges durch die deutschen Machthaber nicht als solche durchschaut, sie hat in einer großen Einmütigkeit - von der offiziellen Reichskirche bis in die Bekennende Kirche hinein - ihre Gläubigen nach überlieferter Tradition zu

105 Holzem (2002), 283.

106 Damberg (2002), 323.

107 Gröber (1940), 164.

108 Damberg (2002), 323.

109 Missalla (1999), 29.

110 Haecker (1989), 89; zitiert nach: Missalla (1999), 41.

111 Missalla (1999), 52.

112 Boberach (1971), 356. 
Pflicht und Dienst und Opfer für das Vaterland aufgerufen - sie hatte in diesem Bereich keinerlei kritisches Potential".113 Die Pastoren der Bekennenden Kirche, obwohl auch sie der allgemeinen nationalprotestantischen Mentalität verbunden waren, wandten sich ab, sahen den Krieg ,weniger als das alles überragende, lebensbestimmende Schlüsselerlebnis“, 114 predigten Abwehr gegen die modernen Götzen Staat, Rasse und Volkstum, ermahnten zur christlichen Einheit über alle Nationen hinweg, bewerteten den Krieg als Strafe Gottes, ja befürchteten eine Christenverfolgung bei siegreichem Kriegsende. ${ }^{115}$

Die ersten Atombomben im August 1945 brachten eine zuvor nicht vorstellbare Eskalation zum Bewusstsein. Sofort stellte z.B. der münstersche Bischof von Galen die Frage, „ob derartige Kriege noch moralisch vertretbare Mittel sind zur Entscheidung von Streitfragen zwischen den Völkern“. ${ }^{116}$ Das Zweite Vatikanum konstatierte ,eine Barbarei der Kriegsführung, die die Kämpfenden zu Grausamkeiten verleitet, die die vergangener Zeiten weit übersteigt. [...] Mit der Fortentwicklung wissenschaftlicher Waffen wachsen der Schrecken und die Verwerflichkeit des Krieges ins Unermeßliche [...] Jede Kriegshandlung, die auf die Vernichtung ganzer Städte oder weiter Gebiete und ihrer Bevölkerung unterschiedslos abstellt, ist ein Verbrechen gegen Gott und gegen den Menschen, das fest und entschieden zu verwerfen ist." "117

Ungewohnt war für beide Großkirchen die Idee einer Wehrdienstverweigerung, hatte doch der Soldatendienst unhinterfragt als allgemeine und selbstverständliche Pflicht gegolten. Doch schon nach dem Ersten Weltkrieg meldeten sich pazifistische Stimmen, sowohl katholische wie evangelische, bis hin zur KriegsdienstVerweigerung. Aber unter der NS-Herrschaft galt eine wirkliche Kriegsdienst-Verweigerung ,nicht einmal als Denkmöglichkeit“. ${ }^{118}$ Erst bei der Wiederbewaffnung der Bundesrepublik in den fünfziger Jahren begann sich das zu ändern. Unvergessen ist Heinrich Bölls (†1985) Brief an einen jungen Katholiken, wo er den vor seiner Einberu- 
fung im Jahre 1938 mitgemachten religiösen Besinnungstag schildert, auf dem hauptsächlich vor sexuellen Gefahren gewarnt wurde, aber „kein Wort über Hitler, kein Wort über Antisemitismus, über etwaige Konflikte zwischen Befehl und Gewissen [fiel ...] Aber jene Männer, Prälat Lichtenberg, Pater Delp und die vielen anderen, sie handelten nicht auf kirchlichen Befehl, sondern ihre Instanz war eine andere [...]: das Gewissen." 119 Das Zweite Vatikanum anerkannte diejenigen, „die aus Gewissensgründen den Wehrdienst verweigern, vorausgesetzt, daß sie zu einer anderen Form des Dienstes an der menschlichen Gemeinschaft bereit sind [...] Solange die Gefahr von Krieg besteht und solange es noch keine zuständige internationale Autorität gibt, die mit entsprechenden Mitteln ausgestattet ist, kann man, wenn alle Möglichkeiten einer friedlichen Regelung erschöpft sind, einer Regierung das Recht auf sittlich erlaubte Verteidigung nicht absprechen. " 120

Heute besteht gar keine Wahl: Wenn der Frieden nicht gewahrt bleibt, wird ein Krieg unsere Erde vernichten. Von hieraus sei an eines der jesuanischen Schwertworte erinnert. Als die Jünger Jesus bei seiner Verhaftung mit einem realen Schwert verteidigen wollen, gebietet er: „Steck dein Schwert in die Scheide; denn alle, die zum Schwert greifen, werden durch das Schwert umkommen“ (Mt 26.52). Das Jesus-Wort ist auf Nachdrücklichkeit hin zugespitzt, denn tatsächlich sind ja nicht alle, die zum Schwert gegriffen haben, deswegen auch umgekommen. Aber die Welt der Waffen hat sich so gewaltsam verändert, dass eine verheutigte Version des Jesus-Wortes an die Stelle des Schwertes die Atombombe setzen müsste und dann die blanke Realität ausdrückt: Wer den Atomkrieg riskiert, wird selbst dadurch umkommen.

\section{Literatur}

Angenendt, Arnold (1994): Heilige und Reliquien. Die Geschichte ibres Kultes vom frühen Christentum bis zur Gegenwart. München.

Angenendt, Arnold (22005a): Liudger. Missionar - Abt-Bischof. Münster. Angenendt, Arnold (2005b): „Die Welt des Thietmar von Merseburg“, in: Kunde, Holger, Hg.: Zwischen Kathedrale und Welt. 1000 Jabre Domkapitel Merseburg. Petersberg, 35-62. 
Angenendt, Arnold (42008): Toleranz und Gewalt. Das Christentum zwischen Bibel und Schwert. Münster.

Beestermöller, Gerhard (31997): „Krieg““, in: Lexikon für Theologie und Kirche. Band 6: 475-479.

Bireley, Robert (1975): Maximilian von Bayern, Adam Contzen S. J. und die Gegenreformation in Deutschland 1624-1635. Göttingen.

Boberach, Heinz (1971): Berichte des SD und der Gestapo über Kirchen und Kirchenvolk in Deutschland 1934-1944. Mainz.

Boberach, Heinz (1991): „Die evangelische Kirche im Zweiten Weltkrieg in der Sicht ihrer Gegner“", in: Norden, Günther van/Wittmütz, Volkmar, Hg.: Evangelische Kirche im Zweiten Weltkrieg. Köln, 129-139.

Böll, Heinrich (1961): Brief an einen jungen Katholiken. Köln.

Brittnacher, Hans Richard (2001): Erschöpfung und Gewalt. Opferphantasien in der Literatur des Fin de siècle. Köln.

Burkert, Walter (1995): „Krieg und Tod in der griechischen Polis“, in: Stietencron, Heinrich von/Rüpke, Jörg, Hg.: Töten im Krieg. FreiburgMünchen, 179-196.

Burkhardt, Johannes (1992): Der Dreißigjährige Krieg. Frankfurt/M.

Bumke, Joachim (1999): „Wolfram von Eschenbach“, in: VerLex 10, 13761418.

Christ-von Wedel, Christine (2003): Erasmus von Rotterdam. Anwalt eines neuzeitlichen Christentums. Münster.

Cole, Penny J. (1993): „O God, the heathen have come into your inheritance' (Ps. 78,1): The theme of religious pollution in Crusade documents, 1095-1188“, in: Shatzmiller, Maya, Hg.: Crusaders and Muslims in twelfth-century Syria. Leiden, 84-111.

Cowdrey, H. E. J. (1992): „Canon Law and the First Crusade“, in: Kedar, Benjamin Z., Hg.: The Horns of Hattin. Jerusalem, 41-48.

Damberg, Wilhelm (2002): „Kriegserfahrung und Kriegstheologie 19391945“, in: ThQ 182, 321-341.

Duby, Georges (21981): Krieger und Bauern. Die Entwicklung von Wirtschaft und Gesellschaft im frühen Mittelalter. Frankfurt/M.

Elm, Kaspar (1998): „Die Kreuzzüge - Kriege im Namen Gottes?“, in: Elm, Kaspar, Hg.: Umbilicus Mundi, Beiträge zur Geschichte Jerusalems, der Krenzzüge, des Kapitels vom Hlg. Grab in Jerusalem und der Ritterorden. Sint-Kruis, 23-45.

Elm, Kaspar (2001): „Die Eroberung Jerusalems im Jahre 1099. Ihre Darstellung, Beurteilung und Deutung in den Quellen zur Geschichte des Ersten Kreuzzugs“, in: Bauer, Dieter/Herbers, Klaus/Jaspert, Nikolas, Hg.: Jerusalem im Hoch- und Spätmittelalter. Konflikte und Konfliktbewältigung - Vorstellungen und Vergegenwärtigungen. Frankfurt/M.-New York, $31-54$. 
Erasmus von Rotterdam (21995): „Querela pacis/Die Klage des Friedens“, in: Erasmus von Rotterdam: Ausgewählte Schriften. Band 5. Darmstadt, 359-451.

Feldgesangbuch für die katholischen Mannschaften des Heeres (o.J.): Feldgesangbuch für die katholischen Mannschaften des Heeres. Mit kirchlicher Approbation. Berlin.

Flahiff, George B. (1947): „'Deus non vult'. A Critic of the Third Crusade“, in: Medieval Studies 9, 162-188.

Flaig, Egon (1998): „Ehre gegen Gerechtigkeit. Adelsethos und Gemeinschaftsdenken in Hellas", in: Assmann, Jan, Hg.: Gerechtigkeit. Richten und Retten in der abendländischen Tradition und ibren altorientalischen Ursprïngen. München, 97-140.

Fleckenstein, Josef (1989a): „Das Großfränkische Reich: Möglichkeiten und Grenzen“, in: Fleckenstein, Josef, Hg.: Ordnung und formende Kräfte des Mittelalters. Ausgewählte Beiträge. Göttingen, 1-27.

Fleckenstein, Josef (1989b): „Die Grundlegung der europäischen Einheit im Mittelalter", in: Fleckenstein, Josef, Hg.: Ordnung und formende Kräfte des Mittelalters. Ausgewählte Beiträge. Göttingen, 127-145.

Flori, Jean (1999): Pierre l'Eremite et la première croisade. Paris.

Friedberg, Emil, Hg. (1879): Corpus Iuris Canonici. Band 1. Leipzig.

Galen, Clemes August von (1988): „Predigt vom 8. Juli 1945 in Münster, Nr. 488“, in: Löffler, Peter, Hg.: Bischof Clemens August Graf von Galen. Akten, Briefe und Predigten 1933-1946. Band 2. Mainz, 1183.

Gerlings, Wilhelm (2001): „Augustinus und der antike Friedensgedanke“, in: Garber, Klaus et al., Hg.: Der Frieden. Rekonstruktion einer europäischen Vision. Band 1. München, 63-81.

Gilchrist, John (1988): „The papacy and war against the 'Saracens", in: The International History Review 10, 174-197.

Gröber, Konrad, Hg. (21940): Handbuch der religiösen Gegenwartsfragen. Freiburg/B.

Haecker, Theodor (1989): Tag- und Nachtbücher 1939-1945. Innsbruck.

Hahn, Johannes (2004): Gewalt und religiöser Konflikt. Studien zu den Auseinandersetzungen zwischen Christen, Heiden und Juden im Osten des Römischen Reiches (von Konstantin bis Theodosius II.). Berlin.

Hamm, Berndt (2002): „Hanns Rückert als Schüler Karl Holls. Das Paradigma einer theologischen Anfälligkeit für den Nationalsozialismus“, in: Kaufmann, Thomas/Oelke, Harry, Hg.: Evangelische Kirchenbistoriker im ,Dritten Reich! Gütersloh, 273-309.

Hammer, Karl (1971): Deutsche Kriegstheologie 1870-1918, München.

Harnack, Adolf von (1996a): „Was wir von der römischen Kirche lernen und nicht lernen sollen", in: Nowak, Kurt, Hg.: Adolf von Harnack als Zeitgenosse. Reden und Schriften aus den Jabren des Kaiserreiches und der Weimarer Republik. Band 1. Berlin, 344-360. 
Harnack, Adolf von (1996b): „Protestantismus und Katholizismus in Deutschland“, in: Nowak, Kurt, Hg.: Adolf von Harnack als Zeitgenosse. Reden und Scbriften aus den Jabren des Kaiserreiches und der Weimarer Republik. Band 1. Berlin, 410-412.

Herde, Peter (1967): „Christians and Saracens at the time of the crusades. Some comments of contemporary medieval canonists", in: Collectanea Stephan Kuttner. Band 2. Bologna, 359-376.

Höffner, Joseph (31972): Kolonialismus und Evangelium. Spanische Kolonialethik im Goldenen Zeitalter. Trier.

Holzem, Andreas (2002): „Christoph Holzapfel, Kriegserfahrung als Forschungsproblem. Der Erste Weltkrieg in der religiösen Erfahrung von Katholiken“, in: ThQ 182, 279-297.

Hübinger, Gangolf (2000): „Sakralisierung der Nation und Formen des Nationalismus im deutschen Protestantimus“, in: Krumeich, Gerd/Lehmann, Hartmut, Hg.: ,Gott mit uns؛ Nation, Religion und Gewalt im 19. und frühen 20. Jabrbundert. Göttingen.

Hürten, Heinz (1992): Deutsche Katholiken 1918-1945. Paderborn.

Janssen, Wilhelm (1982): „Krieg“, in: GGB 3, 567-615.

Kahl, Hans-Dietrich (1989): „Was bedeutet ,Mittelalter?“, in: Saeculum 40, 15-38.

Kedar, Benjamin Z. (1984): Crusade and mission. European approaches towards the Muslims. Princeton.

Krumeich, Gerd/Lehmann, Hartmut, Hg. (2000): ,Gott mit uns . Nation, Religion und Gewalt im 19. und früben 20. Jabrbundert. Göttingen.

Kuhlemann, Frank-Michael (2001): „Pastorennationalismus in Deutschland im 19. Jahrhundert - Befunde und Perspektiven der Forschung“, in: Haupt, Heinz-Gerhard/Langewiesche, Dieter, Hg.: Nation und Religion in der deutschen Geschichte. Frankfurt/M., 548-586.

Kurze, Dietrich (1991): „Krieg und Frieden im mittelalterlichen Denken“, in: Duchhardt, Heinz, Hg.: Zwischenstaatliche Friedenswahrung in Mittelalter und Früber Neuzeit. Köln-Wien, 1-44.

Lewis, Bernard (2003): Die Wut der arabischen Welt. Warum der jabrhundertelange Konfliket zwischen dem Islam und dem Westen weiter eskaliert. Frankfurt/M.New York.

Luther, Martin (1914): Tischreden. Weimar.

Lutz, Heinrich (1984): „Friedensideen und Friedensprobleme in der frühen Neuzeit", in: Heiss, Gernot/Lutz, Heinrich, Hg.: Friedensbewegungen: Bedingungen und Wirkungen. München, 28-54.

Maier, Johann (1990): Krieg und Frieden sowie das Verbältnis zum Staat in der Literatur des frühen Judentums. Barsbüttel.

Maron, Gottfried (1996): „Frieden und Krieg: Ein Blick in die Theologieund Kirchengeschichte", in: Herrmann, Peter, Hg.: Glaubenskriege in Vergangenheit und Gegenwart. Göttingen, 17-35. 
Mausbach, Joseph (1912): „Nationalismus und christlicher Universalismus“, in: Hocbland 9(1), 401-418, 584-599.

Mausbach, Joseph (1917): „Das Friedensprogramm des Heiligen Vaters“, in: Hochland 15(1), 81-99.

Mayer, Hans Eberhard (82005): Geschichte der Kreuгzüge. Stuttgart-Köln.

Menzel, Michael (2000): „Kreuzzugsideologie unter Innocenz III.“, in: Historisches Jabrbuch 120, 39-79.

Missalla, Heinrich (1968): ,Gott mit uns: Die deutsche katholische Kriegspredigt 1914-1918. München.

Missalla, Heinrich (1999): Für Gott, Führer und Vaterland. Die Verstrickung der katholischen Seelsorge in Hitlers Krieg. München.

Mitterauer, Michael (2003): Warum Europa? Mittelalterliche Grundlagen eines Sonderwegs. München.

Mommsen, Wolfgang J. (2000): „Die nationalgeschichtliche Umdeutung der christlichen Botschaft im Ersten Weltkrieg“, in: Krumeich, Gerd/Lehmann, Hartmut, Hg.: ,Gott mit uns: Nation, Religion und Gewalt im 19. und frühen 20. Jahrbundert. Göttingen.

Müller, A. (1976): „Krieg“, in: Historisches Wörterbuch der Philosophie. Band 4. 1230-1233.

Nipperdey, Thomas (1983): Deutsche Geschichte 1800-1860. Bürgerwelt und starker Staat. München.

Norden, Günther van (1991): „Die evangelische Kirche und der Kriegsausbruch 1939“, in: Norden, Günther van/Wittmütz, Volkmar, Hg.: Evangelische Kirche im Zweiten Weltkrieg. Köln, 121-127.

Radulfus Niger (1977): De re militari et triplici via peregrinationis Ierosolimitane. Einleitung und Edition von Ludwig Schmugge. Berlin-New York: de Gruyter.

Ratzinger, Joseph (2005): „Was die Welt zusammenhält“, in: Habermas, Jürgen/Ratzinger, Joseph, Hg. (32005): Dialektik der Säkularisierung. Über Vernunft und Religion. Freiburg, 39-60.

Repgen, Konrad (1988): „Kriegslegitimationen in Alteuropa. Entwurf einer historischen Typologie“, in: Repgen, Konrad, Hg.: Von der Reformation zur Gegenwart. Beiträge zu Grundfragen der nenzeitlichen Geschichte. Paderborn, 67-83.

Reinhard, Wolfgang (1985): Geschichte der europäischen Expansion. Band 2. Stuttgart.

Rief, Josef (1981): „Die bellum-iustum-Theorie historisch“, in: Glatzel, Norbert/Nagel, Ernst J., Hg.: Frieden in Sicherheit. Zur Weiterentwicklung der katholischen Friedensethik. Freiburg/Br.-Wien, 15-40.

Riley-Smith, Jonathan (1990): „Kreuzzüge“, in: Theologische Realenayklopädie. Band 20, 1-10.

Riley-Smith, Jonathan (2003): Wozu heilige Kriege? Anlässe und Motive der Kreuzzüge. Berlin.

Runciman, Steven (31995): Geschichte der Kreuг̃üge. München. 
Schindling, Anton (22002): „Das Strafgericht Gottes. Kriegserfahrungen und Religion im Heiligen Römischen Reich Deutscher Nation im Zeitalter des Dreißigjährigen Krieges. Erfahrungsgeschichte und Konfessionalisierung“", in: Matthias Asche/Anton Schindling: Das Strafgericht Gottes. Kriegserfabrungen und Religion im Heiligen Römischen Reich Deutscher Nation im Zeitalter des Dreißigjäbrigen Krieges. Münster, 11-51.

Schreiner, Klaus (2000): „Die Makkabäer. Jüdische Märtyrer und Kriegshelden im liturgischen Gedächtnis der abendländischen Christenheit", in: Schreiner, Klaus, Hg.: Märtyrer, Scblachtenhelfer, Friedensstifter. Krieg und Frieden im Spiegel mittelalterlicher Heiligenverehrung. Opladen, 1-53.

Schreiner, Klaus (2006): „Helm ab zum Ave Maria‘. Kriegstheologie und Kriegsfrömmigkeit im Ersten Weltkrieg“", in: Rottenburger Jabrbuch für Kirchengeschichte. Band 25, 99-126

Soggin, Alberto (1990): „Krieg II. (Altes Testament)“, in: Theologische Realensyklopädie. Band 20, 19-25.

Vitoria, Francisco de (1997): „Relectiones. De Indis I,4“, in: Horst, Ulrich, Hg.: Francisco de Vitoria. Vorlesungen II (Relectiones). Völkerrecht, Politik, Kirche. Stuttgart.

Vives, Juan Luis (1964): „Politico-moralia“ (Liber IV,13), in: Opera omnia 5. London.

Weissenberg, Timo J. (2005): Die Friedenslehre des Augustinus. Theologische Grundlagen und ethische Entfaltung. Stuttgart.

Wiedemann, Heinrich (1949): Karl der Große, Widukind und die Sachsenbekehrung. Münster.

Wohlmuth, Josef, Hg. (2000): Dekrete der ökumenischen Konzilien. Band 2: Konzilien des Mittelalters. Vom Ersten Laterankonzil (1123) bis zum Fünften Laterankonzil (1512-1517). Paderborn. 
Nicolaus Cusanus, De pace fidei (1454)

Hanna-Barbara Gerl-Falkovitz

\section{Zwei Modelle der europäischen Geistesgeschichte: Lessing und Nicolaus Cusanus}

Gotthold Ephraim Lessing gab mit der berühmten Ringparabel in Nathan der Weise 1779 dem Toleranzgedanken der Aufklärung eine geniale Fassung: Ein echter Ring und zwei davon ununterscheidbare Nachbildungen werden drei Brüdern als Erbe ausgehändigt. Jeder Streit muss unterbleiben, jede eingebildete Sicherheit auch; der wahre Ring wird sich nicht mehr erweisen lassen. Lessing leistet damit zweierlei: Er vermeidet durchaus eine skeptische Position, denn es gibt das Echte, das Wahre, das Einzig-Gültige; andererseits bleibt es dem menschlichen Urteil rundweg entzogen und somit auch jedem Streit und Sonderanspruch. Damit gründet sich Toleranz auf dem Schleier über der Wahrheit, womit Lessing für die Aufklärung den Streit um die Religionen erübrigt hatte. Für die Aufklärung erübrigte sich so dank Lessing der Streit um die Religionen.

Diese Haltung ist die späte Frucht einer langen, wenig guten Entwicklung des europäischen Denkens und Streitens. Und als Frucht dieses generationenalten, alles vergiftenden Streitens trägt die Toleranz Lessings doch eine Narbe: die Narbe des Kompromisses. Für den so bitter nötigen Religionsfrieden wird der Begriff der Wahrheit dem Begreifen entzogen, der Vernunft verwehrt. Nimmt man die Parabel wörtlich, so wird Wahrheit sogar gleich-gültig. Der Wert des echten Ringes besteht ja nur noch abstrakt.

Lessings Ausweg versteht sich aus der Zeitgeschichte, ist sogar unabdingbar zu würdigen als ein Schritt zu höherer Zivilisation. Sei- 
ne Lösung hat notwendig die Toleranz erstrangig gesetzt, also die Spannung zwischen ihr und der Wahrheit gleichsam menschlich verkraftbar gemacht und aus ihrem zerreißenden Widerspruch befreit. Böseste Erfahrungen der seit der Reformation andauernden Religionskriege wurden damit befriedet, denn nachdem die Schlachten im 17. Jahrhundert verstummt waren, tobte ja weiterhin der geistige und geistliche Kampf in Herz und Hirn der getrennten Gläubigen. Lessings Großvater Theophil verteidigte an der Leipziger Universität 1669 eine „politische Disputation“ mit dem Titel De religionum tolerantia - das brennende ungelöste Thema einer ganzen Epoche.

Und trotzdem ist Lessings noble, späte Lösung nicht die einzig mögliche, die vor dem Forum der Vernunft bestehen kann. Noch vor dem Ausbruch der verzehrenden Glaubenskriege gab es eine Denkbemühung von europäischem Maßstab, die im Vorgriff auf das Kommende das gefährdete Verhältnis von Wahrheit und Toleranz neu bestimmte. Und dies nicht als eine Schreibtischgeburt, sondern aus der Erfahrung einer enormen Bedrohung entworfen, lebendigpolitisch ebenso wie lebendig-kirchlich gedacht und der zeitgenössischen Christenheit in aktuellster Stunde gewidmet. Anders als Lessing geht dieser Entwurf vom ersten Rang der Wahrheit aus und kommt in einer hoch überraschenden Wendung von der Wahrheit selbst zur Toleranz. Es handelt sich um die Schrift De pace fidei/Vom Frieden im Glauben des Nicolaus Cusanus von 1454. In dieser Schrift ist ein systematischer Ansatz gelungen, der das Problem bis zum heutigen Tag befruchten könnte.

\section{Der Fall: Konstantinopel, das „zweite Rom“, in den Händen der Muslime}

Welche enorme Bedrohung steht im Hintergrund? Am 29. Mai 1453 war das christliche Konstantinopel an Sultan Mehmed II. gefallen; die Bevölkerung wurde in grauenhafter Weise in einem tagelangen Blutbad umgebracht. (Erstaunlicherweise steht 1204, das Blutbad durch die Kreuzritter, deutlicher im europäischen Gedächtnis.)

Dadurch geriet ganz Europa in äußerste Erregung. Der Krakauer Domherr und Historiker Jan Dlugosz schrieb mit Entsetzen: „Eines der beiden Augen der Christenheit wurde ausgerissen, eine ihrer beiden Hände wurde abgeschlagen." Die Christenheit empfand sich als in einen Winkel, angulus orbis, gedrängt, wie Enea Silvio Piccolomini 1454 klagte, und dieses „Winkel-Syndrom“ hielt lange 
an. Tatsächlich galten ja die Bedrohung durch das osmanische Reich und die Unterwerfung christlicher Nationen für rund 250 Jahre und nötigten zu immer erneuten Rufen nach einer schnellstens zu schaffenden pax christiana.

Diese Rufe bildeten ironischerweise die positive Rückseite des tragischen Falls von Konstantinopel: Unter dem Druck des Überlebens trat nunmehr plötzlich eine Fülle von Friedensprogrammen auf den Plan, um die zerstrittenen europäischen Fürsten gegen den gemeinsamen Feind zusammenzuschmieden. ${ }^{1}$ Erst der Feind befriedete, was sich aus freien Stücken nicht befrieden konnte. Durch den Donnerschlag von 1453 erwachte ein vielfältiger Handlungswille, der grundsätzliche politische und religiöse Friedensanstöße ernsthaft verwirklichen wollte. Geschichtlich ist freilich $\mathrm{zu}$ sagen, dass alle Bemühungen um die politische Einung Europas gegen die Türkengefahr immer erneut bröckelten. Wenig später zerstörten die Reformation und die sich daran entzündenden Konfessionskriege endgültig den Traum einer pax christiana. Im Gegenteil: Auf rund 200 Jahre war jede tragfähige, parteiübergreifende religiöse und politische Einigung dahin. Erst der Westfälische Friede von 1648 schuf mit Cuius regio eius religio eine - freilich im Kern gefährdete - Regelung, was zu einigermaßen religiös homogenen Landschaften führte - um den Preis der Vertreibung und Auswanderung der jeweils ,anderen" Konfession. Norden und Osten Europas waren und blieben protestantisch (die nordischen Staatskirchen, Preußen), während der Einflussbereich des habsburgischen Kaisertums katholisch blieb.

\section{Cusanus' Programmatik}

Vor diesem gefährlich verdunkelten Hintergrund des Falles von Konstantinopel und der Vision „Türken vor Rom!“” entwickelt Nicolaus Cusanus 1454 einen groß gedachten, riskanten Ansatz: die Begründung religiöser Toleranz aus der Gewissheit der einen Wahrheit. De pace fide $i$ ist eine unerhörte, alle Tagesaktualitäten weit überholende Schrift. Sie sucht den beschämenden Fall von Konstantinopel unter dem Maß einer äußersten christlichen Reflexion aufzuarbeiten und für die Zukunft fruchtbar zu machen - eine geistige Umwertung, wie sie Cusanus auch für das spätmittelalterliche Denken durchführ- 
te, um es aus seinem „herbstlichen“ Niedergang zu lösen. Der „Friede im Glauben“ setzt an beim Aushalten einer Spannung zwischen Toleranz und Wahrheit. Gerade weil es diese Spannung gibt, ist das Verhältnis zwischen beiden Größen nicht ein für alle Mal „festzumachen", sondern bedarf immer neu angemessener Balance. Um dies in seiner reflexiven Dignität zu würdigen, muss das Grundkonzept des Cusanus gegenwärtig gehalten werden: die Verschränkung endlicher Gegensätze in der Unendlichkeit und deren Berührung (attingere) in der Vernunft.

\section{Vernunft, Gegensatz, Unendlichkeit}

Cusanus hat in seiner Philosophie eine Grundeinsicht zur Entfaltung gebracht, die vor ihm anders und beschränkter gefasst war und seit seinem neuartigen Entwurf zur Denkvorgabe der neuzeitlichen Philosophie zählt. Diese Grundeinsicht, die - als Inspiration einbrechend - in De docta ignorantia wie eine „Regel“ erstmals festgehalten ist, entwirft die Kontur eines neuen Problemzusammenhanges überhaupt. Es lassen sich drei Themen hervorheben, die, obwohl unterschieden, in einen unlösbaren gegenseitigen Verweis eintreten: 1. die menschliche Vernunft in ihrem Unterschied zum Verstand, 2. Gegensatz und Einheit, 3. Unendlichkeit. Wesentlich ist es aber das letzte Thema, das die vorangehenden zu ihrer gedanklichen Lösung führt, und nur in seinem Horizont sind sie auch zu entwerfen; insofern bildet das Denken der Unendlichkeit die neue Voraussetzung und den Kontext philosophischen Fragens überhaupt.

Ansetzend an den (schon im Mittelalter) unterschiedenen Kräften menschlicher Erkenntnis bestimmt Cusanus den Verstand (ratio) als das Vermögen, welches das Sein diskursiv („durchlaufend“, also im Nach und Nach) erarbeitet und folglich dessen Gegensätze in ihrer Ausschließlichkeit festhält. Ja der Verstand kann nur in dieser objektiven Fixierung mit ihnen verfahren, d.h. logische Regeln anwenden (dem aristotelischen Satz vom Widerspruch gemäß), denn er bedient sich grundsätzlich des Vergleichs zwischen den Objekten (das Verfahren der Einzelwissenschaft!), er stellt Verhältnis, Proportion her. Dieses Bezugsdenken ist zugleich die Grenze der Verstandeswahrnehmung und -aussage: nie wird er ein Absolutes erkennen, nie ein Unvergleichliches, insofern nie die Präzision oder Exaktheit der Ursprungswahrheit. 
So erweist die Prüfung das diskursive Verfahren als ein zweitrangiges, nämlich abgeleitetes: Notwendig bedarf es eines vorausliegenden Vermögens, das die fest-gestellte Gegenteiligkeit, überhaupt die Teilbarkeit und Vielheit der Welt zuerst aus einer Ursprungseinheit, einer Ganzheit begreifen und wahrnehmen muss, damit es statt zu einer logischen Differenzierung nicht bloß zu einem chaotischen Auseinanderfallen isolierter Dinge kommt. Dieses die Einheit wahrnehmende, erstrangige Vermögen ist die Vernunft (intelligentia), welche aus der allem Gegensatz vorausliegenden Seinseinheit denkt. Sie muss sogar vom Verstand erkenntnislogisch als Erstes vorausgesetzt, ja gefordert werden: vor dem Vergleich und der Proportion muss sie die „Bedingung der Möglichkeit“ von Verhältnis denken, kraft ihrer Einsicht (intelligentia) der absoluten Identität jenseits allen Vergleichs. Erst damit wird der rationale Gegensatz aus dem bloßen, ausschlieBenden Widerspruch befreit und in ein ergänzendes oder ganzheitliches Verhältnis genommen.

Die Vernunft ist also eine das Wesen des Gegensatzes überholende, genauer: dessen zerstörerischen Widerspruch einigende Kraft. Damit wären Verstand, Gegensatz, Einheit in einen erhellenden Bezug gebracht. Doch fehlt noch ein drittes Moment des Denkens.

Die alles begründende, denknotwendige Einheit - und hierin liegt die gedankliche Spitze des cusanischen Entwurfs - ist in ihrem Wesen zu fassen als Unendlichkeit. Erst das Ineinssetzen von Einheit und Unendlichkeit ist der Cusanus aus den alten Weltbildern und Denksystemen in die Neuzeit hinauskatapultierende Schritt.

Denn die Vernunft denkt nun - als Einheitsgrund allen Denkens! - das Infinite: es liegt aber auf der Hand, dass sie es nicht denken kann, gewiss nicht im unmittelbaren Zugriff. Ihr fehlt jene Adäquation (als Vernunft des endlichen Menschen), die zweifellos der teilende Verstand gegenüber den teilbaren, gegensätzlichen Dingen aufbringt, etwa in deren mathematischer, also separierender Behandlung. Das Unendliche aber kann nicht vom Vernunftdenken ermessen werden, weil es selbst das Maß des Vernunftdenkens ist.

Für den philosophischen Prozess heißt das: Als absolute und präzise Wahrheit für das philosophische Denken uneinholbar, bleibt die Wahrheit trotzdem für das Denken schlechthin konstitutiv. Philosophie kann nur die Andersheit des Nicht-Absoluten denken und sie als Nicht-Identität aufweisen: sie zeigt damit das „Andere“ des Absoluten, der Identität, der Wahrheit - insofern kann auch sie Wahrheit (proportional und relativ!) beanspruchen, also wissen- 
schaftsfähig bleiben. So wird der Verstand in die Vernunft aufgehoben: sein rational definiertes Endliches wird in sein „Anderes“, das indefinierte Unendliche, aufgehoben; im „Überschritt“ (wobei excessus keine Mystifikation ist, sondern ein Prozess der dialektischen Vernunft) wird über die Grenze des Endlichen hinaus gedacht. ,Jenseits“ dieser Grenze erfährt die Vernunft ihr Nichtwissen, aber als docta ignorantia, die über ihre eigene Grenze - über ihre Inadäquation, wesentlich auch über ihr Sprachversagen ${ }^{2}$ - belehrt ist.

Und gerade dieses Wissen von Grenze ermöglicht den neuen Typus des Denkens: denn innerhalb der Grenzen des Endlichen kann das Denken selbst beliebig seinen Ausgangspunkt setzen und sich relativ-messend (nach dem selbst gewählten Maß) verhalten. Das Denken wird zum Messen, mens wird richtig von mensurare abgeleitet: Anmessen an den selbst gesetzten Maßpunkt. Gewicht, Maß und Zahl sind Instrumente und Ausdruck dieses Sich-selbst-Setzens im Endlichen (Idiota de mente).

Damit begründet Nicolaus Cusanus den neuzeitlichen Entwurf der Subjektivität: sie erfährt das Unendliche, Absolute als Grenze und als das „Andere“ ihrer selbst, aber gerade kraft dessen kann sie im Endlichen mensurierend und sich selbst als Maß setzend denken. ${ }^{3}$

Wenn das Unendliche nicht einfachhin das Sich-Entziehende, Dunkle ist, sondern das im Überstieg Erreichbare (wenn auch nicht präzise und exakt), welches sind seine aussagbaren Bestimmungen?

Hier liegt die wesentliche Erhellung darin, das Unendliche als unbedingte Identität, idem und non-aliud, zu denken, in der Weise der Verneinung des Endlichen und aller Andersheit (infinitum negative). Es lässt keine unterscheidbaren „Teile“ zu: es ist das Ununterschiedene (auch insofern gegensatzlos), in nichts in ein Mehr und Weniger differenzierbar. Es ist überhaupt unquantitativ, ja es hat keinen Verhältnisbezug zum Relativen und zur Quantität. Es ist aus derselben Absolutheit das schlechthin Größte (aber als Qualität: als Bedingung aller Größe!) wie das schlechthin Kleinste: als absolut notwendiger, vom Denken erschlossener Maßpunkt aller relativen Messeinheiten. Das absolut Kleinste ist dem Gegensatz zum absolut Größten über-

2 Zum Problem einer notwendig neuen, aber nicht zu leistenden Sprachgebung siehe Apel (1955), Cassirer (1927), Peukert (1964), und Duclow (1977).

3 Vgl. den Sammelband Facoltà di Magistero dell'Università di Padova, Hg. (1970), darin besonders: Martinez-Gomez (1970). Vgl. auch Fräntzki (1972). 
hoben. Da beide nicht quantitativ, sondern als Bedingung von Quantität zu fassen sind, sind sie identisch in allen qualitativen Bestimmungen. Sie konzedieren eine Ausgangnahme nach Wahl: Von beiden her lässt sich in gleicher Weise die Qualität der infinitas infinita entwickeln. Und umgekehrt ist es die absolute Unendlichkeit, welche als uniens contradictoria eine coincidentia oppositorum auslöst. (Dazu ein mathematisches Beispiel, wie grundsätzlich bei Cusanus, als Hilfsmittel der Vorstellung für Unvorstellbares: Die gekrümmte Linie, ins Unendliche extrapoliert, ist identisch mit der geraden Linie.)

Gegenüber diesem absolut Unendlichen gibt es ein anderes (Hegel wird später sagen: schlechtes) Unendliches, das der erfahrbaren Welt, der Gegenwelt zum Absoluten. Auf ihrer Seite herrscht das Verschiedensein schlechthin, das Immer-Andere als Grundsatz. Insofern wird auch in der Beziehung des aliud zum aliud eine Unendlichkeit erfahren, aber eine solche der immer wechselnden Bezugsmöglichkeit, der änderbaren Funktion: eine potentielle Unendlichkeit (infinita possibilitas oder infinitas finita). Sie ist unendlich dank der unendlich möglichen Modalitäten/Funktionalitäten der Dinge, endlich durch die Grenze am non-aliud. Ihre Unendlichkeit ist daher eine privative: sie ist ein Mangel, nämlich an der Qualität des in seiner Fülle, Einheit und Vollkommenheit Unendlichen, sie ist das quantitativ und defizient einfach Grenzenlose, das (zeitlich wie räumlich) nur immer weitergeht, ohne einen einigenden Ausgangs- und Zielpunkt zu besitzen.

Daraus ist einsichtig, dass diese Welt unendlich möglicher Beziehungen des anderen zu einem wieder anderen nicht selbst ein absolutes, sondern das relative Maß des (gedachten) Vergleichs untereinander kennt. In diesem Verfahren der comparatio kann ein Größer und Kleiner (maius et minus), mangels eines absoluten Bezugspunktes aber nicht ein maximum oder minimum überhaupt festgehalten werden. Eben deswegen muss das Denken subjektive Maßpunkte setzen, die hypothetisch gewählt sind; Erkenntnis muss standpunktgebunden, nicht dinggebunden sein: sie wird coniectura, Vermutung (De coniecturis), Anmessung oder Anmaßung noch im positiven Sinn. Insofern ändert sich auch der Wahrheitsbegriff in dieser unendlich-endlichen Welt: Während in dem Sein als idem die Ursprungswahrheit als absolut genaue (veritas praecisa) zu denken ist, kann sie in dem Sein als aliud freilich nur als hinsichtliche, nur in Relation gültige Wahrheit (veritas in respectu ad) bestimmt werden. Dabei hebt die Hinsicht nicht den Charakter der Wahrheit auf: Es gibt (z.B. in jeder Wissenschaft) 
die Wahrheit eines Relationsgefüges, die sich aus der logischen Einhaltung der (coniectural) gesetzten Maßpunkte ergibt. Die mens baut die Welt als unendlichen Zusammenhang dieser Struktur- oder Funktionsgefüge auf: Sie sind insgesamt das maximum contractum, die Welt als verschränkte Unendlichkeit und Unendlichkeit der Verschränkung, gegenüber dem maximum absolutum, wo jene Fremdbezüglichkeit kraft der Identität nicht auftritt. Dass auch das idem eine Relation in sich und zu sich selbst besitzt, und zwar in einer dreifachen, also trinitarischen Weise, ist noch zu zeigen. Jedenfalls handelt es sich um eine wesentlich andere Relation als die komparative, äußerlich bleibende, hypothetische.

In dieser komparativen Unendlichkeit gilt schließlich notwendig das Gesetz des Kontradiktorischen $(\mathrm{a} \neq \mathrm{b})$, weil nur Nicht-Identisches, Immer-Anderes methodisch zu einem unendlichen Vergleich auf Ähnliches und Unähnliches gebracht werden kann. Zwingend kann ebenso auch nicht mehr Einzelnes für sich sinnvoll in dieser Welt gedacht werden, sondern nur sein unendlicher Bezug auf anderes: Die Relation wird Denkhorizont des Dings, so wie die ganze relational verschränkte Welt Horizont aller Dinge wird. Das Ding wird auf Welt, nämlich auf Struktur verwiesen. Es wird seinerseits in aspekthafte Unendlichkeit gehoben (die freilich defizitär, mangelhaft gegenüber der präzisen Unendlichkeit bleibt).

\section{Gott und das Universum}

Dieser dreifache Zusammenhang des Denkens von Vernunft, Gegensatz und Unendlichkeit wird von Cusanus angewandt in Hinblick auf Gott, das Universum und den Menschen (De docta ignorantia).

Gott ist die allem Werden und Sichändern überhobene Ureinheit, das Identische überhaupt, das Sein als idem: in ihm sind alle erarbeiteten Bestimmungen der infinitas infinita anzutreffen. Wesentlich ist: Hierin wird das Absolute als Subjektivität gedacht, als geistiger Selbstvollzug, nicht bloß als dinghafte Substanz. ${ }^{4}$ Denn Cusanus entwickelt eine Metaphysik des Absoluten als eines Geistig-Ichhaften, in welcher dessen Ureinheit immer schon eine vermittelte und voll-

4 Die Filiation von Meister Eckhart ist offenkundig. Er hat als Erster das intelligere Gottes seinem esse fundamental vorgeordnet (Quaestiones Parisienses 1, n. 4 von 1302/03). Vgl. dazu Flasch (1978), wo auch auf die Weiterführung des eckhartschen Gesichtspunktes durch Dietrich von Freiberg eingegangen wird. 
zogene, eine Dreieinheit ist. Diese eint die drei Momente Einheit Gleichheit - Verbindung beider (unitas - aequalitas - connexio oder auch indivisio - discretio - connexio), dabei ist sie aber nicht die bloß rational vorgestellte, leere Einheit der Substanz, sondern die lebendige, sich selbst vollziehende Einheit des ursprünglichen Geistes, sein dadurch bedingtes Unterscheiden von sich selbst und der Rückbezug des Unterschiedenen auf den einen Ursprung - all das gedacht als eine sich zu sich verhaltende absolute Lebendigkeit. ${ }^{5}$ Sie kann analog in der Bewegung der Einsicht erfasst werden, die eine Einheit des Einsehenden, Einsehbaren und Einsehens ist (intelligens - intelligibileintelligere).

Diese Einheit der göttlichen oder absoluten Subjektivität ist weiter dadurch gekennzeichnet, dass sie die Gegensätze an sich hält, denn es gehört gerade zu ihrer Selbstbewegung, dass sie in ihrem Verhalten zu sich das Andere (Negative) ihrer selbst unterscheidet und es in die Ursprungseinheit einbezieht. Dazu gehört nicht nur der aufgehobene Gegensatz von maximum und minimum, sondern auch der des Seins und des Nichts, d.h. der Negation des Seins. Das antike und mittelalterliche Denken von Substanz schließt diese Negativität aus: ein Denken statischer Ruhe; das cusanische Denken von Subjektivität schließt diese Negativität ein: ein Denken dynamischer (Vermittlungs)bewegung. Die rational zerreißende Widersprüchlichkeit der Widersprüche ist in die Selbstbewegung des Subjektiven eingebunden - als der zugehörige Unterschied des Anderen in der Einheit selber. Ja die Einheit kann nur immer Einheit sein im Einbegreifen des Unterschiedes.

Es ist gerade diese alles einschließende, gesamtheitliche Verfasstheit der göttlichen Subjektivität, die sie im strengen Sinne namenlos macht: sofern ein Name Bestimmtheit und Unterschiedenheit artikuliert, was aber beides der rationalen Sonderung entspringt und sprachlich in der Fixierung des Entweder-oder bleibt. Alles, was von der absoluten Subjektivität gesagt wird, bezeugt das Unzureichende, nämlich das verstandhaft-rationale Vorstellen als Grundmuster der Benennung: Der absolute Name, von dem Cusanus spricht (De venatione sapientiae), findet sich nur im Schweigen und Schauen. Dennoch haben die verwendeten Namen und Worte Hinweischarakter auf ein 
ihre Trennung Übersteigendes: Die Vernunft muss auch über die Sprache ausgreifen.

Wie ist das Universum, die geschaffene Welt unter einem solchen Schöpfer neu zu fassen?

Zunächst gibt es keine aussagbare Relation, da es kein logisches Verhältnis zwischen dem Mehr und Weniger und dem Größten/Kleinsten, zwischen dem Komparativen und dem Absoluten, dem Einen und dem Vielen geben kann. Und doch: Schon dieser logisch verneinte - Bezug weist auf eine translogische Relation eigener Art hin. Denn Gott, in der Selbstvermittlung seiner Einheit, bringt ja das Andere seiner selbst oder sich als Andersheit hervor: Einheit in der (Ent)äußerung der Andersheit aber zeigt sich als Vielheit, das Absolute zeigt sich im Komparativen, das UnendlichUnendliche im Endlich-Unendlichen. Es ist nicht einfach darin verschwunden, geleugnet oder zerstört, sondern das Immer-Andere ist die Ausfaltung, Darstellung des Nie-Anderen. Vielheit der Welt ist nicht (schlechte) Vervielfältigung der Einheit, sondern sie gehört zum Selbstvollzug der Einheit selbst: Die ausgegossene Quantität ist „das Andere“ der Abundanz der Qualität. Dieser das Wesen der Einheit ausmachende Vorgang und Hervorgang der Vielheit ist die cusanische explicatio, die sich in der Welt nach dem Gesetz der Zahl ausfaltet. Complicatio und explicatio sind grundsätzlich Weisen des Selben: Schöpfung wird gesehen als ein - nicht zeitlich zu verstehender - Selbstvollzug des Absoluten. Von daher das berühmte (und freilich auch pantheistisch misszuverstehende) Wort des Cusanus: „Gott ist nichts ohne die Welt, die Welt nichts ohne Gott“ (,Tolle Deum a creatura et remanet nihil"). Darauf beruht die cusanische Lehre von der Nichtwissbarkeit und Unergründbarkeit der Schöpfung. Sie gehört zum unerkennbaren Wesen Gottes selbst.

Freilich ist darauf zu achten, dass Welt und Dinge Verschiedenes sind. Die Dinge als endliche mit aller zugehörigen Raum- und Zeitgebundenheit und Kontrarietät sind erkennbar, nämlich messbar nach Maßgabe der mens. Die Welt ist nicht Addition der Dinge, sondern ihre Bedingung: universum praeveniens opposita. Die Welt wird vor den Dingen, als Voraussetzung ihrer Pluralität gedacht, denn ohne sie als Ganzes ist das Einzelne nicht denkbar. Zugleich zeigt sich an jedem Einzelnen die Mächtigkeit des Ganzen (wie der Mensch in jedem einzelnen Glied er selbst ist); die implicatio, Gott, lebt in der explicatio, in jedem Geschaffenen auf einzigartige Weise, singulariter. Dies verursacht letzten Endes sowohl die Ähnlichkeit, also den 
grundsätzlich komparativen Charakter aller Dinge, wie auf der anderen Seite umgekehrt ihre niemals restlose Gleichheit: da jedes am Einen eben einzigartig teilhat. So sind die einzelnen Dinge die ganze Welt contracto modo, während die Welt insgesamt contractio, Verschränkung, Relationsgefüge aller Dinge ist.

\section{Glaube als wissende Unwissenheit: Von der menschlichen Teilhabe am verborgenen Gott}

Auf der Seite des Geschaffenen nimmt der Mensch eine ausgesuchte Stellung ein: Er ist unter allen Ausfaltungen der göttlichen Einfalt der, in dem diese Ausfaltung zum Wissen ihrer selbst gelangt.

Dieses Wissen ist mit einer Problematik beladen. Denn der menschliche Geist ist - wie der göttliche oder absolute - zwar auf Selbsterkenntnis qua Selbstverhältnis angelegt, eine Vermittlung aber lässt sich nicht gewinnen, weil die von dem Geist „messend“ hervorgebrachten Dinge, in denen er sich selbst zu erkennen sucht, ihn sich nicht wiederfinden lassen. Im Sehen des Nicht-Absoluten, des aliud, bleibt der menschliche Geist vielmehr sich selbst verborgen, uneinsichtig: Er verfehlt gerade die Erkenntnis des eigenen Wesens; an das „Andere“ weggegeben verharrt er im „Schlaf“ der Beziehungslosigkeit zu sich selbst. Dennoch gewahrt er im Nach und Nach der Erfahrung, dass sein Sehen auf die Dinge ihn als Sehenden voraussetzt. Dies ist der Beginn der mittelbaren Reflexion auf sich selbst, die sich zum Ausdruck bringt in einem Bild, das der Geist von sich gewinnt, ebenso wie er anderes seinem Maß entsprechend aus-bildet. Aber dieses Bild ist ein in den Dingen - wenngleich ein reflexiv durch sie erschlossenes - nicht zu findendes, nachträgliches und nicht der lebendige, sich selbst vermittelnde Vollzug des absoluten Geistes. So verhält sich zwar der menschliche Geist auch zu sich, aber in grundsätzlich entzweiter und nicht ursprünglicher Form. Die Entzweiung rührt von der Andersheit der vom Geist durchlaufenen und ermessenen Dinge her: Sie sind insgesamt „Natur“ als Gegenbegriff zum Geist, als sein Gegenüber in Andersheit. Zwar wird dieses erfahrene Gegenüber in das bildliche Selbstverhältnis mit einbezogen, damit aber eben auch als unterschiedenes Anderes festgehalten und nicht - wie im göttlichen oder ursprünglichen und d.h. auch wahren Geist - als das unterschiedene Andere des Einen selbst gesehen. Auch insofern hat der menschliche Geist etwas Unwahres, Uneigentliches, Unpräzises an sich. Der Geist als ratio, mensura, steht 
zu sich selbst im Gegensatz, erreicht sich nur im selbst erstellten, am Anderen der Dinge abgenommenen Bild, erreicht sich nur defizient.

Diese unbefriedigende Sicht des Menschen in seiner sowohl Maß-geblichen wie entäußerten Stellung zu den Dingen ist für Cusanus nur eine, die „natürliche“ Seite aufdeckende Sicht. Alle notwendig verbleibenden Zweiheiten des menschlichen Geistes werden überholt in der Teilhabe am Absoluten (in der platonischen methexis). Ja es ist diese Teilhabe, welche überhaupt das Erkennen der defizienten Subjektivität ermöglicht, des Unlebendigen des erstellten Bildes. Darüber hinaus ist ein „Sprung“ oder ein „Überschritt" zu machen, der zugleich der Entzweitheit des noch nicht zu sich selbst bzw. zum Absoluten gekommenen Geistes ein Ende setzt - im Eingehen in die Einheit des Selbstvollzuges Gottes, als dessen wesentliches Moment sich der Mensch plötzlich begreift. Cusanus bringt zur Klärung das Beispiel des allsehenden Auges, das auf einem ruht, aus welcher Richtung man auch immer auf es blicken mag, aber den Betrachter eben nur so lange ansieht, wie dieser es betrachtet. Sehen und Sich-Ansehen-Lassen sind ein und derselbe Vollzug: Gott und der Mensch sind in Einheit einander zugeordnet (De visione Dei).

Dieses Schauen des Absoluten ist freilich nicht begleitet vom diskursiven Wissen, d.h., es ist nicht ein Schauen von teilbaren Eindrücken, weil gerade das feststellbare Andere des sinnlichen Sehens fehlt. Die Schau vollzieht sich in der ursprünglichen, vor und über allem teilenden Wissen liegenden Einheit von Schauendem, Geschautem und Schauen. Hier ist der Ort der wissenden Unwissenheit, die in der Schau ihr Nichtwissen erfährt, aber nicht negativ, sondern kraft einer unerhörten Belehrung. Insofern ist der Mensch, wenn er sein eigentliches Sein durch den Überstieg zum Absoluten und nicht mehr Bildhaften erreicht, für Cusanus wesentlich der Laie, idiota: nicht einer, dem es naiv an Kenntnissen mangelt, sondern einer, der im Erreichen seines wahren Selbst das Wissen gegen das Nichtwissen eintauscht. Die geschaute Wirklichkeit nimmt ihm die Möglichkeit, alia voneinander zu sondern, da sie nichts anderes als einfachste Einheit zeigt. Diese Einheit, gerade weil sie keine Synthesis vorstellt, ist unaussagbar, unwissbar und unvorstellbar: nicht mehr sich gegenüber zu halten. Der Laie ist der Mensch in der präzisen, nicht entäußerbaren Ursprungswahrheit.

Cusanus hat auch hier den die Neuzeit prägenden Schritt vollzogen - und seine Schriften bieten zwar Modifikationen, dem The- 
ma bleiben sie jedoch treu -, Mensch und Gott in einer unterschiedenen, gleichwohl einfachen und nicht gegensätzlichen Einheit einander zuzuordnen, als Vollziehende desselben Aktes. Entscheidend ist dabei der methodologische Schritt, das relative, messende Wissen im Bereich des Mehr und Weniger festzumachen an dem vorausgesetzten „Nichtwissen“ qua absolutem Maß oder funktionale Wahrheit festzumachen an präziser Wahrheit. Des Cusanus Leistung ist, nicht mehr Unendliches und Endliches, Absolutes und Relatives, Sein und Seiendes, theologisch gewendet: Schöpfer und Schöpfung in der Differenz festzuhalten, sondern eine ins Einzelne entfaltete neue Weise der Beziehung zu denken, welche die Differenz als einen Modus ursprünglicher Einheit sehen lehrt. Dies kann gelingen, weil die Einheit als Einheit einer alles einbegreifenden Subjektivität gesehen wird, deren Selbstvollzug den Charakter des Unendlichen, also Unerschöpflichen, und des Lebendigen, also immer Neuen und Möglichen, hat. Und zugleich gelingt der methodologische Durchbruch einer Rückkopplung des Relativen an das Absolute, der Funktion an die Präzision, des Verstandes an die Vernunft, ohne deren Differenz für das Denken und hypothetische Weiterarbeiten aufzugeben. Obwohl der Mensch Gott nicht erkennt, den Verborgenen nicht enthüllt, den Unfasslichen nicht fasst, ist er umgekehrt von ihm erfasst und dadurch tätig, im Denken und im Werk.

In einem Gebet formulierte Nicolaus Cusanus: „Du, Herr, steigst hernieder zu uns und bleibst doch unfaßlich, unendlich. Du bist unendlich, um unserer Sehnsucht ewiges Ziel zu sein. Du, Herr, bist die Unendlichkeit, die ich ersehne in all meinen Sehnsüchten.“

\section{Jesus Christus als inklusive Wahrheit: De pace fidei}

Menschliche Religiosität arbeitet an einer „Ausfaltung“ des unendlich einfachen Gottes, seiner „Einfalt“. Nicht nur die Sprache, auch das Verständnis nähert sich dieser Einfalt nur uneigentlich. „Du bist jener, der offenbar und mit den verschiedenen Namen genannt wird, da $\mathrm{Du}$, wie Du bist, für alle unerkannt und unaussprechlich bleibst. Du, der Du die unendliche Kraft bist, bist nicht von dem, was Du geschaffen hast, noch kann das Geschöpf den Gedanken Deiner 
Unendlichkeit begreifen, da es von Endlichem zu Unendlichem keinen Verhältnisbezug gibt." ${ }^{\text {"6 }}$

So gleich am Anfang von De pace fidei die These eines Erzengels, auch Bote (angelus) und Geistmacht (intellectualis virtus) genannt. Gehört und gesehen wird er in der Vision eines ungenannten Mannes (quidam vir), der „früher jene Gegenden gesehen hatte“. Es handelt sich also um Cusanus selbst, der 1437 als Gesandter des Papstes nach Konstantinopel reiste, um das Einigungskonzil von Florenz/ Ferrara vorzubereiten. (Die Einigung zwischen der orthodoxen und katholischen Kirchenführung kam zwar zustande, wurde aber praktisch vom Volk nicht nachvollzogen.) Es war auf der Rückreise von Konstantinopel, wo Cusanus im Adriatischen Meer, auf dem Deck des Schiffes liegend, die blitzartige Einsicht in den ,Zusammenfall der Gegensätze“ hatte, den er in allen folgenden Werken verarbeitete.

Die Grausamkeiten bei der Einnahme von Konstantinopel bringen den Bekümmerten zu der Frage, ob und wie eine ,leichte Konkordanz" (facilem [...] concordantiam) und ein „ewiger Friede“ (perpetuam pacem) unter den Religionen zu erreichen seien. ${ }^{7}$ Die Vision, so die Rahmenhandlung, entrückt ihn in ,geistige Höhe“, wo der Allmächtige vor dem Konzil der Himmlischen die Klagen über die gegenwärtigen Religionskämpfe (Ursache der politischen Kriege) anhört. Der Erzengel, erster Kundschafter und Analysator der Lage, bittet Gott, sein Antlitz zu enthüllen, damit alle „,erkennen, daß und wie es nur eine einzige Religion in der Mannigfaltigkeit von Übungen und Gebräuchen gibt. Wohl wird man diese Verschiedenheit von Übungen und Gebräuchen nicht abschaffen können, [...] doch sollte es wenigstens - so wie Du nur einer bist - nur eine einzige Religion und einen einzigen Kult der Gottesverehrung geben. " ${ }^{\text {" }}$ Gott antwortet, er habe bereits genug getan, indem er den Menschen verschiedene Propheten und schließlich das fleischgewordene Wort gesandt habe. ${ }^{9}$ Doch „das Wort“ selbst bietet sich an, mit den „erfahrenen Menschen“ aller Völker und Sprachen in Jerusalem in einen Disput zu treten, um alle Verschiedenheit der Religionen durch gemeinsame 
Zustimmung aller Menschen „einmütig auf eine einzige, fürder unverletzliche Religion zurückzuführen“.10

Nun entspinnt sich ein unerhörter Dialog. Der Grieche, senior, bezweifelt, dass man „einen anderen Glauben“ annehmen könne; der Italer fragt nach der Aussagbarkeit der Weisheit; der Araber nach der Verwerflichkeit der Vielgötterei; der Inder nach der Möglichkeit, Statuen und Götterbilder zu verehren, und ob Trinität nicht drei Götter meine; der Chaldäer (Stammesgenosse Abrahams), der Jude, der Skythe und der Gallier versuchen, den Begriff der Trinität gedanklich zu fassen. In all dem erweist „das Wort“ den Sinn des bisherigen religiösen Gebrauchs: „Ihr werdet nicht einen anderen Glauben, sondern ein und dieselbe einzige Religion allseits vorausgesetzt finden."11 Sogar und gerade die Vielgötterei erweist die eine Wahrheit: „Und wer sagt, daß es mehrere Götter gibt, sagt auch, daß es den einen Ursprung gibt, der allem vorausgeht."

Hier ergibt sich eine zwingende intellektuelle Übereinstimmung im Ein-Gott-Glauben, der zumindest latent aufzuweisen ist. Doch berührt Cusanus über die allgemeine Gotteslehre hinaus nun spezifisch das Ärgernis der neutestamentlichen Offenbarung, die „Menschwerdung“. In einer kühnen theologischen Anstrengung unternimmt es Petrus, zu erweisen, was an diesem Ärgernis denkbar und mithin mit den entlegensten Religionen, vertreten durch Perser, Syrer und Türken, vereinbar ist. Auch dort, wo im Einzelnen ausdrücklich gegenläufige religiöse Vorschriften geboten sind, wird das Argument auf den Kern zurückgeführt. Der Tartar, ein Monotheist, beanstandet gezielt: „Unter diesen verschiedenen Ausführungen gibt es das Opfer der Christen, bei welchem sie Brot und Wein darbringen und sagen, es sei der Leib und das Blut Christi. Daß sie dieses Opfer nach der Darbringung essen und trinken, scheint am verabscheuungswürdigsten. Sie verschlingen nämlich, was sie verehren. Wie in diesen Fällen, die dazu noch nach Ort und Zeit verschieden sind, eine Einung zustande kommen kann, begreife ich nicht. Solange es sie jedoch nicht gibt, wird die Verfolgung nicht aufhören. Verschiedenheit erzeugt nämlich Trennung und Feindschaft, $\mathrm{Haß}$ und Krieg. "13 Hier entscheidet Paulus im Auftrag „des Wortes“ über alle 
Äußerlichkeiten hinweg nach dem Glauben, nicht nach den Werken, nach der Wahrheit des Gemeinten, nicht nach den sinnlichen Zeichen. Abraham, Vater des Glaubens für Christen, Juden und Araber, habe eben, behauptet er, dieses Kriterium erfüllt - unabhängig von allen Einzelaktionen. „Wird das zugegeben, dann stören die verschiedenen Arten der Gebräuche nicht, denn sie sind als sinnliche Zeichen der Glaubenswahrheit eingesetzt und verstanden."14 In Bezug auf die Sakramente, z.B. wenn das Geheimnis der Eucharistie nicht begriffen oder auch aus Furcht nicht empfangen wird, erklärt Paulus: „Seinen sinnenhaften Zeichen nach ist dieses Sakrament, sofern der Glaube da ist, nicht von solcher Notwendigkeit, daß es ohne es kein Heil gäbe. Es genügt nämlich zum Heil, zu glauben und so diese Speise des Lebens zu essen. Darum gibt es kein notwendiges Gesetz bezüglich seiner Austeilung; ob es, wem es und wie oft es dem Volk gegeben werden soll.“ Der Grundsatz lautet: „Eine genaue Gleichförmigkeit in allem zu verlangen, bedeutet eher, den Frieden zu stören." 15

Schließlich wird die Eintracht der Religionen ,im Himmel der Vernunft" (in coelo rationis) ${ }^{16}$ beschlossen: Jerusalem wird Mittelpunkt des einen Glaubens und des ewigen Friedens.

Die Vision des Cusanus lässt sich in ihrer reflexiven Tragweite gar nicht hoch genug schätzen. Hier ist eine Toleranz der Riten und religiösen Übungen, bis in scheinbare Widersprüche hinein, grundgelegt, grundgelegt nämlich auf eine klare Katholizität im Wortsinne: kat'holon als „,auf das Ganze bezogen“ verstanden. Die Unerkennbarkeit, Unaussprechlichkeit Gottes nötigt zu Zeichen aller Art; deren Kriterium liegt einzig - und nur darauf besteht Cusanus - in der Durchsichtigkeit auf das Urbild, im Wissen um die eigene Vorläufigkeit. Verselbständigen und versteinern sich die Bilder stattdessen, sind sie, ihrer eigenen Wahrheit abtrünnig geworden, zu zerstören. ${ }^{17}$ Dem Christentum kommt dabei die höchste Aufgabe zu, und zwar die, diese Durchsicht auf das Urbild und die Aufdeckung der Götzen im Bewusstsein zu halten - es wird die äußerste Möglichkeit des Christentums, an den Grundanspruch der (anderen) Religionen zu erinnern und ihn reflexiv zu klären. Zugleich anerkennt Cusanus die 
Andersheit der religiösen Zeichen auch als den Wert, den die Subjektivität grundsätzlich bei ihm hat: den Wert der Vielfalt, welche die Einfalt ihrem eigenen Auftrag gemäß ausfaltet, den Wert des Überflusses, welcher der göttlichen Güte ungezählt entströmt. „Vielleicht wird sogar die Hingabe aufgrund der Unterschiedlichkeit vergrößert, da jede Nation versuchen wird, ihren Ritus mit Eifer und Sorgfalt herrlicher zu gestalten."18 Diese „Theodizee der religiösen Formen und Gebräuche"19 anerkennt das Andere, den Anderen als Ausdruck der einen Wahrheit selbst: eine zutiefst christliche Grundlegung des Friedens. Sie begreift nämlich Frieden nicht als Indifferenz, sondern als Differenz auf dem Boden der umfassenden, einfachen Wahrheit. Cusanus zeigt, dass dieses Paradox tatsächlich christlich gedacht werden kann: Frieden, weil Unterschied der Religionen, weil Einheit Gottes.

\section{Abwägung des Verhältnisses von Toleranz und Wahrheit: Lessing und Cusanus}

Lessing hatte die Wahrheit dem menschlichen Erkennen entziehen müssen, um Toleranz sinnvoll und einsichtig zu machen. Damit hat sich aber die Deutung und Gewichtung beider Begriffe eigentlich verunklart, ist zumindest nicht auf den Boden wirklicher Begründung vorgestoßen. Letztlich heißt Lessings Lösung: Der Mensch ist nicht wahrheitsfähig, deswegen tolerant.

Cusanus dagegen hatte den Anspruch der Wahrheit behalten, ja ihre Folgen als verbindlich gezeigt. Zwar übersetzt sich die absolute Wahrheit (ähnlich wie bei Lessing) nicht unmittelbar ins hiesig Greifbare, Unvermittelte; aber (anders als bei Lessing) zeigt sie sich in einleuchtenden Spuren, gültigen und dem Denken zugänglichen Merkzeichen, im durchaus verlässlichen Relativen dieser Welt. So heißt hier die Lösung: Der Mensch ist sehr wohl wahrheitsfähig und deswegen tolerant. Denn er trifft auf die Wahrheit auch in ihren Verkleidungen, ja Verdunkelungen und muss deren wahren Kern achten. Achten und gelten lassen muss er alles, was „aus der Wahrheit" stammt. 
Erst eine solche Begründung scheint das schwierige Verhältnis richtig aufzubauen. Wer die Wahrheit liebt, hört auf ihre Stimme auch im Gewand des Fremden, erst recht im Gewand des Eigenen, das die Haltung und Stimme Christi zu wahren sucht. Toleranz gibt es gerade innerhalb, nicht außerhalb der Reichweite des Wahren. Toleranz entspricht der Polyphonie der einen Wahrheit. Hüterin der einen Wahrheit ist die Kirche, daher auch Hüterin der Vielfalt polyphoner Ausdrucksweisen. Konkreter: Sie sucht das Antlitz Christi nicht nur in jedem Menschen, sondern auch in den Heiligen Schriften und Ritualen anderer Religionen zu achten. Eben dies scheint das II. Vatikanische Konzil mit seiner Hochschätzung der anderen Religionen formuliert zu haben - und dies keineswegs als Neuheit. Seit der Patristik ist es Konsens, dass die spermata tou logou, die semina veritatis, anzuerkennen und in das „Eigene“ aufzunehmen seien. Athen hat auch mit Jerusalem zu tun, wie es Augustinus gegen Tertullian entschied - selbst wenn Abgrenzungen gegen „Athen“ zur Wahrung der unvergleichlichen Kontur ,Jerusalems“ immer wieder in der Theologiegeschichte notwendig wurden.

Dennoch ist anzuerkennen: Zwischen Vernunft und (monotheistischem) Glauben besteht weiterhin eine Kontrastbeziehung. Sie kann in zweierlei spannungsvoller Hinsicht gelesen werden: einerseits als komplementär, was die gemeinsame Denkgeschichte zumindest bis zur Aufklärung betrifft. Vernunft kann den Glauben stützen, denn seine positiven Vorgaben aus der Offenbarung können intelligibel oder luzide gemacht werden (wie die Auslegung des Logos durch die Patristiker bis hin zu Joseph Ratzinger zeigt). Dies gilt sogar und auch für die Trinität, die keineswegs irrational für das Denken ist, sondern als Paradigma von Verhältnisbeziehung, genauer: einer in sich unterschiedenen, das Andere ihrer selbst einschließenden Einheit erhellt werden kann, wie es Cusanus und noch Hegel vorlegen (freilich ist dies nicht mit einer erschöpfenden Erklärung zu verwechseln).

Andererseits: Der Glaube provoziert auch die Vernunft und führt sie in Aporien, in Trans-Rationales, zuweilen weist er sie sogar ab als „Hure Vernunft“, wie die Reihe von Tertullian über Martin Luther zu Sören Kierkegaard und Leo Schestow zeigt. „Was hat Athen mit Jerusalem zu tun?“, so Tertullians Schlagwort, ${ }^{20}$ welches 
Schestow 1937 herausfordernd und verstörend wieder aufnimmt. ${ }^{21}$ Kierkegaard, seinen Zeitgenossen zum Ärgernis, schreibt in der Einleitung zu Furcht und Zittern: „Die Theologie sitzt geschminkt am Fenster und bietet der Philosophie buhlerisch ihre Dienste an" - auf Hegels Aufhebung der Theologie in das absolute Wissen hin gesprochen. Im Blick auf Abraham und Christus gilt keine einfache Versöhnung, kein Sinnvertrauen in die Vernunft, keine harmonisierende Gleichsetzung des menschlichen und göttlichen Geistes.

In diese Richtung deutet der jüngste Aufsatz des französischen Philosophen Rémi Brague, Spezialist auf dem Gebiet der arabischen Philosophie des Mittelalters, mit dem herausfordernden Titel, gleichsam einem Fanal: „Schluß mit den ,drei Monotheismen‘'“22 Für Brague ist die Gleichsetzung von Jahwe, dem trinitarischen Gott und Allah ein Wunschdenken, das der Selbstauslegung der drei großen Religionen nicht entspricht, ihr auch weder historisch noch den Texten gemäß entsprechen kann. Ebenso wenig sei Abraham mit Ibrahim einfachhin identisch; die Bibel betont die Sohneslinie über Isaak, der Koran diejenige über Ismael in entschieden anderer Deutung. Wie in einem Brennpunkt wird diese Unterschiedenheit deutlich in der Gestalt Jesu, zu dem sich alle drei Religionen höchst uneinheitlich verhalten. „Harmonie an der Oberfläche“ 23 verdeckt, ja zerstört nach Brague den notwendigen Dialog.

Würde Cusanus dieser These recht geben? Vermutlich insoweit, als in unserer Lebenswelt sachliche Gegensätze keineswegs - aus welchen Motiven immer - aufgehoben werden sollen, da die Andersheit und damit die Wirklichkeit tatsächlich zerstört würden. Wie diese Gegensätze im Lichte des einen Logos Gottes letztlich zusammengefügt werden könnten, bleibt jenem concilium vorbehalten, das eschatologisch in coelo stattfindet. Unsere Intelligenz kann es ahnend „berühren“, nicht aber verfügt sie über eine Einheit, kann diese doch in unserer empirischen Welt keine wahre, sondern nur eine vorgetäuschte sein. Auch Cusanus ist eine Warnung vor der Ungeduld des vorwegnehmenden Denkens.

21 Schestow (1937). Vgl. Schestow (2006): Schestow sieht in Plotin den späten Vertreter der griechischen Philosophie, der aufgrund seiner mystischen Sicht des Einen „das Vertrauen in die Vernunft verlor".

22 Brague (2007).

23 Brague (2007), 113. 


\section{Literatur}

Apel, Karl Otto (1955): „Die Idee der Sprache bei Nicolaus von Cues“, in: Archiv für Begriffgeschichte 1, 200-221.

Brague, Rémi (2007): „Schluß mit den ,drei Monotheismen!“, in: IKZ Communio 36(2), 98-113.

Cassirer, Ernst (1927): „Die Bedeutung des Sprachproblems für die Entstehung der neueren Philosophie“, in: Festschrift für Carl Meinhof. Hamburg: L. Friedrichsen.

Cassirer, Ernst (31963): Individuum und Kosmos in der Philosophie der Renaissance. Darmstadt: WBG.

Duclow, Donald F. (1977): „The Analogy of the Word: Nicholas of Cusa's Theory of Language“, in: Bijdragen 38, 282-299.

Facoltà di Magistero dell’Università di Padova, Hg. (1970): Nicolò Cusano agli inizi del mondo moderno, Firenze: Sansoni.

Flasch, Kurt (1978): „Zum Ursprung der neuzeitlichen Philosophie im Mittelalter. Neue Texte und Perspektiven", in: Philosophisches Jabrbuch 85(1), $1-18$.

Fräntzki, Ekkehard (1972): Nikolaus von Kues und das Problem der absoluten Subjektivität. Meisenheim/Glan: A. Hain.

Gerl-Falkovitz, Hanna-Barbara (1993): „Pax christiana“, in: Gerl-Falkovitz, Hanna-Barbara: Die zweite Schöpfung der Welt. Mainz: Grünewald.

Martinez-Gomez, Luis (1970): „El hombre ,mensura rerum“ en Nicolas de Cusa“, in: Facoltà di Magistero dell'Università di Padova, Hg.: Nicolò Cusano agli inizi del mondo moderno. Firenze: Sansoni, 339-345.

Metzke, Erwin (1956/57): „Nicolaus von Cues und Hegel“, in: Kantstudien 48, 216-246.

Nicolaus Cusanus (21989): „De pace fidei“, in: Nicolaus Cusanus, Philosophisch-theologische Schriften III (lat.-dt.), hg. v. Leo Gabriel. Wien: Herder.

Peukert, Kurt Werner (1964): „Die Entsprachlichung der Metaphysik durch den Unendlichkeitsbegriff des Cusanus“, in: Philosophisches Jabrbuch 72, 49-65.

Schestow, Leo (1937): Athen oder Jerusalem? Berlin.

Schestow, Leo (2006): Fatales Erbe. Über die mystische Erfahrung Plotins. Dresden.

Stallmach, Josef (1964): „Das Absolute und die Dialektik bei Cusanus im Vergleich zu Hegel“, in: Scholastik 39, 495-509. 


\section{Gewalt, Transzendenz und Vatergott. Patriarchatskritische Fragen zum „Anderl von Rinn“, einer Ritualmordlegende aus der Retorte}

Sibylle Auer

\section{Vorbemerkung}

Da ich in Rinn lebe und weil ich mich für vorchristliche Kultorte in Tirol seit meiner Dissertation ${ }^{1}$ interessiere, werde ich patriarchatskritische Fragen zur Legende des Anderl von Rinn stellen, um zu versuchen, diese Legende als Instrument der Herrschaft zu entlarven.

Die Legende des Andreas von Rinn brw. Judenstein (Ortsteil von Rinn) ist eine Erzählung aus der Retorte, ${ }^{2}$ d.h. eine willkürlich erdichtete, antisemitische Ritualmordlegende. Diese Legende wurde von Dr. Hippolyt Guarinoni, dem Haller Stadtphysikus, um $1620^{3}$ erfunden, der sich selbst als Volkserzieher ${ }^{4}$ verstand. Dieser „Volkserzieher“ Guarinoni bedient sich antisemitischer Projektionen und diffamiert „Andersgläubige“/Nichtchrist(inn)en u.a. durch diese Dichtung und erweist sich damit als Verfechter einer patriarchalen Religion. Ziel seiner Bestrebungen ist die Festigung der Herrschaft durch die Staatsreligion. Mittels der Missionierung und Verbreitung des katholischen Glaubens an einen abstrakten Vatergott im Rahmen der Monotheismusdoktrin wird die weltliche Herrschaft des Landesfürsten - ein „ehrgeiziger und kriegserprobter Haudegen" ${ }^{5}$ und Bischof -, der oberen Schichten und der Männer über das (Gottes)volk, die Nichtbesitzenden, die 
Frauen legitimiert. Die Anderl-Legende wirkt als „fantastisches“ Herrschaftsinstrument im Dienste der Gegenreformation und Staatsmacht. Das Ziel der patriarchalen Bestrebungen ist die Festigung von Herrschaft durch die monotheistische Religion als eine zur einzig legitimen schöpferischen wie staatlichen Ordnung erkorene, ${ }^{6}$ was zugleich die Vernichtung ${ }^{7}$ matriarchaler sakeraler Riten, Orte und Sinnbilder sowie der Nichtchrist(inn)en bedeutete. Kann also die Erfindung der Judensteinlegende als die patriarchale Konstruktion einer „Gegenerinnerung“ 8 zur Auslöschung vorpatriarchaler, vormonotheistischer Verhältnisse analysiert werden?

\section{Über die Zeit und die Person des Erfinders}

Die Legende wurde erstmals 1620/1622 verfasst und ist in der Fassung von 1651 erhalten, ${ }^{9}$ sie wurde also am Ende des „spanischen Zeitalters“ (1550-1650), ${ }^{10}$ zur Zeit der Gegenreformation und der Hexenverfolgung geschrieben. Die Einfälle der Türken im 16. und 17. Jahrhundert charakterisieren diese Epoche ebenso, ${ }^{11}$ wie Pest und Hunger als Folge des Dreißigjährigen Krieges (1618-1648) die Menschen plagten. ${ }^{12}$ Nach den Bauernunruhen und in der Zeit der Religionskriege wird die Erhaltung des einheitlichen Glaubens ein staatspolitisches Axiom, denn Religion ist dem Tiroler Landesfürsten des 16. Jahrhunderts, dem Erzherzog Ferdinand II., zufolge Domestizierungsideologie. ${ }^{13}$

Anhand der Person Guarinoni wird der herrschaftsideologische und volkeserzieherische Charakter ${ }^{14}$, der diese Epoche wie die Legende prägte, deutlich. Der Erfinder und Verfasser der Legende war Arzt ${ }^{15}$,

6 Pallaver (1987), 230.

7 Benedikter (2000), 39 und Dörrer (1954), 141.

8 „Die wirksamste Art, eine Erinnerung auszulöschen, besteht darin, sie mit einer Gegenerinnerung zu überlagern.“ Assmann (2003), 113.

9 Schroubek (2003), 176.

10 Kunze (1990), 39.

11 Die früheren Figuren in der Judensteinkirche, die die Juden darstellen sollten, hatten türkische Trachten an. Siehe Mantl (1967), 12, Anmerkung 6.

12 Beimrohr (1995), 346.

13 Pallaver (1987), 12.

14 Dörrer (1954), 174.

15 Amann (2004). 
Anhänger der Gegenreformation ${ }^{16}$, fanatischer Katholik ${ }^{17}$, Erbauer der Karlskirche bei Volders und Antisemit ${ }^{8}$.

\section{Die Legende}

Bevor die Legende kritisch hinterfragt werden kann, sollte diese kurz wiedergegeben werden:

Laut Legende verkaufte der mit der Aufsicht des Kindes beauftragte Taufpate den kleinen Andreas an jüdische Kaufleute. Angeblich quälten diese das nackte Kleinkind u.a. mit einer Zange im nahen Birkenwald, schächteten es auf einem Stein, sammelten dessen Blut und hängten die Leiche an eine Birke. Die Mutter, die Witwe Anna Oxner, ahnte Unheilvolles - Blutstropfen fielen auf ihre Hand - und sie eilte vom Kornschnitt herbei. Sie suchte das Kind und fand es schließlich tot im Wald, wie die Legende berichtet. Auf dem Grab des Kindes soll eine dreifache Lilie gewachsen sein, die Kinder ausrissen, so wie ein unachtsamer Hirte diese fortwährend immergrüne Birke fällte und dafür - wie die Kinder - Unglück erntete. Auch der Zusatz, dass Kaiser Maximilian Geld für einen Kirchenbau gespendet habe, gehört zur Legende. ${ }^{19}$

Guarinoni projizierte diese Gewaltgeschichte ca. 170 Jahre in die Vergangenheit zurück, gibt als erfundenes Todesjahr $1462^{20}$ an.

Eine besondere Form des Erzählens, zumal das Nennen von Namen, blutrünstigen Details, Daten und Orten, verleiht der Erzählung den Anschein von Historizität, welche aufgrund fehlender Urkunden ${ }^{21}$ sowie aufgrund Guarinonis eigener Aussagen ${ }^{22}$ widerlegt wurde..$^{23}$

19 Weitere Nacherzählungen: siehe Langer (1995), 38 und Schroubek (2003), 181-182.

20 Schroubek (2003), 187.

21 Schroubek (2003), 183.

22 Schroubek (2003), 190, 184.

23 Langer (1995), 35. 


\section{Fragen zur Legende}

Bei kritischer Betrachtung der Legende von Judenstein bzw. vom Andreas von Rinn und seinem geistigen „Vater" Guarinoni stellen sich aus patriarchatskritischer Sicht viele Fragen.

Einerseits finden sich hier viele Formen der Gewalt und ibrer religiösen Verehrung, andererseits können aber vereinzelte Elemente matriarchaler Naturverehrung entdeckt werden. Die Legende war ein Instrument einer monotheistischen Religion zur Legitimierung von Gewalt und zur Züchtung eines Erduldens von Gewalt, ${ }^{24}$ wie noch gezeigt werden wird. Obwohl von Befürwortern des Monotheismus dieser aufgrund der angeblichen ${ }^{25}$ Abschaffung von Menschenopfern gepriesen wird, ${ }^{26}$ nutzte gerade das Christentum Märtyrererzählungen ${ }^{27}$ und Ritualmordlegenden als Glaubensbeweise. Es ist auch zunächst nicht verständlich, warum eine monotheistische Religion, die sich mit der Abschaffung von Menschenopfern brüstet, sich Analogien „heidnischer“ Riten ${ }^{28}$ bedient. Auch bereits patriarchalisierte Fruchtbarkeitsriten - das Töten wird hier zur Macht verkehrt ${ }^{29}$ - versinnbildlichen noch immer den Zusammenhang von Natur, Menschen und Gottheit, den der exklusive Monotheismus ${ }^{30}$ zerstören will und nicht anerkennt. ${ }^{31}$ Gerade in der Gegenreformation wird die Frage nach der „wahren "Religion verschärft, ${ }^{32}$ der katholi-

24 Pallaver 1987, 12.

25 „Es ist aber zu sagen, dass längst vor der Christianisierung der patriarchale Staat die Todesstrafe als Fundament seines Gewaltmonopols einführte. Damit hat er, wie noch an den Hinrichtungsarten abzulesen ist, das sakrale Menschenopfer abgelöst. " MeierSeethaler (2004), 65. Meier-Seethaler diskutiert jedoch nicht die Ursprünge des Menschenopfers als Bemächtigungsversuch des Geburtsmysteriums, sie vermengt durch den Begriff „sakral“ patriarchale Riten mit matriarchalen Verhältnissen. Vgl. Auer (2007).

26 Entgegen einem Diskussionsbeitrag am 15.6.07 bei der Innsbrucker Tagung „Westliche Moderne, Christentum und Islam“, in dem die Erzählung von der Ersetzung Isaaks durch einen Widder als Abschaffung des Menschenopfers im Monotheismus gedeutet wurde, diskutiert Eliade das große Vertrauen Abrahams, das zu seiner Bereitschaft führt, sogar seinen Sohn Isaak zu opfern, als Vorbild für das Vertrauen in Gott und daher auch die Annahme von Leid und Tötung, das/die nur Gott in seinem Zusammenhang verstehe. Der ,abrahamische Glaube“ befähigt das jüdische Volk zur Erduldung von Gewalt und schafft keineswegs das Menschenopfer ab; siehe Eliade (1978), 167.

27 Meier-Seethaler (2004), 68.

28 Meier-Seethaler (2004), 65.

29 Werlhof (1991), 12.

30 Assmann (2003), 62-63.

31 Assmann (2003), 64, 63.

32 Assmann (2003), 53. 
sche Monotheismus versteht sich als exklusive Religion, ${ }^{33}$ als Gegenreligion zu z.B. „Heiden“34 oder Juden. Daher ist es zunächst nicht verständlich, warum eine monotheistische Religion wie das Christentum, das Gott als Allmächtigen jenseits der Welt annimmt, ${ }^{35}$ sich totemistisch-animistischer Sinnbilder wie Kultsteine oder sakraler Bäume bzw. Quellen oder des Blutes in religiösen Erzählungen bedient. Steine, Bäume und Quellen wie das mütterliche Geburtsblut/Menstruationsblut (und in der vormonotheistischen patriarchalen Phase das Opferblut) machen die Göttin (Gott) erfahrbar, sind Träger bzw. Wandlungsorte/-leiber des Lebens und zeichnen sich durch Immanenz aus. ${ }^{36}$ „Der Geist ist das die Natur durchziehende

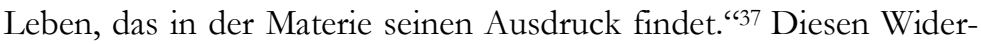
sprüchen von transzendenten und immanenten Gottesbildern oder Göttinnenerfahrungen sowie gewaltimmanenten oder friedlich-sakralen $\mathrm{Zi}$ vilisationsverbältnissen ${ }^{38}$ gilt es nachzugehen. Was steckt also hinter der willkürlichen Vermengung alter, vorreligiöser Sinnbilder und patriarchaler, „heiliger" Gewalt, von Usurpation und Perversion kosmotheistischer ${ }^{39}$ Erfahrungen einerseits und exklusiven Monotheismus andererseits? Eine Reihe von Fragen soll diese willkürliche Vermengung in der Legende als Herrschaftsinstrument aufzeigen.

\section{Warum konstruiert Guarinoni einen blutigen Ritualmord?}

Die Ritualmordvorwürfe wurzeln u.a. in der Gottesmordbehauptung ${ }^{40}$. Ritualmorde ${ }^{41}$ schildern die Gewalttat als Wiederholung der Kreuzigung Christi. ${ }^{42}$ Guarinoni verknüpft in der Geschichte die Gewalt am Kind mit der Verhöhnung des christlichen Vatergottes und des Sohnes. ${ }^{43}$ Die Gottesmordbehauptung wie die Ritualmordbeschuldigungen diffamieren und denunzieren die Juden als Gewalttäter und versuchen damit christliche Gewalt/Pogrome als Verteidigung bzw.

33 Vgl. Assmann (2003), 52, 56.

34 Benedikter (2000), 39.

35 Assmann (2003), 62-63.

36 Vgl. Baudler (1994), 71.

37 Werlhof. Zitiert nach Göttner-Abendroth (1998), 179.

38 Meier-Seethaler (2004), 18-19.

39 Assmann (2003), 62.

40 Langer (1995), 32.

41 Pomella (2003), 155.

42 Langer (1995), 47.

43 Schroubek (2003), 182. 
als scheinbar „gute“ Gewalt darzustellen. Guarinoni schürt also mit dieser Parallelisierung Antisemitismus, konstruiert eine scheinbare jüdische Tradition des Mordes an christlichen Söhnen.

Die Verhöhnung, die Folter und der Mord am Anderl sollen der Passion Jesu gleichen, ${ }^{44}$ darüber hinaus können aber weitere Parallelen zwischen dem Anderl und Jesus gefunden werden. Die Mütter der getöteten Söhne teilen denselben Vornamen, ${ }^{45}$ die Väter sind unsichtbar (im himmlischen Jenseits). ${ }^{46}$ Eventuelle subtile und unterschwellige Anklänge an alte Muttergöttinnen in diesen Mariengestalten ${ }^{47}$ doppeln die Anklage Guarinonis gegen die Juden. ${ }^{48}$ Sie sind nicht nur des Gottesmordes angeklagt, sondern sie brechen zudem der alten, inzwischen ,inoffiziellen“ Muttergöttin das Herz, ${ }^{49}$ zerstören den Mütter-Kinder-Zusammenhang. Durch diese gedoppelten Beschuldigungen werden die Juden als die „bösen“ Patriarchen, die Gott, die Söhne und die Mütter vernichten, verleumdet. ${ }^{50}$ Die Konstruktion überlagert die Erinnerung ${ }^{51}$ an die Muttergöttinnenmorde der Christen. Diese Beschuldigung der Juden verdeckt und verschweigt die Rolle der christlichen Missionare und der Amtskirche, ${ }^{52}$ die die Muttergöttinnen dämonisierten, ${ }^{53}$ leugneten und ihre Naturkultorte bewusst besetzten. ${ }^{54}$ Die Legende lenkt den Blick auf die Beschuldigung der Juden als Gottesmörder und - subtiler und verdeckt - als Göttinnenmörder. Die Juden zur Zeit Jesu wie jene zur Zeit des fiktiven Anderls wurden durch diese Legende als jene gewalttätigen, patriarchalen Männer diffamiert, vor denen die Bevölkerung von den „guten“ Patriarchen wie dem König bzw. Landesund Kirchenfürsten durch ihre ,gerechte“ Herrschergewalt angeb-

44 Schroubek (2003), 174.

45 Maria, Mutter des Andreas, und Maria, Mutter Jesu; siehe Schroubek (2003), 186.

46 Maria, die Mutter des Andreas, ist Witwe, siehe Schroubek (2003), 181.

47 Walker (2003), 678.

48 Vgl. dazu Ruaults Arbeit über die Inszenierung von Rassenschande: Ruault (2006), 27.

49 Tiberino, der Leibarzt des Trienter Bischofs, verfasste auf dessen Veranlassung hin eine „agitatorische“ Schrift, die zur Verbreitung der Ritualmordlegende des Simon gedruckt wurde. Hierin findet sich ebenfalls die Parallelisierung der (mit)leidenden Mütter. Siehe Dorninger (2004), 12.

50 Vgl. Ruault (2006).

51 Vgl. Assmann (2003), 113.

52 Missionare: Angenendt (1990), 426; Inquisition: Frederici (2004), 185 und Köfler (1986), 69.

53 Kutter (1993), 23.

54 Durliat (1985), 37. 
lich beschützt wurde. ${ }^{55}$ So ernennt die Legende auch Kaiser Maximilian I. zum Verehrer des Anderls. ${ }^{56}$

Guarinoni konstruierte einen Ritualmord zur scheinbaren Bestätigung der Gottesmordbehauptung, zur subtilen Anprangerung der Juden als Gottes-/Göttinnenmörder und damit zur Rechtfertigung der Herrschergewalt gegen Juden. Der Ritualmordwahn wurzelt in der Leiden-Christi-Mystik sowie in der Theologie der Oster- und Passionsliturgie ${ }^{57}$ und ist damit nicht „Ausgeburt ${ }^{658}$ des einfachen Volkes, sondern ,steht in enger Beziehung zu subtilen theologischen Erörterungen des Hochmittelalters von den Fragen der Passionsdevotion, der eucharistischen Frömmigkeit bzw. der Transsubstantiationslehre“. ${ }^{59}$ Daher trägt die Erfindung des Ritualmordes nicht nur zur Bewirtschaftung der Ängste und Gewaltbereitschaft gegen Juden bei, sondern prägt innerhalb der Kirche das Akzeptieren des Erleidens von (Herrscher)gewalt. Jan Assmann verdeutlicht, dass es „bei dem Problem des ,Monotheismus und Gewalt" ebenso um das Erleiden wie um das Ausüben von Gewalt geht". ${ }^{60}$ Weil der Gottessohn litt, die Passion erduldete, weil dieser Knabe dies wiederholte, hat das Volk - insbesondere das Geschlecht der Frauen - ebenso das Leiden durch Gewalteinwirkung zu erdulden. Günter Funke zeigt dies anhand von Hiob auf. ${ }^{61}$ Auch Claudia von Werlhof analysiert den Krieg und die Gewalt als die grundlegenden und zentralen Charakteristika des Patriarchats, ${ }^{62}$ wie Carola Meier-Seethaler auf die feministische Kritik an den gewaltimmanenten Denkstrukturen verweist. ${ }^{63}$

Das Leiden Jesu und der Blutzeugen durch Gewalteinwirkung wurde also politisch zur Untergrabung von Widerstand ${ }^{64}$ gegen Gewalt und Herrschaft sowie zur Erstickung der Forderung nach einem guten Leben für alle benutzt. Das Suchen und die Forderung nach ei-

55 Angenendt bestätigt, dass mit der Christianisierung immer eine Intensivierung von Herrschaft einhergeht. Siehe Angenendt (1990), 423.

56 Schroubek (2003), 176.

57 Dorninger (2004), 4.

58 Schroubek (2003), 173.

59 Schroubek (2003), 173.

60 Assmann (2003), 35.

61 Funke (1994), 1.

62 Werlhof (2006) und Werlhof (2007b).

63 Meier-Seethaler (2004), 9-10.

64 Die Hexenverfolgung hatte auch den Zweck, die Widerstandskraft von Frauen zu brechen. Siehe Frederici (2004). 
nem gewaltfreien Sein würden ja bedeuten, es besser haben zu wollen als der Sohn Gottes, der für uns gestorben ist. Das untergräbt die hierarchische Vorstellung des Monotheismus, wonach Gott an erster Stelle steht und ihm (nach)gefolgt werden soll.

Die Abkehr von der sinnlichen Welt ${ }^{65}$ ist die logische Konsequenz aus dem exklusiven Monotheismus, der auf der Herauslösung Gottes aus der Welt basiert. ${ }^{66}$ Zugleich folgt aus dem Monotheismus die Abkehr von der „Gerechtigkeit von unten“67 zugunsten des abstrakten Rechtes und Wortes Gottes. ${ }^{68}$ Waren die ägyptischen Pharaonen vor Echnaton, dem Erfinder des Monotheismus, sich noch der Verantwortung für die Abhängigen bewusst, ${ }^{69}$ so „,befreit“ das göttliche Gesetz die Herren von der Einforderung dieser Fürsorge, indem dieses Recht von Gott, also von oben und außerhalb gesetztes Recht ist. ${ }^{70}$

Warum konstruiert Guarinoni also einen blutigen Ritualmord? Er konstruiert diesen, um Juden für Gewalt und Leid zu beschuldigen, die eigentlich durch die Machtgelüste der Herrscher entstanden. ${ }^{71}$ Weiters wurde die Legende benutzt, um die Gewalt gegen diese „Gehörnten“ zu rechtfertigen, um die Erinnerung ${ }^{72}$ an vormonotheistische, sakrale, friedliche Verhältnisse und deren Vernichtung durch die christliche Missionierung und die laufende Hexenverfolgung zu überlagern.

\section{Warum wird das Kind angeblich gefoltert und getötet? W arum entschied sich Guarinoni für die Zange als Folterinstrument?}

Die Art der angeblichen Tötung des Anderl verfolgt ideologische Ziele, verkehrt die Realität. Die Nacktheit ${ }^{73}$, die Einstiche, das Drosseln, die Zangenmarter ${ }^{74}$ sind Methoden, die aus den Inquisitionsverfahren bekannt sind. In der Zeit, als Guarinoni die Legende schreibt, agieren die Kirche und der Staat schon lange als Inquisitoren. Die

65 Assmann (2003), 63.

66 Assmann (2003), 63.

67 Vgl. Maát bei Assmann (2003), 72.

68 Assmann (2003), 70.

69 Assmann (2003), 75.

70 Assmann (2003), 75-76.

71 Beimrohr (1995), 346.

72 Benedikter (2000), 39.

73 Merchant (1987), 152.

74 Benedikter (2000), 46. 
Ketzer- und Hexenverbrennungen, ${ }^{75}$ die diesen vorausgehenden peinlichen Befragungen ${ }^{76}$ und die Judenpogrome (aufgrund angeblicher Hostienfrevel und Blutbeschuldigungen ${ }^{77}$ ) sind von der Kirche und den von ihr autorisierten Vertretern durchgeführte Gewaltakte. Die Folterungen und Hinrichtungen als Justizmorde sind auch mit einem ökonomischen Nutzen verbunden ${ }^{78}$ bzw. werden dem ,weltlichen Arm“ übertragen. Somit werden eigentlich Juden (wie Hexen) von Christen mit der Zange gefoltert und nicht umgekehrt. So werden weiters jüdischen Eltern ihre Kinder weggenommen und nicht christlichen. ${ }^{79}$ Die Legende verdreht zum wiederholten Mal die Realität. Diese Folter-Methoden dienten darüber hinaus als Vorlage für die Durchführung naturwissenschaftlicher Experimente. ${ }^{80}$

\section{Warum wurden jüdische Kaufleute als Täter eines nie stattgefundenen Ritualmordes denunziert?}

Dafür gibt es mehrere Begründungen wie jene, dass das Wort „Ju$\mathrm{de}^{\text {“ }}$ als Synonym für „Nichtchrist ${ }^{\text {"81 }}$ (in Tirol ${ }^{82}$ ) gebraucht wurde, sowie den christlichen Antijudaismus ${ }^{83}$ oder den Sündenbockmechanismus als patriarchale „Gewaltenteilung“: Gerade in Tirol dienten die Juden/Jüdinnen als Projektionsfläche für Verleumdungen. Juden wie Hexen ${ }^{84}$ als Nichtchrist(inn)en standen außerhalb der christlichen Ordnung, ${ }^{85}$ waren nach Guarinoni wortwörtlich (!) „Teufelskinder". 86 Die Beschuldigung von Juden, Ungläubigen, Ketzern und Hexen, ${ }^{87}$ also die Konstruktion eines außerhalb stehenden Feindes, dient zur inneren Festigung. Der Sündenbockmechanismus ist eine

75 Daly (1991), 205 und Merchant (1987), 152.

76 Merchant (1987), 152 und Benedikter (2000), 70.

77 Wenninger (2003), 209.

78 Wenninger (2003), 198 (Besitz einziehen), 201-202, Benedikter (2000), 110 und Walker (2001), 137.

79 Pinzer (1986), 10.

80 Merchant (1987), 163.

81 „Gemäß dem exklusiven Monotheismusverständnis ist „der ,Heide $[$ [...] nicht einfach ,der Andere', sondern das Produkt einer polemischen Konstruktion. [...] und um die Ausgrenzung des Heidentums in der eigenen Gruppe und Kultur.“ Assmann (2003), 39.

82 Mantl (1967), 15, Anmerkung 8.

83 Schubert (1995), 12; Assmann (2003).

84 Schroubek (2003), 191.

85 Assmann (2003), 38.

86 Nichtgetaufte sind Teufelskinder. Siehe Angenendt (1990), 427, 429.

87 Benedikter (2000), 39-40. 
typisch patriarchale Mimesis an die Gewalt ${ }^{88}$ bzw. nach Genth verdorbene Mimesis. ${ }^{89}$ Die Sündenböcke wurden für die Missstände, den Hunger, die Pest etc. verantwortlich gemacht und die Gewalt gegen sie soll angeblich Frieden schaffen (vgl. René Girard). Eigentlich aber bietet die Gewalt gegen den Sündenbock die Illusion, an der Herrschaftsgewalt beteiligt zu sein, und vermittelt den Anschein des Auch-mächtig-Seins, was als patriarchale „Gewalten(be)teil(ig)ung“" bezeichnet werden könnte.

Die Juden- wie die Hexenverfolgung ist im Zusammenhang mit der Gegenreformation und dem verstärkten Bemühen zur Errichtung eines exklusiven Monotheismus ${ }^{90}$ in Verbindung mit dem Sichherausbilden des modernen (Rechts)staats zu verstehen. Daher ist das Zusammenspiel von Kirche und Staat so zentral in der Juden- wie Hexenverfolgung. ${ }^{91}$ Diese Verfolgungen dienten zur verschärften Abgrenzung der zur einzigen Wahrheit deklarierten Religion, Glaubensform und -richtung von den anderen. ${ }^{92}$

\section{Warum aber werden die Tötung Jesu und des Anderls als heiliges (Todes)opfer verehrt?}

Das Patriarchat braucht über alle Religionen hinweg das (Todes)opfer, die Gewalttat, denn durch die Gewalt (beginnend mit dem Muttermord $^{33}$ ) wird der sakrale Mütter-Kinder-Zusammenhang zerstört und männliche Eroberungsmacht errungen. Das Blut der Gewalttat ver-

88 Werlhof (2007b), 6 .

89 Genth (2002), 38.

90 Assmann (2003), 53.

91 Der exklusive Monotheismus legitimiert den Staat nicht nur, sondern setzt das Recht als göttliches Gesetz. Siehe Assmann (2003), 75. Im Monotheismus wird das Recht abstrakt als Ausdruck der Norm gedacht. Siehe Werlhof (1996), 38, 40. Mies deckt weiters die enge Beziehung von Kirche, Herrschern, Feudalstaat und Rechtsanwälten auf. Siehe Mies (1996), 105.

92 Mit dem Missionierungsauftrag wird das Christentum (und der Islam) gewalttätig, da diese nicht wie das Judentum die Allgemeingültigkeit der mosaischen Unterscheidung auf die Endzeit verlegen. Weil die mosaische Unterscheidung im Christentum für alle Menschen zu gelten hat, gibt es kein ,legales“ bzw. ,gottgefälliges“ Draußen. Jene, die den christlichkirchlichen Glaubenssätzen nicht folgen, bedrohen den Staat wie Gott, Frauen strafen durch ihre Existenz, durch ihre Sinne und durch die Gebärfähigkeit den Schöpfungswahn und den daraus abgeleiteten Herrschaftsanspruch des christlichen Vatergottes Lügen. Die politische Gewalt gegen die Anders-Gläubigen wird in der monotheistischen Religion theologisch legitimiert. So kam es z.B. zu Zwangstaufen von Juden. Siehe hierzu Assmann (2003), 30-32.

93 Tazi Preve (1992). 
leugnet das friedliche Geburts-/Menstruationsblut, das - ohne Gewaltakt - bei der Geburt bzw. monatlich strömt.

Christa Mulack schreibt, dass das matriarchale Weltbild mit der schöpferischen Urkeraft der Göttin dem kriegerischen Stammesgott, dem Herr der Heerscharen, vorausging. ${ }^{94}$ Matriarchate sind demnach als herrschaftsfreie Verwandtschafts-, Ausgleichs-, und Sakralgemeinschaften zu beschreiben. ${ }^{95}$ Im Unterschied dazu bedeutet die Patriarchalisierung dieser Gesellschaften, dass die Lebensquellen wie z.B. der Wald, der Ackerboden oder der (das) Frauenleib(blut) besetət und unter Kontrolle gebracht werden und dass die Eigenmacht der Menschen $^{96}$ der religiös verbrämten politischen Über-Macht von Invasoren und Eroberern weicht, die seit dem 5. Jahrtausend v.Chr. gerade auch in Europa patriarchale Verhältnisse etablieren. ${ }^{97}$

Patriarchat bedeutet, als Negation des Matriarchats, einen sogenannten Vater bzw. Kriegsherren oder Gott an den Anfang des Lebens zu setzen. Also: „Am Anfang die Väter“. „Denn das hieße ja, der Lebensursprung käme aus den Vätern (oder Väter seien Männer mit Gebärmüttern) “98. Diese wortwörtliche Bedeutung von Patriarchat ist utopisch und verdeutlicht die komplizierte Veränderung des Begriffs „arché“ von „Ursprung“ zu „Herrschaft“ und die damit einhergehende Veränderung der gesellschaftlichen Verhältnisse. ${ }^{99}$ Durch die Bemächtigung des Schöpfungsursprungs wird ein Herrschaftsanspruch abgeleitet, ${ }^{100}$ sodass das Patriarchat (patér árchein $=$ am Anfang der Vater bzw. angeblich auch Vaterherrschaft) für ein durch Raub und Gewalt entstandenes System steht. Damit wird versucht, die neuen, für matriarchale Gesellschaften skandalösen, herrschaftlichen Verhältnisse und Veränderungen zu legitimieren. Da es aber in der Realität des Lebens keine ,gebärenden Väter" gibt, muss ein enormer ideologischer Aufwand betrieben werden, der dafür sorgt, dass die angeblich zentrale Bedeutung von Herrschaft für die Entstehung und Erhaltung des Lebens anerkannt wird. ${ }^{101}$

94 Mulack (1998), 68.

95 Göttner-Abendroth (1998), 45 sowie Göttner-Abendroth (1995) und Göttner-Abendroth (1997).

96 Werlhof (1996), 142.

97 Gimbutas (1996), 389, 395 sowie Gimbutas (1994), 35.

98 Werlhof (2003), 44.

99 Werlhof (2003).

100 Peegy Reeve Sanday, zitiert nach Lerner (1997), 187.

101 Werlhof (1991), 37 und Werlhof (2003). 
Als Negation der weiblichen (Gebär)potenz setzt das Patriarchat den Kriegergott, den Vatergott, den leiblosen Schöpfer an den Anfang, um die irdische Vormachtstellung einiger weniger Männer (und auch Frauen) zu legitimieren. Der furchtbare Gott wird zur Legitimation der Gewalt. ${ }^{102}$ Diese Gewalt muss zur Machterhaltung fortgesetzt werden, direkt und indirekt, innerhalb und außerhalb, da sonst die (besiegten) Menschen wieder $\mathrm{zu}$ friedlichen, herrschaftsfreien Verhältnissen zurückkehren würden. Davon zeugt der fortgesetate Krieg in allen gesellschaftlichen Bereichen. ${ }^{103}$ Die Gewalt und der Krieg werden aber nicht dem Herrscher oder Gottvater angelastet, sondern denjenigen, die der Bosheit bezichtigt werden, ${ }^{104}$ z.B. den Hexen und den Juden.

Durch das Opferblut, das beim Gewaltakt fließt, setzt sich der (Vater)herrscher als vermeintlicher Schöpfer willkürlich an den Anfang des Lebens bzw. des Am-Leben-Lassens. ${ }^{105}$ „Diesen letztgenannten Weg [des Imponierens durch Töten - „power“ und „violence“, S.A.] ist der Mensch in der von Burkert und Girard ausgearbeiteten religiösen Urszene (d.h. in der Opfertötung) gegangen. Er hat das biologisch vorgeprägte männliche Imponierverhalten transzendiert, indem er die in dieses Verhalten eingeprägte KommentRegel, die Regel, im Rivalenkampf den Gegner nicht zu töten oder ernsthaft zu verletzen, durchbrach und sich im Zu-Tode-Stoßen des Mitlebewesens, dem dadurch erzeugten Todeskampf und dem rinnenden Blut, selbst zu göttlicher Größe und Schrecklichkeit erhob."106 Der Akt der Geburt, des fließenden Lebensblutes beim Hervorbringen des neuen Lebens, wurde durch den Opferakt aus dem heiligen Geschehen verdrängt, um die Macht des Lebens zu usurpieren. Gerade auch Edwin O. James verdeutlicht den Akt der „Vaterschaft“ beim Opfer. ${ }^{107}$

Das Blut Christi wie das der offiziellen Märtyrer und der inoffiziellen Blutzeugen verleugnet damit die Göttin des Anfangs und ist die Usurpation der (Geburts)gabe. „Das männliche Blut, auch das Blut Jesu, ist und bleibt Tötungsblut und kann daher als Wand- 
lungsmysterium nur symbolisch verstanden werden. Das Wandlungsmysterium des weiblichen Blutes ist immer real." ${ }^{\text {"108 }}$

Das Opferblut wird also im Patriarchat an die Stelle des Gebärblutes gesetzt, denn das Blut bleibt die Essenz des Lebens. Indem nun Juden, denen jeder Blutgenuss verboten ist, ein gewalttätiges Blutritual unterstellt wird, werden Juden und alte Kultpraktiken gleichermaßen diffamiert. Die Behauptung, dass Christenblut zur Beseitigung der Hörner der jüdischen Knaben gebraucht werde - wie Guarinoni in der Legende schreibt ${ }^{109}$-, verdeutlicht, dass diese Legende zur Verteufelung der Juden bzw. der Nichtchristen und des Blutes benutzt wurde. ${ }^{110}$ Die Hörner ${ }^{111}$ waren in matriarchalem Kontext Sinnbild für die Mondphasen, den Zyklus sowie (Hörner zusammen mit dem Kuhschädel) den Uterus und wurden im Zuge der christlichen Missionierung zu den Symbolen des Bösen, des Teufels ${ }^{112}$ umgedeutet. Nicht nur die jüdischen Kinder, auch die Göttin Diana ${ }^{113}$ (Herrin der Wälder) wurde von Klerikern als Gehörnte bezeichnet.

Durch die gegen die Juden gerichtete Anklage des Ritualmordes wird die (Gewalt)täterschaft der Christen (Missionierungen, Kreuzzüge, Ketzer-, Juden- und Hexenverfolgungen) verschleiert, die Opfer christlicher Gewalt werden hinter der Beschuldigung versteckt. Das (Tötungs)blut erscheint nun als christliches Opfer und verdrängt zugleich das (als teuflisch verunglimpfte) Geburtsblut.

Das patriarchale Transzendenzverhältnis ist daher untrennbar mit Gewalt verbunden, ${ }^{114}$ die scheinbare Beherrschung des Todes durch das Töten erzeugt die Illusion von Schöpfung und Allmacht. Neben Mulack thematisiert von Werlhof, durch die kritische Betrachtung von Sigmund Freud, diese Gewaltimmanenz des Monotheismus - der Umgang mit dem „Heiligen“ wird im Patriarchat zum Gewaltakt. ${ }^{115}$

111 Vgl. Königs Beschreibung von Höhlenmalereien und -ritzungen in: Meixner (1997), 150151.

112 Walker (2003), 433.

113 Kutter (1997), 23.

114 Vgl. Pallaver (1987), 27.

115 „Dass der Umgang mit dem ,Heiligen“ im Patriarchat ein Gewaltakt geworden ist, zu ihm als Gesellschaftsordnung unentrinnbar gehört (vgl. R. Girard), wenn man diese Gesellschaft aufrecht erhalten will, wird von Freud zugegeben."Werlhof (1996), 70. 
Warum erhebt Guarinoni die Anklage der Schwarzmagie gegen die Juden?

Die Anklage gegen Juden und Hexen thematisiert nicht nur Georg R. Schroubek, ${ }^{116}$ sondern zeigte sich auch jüngst in Polen. ${ }^{117}$ Schroubek verdeutlicht, dass die Theologie der Ritualmorde die „Synagoge“, also den Kult und Glauben der Juden, die „Kirche“, also die ecclesia, angeblich spiegelbildlich ins Negative verzerre. ${ }^{118}$ Somit wird in der Diffamierung des Judentums, vergleichbar mit der Diffamierung von matriarchaler Naturverehrung, eine Perversion (Verkehrung) von Magie als angeblich außerchristliche Schwarzmagie erdichtet, die als Gegenerinnerung die Geschichte und ihre Abfolge verdreht. Weder Juden noch Hexen spiegeln oder verzerren das (relativ junge) Christentum, sondern im Christentum finden sich transformierte Relikte jüdischer und naturverehrender Kulte bzw. im Judentum (noch) Spuren matriarchaler Sakralität, wie z.B. die Frau Weisheit/Chokma im Alten Testament. ${ }^{119}$ Auch die Kabbala als jüdische Mystik beinhaltet Elemente einer „kosmischen oft ungenau ,pantheistisch“ genannten Religiosität " ${ }^{120}$ so wie christliche Wallfahrtskulte vormalige Naturheiligtümer besetzen. ${ }^{121}$ Günther Pallaver verdeutlicht das Vorantreiben der Usurpation und Transformationen der Kirche in der Neuzeit, indem er von einer Entwicklung spricht, die von einer ecclesia materna zu einer ecclesia paterna verläuft. ${ }^{122}$

Im Sinne der Verkehrung als Herrschaftsmethode bezichtigte Guarinoni die Juden der Schwarzmagie und festigte damit die christliche „Gegenerinnerung“. Die Magie, eine Wissenschaft der Zusammenhänge, ${ }^{123}$ wurde als schädlich und feindlich dämonisiert, wohingegen eigentlich die christliche Kirche die Magie und die kosmischen Zusammenhänge verbieten bzw. zerstören wollte. Magische Kenntnisse verband Guarinoni nicht mit Ausgleich und Pflege der zivilisatorischen Grundverhältnisse, ${ }^{124}$ sondern offenbar mit Macht,

116 Schroubek (2003), 191.

117 Pater Tadeusz Rydzyk hat behauptet, dass Kaczynski der jüdischen Lobby ergeben und seine Frau eine Hexe sei. Siehe Wölfl (2007).

118 Schroubek (2003), 173.

119 Mulack (1998), 74.

120 Elsas (2002), 177.

121 Auer (2007).

122 Pallaver (1987), 30.

123 Mies (1984), 84.

124 Zivilisatorische Grundverhältnisse liegen jeder Gesellschaft zugrunde; siehe Werlhof (2007a), 38. Anhand der Art der folgenden fünf Verhältnisse, kann eine Zivilisation herr- 
Reichtum und elitärem Wissen, denn er dichtete den Juden ${ }^{125}$ als Motive für die erfundene Opferung Schadens- und Fruchtbarkeitszauber $^{126}$ an. Seine Furcht und seine Anklage zeigen, dass er Magie für wirkungsvoll hielt und seine Macht- und Geltungsbestrebungen $^{127}$ auf die Juden projizierte. ${ }^{128}$

Angesichts der Tatsache, dass es in Rinn keine ${ }^{129}$ und in Tirol kaum Juden gab, ${ }^{130}$ eignete sich die Gruppe der Juden als Projektionsfläche. ${ }^{131}$ Gesellschaftlich tabuisierte Regungen werden nach Theodor W. Adorno ${ }^{132}$ vom Subjekt auf das Objekt übertragen. ${ }^{133}$ Demzufolge durfte die Wut auf die Armut, auf den Hunger, auf die Steuer eintreibenden Herren ${ }^{134}$ und auf den Vatergott, der die Herrschaft wie das Leiden (Pest) zuließ bzw. als Unterpfand für das Himmelreich forderte, nicht erkannt und ausgesprochen werden und wurde daher auf die Juden oder die Hexen projiziert. ${ }^{135}$ Gerade auch Guarinoni wird diese Projektion von Maria Dorninger vorgeworfen $^{136}$ - ein Vorwurf, der durch dessen mögliche Angst vor jüdischer Konkurrenz in der Ärzteschaft untermauert wird. ${ }^{137}$

Die Bezichtigung der Juden, schwarzmagische Praktiken als Ritualmorde auf Kultsteinen durchzuführen, verleumdete nicht nur Juden, ${ }^{138}$ sondern alle nicht christlichen Kulte, insbesondere solche

schaftsfrei oder herrschaftsimmanent beschrieben werden: Natur-, Geschlechter-, Generationenverhältnis, politisches Verhältnis (Art der Entscheidungsfindung) und transzendentes Verhältnis (Fragen nach dem Woher und Wohin der Menschheit). Siehe Genth (2006).

125 Schroubek (2003), 191.

126 Guarinoni behauptete entgegen seinem ärztlichen Fachwissen, dass Juden das Christenblut als Geburtshilfe für jüdische Frauen benötigen würden oder dass damit jüdische Kinder die ihnen angeborene geballte Faust erst öffnen könnten oder dass das Blut der Christenknaben zum Backen von jüdischen Osterbroten verwendet würde bzw. dass das Christenblut für Schadenzauber verwendet worden wäre. Siehe Schroubek (2003), 191.

127 Schroubek (2003), 178.

128 Dorninger (2004), 21.

129 Dorninger (2004), 21.

130 Wenninger (2003), 204, Stainer (1986), 22 und Pinzer (1986), 9-10.

131 Adorno (2006), 211.

132 Adorno (2006), 201.

133 Adorno (2006), 201.

134 Beimrohr (1995), 346.

135 Adorno (2006), 195.

136 Dorninger (2004), 21.

137 Dorninger (2004), 21.

138 Schroubek (2003), 179. 
sakraler Naturverehrung. ${ }^{139}$ Damit überlagert die Konstruktion der Legende die Erinnerung ${ }^{140}$ an friedlich-sakrale Kulte, deren Reste wie Wilde-Mann-Spiele, jahreszeitliche Umzüge und Almfeste oder „Fraß und Völlerei bei Festen und im Wochenbett“"141 durch die Intensivierung der Patriarchalisierungsprozesse in der Neuzeit verdrängt wurden. ${ }^{142}$

\section{Wieso suchte sich Guarinoni einen großen Stein als Schauplatz für seine} Retortenerzählung aus? W arum benutzte er eine Birke für seine Gewaltfantasiegeschichte? Wieso ziert eine Anderlefigur noch heute den Brunnen vor der Kirche?

Steine, Bäume und Quellen galten in matriarchalen Gesellschaften als Kultorte. „Die Steine waren eine Verkörperung der ,Mutter Erde“, aus der alles Leben hervorgeht und in die alles Leben nach dem Tode geht. "143 Die Menschen erfuhren sich als verbunden mit der Natur, ${ }^{144}$ die gesamte Natur wurde als belebt und beseelt erlebt. ${ }^{145}$

Die Verbundenheit mit der Natur sowie die Natur als beseelt und lebendig, als hervorbringende Mutter zu erfahren widerspricht den patriarchalen Natur- und Transzendenzvorstellungen von einem abstrakten, leiblosen Vaterschöpfer und toter Materie. Wieso benutzt dann Guarinoni, der „fanatische“ Katholik, einen dolmenartigen Stein und eine Birke, einen vielleicht ${ }^{146}$ ehemaligen, matriarchalen Kultort, für die Legende?

Guarinoni teilt und herrscht, er trennt Baum und Stein aus dem sakralen Zusammenhang heraus und nutzt diese als Opfertisch und Todesbaum/Kreuz. Er nutzt die frühere Naturverehrung für die Legende aus und überlagert diese gleichzeitig mit einer gewaltvollen Erinnerung. ${ }^{147}$ Indem er den Stein und den Baum auf Gegenstände des „Bühnenbildes“ reduziert, verfremdet er den mütterlichen, generativen Zusammenhang von Stein und Baum mit Mutter und Kind, von

139 Sakral-matriarchale Naturverehrung zeichnet sich durch die Achtung vor der Natur aus und pflegt das Leben, vermeidet Gewalt; siehe Werlhof (2006), 35.

140 Assmann (2003), 113.

141 Dörrer (1954), 145.

142 Dörrer (1954), 141.

143 Fleischer (1992), 24.

144 Derungs (2006), 10.

145 Merchant (1987), 17.

146 Stecher (1995), 6.

147 Vgl. Assmann (2003), 113. 
der Erde als der Hervorbringerin. Diese antisemitische Legende vereinnahmt die Natur. Das ist Usurpation. Stein und Baum werden als Schauplatz patriarchaler Gewalt besetzt. Die Besetzung der (Kult/Natur)räume verdrängt und zerstört sakrale Naturverehrung und ermöglicht die Ausbeutung der Natur als tote Rohstofflieferantin.

Die neuzeitliche Besetzung alter Kultorte - wie bei der AnderlLegende - zielte auf die Diffamierung alter, vorchristlicher Kulte und auf die Dämonisierung der Natur(wesen) und die Rechtfertigung von Herrschergewalt gegen diese ab.

\section{Abschluss und Zusammenfassung}

Bei kritischer Betrachtung der Legende stellen sich eine Reihe von Fragen. Warum konstruiert Guarinoni einen blutigen Ritualmord, bei dem ein kleines Kind geopfert wird, das vorher u.a. mit einer Zange gefoltert worden ist? Warum werden jüdische Kaufleute als Täter denunziert, warum wird gegen diese der Vorwurf der Schwarzmagie erhoben? Warum wird diese grausige Dichtung auf ein mögliches vorchristliches Naturheiligtum projiziert? Warum werden im christlichen Monotheismus die Tötung Jesu und des Anderls als heiliges (Todes)opfer verehrt?

Die Fragen machen deutlich, dass die Legende ein patriarchales Herrschaftsinstrument ist, das patriarchale/religiöse/staatliche Gewalt legitimieren soll. Durch die Besetzung des Ortes und der Erinnerung mit blutrünstiger Fiktion wurde die Gewalt scheinbar zu Lasten der Juden verschoben. Zugleich wurde die christliche/staatliche Gewalt an Juden, Ketzern, Hexen durch den starken Arm der göttlichen Ordnung scheinbar legitimiert. Das Anprangern grausamer - rein erfundener - Schwarzmagie und damit das Diffamieren vorchristlicher Naturverehrung und das Ausblenden vormonotheistischer, friedlicher Rituale wurde ebenso erstrebt wie das Verschleiern des Geburtsmysteriums und dessen Besetzung durch das Opferblut und den Vatergott. Das Verherrlichen des Erleidens von Gewalteinwirkungen stilisiert die Verlassenheit (vgl. Hannah Arendt) Einzelner zur christlichen Tugend und untergräbt die Widerstandspflicht und die Kritikeähigkeit an Herrschaft. Die Besetzung und Zerstückelung matriarchaler Sinnbilder wurde instrumentalisiert zur Köderung von Gefühlen und zur Verdrängung/Vernichtung von sakraler Naturverehrung.

Hinter der willkürlichen Vermengung alter, vorreligiöser Sinnbilder und patriarchaler, „heiliger“ Gewalt, hinter der Usurpation 
und Perversion kosmostheistischer ${ }^{148}$ Erfahrungen bzw. hinter den Verkehrungs- und Besetzungsbestrebungen des exklusiven Monotheismus steht das Herrschaftsinteresse. Die Erfindung der Judensteinlegende kann also als die patriarchale Konstruktion einer „Gegenerinnerung “ 149 zur Auslöschung vorpatriarchaler, vormonotheistischer Verhältnisse und zur Festigung von Herrschaftsideologie ${ }^{150}$ verstanden werden.

Mit der Besetzung von Natur-Kultorten und derartiger patriarchaler Legendenbildung werden herrschaftsfreie Verhältnisse zerstört und verleugnet und es wird Gewalt als „Heilmittel“ propagiert. Dadurch werden Gewaltbereitschaft, Furcht- und Rachegefühle sowie das Erdulden von Gewalteinwirkungen (Verlassenheit) gefördert. „Mit dem Krieg[151] als ,Vater aller Dinge‘ anstelle des Lebens als ,der Mutter aller Dinge' scheinen Schöpfung und Reichtum aus bewusster Zerstörung anstatt aus der Kooperation alles Lebendigen zu kommen." ${ }^{152}$

\section{Literatur}

Adorno, Theodor W./Horkheimer, Max (162006): „Elemente des Antisemitismus. Grenzen der Aufklärung“", in: Dialektik der Aufklärung. Philosophische Fragmente. Frankfurt/M.: Fischer Taschenbuchverlag, 177-217.

Amann, Klaus (2004): „Die Greuel der Verwüstung menschlichen Geschlechts. Symposium zur 350. Wiederkehr des Todesjahres von Hippolytus Guarinonius. Sterzing, 5.4.-7.4.2004.“, online unter: http://www.perspicuitas.uni-essen.de/projekte/amannsymp.pdf (Zugriff am 9.3.2008).

Angenendt, Arnold (1990): Das Frühmittelalter. Köln: Kohlhammer.

Assmann, Jan (2003): Die Mosaische Unterscheidung oder der Preis des Monotheismus. München: Carl Hanser Verlag.

Auer, Sibylle (2007): „Heiliges Land Tirol"? Enteignung, Zerstörung und Transformation von alten Stein-, Baum- und Quellkulten. Innsbruck: Dissertation.

Baatz, Ursula (2001): „Wem gehört der Leib des Herrn? Der Streit um die Eucharistiefeier. Interview mit Exeget Peter Trummer.“ ORF: Ö1, 6. Oktober 2001, 19:05 (schriftliches Manuskript).

148 Assmann (2003), 62.

149 Assmann (2003), 113.

150 Pallaver (1987), 12 und 230.

151 Die Bedeutsamkeit der Legende für den Dreißigjährigen Krieg verdeutlicht Dörrer. Siehe Dörrer (1954), 161.

152 Werlhof (2006), 39. 
Baudler, Georg (1994): Töten oder Lieben. Gewalt und Gewaltlosigkeit in Religion und Christentum. München: Kösel.

Beimrohr, Wilfried (1995): „Tirol im 17. und 18. Jahrhundert“, in: Heizer, Martha, Hg.: Tiroler Jungbürgerbuch. Thaur: Kulturverlag, Wort und Welt Verlag, 345-351.

Benedikter, Hans (2000): Hexen und Zauberer in Tirol. Bozen: Athesia.

Benedikter, Hans (1995): „Reformation und Bauernkrieg“, in: Heizer, Martha, Hg.: Tiroler Jungbürgerbuch. Thaur: Kulturverlag, Wort und Welt Verlag, 339-344.

Durliat, Marcel (1985): Die Kunst des frühen Mittelalters. Paris: Herder.

Derungs, Kurt (2003): „Die Natur der Göttin“, in: James, Edwin Oliver: Der Kult der Grossen Göttin. Bern: Amalia, 12-56.

Derungs, Kurt/Derungs, Isabelle M. (2006): Magische Stätten der Heilkraft. Marienorte mythologisch neu entdeckt. Quellen, Steine, Bäume und Pflanzen. Grenchen: Amalia.

Deschner, Karlheinz (171994): Das Kreuz, mit der Kirche. München: Wilhelm Heyne.

Dorninger, Maria (2004): „Ritualmordvorwürfe im Mittelalter. Urteile Prozesse - Wirkungen“, online unter: http://www.sbg.ac.at/ger/ samson/rvws2004-05/dorninger2004.pdf (Zugriff am 9.3.2008).

Dörrer, Anton (1954): „Guarinoni als Volksschriftsteller“, in: Dörrer, Anton/Grass, Franz, Hg.: Hippolytus Guarinoni (1571-1654). Zur 300. Wiederkehr seines Todestages. Innsbruck: Universitätsverlag Wagner, 137187.

Eliade, Mircea (1978): Geschichte der religiösen Ideen. Band 1. Breisgau: Herder Spektrum.

Elsas, Christoph (2002): Religionsgeschichte Europas. Darmstadt: Primus.

Esposito, Anna (2003): „Das Stereotyp des Ritualmordes in den Trienter Prozessen und die Verehrung des ,seligen" Simone", in: Buttaroni, Susanne/Musial, Stanislaw, Hg.: Ritualmord. Legenden in der europäischen Geschichte. Wien: Böhlau, 131-172.

Fleischer, Eva (1992): Macht, Wissen und die Unfruchtbarkeit der Frauen. Zur Ambivalen₹ der Unterwerfung in der Reproduktionsmedizin. Innsbruck: Dissertation.

Fresacher, Bernhard (1998): Anderl von Rinn. Ritualmordkult und Neuorientierung in Judenstein 1945-1995. Innsbruck: Tyrolia Verlag.

Frederici, Silvia (2004): Caliban and the witch. New York: Autonomedia.

Funke, Günter (1994): Das Ende der Vorstellung - ein Gespräch mit Hiob, Vortragsmanuskript.

Genth, Renate (2002): Über die Maschinisierung und Mimesis, Frankfurt/M.: Lang.

Genth, Renate (2006): „Projekt: Zivilisationspolitik“, online unter: www.uibk.ac.at/forschung/genth.pdf (Zugriff am 6.11.2006). 
Gimbutas, Marija (1994): Das Ende Alteuropas: der Einfall von Steppennomaden aus Südrußland und die Indogermanisierung Mitteleuropas. Innsbruck: Verlag des Institutes für Sprachwissenschaft der Universität Innsbruck.

Gimbutas, Marija (1996): Die Zivilisation der Göttin. Frankfurt/M.: Zweitausendeins.

Göttner-Abendroth, Heide (1998): Für Brigida. Göttin der Inspiration. Frankfurt/M.: Zweitausendeins.

Göttner-Abendroth, Heide et al. (1997): Matriarchate als herrschaftsfreie Gesellschaften. Bern: Amalia.

Göttner-Abendroth, Heide (1995): Das Matriarchat I. Stuttgart-Köln: Kohlhammer.

Hauer, Nadine (1986): „,Ich bin mit Judenstein aufgewachsen!“ Die Geschichte vom Anderl von Rinn“, in: Pallaver, Günther: Sturaflüge. Band 15-16. Bozen, 109-126.

James, Edwin Oliver (1937): Origin of sacrifice. London: Murray.

Köfler, Gretl/Forcher, Michael (1986): Die Frau in der Geschichte Tirols. Innsbruck: Haymon Verlag.

Kunze, Karl/Wolff, Karl (61990): Grundwissen Geschichte. Stuttgart: Klett.

Kunzenmann, Werner (1995): Judenstein. Das Ende einer Legende. Dokumentation. Innsbruck: Redaktion „Kirche“, Wochenzeitung der Diözese Innsbruck.

Kutter, Erni (1997): Der Kult der Drei Jungfrauen. Eine Kraftquelle weiblicher Spiritualität neu entdeck.t. München: Kösel.

Langer, Michael (1995): „,Blutbegier'ge Judenhunde streichen durch dies fromme Land ...'Ritualmordwahn und Tiroler Volksfrömmigkeit", in: Kunzenmann, Werner: Judenstein. Das Ende einer Legende. Dokumentation. Innsbruck: Redaktion „Kirche“, Wochenzeitung der Diözese Innsbruck, 31-62.

Lerner, Gerda (1997): Die Entstehung des Patriarchats. München: Deutscher Taschenbuch Verlag.

Mantl, Norbert (1967): Vorchristliche Kultrelikte im oberen Inntal. Innsbruck: Wagner.

Merchant, Carolyn (1987): Tod der Natur. München: C.H. Beck.

Meier-Seethaler, Carola (2004): Das Gute und das Böse. Stuttgart: Kreuz.

Meixner, Gabriele (1997): „Marie E.P. König - ihre Konzepte und ihre Bedeutung für die feministische Forschung", in: Karlisch, Sigrun et al., Hg.: Fem Arc: Vom Knochenmann zur Menschenfrau. Feministische Theorie und archäologische Praxis. Münster: Agenda Verlag, 140-160.

Mies, Maria (1984): „Tantra - Magie oder Spiritualität“, in: Feministische Theorie und Praxis 12, 82-98.

Mies, Maria (51996): Patriarchat und Kapital. Frauen in der internationalen Arbeitsteilung. Wien: Rotpunktverlag.

Mikschik, Jürgen (2002): „,Wider die Metaphysik“, in: Beiträge zur Dissidenz 11. Frankfurt: Lang. 
Mulack, Christa (1988): Im Anfang war die Weisheit. Stuttgart: Kreuz Verlag.

Mulack, Christa (1998): Religion ist zu wichtig, um sie den Männern zu überlassen.

Stuttgart: Kreuz Verlag.

Pallaver, Günther (1986): Sturaflüge. Band 15-16. Bozen.

Pallaver, Günther (1987): „Das Ende der schamlosen Zeit. Die Verdrängung der Sexualität in der frühen Neuzeit am Beispiel Tirols“, in: Österreichische Texte zur Gesellschaftskritik. Band 32. Wien: Verlag für Gesellschaftskritik.

Pomella, Birgit (2003): “Women are not for burning!” Feuer in Mythen und Politik. Innsbruck: Diplomarbeit.

Quaglioni, Diego (2003): „Das Inquisitionsverfahren gegen die Juden von Trient (1475-1478)", in: Buttaroni, Susanne/Musial, Stanislaw, Hg.: Ritualmord. Legenden in der europäischen Geschichte. Wien: Böhlau, 85-130.

Ruault, Franco (2006): „Neuschöpfer des deutschen Volkes": Julius Streicher im Kampf gegen „Rassenschande“. Frankfurt/M.: Lang.

Schubert, Kurt (1995): „Vom Missverständnis über Verständnis zum Einverständnis“, in: Kunzenmann, Werner: Judenstein. Das Ende einer Legende. Dokumentation. Innsbruck: Redaktion „Kirche“, Wochenzeitung der Diözese Innsbruck, 7-30.

Schroubek, Georg R. (2003): „Zur Frage der Historizität des Andreas von Rinn“, in: Buttaroni, Susanne/Musial, Stanislaw, Hg.: Ritualmord. Legenden in der europäischen Geschichte. Wien: Böhlau, 173-196.

Stecher, Reinhold (1995): „Vorwort“, in: Kunzenmann, Werner: Judenstein. Das Ende einer Legende. Dokumentation. Innsbruck: Redaktion „Kirche“, Wochenzeitung der Diözese Innsbruck, 6.

Tazi Preve, Irene (1992): Der Muttermord. Innsbruck: Diplomarbeit.

Voss, Jutta (1998): Das Schwarzmondtabu. Die kulturelle Bedeutung des weiblichen Zykelus. Stuttgart: Kreuz.

Walker, Barbara (32001): Die weise Alte. Kulturgeschichte. Symbolik. Archetypus. München: Frauenoffensive.

Walker, Barbara (2003): Das geheime Wissen der Frauen. Lexikon. Engerda: Arun.

Weissensteiner, Fritz et al. (1984): Zeitbilder. Band 5 und Band 6. Wien: Ueberreuter.

Werlhof, Claudia von (1991): Männliche Natur und künstliches Geschlecht. Wien: Wiener Frauenverlag.

Werlhof, Claudia von (1996): MutterLOS. Frauen im Patriarchat zwischen Angleichung und Dissiden\%: München: Frauenoffensive.

Werlhof, Claudia von (2003): „Fortschritts-Glaube am Ende? Das kapitalistische Patriarchat als ,Alchemistisches System“", in: Werlhof, Claudia von, Hg.: Subsistenz und Widerstand. Alternativen zur Globalisierung. Wien: Promedia,.41-68.

Werlhof, Claudia von (2006): „Das Patriarchat als Negation des Matriarchats. Zur Perspektive eines Wahns“, in: Göttner-Abendroth, Heide, 
Hg.: Gesellschaft in Balance. Stuttgart: Edition Hagia und Kohlhammer, $30-41$.

Werlhof, Claudia von (2007a): „Auf dem Weg in eine neue Zivilisation? Interview mit Madeisky", in: MatriV al 1, 37-46.

Werlhof, Claudia von (2007b): „Satanologie angesichts der Apokalypse Wovon René Girard (nicht) spricht und was daraus folgt", in: Palaver, Wolfgang/Exenberger, Andreas/Stöckl, Kristina, Hg.: Aufgeklärte Apokalyptik: Religion, Gewalt und Frieden im Zeitalter der Globalisierung. Innsbruck: Innsbruck University Press, 355-390.

Wenninger, Markus J. (2003): „Die Instrumentalisierung von Ritualmordbeschuldigungen zur Rechtfertigung spätmittelalterlicher Judenvertreibungen“, in: Buttaroni, Susanne/Musial, Stanislaw, Hg.: Ritualmord. Legenden in der europäischen Geschichte. Wien: Böhlau, 197-212.

Wittfogel, Karl A. (1977): Die Orientalische Despotie. Ulm: Ullstein Buch.

Wölfl, Adelheid (2007): „Bauer statt Pater“, in: Der Standard, 10. Juli 2007, letzte Seite. 


\section{Systematische Perspektiven}





\section{Im Zeichen des Opfers. Die apokalyptische Verschärfung der Weltlage als Folge des Monotheismus}

Wolfgang Palaver

Die folgenden Überlegungen wollen - aufbauend auf die mimetische Theorie René Girards ${ }^{1}$ - eine Skizze der kulturellen Evolution von Religion bieten und dabei zeigen, dass diese Entwicklung durch eine apokalyptische Verschärfung der Weltlage gekennzeichnet ist. Während wir gerade auch von religiösen Motiven angetrieben immer sensibler auf zwischenmenschliche Gewalt reagieren und immer kritischer alle ihre Formen zu durchschauen beginnen, ist die moderne Welt gleichzeitig von einer gefährlichen Zunahme des Gewaltpotenzials und auch einer faktischen Vermehrung von Opfern zwischenmenschlicher Gewalt begleitet. Das 20. Jahrhundert ist ein nur zu blutiges Kapitel der Menschheitsgeschichte, indem ein bisher noch nie erreichtes Quantum an Gewalt für Millionen von Menschen zum Tod führte. Ich teile die Einschätzung des Zweiten Vatikanischen Konzils, nach der für die „,moderne Welt [...] der Weg offen ist zu Freiheit oder Knechtschaft, Fortschritt oder Rückschritt, Brüderlichkeit oder Haß““. ${ }^{2}$ Ähnlich spricht René Girard davon, dass die Moderne die beste und schlechteste Welt zugleich ist. ${ }^{3}$

Für die apokalyptische Lage sind vor allem auch die religiösen Entwicklungen in unserer Welt von Bedeutung. Gegen die heute oft vorgebrachte Anklage, dass vor allem Religion zur Gewalt in unserer Welt anstachle, möchte ich aber zuerst und vor allem auf die Frie- 
denskraft der Religionen hinweisen. Dies soll allerdings nicht in naiver Weise geschehen. Das menschliche Potenzial zur Gewalt hat auch die Religionen von Anfang an in ein enges Verhältnis zur Gewalt gebracht, das unter bestimmten Umständen tatsächlich zu einer Gewaltverschärfung führen konnte und kann. Meine Überlegungen werden dabei gerade auch die historische Entwicklung von Religion in den Vordergrund stellen. In dieser Hinsicht unterscheidet sich der Beginn der menschlichen Zivilisation ganz wesentlich von unserer modernen Welt. Zustimmend kann ich hier den französischen Religionssoziologen Émile Durkheim zitieren, der schon im Jahre 1898 sowohl die bleibende gesellschaftliche Bedeutung von Religion als auch ihren deutlichen historischen Wandel ansprach: „Wenn es wahr ist, daß eine Religion in bestimmter Hinsicht unentbehrlich ist, so ist es nicht weniger gewiß, daß die Religionen sich wandeln, daß die Religion von gestern nicht die von morgen sein kann. "4 Ähnlich erkannte auch der Kommunist und Atheist Bert Brecht im Jahre 1939 gegen Tendenzen in seiner eigenen politischen Bewegung, Religion pauschal und ohne Differenzierungen abzulehnen, dass im Nationalsozialismus eine „rückständige Religion“ das Christentum bekämpft. ${ }^{5}$

\section{Archaische Religionen: Friede durch Menschenopfer}

Der Beginn der menschlichen Zivilisation ist religiös geprägt, insofern ein nichtbewusster Sündenbockmechanismus Frieden und Ordnung aus einem ursprünglichen Chaos zwischenmenschlicher Gewalt entstehen ließ, indem ein Opfer als vermeintlicher Verursacher der Krise getötet oder verstoßen, aber gleichzeitig auch als Friedensbringer vergöttlicht wurde. Der religiöse Ursprung von Kultur wird von Girard als Vorgang einer doppelten Übertragung beschrieben, der den geopferten Sündenbock in einen Gott verwandelt. Ein Akt der Dämonisierung geht in einen Akt der Divinisierung über: „Ist die das Opfer dämonisierende Übertragung durchschlagend, tritt die Versöhnung so plötzlich und so vollkommen ein, daß sie wie ein Wunder wirkt und eine zweite, die erste überlagernde Übertragung

4 Durkheim (1986), 62. Mit Girard muss allerdings festgehalten werden, dass Durkheim den „unüberbrückbaren Unterschied zwischen den archaischen und den jüdisch-christlichen Religionen“ nicht wirklich erkannt hat. Girard (2002), 131; vgl. Graham (2007).

5 Brecht (1939), 589; vgl. Berman (1999). 
auslöst: die Übertragung der mythologischen Divinisierung. "6 Aus moderner Sicht erscheinen uns die aus dem Sündenbockmechanismus hervorgehenden archaischen Religionen als blutrünstige Opferreligionen, die gut ins Vorurteil religiöser Gewaltverursachung passen. Diese Haltung ist zwar besser als die heute auch verbreitete Leugnung der Existenz solcher Menschenopferreligionen, aber auch sie reduziert sich letztlich auf eine bloß hochmütige Geste, die nicht erkennt, dass schon die archaischen Opferreligionen auf den Frieden zielen und einen ersten wichtigen Beitrag zur Überwindung zwischenmenschlicher Gewalt leisten. In dieser Ausrichtung auf den Frieden zeigt sich die von Girard erkannte „paradoxale Einheit alles Religiösen“. ${ }^{7}$ Ein Menschenopfer war aber der Preis, der für den Frieden dieser ersten Formen menschlicher Gemeinschaft bezahlt werden musste.

Der deutsche Ethnologe Wilhelm E. Mühlmann erwähnte unter dem Stichwort „Gottesfrieden“ Beispiele aus Tacitus’ Germania, die den Beitrag archaischer Religionen zum Frieden anschaulich machen. ${ }^{8}$ Deutlich lassen sich an ihnen Spuren des Sündenbockmechanismus erkennen. Das erste Beispiel handelt vom Stamm der Semnonen, die sich regelmäßig in einem heiligen Hain trafen, den man nur ,,in Fesseln“ betreten durfte, um den Gebrauch von Waffen auszuschließen. ${ }^{9} \mathrm{Zu}$ diesem Treffen im heiligen Hain gehörte notwendig auch das Blutopfer, denn ein Mensch wurde zu Beginn der Versammlung geschlachtet. Das noch deutlichere Beispiel handelt von Ostseestämmen, die die mit der Mutter Erde identifizierte Fruchtbarkeitsgöttin Nerthus verehrten. Regelmäßige Feste dieser Göttin fanden in einem auf einer Insel gelegenen heiligen Hain statt und bewirkten eine Zeit heiligen Friedens: „Keine Kriege beginnen sie, greifen nicht zu den Waffen, alles Eisen ist weggesperrt; dann kennt man, dann liebt man nur Frieden und Ruhe." 10 Auch hier fehlen die mit diesem Kult verbundenen Menschenopfer nicht. Nach dem Kult wurden die verwendeten Gegenstände in einem See gewaschen, wobei die dazu verwendeten Sklaven vom See sofort verschlungen wurden. Nach Tacitus trug dies zu jenem ,geheimen Schauder“ und 
jener „heiligen Unwissenheit“ bei, von denen diese Göttin umgeben war.

\section{Die abrahamitische Revolution: Der Exodus aus der Welt der Menschenopfer}

Nur wenn wir die Bedeutung der archaischen Religionen hinsichtlich ihrer Friedenswirkung verstanden haben, lässt sich erkennen, welche Revolution die abrahamitische Tradition mit ihrer Absage an das Menschenopfer bedeutete. Menschen- und Kinderopfer waren zentraler Bestandteil archaischer Formen der Gewalteindämmung und Friedenssicherung. Erst vor diesem Hintergrund wird verständlich, dass es gar nicht so außergewöhnlich war, dass Abraham seinen Sohn Isaak Gott als Opfer darbringen wollte. Die tiefsten Schichten des entsprechenden biblischen Textes im Buch Genesis lassen noch deutlich Spuren eines vollzogenen Kinderopfers erkennen. ${ }^{11}$ Die Revolution in diesem biblischen Text besteht darin, dass Gott dieses Opfer gerade nicht will und ein Tier stellvertretend für das Kind bereitstellt. Der deutsche Schriftsteller Thomas Mann, der sich jahrelang mit diesen Themen der Bibel auseinandergesetzt hat, beschreibt präzise, wie der biblische Text einer religiösen Revolution Ausdruck verleiht, die mit dem Menschenopfer bricht, weil es eine veränderte Vorstellung von Gott erforderlich macht: „Das eigentliche und ursprüngliche Opfer war Menschenopfer. Wann kam der Augenblick, wo es zum Greuel und zur Dummheit wurde? Die Genesis hält ihn fest, diesen Augenblick, im Bilde des verwehrten Isaak-Opfers, der Substituierung des Tieres. Hier löst sich ein in Gott fortgeschrittener Mensch von überständigem Brauch, von dem, worüber Gott mit uns hinauswill und schon hinaus ist." 12 Girards mimetische Theorie fasst die abrahamitische Revolution in ihrer Betonung der „biblischen ,Differenz"“, d.h. der Unterscheidung zwischen der mythischen Parteinahme für den Mob der Verfolger und der biblischen Solidarität mit den verfolgten Sündenböcken, zusammen. ${ }^{13}$

Im Blick auf das Alte Testament hat Girard immer wieder auf den offensichtlichen Unterschied zwischen dem Ödipus-Mythos und der biblischen Josefsgeschichte hingewiesen. Beide Traditionen 
knüpfen an die urtümliche Praxis von Kinder- bzw. Menschenopfern an, indem sie zeigen, wie Ödipus und Josef schon als Kinder Opfer ihrer jeweiligen Gemeinschaften werden. Ödipus wird von seinen Eltern fortgelegt und Josef von seinen Brüdern verkauft. Doch die Unterschiede zwischen diesen beiden Erzählungen sind wichtiger als die Parallelen. Während Ödipus wegen seiner angeblich inzestuösen Beziehung zu seiner Mutter für die Pest in Theben verantwortlich gemacht wird, spricht der biblische Text Josef von einem ähnlichen Vergehen frei. Er hat die Frau seines väterlichen Freundes Potifar nicht vergewaltigt, sondern diese versuchte, ihn zu verführen. Die Bibel steht eindeutig auf der Seite des Opfers Josef. Sie solidarisiert sich weder mit seinen neidischen Brüdern noch mit seinen ägyptischen Anklägern. Während Ödipus nach seiner Vertreibung zu einer Art Gott erhoben wird, weist Josef ein solches Ansinnen seiner ihn früher verfolgenden Brüder entschieden zurück. ${ }^{14}$ In der Offenlegung des Sündenbockmechanismus deckt der biblische Monotheismus jene Gewalt auf, die die scheinbar harmonische Welt des Polytheismus kennzeichnet, und verweigert sich außerdem jener Divinisierung, die die zuerst dämonisierten Opfer in den Himmel hebt: „In der hebräischen Bibel macht die Gleichsetzung von Opferlogik und Göttlichem einer absoluten Trennung Platz. Die jüdische Religion [...] entgöttlicht die Opfer und entviktimisiert das Göttliche. Der Monotheismus ist Ursache und Folge dieser Revolution zugleich." $" 15$

Aus christlicher Sicht erfährt die abrahamitische Revolution in der Passion und Auferstehung Jesu Christi ihren Höhepunkt und Abschluss. Was oberflächlich wie ein Rückfall auf die Ebene archaischer Mythen aussehen mag, wenn Tod und Auferstehung Jesu im mythischen Sinne interpretiert werden, bestätigt tatsächlich die biblische Überwindung der mythischen Opferlogik. Auch Jesus wird als unschuldiges Opfer einer kollektiven Tötung rehabilitiert. Seine Göttlichkeit ist nicht Folge einer vorgängigen Dämonisierung, sondern wird nur von jener kleinen Schar von Jüngern und Jüngerinnen erkannt und bezeugt, die durch die Begegnung mit dem auferstandenen Jesus ihr eigenes Versagen während der Zusammenrottung

14 Genesis, 50.18-19: „Seine Brüder gingen dann auch selbst hin, fielen vor ihm nieder und sagten: Hier sind wir als deine Sklaven. Josef aber antwortete ihnen: Fürchtet euch nicht! Stehe ich denn an Gottes Stelle?“

15 Girard (2002), 156. 
überwinden kann. Weil er schon vor seiner Menschwerdung der Sohn Gottes ist, kann Jesus seiner Botschaft vom Reich Gottes treu bleiben und in der gewaltfreien Hingabe am Kreuz die tötenden Mächte und Gewalten bloßstellen und ihrer Macht berauben.

Auch der Islam ist wesentlich von der abrahamitischen Revolution und ihrer Absage an Kinder- und Menschenopfer geprägt. Das zeigt sich schon an der Parallele, die das verwehrte Opfer Isaaks im Koran findet. In Sure 37 wird berichtet, dass Abraham anstelle seines Sohnes Ismael ein Tieropfer darbringt: „Und Wir lösten ihn mit einem großen Schlachtopfer aus.“ (37.107) Ein solches verhindertes Kinderopfer prägt auch die klassische Biografie des Propheten Mohammed. ${ }^{16}$ Dort heißt es, dass Mohammeds Großvater Abd alMuttalib einst aufgrund des fehlenden Kindersegens gelobt hat, einen seiner Söhne zu opfern, würde er je zehn erwachsene Söhne erhalten. Als er dann später tatsächlich zehn Söhne hat, schlachtet er mit viel Skrupel, weil er eigentlich sein Gelöbnis nicht brechen will, anstelle seines Sohnes Abdallah hundert Kamele - zehnmal mehr als üblicherweise für ein Menschenleben zu bezahlen war. Der Vater Mohammeds entging also ähnlich wie Isaak bzw. Ismael der Opferung durch seinen eigenen Vater. Das Verbot von Kinderopfern im Islam bedeutete einen radikalen Bruch mit der arabischen Stammesgesellschaft, in der gerade die Tötung von Mädchen alltäglich war. Die englische Religionswissenschaftlerin Karen Armstrong betont, welchen Bruch mit der vorherrschenden Moral die im Koran verkörperte abrahamitische Revolution zur Folge hatte: „Der Koran hat wiederholt die Praxis verboten, weibliche Neugeborene zu töten: Es wurde zu einem der Grundsatzgebote, dem sich jeder Bekehrte zu unterwerfen hatte. Anstatt diese grausame Methode der Geburtenkontrolle anzuwenden, sollen die Muslime in einer Gesellschaft auf Gott vertrauen, in der allen Menschen, auch den Alten, Waisen und Kleinkindern, gleiche Rechte zugestanden sind und in der sie gleichbehandelt werden müssen." 17 Auch die biblische Josefsgeschichte wird im Koran aufgegriffen und in der Sure 12 - die ausdrücklich den Namen ,Joseph" trägt - nacherzählt. Wiederum ergibt sich eine Parallele zum Leben Mohammeds. Denn ähnlich wie Josef aus Neid zum Sündenbock seiner Brüder wird, die ihn aus der Familie vertrei- 
ben, wird auch Mohammed wie ein Sündenbock von seinen Verwandten aus der Vaterstadt Mekka vertrieben.

Ein erster deutlicher Unterschied zwischen mythischer Perspektive und biblischer Offenbarung zeigt sich bereits in der archaischen Geschichte vom Brudermord Kains an seinem Bruder Abel. Während die Mythen - die römische Geschichte von Romulus und Remus kann als Beispiel dienen - für den Mörder Partei nehmen, steht auch hier die Bibel auf der Seite des Opfers der Gewalt. Mit Abel begann die lange Geschichte der unschuldig verfolgten Opfer auf Erden, die immer noch kein Ende gefunden hat. Auch in dieser Hinsicht nimmt der Koran ähnlich wie die Bibel die Perspektive des Opfers Abel ein, um im Anschluss an die biblische Erzählung die grundsätzliche Heiligkeit jedes menschlichen Lebens zu betonen: „Wenn einer jemanden tötet, jedoch nicht wegen eines Mordes oder weil er auf der Erde Unheil stiftet, so ist es, als hätte er die Menschen alle getötet. Und wenn jemand ihn am Leben erhält, so ist es, als hätte er die Menschen alle am Leben erhalten." (5.32) ${ }^{18}$

Die abrahamitische Revolution führte durch ihre Absage an die Menschenopfer-Kulturen allmählich zu jenem modernen Menschenbild, das jedes menschliche Leben für grundsätzlich heilig hält. Durkheim hat in dieser Form des Individualismus die Religion der modernen Welt zu erkennen geglaubt: „Da jeder von uns etwas von der Menschheit in sich verkörpert, hat jedes individuelle Bewußtsein in sich etwas Göttliches und findet sich so mit einem Merkmal versehen, das es für die anderen heilig und unverletzlich macht."19 Ähnlich wie Durkheim, der von der christlichen Wurzel dieses Individualismus spricht, ${ }^{20}$ hat auch der Literaturnobelpreisträger und Kulturanthropologe Elias Canetti in den Klagereligionen - vor allem im Christentum - die Ursache für die Steigerung des Wertes jedes einzelnen Menschen gesehen: „Das Bild des Einen, um dessen Tod die Christen seit bald 2000 Jahren klagen, ist ins Bewußtsein der gesamten wachen Menschheit eingegangen. Es ist ein Sterbender, und

18 Hier findet sich im Koran eine Parallele zum Talmud, der auch im Anschluss an die KainAbel-Erzählung die Heiligkeit des Lebens betont: „Darum wurde der Mensch einzig erschaffen, um dich zu lehren: Jedem, der eine einzige Seele von Israel verdirbt, rechnet es die Schrift an, als hätte er eine vollständige Welt verdorben. Und jedem, der eine einzige Seele von Israel erhält, rechnet es die Schrift an, als hätte er eine vollständige Welt erhalten. “Mayer (1986), 73-74 (Mischna Sanhedrin IV,5).

19 Durkheim (1986), 63.

20 Durkheim (1986), 64-65. 
er soll nicht sterben. [...] Es gibt keinen Verfolgten, wofür immer er leiden mag, der sich in einem Teile seiner Seele nicht als Christus sieht. [...] Aber auch der Schwächste, der es nie zu einem ernsthaften Feind gebracht hat, hat an diesem Bild teil. Er mag für gar nichts sterben, das Sterben selbst macht ihn zu etwas Besonderem. Christus leiht ihm die Klagemeute. Mitten in der Raserei der Vermehrung, die auch eine der Menschen ist, ist der Wert des einzelnen nicht gesunken, er ist gestiegen." 21 Wenn man übergeht, dass Canettis Konzept der Klagereligionen - übrigens ähnlich wie Durkheim - den radikalen Bruch, den die abrahamitische Revolution gegenüber den polytheistischen Religionen bedeutete, verkennt, ${ }^{22}$ kann man seiner Zusammenfassung der Wirkung des Christentums zustimmen. Viel schärfer blickte hier Friedrich Nietzsche, auch wenn er dabei für das opferwillige Heidentum Partei ergriff. Für Nietzsche bleibt die eigentlich historische Wirkung des Christentums ,gerade die Steigerung des Egoismus, des Individual-Egoismus bis ins Extrem (- bis zum Extrem der Individual-Unsterblichkeit.) Der Einzelne wurde durch das Christenthum so wichtig genommen, so absolut gesetzt, daß man ihn nicht mehr opfern konnte: aber die Gattung besteht nur durch Menschenopfer [...] Die ächte Menschenliebe verlangt das Opfer zum Besten der Gattung - sie ist hart, sie ist voll Selbstüberwindung, weil sie das Menschenopfer braucht. Und diese PseudoHumanität, die Christenthum heißt, will gerade durchsetzen, daß Niemand geopfert wird [...].“ 23 Was Nietzsche hier „PseudoHumanität" schimpft, ist tatsächlich ein genuiner Humanismus und darf nicht automatisch als Egosimus verurteilt werden. In der abrahamitischen Revolution wurzelt die moderne Heiligkeit des Lebens, die im Hintergrund unserer Betonung von Menschenwürde und Menschenrechten steht.

\section{Corruptio optimi pessima: Ein anklagender „Kult des Opfers" ${ }^{\text {(24 } 4}$ als Versuchung des Antichrist}

Der durch die abrahamitische Revolution erfolgte Bruch mit den Menschenopfer-Kulturen bewirkte aber keineswegs eine geradlinige 
Forschrittsgeschichte ohne Schatten oder neue, oft noch gesteigerte Gewaltexzesse. Im Gegenteil, die abrahamitische Revolution muss als Apokalypse im doppelten Sinne des Wortes verstanden werden. Sie enthüllt bzw. offenbart die gewaltsamen Wurzeln der menschlichen Zivilisation und entfesselt dadurch auch bisher eingedämmte Gewaltpotenziale. Jesus deutete auf solche Gefahren hin, als er sagte, dass er nicht gekommen sei, „um Frieden auf die Erde zu bringen [...], sondern das Schwert" (Mt 10.34). Schon David Hume sprach von der corruptio optimi pessima, wenn er die Menschenopfer im Polytheismus mit Formen der Inquisition in den monotheistischen Religionen verglich. ${ }^{25}$ Aus christlicher Sicht kann hier von der Versuchung des Antichrist gesprochen werden, weil diese biblische Figur präzise jene Gefahren veranschaulicht, die nur aus der Pervertierung der biblischen oder genauer der christlichen Botschaft folgen können. René Girard und Ivan Illich haben in diese Richtung wertvolle Überlegungen angestellt. Nach Girard stellt die „Aufmerksamkeit für Sündenbockmechanismen eine echte Überlegenheit unserer Gesellschaft über alle früheren Gesellschaften dar, doch, wie alle Wissensgewinne auch Anlaß zu vermehrtem Übel“'.26 Illich betonte den Gedanken der corruptio optimi pessima und die Bedeutung der Figur des Antichrist in seiner These, dass die moderne Welt in ihrer Tendenz $\mathrm{zu}$ Institutionalisierungen und ihrer Entfachung von Bedürfnissen als eine Pervertierung der christlichen Botschaft verstanden werden müsse. ${ }^{27}$

Diese neue Problematik der Gewalt, die aus der biblischen Aufdeckung des Sündenbockmechanismus hervorgehen kann, zeigt sich beispielsweise an den von Elias Canetti so bezeichneten „Klagereligionen“. ${ }^{28}$ Unter diesem Begriff fasste er jene Religionen zusammen, deren Anhänger sich durch die Identifikation mit einem verfolgten Opfer ihrer eigenen Verfolgungen zu entsühnen versuchen. Solange die Menschen „das Töten in Meuten nicht aufgeben können“, glaubt Canetti, seien die „Klagereligionen für [ihren] seelischen Haushalt unentbehrlich“. ${ }^{29}$ Das die Klagereligionen bestimmende Geschehen bringt er dabei folgendermaßen auf den Punkt: „Die Jagd- oder

25 Hume (1984), 39-40, 42.

26 Girard (2002), 198; vgl. 224-225; Girard (1997), 63.

27 Illich/Cayley (2006), 86, 120, 195.

28 Canetti (1960), 172-194.

29 Canetti (1960), 171. 
Hetzmeute entsühnt sich als Klagemeute."30 Besonders deutlich erkannte er im Christentum und im schiitischen Islam Formen solcher Klagereligionen: „Von den Religionen der Klage ist das Gesicht der Erde gezeichnet. Im Christentum haben sie eine Art von allgemeiner Gültigkeit erlangt. [...] Die Legende, um die sie sich bilden, ist die eines Menschen oder Gottes, der zu Unrecht umgekommen ist. Es ist immer die Geschichte einer Verfolgung, sei es einer Jagd oder einer Hetze. Auch ein ungerechter Prozeß kann damit verbunden sein. "31 Klagereligionen haben zwar einerseits wesentlich zur Steigerung des Wertes der Menschen beigetragen, wie das schon weiter oben deutlich wurde, andererseits tragen sie aber auch eine Versuchung zur Gewalt in sich, die nicht übersehen werden darf. Weil sie auf der Seite eines verfolgten Opfers stehen, fühlen sich die Anhänger dieser Religionen oft allzu schnell und ohne große Bedenken dazu berechtigt, gegen die entlarvten Verfolger gewaltsam vorzugehen und deren Gewaltakte zu vergelten. Der Klage folgt sehr leicht die gewaltsame Rache. ${ }^{32}$ Die klagereligiöse Versuchung wurzelt im möglichen Umschlag der Klage- in die Kriegsmeute. Ein solcher steht nach Canetti beispielsweise häufig am Beginn von Stammeskriegen: „Ein Mann wird getötet, seine Stammesangehörigen beklagen ihn; dann formieren sie sich zu einer Truppe und ziehen aus, seinen Tod am Feinde zu rächen. Die Klagemeute geht in eine Kriegsmeute über." "33

Die hier im Anschluss an Canetti formulierte These von der klagereligiösen Versuchung berührt sich natürlich mit Friedrich Nietzsches und Max Webers Thesen zum Ressentiment, das diese beiden Denker im biblischen Denken grundgelegt sahen. Nach Nietzsche begann ,,mit den Juden der Sklavenaufstand in der Moral" und wuchs die christliche Liebe direkt aus dem „Stamme jenes Baums der Rache und [...] des jüdisches Hasses“ heraus. ${ }^{34}$ Max Weber hat

30 Canetti (1960), 171.

31 Canetti (1960), 168.

32 Schon in archaischen Trauerriten, die auf einen gewöhnlichen Tod folgen, zeigen sich Tendenzen zur Rache, die einen Ausweg aus der Krise weisen sollen, indem die Wut gegen Sündenböcke - oft Fremde oder Frauen - kanalisiert wird. Durkheim greift in seiner Beschreibung solcher Riten - wie Canetti hinsichtlich der „Klagemeute“ - auf das Beispiel der Warramunga in Zentralaustralien zurück. Durkheim (1986), 523-524, 528, 537; Canetti (1960), 122-123.

33 Canetti (1960), 150; vgl. 162.

34 Nietzsche (1988a), 268 (Erste Abhandlung: „Gut und Böse“, „Gut und Schlecht“ Nr. 7-8). 
vor allem am Beispiel der Klagepsalmen des Alten Testaments - die interessanterweise in Canettis Buch trotz seiner jüdischen Abstammung unerwähnt bleiben - das Judentum als eine von Rache und Ressentiment bestimmte Religion beschrieben. Er spricht von den „Klagen und [dem] Rachegeschrei der Psalmisten“ und der „vom leidenschaftlichen Zorn und $\mathrm{Haß}$ oder vom scharfen Ressentiment gegen die Gottlosen, denen es gut geht, getränkte[n] Psalmenreligiosität“ $: 35$ „Die Psalmenreligiosität ist erfüllt von Rachebedürfnis [...] Die Mehrzahl aller Psalmen enthält [...] die moralistische Befriedigung und Legitimierung offenen oder mühsam verhaltenen Rachebedürfnisses eines Pariavolkes ganz handgreiflich. "36

Wir kennen die klagereligiöse Versuchung zur Gewalt nur allzu deutlich aus der Geschichte des Christentums, denn die Aufdeckung des Sündenbockmechanismus durch Passion und Auferstehung Jesu Christi bedeutete keineswegs das abrupte Ende aller Verfolgungen. Sehr rasch neigten Christen in der Geschichte immer wieder dazu, ihre Solidarität mit Christus als Legitimation für die Verfolgung von Juden zu missbrauchen. Der christliche Antijudaismus trägt im Kern die Gewalt einer Klagemeute in sich. Besonders zur Zeit der Kreuzzüge rächten sich Christen im Namen ihrer Solidarität mit dem Gekreuzigten an Juden und Muslimen. ${ }^{37}$ Auch die Massaker der europäischen Konquistadoren folgten diesem Muster, wenn im Namen Christi die Indianer wegen ihrer Menschenopfer in einer Weise abgeschlachtet wurden, die alle archaische Opfergewalt bei Weitem übertraf. Das jüngste Beispiel finden wir im orthodoxen Christentum Serbiens, das die schon lange vergangene Niederlage am Amselfeld in einen Kult des Martyriums verwandelte, der in den jüngsten Konflikten im ehemaligen Jugoslawien zur Aggression gegen politische Gegner anstachelte. ${ }^{38}$

Auch im schiitischen Islam finden wir Beispiele klagereligiös legitimierter Gewalt. Im Zentrum von Canettis Deutung der schiitischen Tradition steht das Muharramfest, das an die Abschlachtung des Prophetenenkels Hussein und seiner Anhänger in Kerbela im

35 Weber (1988), 37, 420.

36 Weber (1980), 301.

37 Bartlett (2001), 109.

38 Gauß (1995); Vrcan (1995), 363-364. Auch die Gegner der Serben in den jüngsten Konflikten im ehemaligen Jugoslawien beriefen sich immer wieder auf ihre vergangenen Opfererfahrungen. Siehe Bartov (1998), 814. 
Oktober 680 erinnert. ${ }^{39}$ Dieses für die schiitische Tradition bedeutsame Gedenken an die Passion Husseins drängt zwar nicht direkt oder automatisch zur Gewalt, aber es trägt wie alle erkannte ungerechte Verfolgung ein großes Potenzial zur möglichen Vergeltung oder Anstachelung neuer Gewalt in sich. Im Iran lassen sich Beispiele finden, wie in der jüngsten Vergangenheit diese Passion zur Legitimation von Gewalt herangezogen wurde. Der muslimische Soziologe und Befreiungsdenker Ali Shariati (1933-1977) leitete beispielsweise aus dieser Passionsgeschichte ein Verständnis von Martyrium ab, das wohl kaum - wie etwa bei Mehdi - als legitime Form gewaltfreien Widerstands verstanden werden kann, sondern eng mit dem Aufruf zum gewaltsamen Kampf gegen Unterdrücker verbunden bleibt. ${ }^{40}$ Der Märtyrertod wird von Shariati mit der Begründung bejaht, dass er aufgrund der fehlenden Möglichkeiten zum Töten als einzige Möglichkeit aktiven Widerstands verblieben sei. ${ }^{41}$ Im Ersten Golfkrieg des Irans gegen den Irak (1980-1988) wurden viele junge Soldaten mit der Erinnerung an das Martyrium Husseins in die Schlacht getrieben. Das Gedenken an die ungerechte Abschlachtung diente als Motivation für die kriegerische Gewalt gegen den Nachbarstaat. ${ }^{42}$ Mit dem Ruf „Ya Hussein“ liefen damals Tausende Kinder und Jugendliche in die Minen der Irakis. ${ }^{43}$ Auch das erste Selbstmordattentat eines Mitglieds der libanesischen Hizbollah im Jahre 1983 knüpft an die Passion Husseins an. ${ }^{44}$

Es gibt einen Zusammenhang zwischen bestimmen Lesarten der Passion Husseins und dem islamistischen Terrorismus in unserer gegenwärtigen Welt. Doch solche Interpretationen müssen mit Sorgfalt durchgeführt werden. Dem Schriftsteller und Orientalisten

39 Canetti (1960), 172-182.

40 Kermani (2006), 15-16; Mehdi (1992), 133.

41 "Shahädat, in summary, in our culture, contrary to other schools where it is considered to be an accident, an involvement, a death imposed upon a hero, a tragedy, is a grade, a level, a rank. It is not a means but it is a goal itself. It is originality. It is a completion. It is a lift. It itself is mid-way to the highest peak of humanity and it is a culture. In all ages and centuries, when the followers of a faith and an idea have power, they guarantee their honor and lives with jihäd. But when they are weakened and have no means whereby to struggle, they guarantee their lives, movement, faith, respect, honor, future and history with shahädat. Shahädat is an invitation to all generations, in all ages, if you cannot kill your oppressor, then die." Taliqani/Mutahhari/Shariati (1986), 214.

42 Volkan (1988), 134-135; Bonney (2007), 246.

43 Kermani (2006), 19.

44 Kermani (2006), 19; Allam (2002), 139-140. 
Navid Kermani ist zuzustimmen, wenn er festhält, dass der 11. September weder durch das Erzählen der Geschichte Husseins noch ohne sie wirklich zu erklären ist. ${ }^{45} \mathrm{Zu}$ Recht wehrt er sich gegen jene vereinfachenden Versuche, die „Ursprünge des 11. Septembers im Koran oder im Mittelalter" - in der Bewegung der Assassinen - zu suchen. ${ }^{46}$ Die Formen des modernen Terrorismus weisen trotz religiöser oder weltanschaulicher Unterschiede Gemeinsamkeiten auf, die viel direkter mit unserer modernen Welt zu tun haben.

Wir leben heute in einer Welt, in der die durch die biblische Offenbarung möglich gewordene Sorge für die Opfer oft leichtfertig als Legitimation für Befreiungskämpfe oder Akte der Vergeltung herangezogen wird. ${ }^{47}$ Darin manifestiert sich eine gefährliche Form des vorherrschenden „Kults des Opfers“. Peter Waldmann, ein deutscher Fachmann für Terrorismus und Bürgerkriege, spricht im Blick auf unsere Zeit von einem „,Siegeszug“ des Opfers“, der meist mit dem Wunsch verbunden ist, zukünftig selbst die überlegene Machtposition einzunehmen. ${ }^{48}$ Terroristen legitimieren sich heute weltweit als Verteidiger der Schwachen und Verfolgten. Im Namen der Unterdrückten rufen sie zur Zerstörung und Gewalt auf. Für islamische, jüdische und christliche Terroristen genauso wie für die Aum-Sekte, die 1995 einen Anschlag mit tödlichem Nervengas in der Untergrundbahn von Tokio ausführte, ist es bezeichnend, dass sie sich alle als eingekreiste Verfolgte fühlen und ihre Terrorakte als Verteidigung gegen eine lebensbedrohende Übermacht verstehen. ${ }^{49}$ Selbst der jüngste Amokanschlag im April 2007, bei dem 32 Menschen an einer amerikanischen Universität ermordet wurden, zeigt diese pervertierte Parteinahme für die Opfer. Der Amokschütze rechtfertigte sich in seiner schriftlichen Botschaft, in der er sich „Ishmael“ nannte, als ohnmächtiges Opfer, das mit seiner Tat die Solidarität mit allen Schwachen beschwört: „Ihr habt mein Herz zerstört, meine Seele vergewaltigt und mein Gewissen in Brand gesetzt. Ihr habt geglaubt, es war nur das Leben eines erbärmlichen jungen Mannes, das Ihr auslöscht. Dank Euch sterbe ich wie Jesus Christus, um Generatio- 
nen schwacher und schutzloser Menschen zu inspirieren. "50 Osama bin Laden rechtfertigte in Interviews seine Unterstützung des islamistischen Terrorismus mit dem Hinweis, auf der Seite unschuldig Verfolgter zu stehen. Er sieht sich und seine Verbündeten als Verteidiger der Opfer der ganzen Welt. Neben unterdrückten Muslimen in Saudiarabien und verfolgten Palästinensern nennt er u.a. die 600.000 Kinder, die im Irak aufgrund der Sanktionen getötet worden seien, die getöteten Muslime in Bosnien-Herzegowina sowie die japanischen Opfer der amerikanischen Atombombenabwürfe. Ganz im Sinne der klagereligiösen Versuchung weist Osama bin Laden Vorwürfe des Terrorismus von sich, um umgekehrt die Welt des Islam als Opfer eines internationalen Terrors darzustellen. ${ }^{51}$ Wie tief das Problem des Missbrauchs des Opferstatus aber tatsächlich reicht, zeigt sich, wenn wir auch die Versuchung der westlichen Welt ansprechen, die uns seit dem 11. September begleitet. Die USA und Teile des Westens sehen sich selbst als Opfer von Gewaltakten, die Krieg und Vergeltung erforderlich machen. ${ }^{52}$ Ebenso hat sich die Situation in Palästina in diese Richtung hin verschärft. Israelis und Palästinenser reklamieren immer lauter ihren Opferstatus, um damit wieder neue Vergeltungsschläge zu legitimieren.

Wie sehr unsere moderne Welt darüber hinaus vom Opfergedanken geprägt ist, zeigt sich im 20. Jahrhundert am Beispiel von Faschismus und deutschem Nationalsozialismus. Auf den ersten Blick ist sicher der Deutung Girards zuzustimmen, dass im Unterschied zur kommunistischen Ideologie, in der die biblische Solidarität mit den Opfern auf bedenkliche und zur Gewalt antreibende Weise verschärft worden sei, der Nationalsozialismus im Anschluss an Nietzsche versucht habe, hinter die biblische Offenbarung zurückzugehen, um Menschen wieder bedenkenlos für Führer, Volk oder Vaterland opfern zu können. ${ }^{53}$ Hitlers Weltanschauung lässt sich so als Kampf gegen die biblisch ermöglichte Sorge um die Opfer und damit als eine Form von Neuheidentum verstehen. ${ }^{54}$ Doch so sehr

50 Seung-Hui (2007).

51 Bin-Ladin (2005), 40, 47; Kepel/Milelli (2006).

52 Tönnies (2002), 46-49.

53 Girard (1997), 18-19, 23; Girard (2002), 214.

54 „Im Dritten Reich spielt sich [...] nicht ein Kampf gegen die Religion ab, sondern ein Kampf zweier Religionen. Das Neuheidentum ist kein Atheismus, sondern, ebenso wie das Altheidentum, eine Religion. Und zwar ist das Neuheidentum gegen das Christentum genommen eine rückständige Religion. Der Nationalsozialismus bekämpft das Christen- 
diese Sichtweise zutrifft, so sehr zeigt sich gleichzeitig auch, dass selbst Faschismus und Nationalsozialismus die Opferrolle für sich beanspruchen mussten, um ihren eigenen Kampf legitimieren zu können. Die positive Bewertung des Opferstatus prägte so sehr unsere Welt, dass auch jene Ideologien ihr nicht entkommen konnten, die den sie ermöglichenden biblischen Geist mit aller Vehemenz zu bekämpfen versuchten. Trotz aller Hoffnungen, eine „HerrenMoral“ verkörpern zu können, scheint beispielsweise im Nationalsozialismus tatsächlich das Ressentiment vorgeherrscht zu haben. Hier zeigt sich indirekt jene Identität von Ressentiment und Willen zur Macht, die Girard am Beispiel von Nietzsche hervorhob. ${ }^{55}$ Der amerikanische Historiker Robert Paxton hat in seiner Studie über den Faschismus deutlich gemacht, dass die Betonung der eigenen Opferrolle zu den typischen Merkmalen des Faschismus gehört. Er fasst dies folgendermaßen zusammen: „Der Glaube, die eigene Gruppe sei ein Opfer - ein Gefühl, das jede Handlung gegen seine inneren wie seine äußeren Gegner rechtfertigt ohne gesetzliche oder moralische Grenzen." 56 Es verwundert daher nicht, dass George Orwell in einer Rezension von Hitlers Buch Mein Kampf im Jahre 1940 die Anziehungskraft des Führers in dessen Selbststilisierung als „gekreuzigter Christus“, als „Märtyrer“ und verfolgtes „Opfer“ begründet sah. ${ }^{57}$ Ähnlich erkannte der österreichische Historiker Friedrich Heer ein solches Selbstverständnis des Nationalsozialismus, als er Canettis Begriff der „Klagemeute“ zur Erklärung der politischen Religion Adolf Hitlers heranzog: „Verfolger bilden Meuten, indem sie sich selbst als Verfolgte erleben. Religiös-politische Klagemeuten werden im 19. und 20. Jahrhundert in unseren Räumen vor allem durch deutsche und christliche Massen infantiler, hilfloser Einzelner gebildet. Deutsche Klagemeuten fühlen sich von Slawen, Franzosen, Juden verfolgt - die sie selbst angreifen möchten. Christliche Klagemeuten fühlen sich von Freimaurern, Liberalen, Juden, Sozialisten verfolgt. Adolf Hitler vereinigt beide Klagemeuten. ${ }^{\text {"58 }}$ Die von Pax-

tum und ersetzt das Christentum durch sein Neuheidentum, gerade weil er eine Religion braucht, die seine rückständigen Ziele besser fördert. Er braucht eine kriegerische Religion, eine Religion der heldischen Aufopferung des einzelnen, eine rein deutsche, d.h. gegen andere Völker gerichtete Religion.“ Brecht (1939), 589.

55 Girard (1978), 91-93.

56 Paxton (2006), 66; vgl. 320; Taylor (2004), 30, 36; Bartov (1998), 811-816.

57 Orwell (2000).

58 Heer (1989), 570. 
ton analysierte Instrumentalisierung des Opferstatus im Faschismus erweist sich auch als hilfreich, um gegenwärtige Formen des Terrors besser verstehen zu können. Der niederländische Schriftsteller Geert Mak greift auf sie zurück, um in seinen Reflexionen über den Mord am Filmemacher Theo van Gogh zu zeigen, dass sich sowohl radikale Islamisten als auch islamophobe Rechtspopulisten als Opfer verstehen und durch diesen Status ihre Gewalttaten rechtfertigen. ${ }^{59}$

Aus der Sicht der mimetischen Theorie Girards handelt es sich bei allen diesen Missbräuchen des Opferstatus um eine Pervertierung der abrahamitischen Aufdeckung des Sündenbockmechanismus. Aus der Offenlegung des Sündenbockmechanismus wird eine „Sündenbockjagd zweiter Ordnung“, d.h. eine ,Jagd auf die Sündenbockjäger". 60 Girard diskutiert diese durch die biblische Offenbarung möglich gewordene klagereligiöse Versuchung ausdrücklich als eine Form des Antichrist, der sich als gefährlicher neuer Totalitarismus zeigt: „Was bedeutet eigentlich das Wort Antichrist? Doch wohl, daß man Christus nachahmen und ins Lächerliche ziehen wird. Es enthält eine genaue Beschreibung einer Welt, unserer eigenen, in der die schlimmsten Verfolgungstaten im Namen der Verfolgungsbekämpfung ausgeführt werden." ${ }^{\text {"61 }} \mathrm{Im}$ Anschluss an Girard verweist auch der kanadische Philosoph Charles Taylor indirekt auf diese Versuchung des Antichrist, wenn er zeigt, wie der missbräuchliche Umgang mit dem Opferstatus den Terrorismus in unserer gegenwärtigen Welt zu erklären vermag: „Das Neue Testament stellt das Opfer und seine Unschuld in den Mittelpunkt; es ermutigt all die Erniedrigten und Beleidigten sich zu erheben. Verschiedene religiöse Reformen, die Reformation selbst und schließlich der moderne Humanismus haben diese Idee weiter radikalisiert. Sie ist heute Teil unserer politischen Ethik geworden. [...] Dies gibt auf der einen Seite eine mächtige Waffe gegen Ungerechtigkeit an die Hand; auf der anderen erlaubt die Logik des Opfers, wieder Grenzlinien zu ziehen und Feinde zu identifizieren. Wenn wir die Opfer sind, seid ihr die Täter. Der Anspruch, Opfer zu sein, macht uns rein und unsere Sache zu einer guten Sache, in deren Namen wir gerechte Gewalt ausüben dürfen. Die Verbindung zum modernen Terrorismus liegt auf der Hand.“62 


\section{Eine Kultur der Vergebung als notwendig gewordener Weg aus der Gewalt}

Die heute so gefährlich gewordene Inanspruchnahme des Opferstatus verlangt nach einer Rückbesinnung auf das biblische Erbe. Ist die aggressive Inanspruchnahme des Opferstatus eine direkte Konsequenz der abrahamitischen Revolution oder nur deren Pervertierung? Der Hinweis auf die Figur des Antichrist gab schon die Antwort. Es handelt sich um eine Pervertierung oder Fragmentierung des biblischen Offenbarungsimpulses. Nach Girard kann nur eine in Einzelaspekte aufgespaltene Offenbarung als Waffe dienen: „Um die Offenbarung als Waffe im Kampf der mimetischen Rivalität zu verwenden und um ihr Spaltkraft zu verleihen, muß sie erst zerteilt werden. Solange sie intakt ist, bleibt sie Friedensmacht; fragmentiert erst stellt sie sich in den Dienst des Krieges." 63 Weil die biblische Offenbarung nicht auf die klagereligiöse Versuchung reduziert werden kann, muss Nietzsches und Webers These von der biblischen Wurzel des Ressentiments zurückgewiesen werden. Diese beiden Denker erkannten zwar eine wichtige Versuchung, die die biblische Parteinahme für das Opfer begleitet. Die Offenbarung darf aber nicht auf diese Gefahr reduziert werden. Girard distanzierte sich deshalb klar von Nietzsches entsprechender These, ohne dabei aber dessen berechtigte Einsicht in die Gefahren eines Kultes des Opfers zu minimieren: „In der heutigen Zeit sind einige Aspekte [...] des Opferwissens so stark verbreitet, daß sie [...] pervertiert sind und zum paradoxen Instrument einer noch subtileren Verfolgung werden. Der singuläre Charakter der heutigen Zeit zeigt sich auch darin, daß es der Öffentlichkeit gegenüber keinen begehrteren Platz mehr gibt als den des Opfers. [...] Dieser Stand der Dinge bei uns ist vom Einfluß der Bibel nicht zu trennen. Man soll sich aber, im Gegensatz zu Nietzsche, vom mimetischen Ressentiment nicht so sehr beherrschen lassen, daß man in ihm das legitime Kind der Bibel in unserer Gesellschaft wie auch deren Grundinspiration zu sehen wähnt. Das Ressentiment ist bloß ein illegitimes Kind, und sicher nicht der Vater der jüdisch-christlichen Schrift. "'64

63 Girard (1988), 170.

64 Girard (1990), 139. Ähnlich weist Girard auch Nietzsches verkürzte These bezüglich der Rache zurück: „Das Alte und das Neue Testament entspringen nicht dem Ressentiment; sie richten sich in Wahrheit vielmehr gegen die Rache in jeglicher Gestalt. Freilich ist es ihnen nicht gelungen, die Rache radikal zu beseitigen; sie konnten ihr nur einen 
Was bedeutet es konkret, dass die biblische Offenbarung nicht fragmentiert werden darf? Die biblische Aufdeckung des Sündenbockmechanismus verdankte sich einer Gruppe von Verfolgern und Mitläufern, die sich ihrer eigenen Verfolgermentalität bewusst wurde, umkehrte und dadurch jene Texte verfassen konnte, die auf der Seite der verfolgten Opfer stehen. Jedem Unschuldswahn, der notwendigerweise in erbarmungslosen Hass gegen entlarvte Verfolger umschlagen müsste, ist damit schon von Anfang an der Boden entzogen.

Sehr deutlich wird das in einem der wichtigsten Texte des Alten Testaments, die den Sündenbockmechanismus überwinden halfen, in den Liedern vom leidenden Gottesknecht im Buch Deuterojesaja. Diese Lieder beschreiben ungeschminkt und in seiner ganzen Brutalität das Schicksal eines Sündenbocks. Doch entscheidend dabei ist, dass sich die Einsicht in sein ungerechtes Schicksal einer Gruppe bekehrter Verfolger verdankt. Weil sie ihre eigene Jagd auf ein Opfer zu durchschauen beginnen, können sie den Leidensknecht rehabilitieren: „Wir meinten, er sei von Gott geschlagen, von ihm getroffen und gebeugt. Doch er wurde durchbohrt wegen unserer Verbrechen, wegen unserer Sünden zermalmt.“ (Jes 53.4-5) Diese Linie setzt sich im Neuen Testament fort. Auch hier steht am Anfang das Versagen aller Jünger - überdeutlich sticht die dreimalige Verleugnung Jesu durch Petrus hervor -, das erst dann zur Enthüllung des Opfermechanismus führt, als sie durch die Gnade Gottes zur Umkehr gelangen. Die radikale Gewaltfreiheit Jesu, die Bereitschaft, selbst noch am Kreuz seinen Feinden zu vergeben (Lk 23.34: „Vater, vergib ihnen, denn sie wissen nicht, was sie tun") und die Friedensbotschaft „Friede sei mit euch!“ (Lk 24.36; vgl. Joh 20.19,26) ${ }^{65}$, mit der er nach der Auferstehung den Jüngern gegenübertritt, ermöglichen letztlich die Umkehr der Jünger. Die christliche Überwindung des Sündenbockmechanismus ist untrennbar mit der Aufforderung zur Feindesliebe und Versöhnung sowie zur Absage an die Rache verbunden: „Liebt eure Feinde und betet für die, die euch verfolgen, damit ihr Söhne eures Vaters im Himmel werdet; denn er läßt seine Sonne aufgehen über Bösen und Guten, und er läßt regnen über Gerechte und Ungerechte.“ (Mt 5.44-45) Nur wer die Botschaft der Feindesliebe von der Aufdeckung des Sündenbockmechanismus abspaltet,

Schlag versetzen und sie, unter Abschwächung ihrer Gewalt, in Ressentiment verwandeln." Girard (2005), 100.

65 Schwager (1990), 174, 182-183, 249. 
kann aus der Solidarität mit den Opfern eine gefährliche Waffe schmieden. Selbst Nietzsche musste einbekennen, dass zumindest Jesu Tod am Kreuz von jedem Ressentiment frei war. Er beschuldigte fälschlich die Jünger, unfähig gewesen zu sein, diesen Tod zu verzeihen, und wieder die Rache in den Vordergrund gestellt zu haben. ${ }^{66}$

Vermutlich ist im Neuen Testament die Absage an jede Rache und die Aufforderung zur Feindesliebe am deutlichsten innerhalb der abrahamitischen Tradition ausgesprochen. Aber auch Judentum und Islam lassen wichtige Anhaltspunkte erkennen, die es zu betonen und vielleicht auch noch auszubauen gilt. Wir haben als wichtiges Beispiel für die abrahamitische Revolution auf die biblische Josefsgeschichte verwiesen. In ihr finden wir aber nicht nur eine Absage an die mythische Sündenbock-Kultur mit ihren vergöttlichten Opfern. Deutlich ist auch der Gedanke der Vergebung erkennbar. Im Anschluss an jene Worte, mit denen Josef das Ansinnen seiner Familie zurückweist, ihn zu einem Gott zu erheben, verzeiht er seinen Brüdern. ${ }^{67}$ Er wird ihnen ihr Vergehen nicht vergelten, sondern umgekehrt sogar für sie sorgen: „Ihr habt Böses gegen mich im Sinne gehabt, Gott aber hatte dabei Gutes im Sinn, um zu erreichen, was heute geschieht: viel Volk am Leben zu erhalten. Nun also fürchtet euch nicht! Ich will für euch und eure Kinder sorgen. So tröstete er sie und redete ihnen freundlich zu." (Gen 50.20-21) Diese Schriftstelle mit ihrer deutlichen Parallele zur Vergebungsbereitschaft Christi steht keineswegs allein im Alten Testament. Für den jüdischen Konfliktforscher Marc Gopin ist es beispielsweise sehr wichtig, alle jene Feindvorstellungen zu überwinden, die den Feind als Inkarnation des Bösen verstehen. ${ }^{68}$ In Ex 23.5 ${ }^{69}$ und Spr 25.21$21^{70}$ sieht er wichtige Schriftstellen im Alten Testament, die zu einer Humanisierung von Feindschaft beitragen können.

Auch im Islam finden sich wichtige Anhaltspunkte, die in Richtung Vergebung weisen. Der Koran betont wie das Alte Testament

66 Nietzsche (1988b), 213 (Nr. 40).

67 Williams (1994), 82.

68 Gopin (2002), 41-42, 78-79.

69 „Wenn du siehst, wie der Esel deines Gegners unter der Last zusammenbricht, dann laß ihn nicht im Stich, sondern leiste ihm Hilfe!“

70 „Hat dein Feind Hunger, gib ihm zu essen, hat er Durst, gib ihm zu trinken; so sammelst du glühende Kohlen auf sein Haupt, und der Herr wird es dir vergelten.“ 
die Vergebung, die Josef seinen Brüdern gegenüber gewährte: „Er sagte: ,Keine Schelte soll heute über euch kommen. Gott vergibt euch, Er ist ja der Barmherzigste der Barmherzigen."“ (12.92) So wie Gott ganz generell im Koran als „Barmherziger“ oder „Allerbarmer" verstanden wird, sind auch die Gläubigen dazu aufgefordert, bloße Vergeltung zu überschreiten und das Böse mit dem Guten zu bekämpfen. Mohamed Fathi Osman fasst mehrere Verse des Korans zusammen, die diese Botschaft der Vergebung zum Inhalt haben: ${ }^{71}$ 42.40-43, 16.126, 60.7, 4.34-35. Die erste dieser Stellen möchte ich ausdrücklich zitieren: „Eine schlechte Tat soll mit etwas gleich Bösem vergolten werden. Wer aber verzeiht und Besserung schafft, dessen Lohn obliegt Gott." (42.40) Diese im Koran sichtbare Vergebungsbereitschaft spiegelt sich auch hier im Leben des Propheten Mohammed selbst. Ähnlich wie Josef seinen Brüdern vergab, verzieh auch der Prophet seiner Sippe, als er später seine Vaterstadt zurückeroberte. ${ }^{72}$ Die Tatsache allerdings, dass Mohammed nicht nur Prophet, sondern auch Herrscher und Kriegsherr war, erschwert es dem Islam, Gewaltfreiheit, Feindesliebe und Vergebung ins Zentrum seiner Aufmerksamkeit zu rücken. Doch sogar in dieser Richtung lassen sich wichtige Hinweise entdecken, die es besonders in unserer Zeit zu stärken gilt. Ein Friedens-Hadith hält z.B. ausdrücklich fest, dass auf Mohammeds Schwertgriff die Aufforderung zur Vergebung gegenüber den Feinden eingeschrieben war: "Forgive him who wrongs you; join him who cuts you off; do good to him who does evil to you, and speak the truth although it be against yourself.' 73

Gerade in unserer Zeit der klagereligiösen Versuchung ist es wichtig, in allen religiösen Traditionen die Bereitschaft zur Vergebung und zur Feindesliebe zu stärken. Christen sind hier besonders zum vorbildhaften Vorangehen aufgefordert. Aber nicht nur die Religionen müssen heute die Bereitschaft zur Vergebung in den Mittelpunkt ihrer Verkündigung stellen, die Notwendigkeit der Vergebung und der mit ihr verbundenen Überwindung der Vergeltung gilt ganz grundsätzlich. Charles Taylor hat darauf hingewiesen, dass wir heute gerade dann besonders leicht zu Gewalt greifen, wenn wir uns selbst für gut und absolut gerecht halten und damit in unseren Gegnern nur noch die Verkörperung des Bösen erkennen. Dieser Gefahr 
können wir nur begegnen, wenn wir auf alle Akte der Vergeltung verzichten und uns auch davor hüten, zu glauben, wir würden in völliger Unschuld die absolute Gerechtigkeit verkörpern. Im Anschluss an Dostojewskijs verstörende, aber dennoch wichtige Einsicht, dass wir uns immer auch unserer eigenen Schuld bewusst bleiben müssen, ${ }^{74}$ sieht Taylor gerade in der Anerkennung unserer Mitverantwortung einen gemeinsamen Boden, der es möglich machen sollte, dass wir die Wahrheit der Opfer anerkennen, ohne deshalb gleichzeitig der Versuchung zur Vergeltung nachzugeben. Neben Polens Rundem Tisch, Adam Michniks Appell zu Versöhnung statt Vergeltung und des Dalai Lamas Haltung gegenüber den chinesischen Unterdrückern verweist er vor allem auf das Beispiel von Nelson Mandela: „Seine politische Weisheit bestand darin, der Versuchung zu widerstehen, den naheliegenden Weg der Vergeltung zu wählen. Er hätte den Aufbau einer neuen, demokratischen Gesellschaft wohl unmöglich gemacht. Aus dieser Überlegung heraus haben viele politische Führer nach einem Bürgerkrieg Amnestie gewährt. Doch in diesem Falle ging es um mehr. Amnestie hat den Nachteil, dass sie gewöhnlich die Wahrheit über das begangene Unrecht weiterhin verdeckt hält, das dann unter der Oberfläche der Gesellschaft weiterarbeitet. Mandelas Weg bestand in der Einrichtung der Wahrheits- und Versöhnungskommission, deren Aufgabe es ist, Unrecht und Schrecken ans Licht zu bringen - auf beiden Seiten, bei den ehemaligen Unterdrückern und bei ihren Opfern -, doch nicht um der Vergeltung willen. "75 Ähnlich wie Taylor hatte schon Dietrich Bonhoeffer in seiner gegen Ende des Zweiten Weltkriegs verfassten Ethik an Dostojews-

74 Mit folgenden Worten warnt Staretz Sossima seine Mitbrüder im Kloster vor falschen Überlegenheitsgefühlen gegenüber der Welt außerhalb der Klostermauern: „Wisset, meine Lieben, daß jeder einzelne von uns gewiß Schuld trägt für alle und für alles auf Erden, nicht nur die uns allen gemeinsame Weltschuld, sondern ein jeder persönlich für alle Menschen und jeden einzelnen auf Erden.“ Dostojewskij (2003), 264. Die große amerikanische Pazifistin und Katholikin Dorothy Day (1897-1980) schickte im Februar 1942 ihren amerikanischen Friedensfreunden, die mit ihr gegen das amerikanische Kriegsengagement während des Zweiten Weltkrieges protestierten, diese Rede Sossimas, um ihnen klar zu machen, dass auch sie sich nicht heiliger als der Rest der Welt fühlen dürfen, sondern sich trotz ihres Engagements gegen den Krieg der eigenen Mitschuld bewusst bleiben müssen. Nur dadurch wäre der Pazifismus auch christlich gerechtfertigt: "I quote this because that accusation 'holier than thou' is also made against us. And we must all admit our guilt, our participation in the social order which has resulted in this monstrous crime of war." Day (1993), 266.

75 Taylor (2002), 71; vgl. Fraser (2001), 38-48. 
kij angeknüpft. ${ }^{76}$ Auch der protestantische Theologe erklärte, dass Christen nicht die Sünde abwiegen und aufrechnen, sondern alle Schuld auf sich nehmen und ihre eigenen Sünden als ,vergiftende Quelle“ erkennen sollen. „Ich kann mich nicht dabei beruhigen, daß mein Anteil nur ein verschwindend geringer sei, hier wird nicht gerechnet sondern ich muß erkennen, daß gerade meine Sünde an allem schuld ist." 77 Bonhoeffer weiß auch, dass nur die Gnade Christi eine solche Schulderkenntnis möglich macht. So bezeichnet er ausdrücklich die Kirche als jenen Ort, wo die Gnade eine solche Schulderkenntnis möglich macht: „Die Kirche ist [...] jene Gemeinschaft von Menschen, die durch die Gnade Christi zur Erkenntnis der Schuld an Christus geführt worden ist. [...] Wo es anders wäre, wäre die Kirche nicht mehr Kirche. " ${ }^{\text {"78 }}$ Wo sich die Kirche der Gnade Christi öffnet und so wie er alle Schuld auf sich nimmt, kann sie alles Moralisieren und alle Schuldabschiebung nach außen überwinden. Der Blick auf die Gnade Christi „befreit gänzlich vom Blick auf die Schuld der anderen und läßt den Menschen vor Christus in die Knie sinken mit dem Bekenntnis: mea culpa, mea culpa, mea maxima culpa." ${ }^{\circ 79}$

Dieser von Bonhoeffer und Taylor beschriebene Weg wurde auch schon in der katholischen Friedensethik angedacht. Die katholischen Bischöfe der USA haben 1983 in ihrem Friedenshirtenbrief ein neues Kriterium zu jenen Prinzipien hinzugefügt, die gemäß der Lehre vom gerechten Krieg die Gewalt eindämmen sollen. Dieses Prinzip der „,komparativen Gerechtigkeit“ richtet sich gegen die heute so dominante klagereligiöse Versuchung mit ihrer Tendenz, auf der eigenen Seite die ,absolute Gerechtigkeit“ verkörpert zu sehen und daraus die Berechtigung zum Kreuzzug abzuleiten: „In einem Konflikt sollte jede Seite die Grenzen des eigenen ,gerechten Grundes' anerkennen und die sich daraus ergebende Forderung, nur begrenzte Mittel zur Verfolgung ihrer Ziele einzusetzen. Weit davon

76 Im jüdischen Denken kann auf Emmanuel Levinas als Beispiel für einen Denker verwiesen werden, der ähnlich wie Bonhoeffer an Dostojewkij anknüpfte. Vgl. Donoghue (1996). Ein schönes Beispiel für die Einsicht in die eigene Schuldhaftigkeit findet sich auch im Koran und dessen Portrait des Josef: „Und ich erkläre mich nicht selbst für unschuldig. Die Seele gebietet ja mit Nachdruck das Böse, es sei denn, mein Herr erbarmt sich. Mein Herr ist voller Vergebung und barmherzig." (12.53).

77 Bonhoeffer (1998), 127-128; vgl. 82, 126.

78 Bonhoeffer (1998), 126.

79 Bonhoeffer (1998), 127. 
entfernt, eine Kreuzzugsmentalität zu legitimieren, soll komparative Gerechtigkeit absolute Ansprüche relativieren und die Anwendung von Gewalt selbst in einer ,gerechten' Auseinandersetzung eindämmen. “80 Der Verzicht auf die Überzeugung, selbst absolut gerecht zu sein, und der dadurch möglich gewordene Verzicht auf Vergeltung sind heute überlebensnotwendig geworden. Sie müssen zu starken Pfeilern einer Kultur der Vergebung werden, damit die Welt nicht in den Abgrund stürzt. Die Weltreligionen, insbesondere die Christen, sind aufgerufen, dazu einen maßgeblichen und nachhaltigen Beitrag zu leisten.

\section{Literatur}

Allam, Fouad (2002): Der Islam in einer globalen Welt. Berlin: Verlag Klaus Wagenbach.

Armstrong, Karen (1993): Mubammad. Religionsstifter und Staatsmann. München: Diederichs.

Bartlett, Anthony W. (2001): Cross Purposes: The Violent Grammar of Christian Atonement. Harrisburg: Trinity Press International.

Bartov, Omer (1998): „Defining Enemies, Making Victims: Germans, Jews, and the Holocaust", in: The American Historical Review 103 (3), 771-816.

Berman, Russell A. (1999): „From Brecht to Schleiermacher: Religion and Critical Theory", in: Telos 115, 36-48.

Bin-Ladin, Usama (2005): Messages to the World: The Statements of Osama bin Laden. London: Verso.

Bonhoeffer, Dietrich (21998): Ethik. München: Chr. Kaiser.

Bonney, Richard (2007): Jibad: From Qur'an to bin Laden. New York: Palgrave Macmillan.

Brecht, Bertolt (1939): „Die Kommunisten und die deutschen Religionskämpfe“, in: Schriften 2 [1933 - 1942]. Teil 2. Frankfurt/M.: Suhrkamp.

Brumlik, Micha (1998): „Die Aufhebung des Menschenopfers in der Isaakund Iphigenieerzählung“", in: Neuhaus, Dietrich, Hg.: Das Opfer. Religionsgeschichtliche, theologische und politische Aspekte. Frankfurt/M.: Haag + Herrchen Verlag, 51-65.

Canetti, Elias (1960): Masse und Macht. München: Carl Hanser Verlag.

Day, Dorothy (21993): Selected Writings. Maryknoll, NY: Orbis Books.

Donoghue, Denis (1996): „The Philosopher of Selfless Love“, in: The New York Review of Books 43 (5), 37-40.

Dostojewskij, Fjodor M. (2003): Die Brüder Karamasow. Zürich: Ammann Verlag.

80 Katholische Bischofskonferenz der USA (1983), 178 (Nr. 93). 
Durkheim, Émile (1986): „Der Individualismus und die Intellektuellen“, in: Bertram, Hans, Hg.: Gesellschaftlicher Zwang und moralische Autonomie. Frankfurt/M.: Suhrkamp, 54-70.

Fraser, Giles (2001): Christianity and Violence: Girard, Nietzsche, Anselm and Tutu. London: Darton, Longman \& Todd.

Gauß, Karl-Markus (1995): „Der Mythos vom Amselfeld“, in: Krüger, Michael, Hg.: Einladung zur Verwandlung. Essays zu Elias Canettis „Masse und Macbt". München: Carl Hanser Verlag, 512-522.

Girard, René (1978): „To double business bound“: Essays on Literature, Mimesis, and Anthropology. Baltimore: The Johns Hopkins University Press.

Girard, René (1988): Der Sündenbock. Zürich: Benziger.

Girard, René (1990): Hiob - ein Weg aus der Gewalt. Zürich: Benziger.

Girard, René (1995): „Mimetische Theorie und Theologie“, in: Palaver, Wolfgang/Niewiadomski, Józef, Hg.: Vom Fluch und Segen der Sündenböcke. Raymund Schwager zum 60. Geburtstag. Thaur: Kulturverlag, 15-29.

Girard, René (1997): Wenn all das beginnt ... Dialog mit Michel Treguer. Münster: LIT.

Girard, René (2002): Ich sab den Satan vom Himmel fallen wie einen Blitz: Eine kritische Apologie des Christentums. München: Carl Hanser Verlag.

Girard, René (2004): „Violence and Religion: Cause or Effect?“, in: The Hedgehog Review 6 (1): 8-20.

Girard, René (2005): Die verkannte Stimme des Realen. Eine Theorie archaischer und moderner Mythen. München: Carl Hanser Verlag.

Girard, René/Doran, Robert (2008): „Apocalyptic Thinking after 9/11: An Interview", in: Substance: A Review of Theory \& Literary Criticism 37 (1): 20-32.

Gopin, Marc (2002): Between Eden and Armageddon: The Future of World Religions, Violence, and Peacemaking. Oxford: Oxford University Press.

Graham, E. Tyler (2007): „The Danger of Durkheim: Ambiguity in the Theory of Social Effervescence“, in: Religion 37 (1): 26-38.

Heer, Friedrich (1989): Der Glaube des Adolf Hitler. Anatomie einer politischen Religiosität. Frankfurt/M.: Ullstein.

Hoffman, Bruce (2001): Terrorismus - der unerklärte Krieg. Neue Gefahren politischer Gewalt. Frankfurt/M.: Fischer Taschenbuch Verlag.

Hume, David (1984): Die Naturgeschichte der Religion. Über Aberglauben und Schwärmerei. Über die Unsterblichkeit der Seele. Über Selbstmord. Hamburg: Felix Meiner Verlag.

Illich, Ivan/Cayley, David (2006): In den Flüssen nördlich der Zukunft. Letətete Gespräche über Religion und Gesellschaft mit David Cayley. München: Beck.

Juergensmeyer, Mark (2001): Terror in the Mind of God: The Global Rise of Religious Violence. Berkeley: University of California Press.

Katholische Bischofskonferenz der USA (1983): „Die Herausforderung des Friedens - Gottes Verheißung und unsere Antwort. Pastoralbrief der 
Katholischen Bischofskonferenz der USA über Krieg und Frieden“, in: Hirtenworte ₹u Krieg und Frieden. Köln: Kiepenheuer \& Witsch, 125-285. Kepel, Gilles/Milelli, Jean-Pierre, Hg. (2006): Al-Qaida. Texte des Terrors. München: Piper.

Kermani, Navid (32006): Dynamit des Geistes. Martyrium, Islam und Nibilismus.

Göttingen: Wallstein Verlag.

Lasch, Christopher (1991): „Liberalism and Civic Virtue“, in: Telos 88: 57-68. Lings, Martin (2006): Muhammad: His Life Based on the Earliest Sources. Rochester, VT.: Inner Traditions.

Mak, Geert (2005): Der Mord an Theo van Gogh. Geschichte einer moralischen Panik. Frankfurt/M.: Suhrkamp.

Mann, Thomas (1996): Essays. Band 5: Deutschland und die Deutschen 19381945. Frankfurt/M.: Fischer Taschenbuch Verlag.

Mayer, Reinhold, Hg. (1986): Der Talmud. München: Goldmann Verlag.

Mehdi, Syed Sikander (1992): „Islam and Nonviolence“, in: Gandhi Marg 14 (1): 116-140.

Mühlmann, Wilhelm E. (1964): Rassen, Ethnien, Kulturen. Moderne Ethnologie. Neuwied: Luchterhand.

Nietzsche, Friedrich (1988a): „Zur Genealogie der Moral“, in: Colli, Giorgio/Montinari, Mazzino, Hg.: Sämtliche Werke. Kritische Studienausgabe in 15 Einzelbänden. Band 5. München: Deutscher Taschenbuch Verlag, 245-412.

Nietzsche, Friedrich (1988b): „Der Antichrist. Fluch auf das Christentum“, in: Colli, Giorgio/Montinari, Mazzino, Hg.: Sämtliche Werke. Kritische Studienausgabe in 15 Einzelbänden. Band 6. München: Deutscher Taschenbuch Verlag, 165-254.

Nietzsche, Friedrich (1988c): „Nachgelassene Fragmente 1887-1889“, in: Colli, Giorgio/Montinari, Mazzino, Hg.: Sämtliche Werke. Kritische Studienausgabe in 15 Einzelbänden. Band 13. München: Deutscher Taschenbuch Verlag.

Orwell, George (2000): „Review of Mein Kampf by Adolf Hitler“, in: Orwell, Sonia/Angus, Ian, Hg.: George Orwell: The Collected Essays, Journalism \& Letters. Vol. 2: My Country Right or Left, 1940-1943. Boston: D.R. Godine, 12-14.

Osman, Mohamed Fathi (2004): „God is the All-Peace, the All-Merciful“, in: Heft, James L., Hg.: Beyond Violence: Religious Sources for Social Transformation in Judaism, Christianity and Islam. Ashland: Fordham University Press, 57-73.

Palaver, Wolfgang (2004): René Girards mimetische Theorie. Im Kontext kulturtheoretischer und gesellschaftspolitischer Fragen. Münster: LIT.

Paxton, Robert O. (2006): Anatomie des Faschismus. München: Deutsche Verlags-Anstalt. 
Scheffler, Thomas (1997): „Vom Königsmord zum Attentat. Zur Kulturmorphologie des politischen Mordes“, in: Trotha, Trutz von, Hg.: Soziologie der Gewalt. Opladen: Westdeutscher Verlag, 182-199.

Schwager, Raymund (1990): Jesus im Heilsdrama. Entwurf einer biblischen Erlösungslehre. Innsbruck: Tyrolia.

Seung-Hui, Cho (2007): „Die Botschaft des Täters“, online unter: http:// www.orf.at $/ 070419-11404 /$ ?href $=\mathrm{http} \% 3 \mathrm{~A} \% 2 \mathrm{~F} \% 2 \mathrm{Fwww}$.orf.at $\% 2 \mathrm{~F} 0$ 70419-11404\%2F11408txt_story.html (Zugriff am 27.03.2008).

Tacitus, Cornelius (22001): Agricola. Germania. Lateinisch und deutsch. Düsseldorf: Artemis \& Winkler.

Taliqani, Mahmud/Mutahhari, Murtazá/Shariati, Ali (1986): Jihäd and Shahādat: Struggle and Martyrdom in Islam. North Haledon, NY: Islamic Publ. Int.

Taylor, Charles (2002): „Gewalt und Moderne“, in: Transit 23: 53-72.

Taylor, Charles (2004): „Notes on the Sources of Violence: Perennial and Modern", in: Heft, James L., Hg.: Beyond Violence: Religious Sources for Social Transformation in Judaism, Christianity and Islam. Ashland: Fordham University Press, 15-42.

Tönnies, Sybille (2002): Cosmopolis Now. Auf dem Weg zum Weltstaat. Hamburg: Europäische Verlagsanstalt.

Volkan, Vamik D. (1988): The Need to have Enemies and Allies: From Clinical Practice to International Relationships. Northvale, NJ: Jason Aronson Inc.

Vrcan, Srdjan (1995): „A Christian Confession Possessed by Nationalistic Paroxysm: The Case of Serbian Orthodoxy“, in: Religion 25 (4): $357-$ 370.

Waldmann, Peter (2003): Terrorismus und Bürgerkerieg. Der Staat in Bedrängnis. München: Gerling Akademie Verlag.

Weber, Max (51980): Wirtschaft und Gesellschaft. Grundriß der verstehenden Soziologie. Tübingen: J.C.B. Mohr (Paul Siebeck).

Weber, Max (81988): Gesammelte Aufsätze zur Religionssożiologie III. Tübingen: J.C.B. Mohr (Paul Siebeck).

Williams, James G. (1994): ,,Steadfast Love and Not Sacrifice': A Nonsacrificial Reading of the Hebrew Scriptures", in: Wallace, Mark I./Smith, Theophus H., Hg.: Curing Violence. Sonoma: Polebridge Press, 71-99.

Zweites Vatikanisches Konzil (141980): „Pastoralkonstitution ,Die Kirche in der Welt von heute“", in: Rahner, Karl/Vorgrimler, Herbert, Hg.: Kleines Konzilskompendium. Sämtliche Texte des Zweiten Vatikanums. Freiburg: Herderbücherei, 449-552. 


\title{
Religiöser Eifer und „reinigende“ Gewalt. Zur Dynamik kollektiver Passionen
}

\author{
Andreas Oberprantacher
}

\begin{abstract}
$D u$, Menschensobn, willst du richten, willst du die blutdürstige Stadt richten? So halte ibr alle Greuel vor und sprich: So spricht Gott, der Herr: O Stadt, die in ibrer Mitte Blut vergießt, damit ibre Zeit komme, und die bei sich selbst Götzen macht, damit sie sich verunreinige! Du hast dich mit Schuld beladen durch das Blut, das du vergossen hast, und hast dich verunreinigt durch deine selbstgemachten Götzen; du hast bewirkt, daß deine Tage berannaben, und bist zu deinen Jahren gekommen! ${ }^{1}$

Zusammen mit der Erniedrigung hat der Rubm, in bald finsteren, bald glänzenden Formen, immer die soziale Existen₹ beherrscht, und ohne ibn kann auch beute nichts unternommen werden, obwobl er von der blinden Praxis persönlicher oder sozialer Verluste bedingt ist . ${ }^{2}$
\end{abstract}

Einen Monat nach den Anschlägen des 11. September 2001 antwortete der britische Evolutionsbiologe Richard Dawkins der englischen Tageszeitung The Guardian auf die Frage „Has the world changed?“, dass Religion wohl doch kein „harmless nonsense“ sei, wie man in „aufgeklärten“ Kreisen lange vermutet habe. Vielmehr müsse man nun davon ausgehen, dass Religion „lethally dangerous nonsense“3 sei.

Trotz der offensichtlichen Simplifizierung, die Dawkins Polemik zugrunde liegt, ist seine Wortwahl bezeichnend. Sie gibt Aufschluss über eine Krise, die nicht allein die Politik fordert, sondern das Selbstverständnis der modernen Wissenschaft ebenso wie den Anspruch funktionalistischer Religionstheorien erfasst $\mathrm{zu}$ haben scheint und folgende Fragen aufwirft: Wie ist zu verstehen, dass religiöser Glauben, dessen Funktion doch eigentlich jene der „Kontingenzbewältigung“4 bzw. der „Stabilisierung des politischen Gemein-

1 Ez 22.2-4.

2 Bataille (1985), 30-31.

3 The Guardian (2001).

4 Wenn in religionswissenschaftlichen Diskursen von „Kontingenzbewältigung“ oder „Kontingenzbewältigungs-Praxis“ die Rede ist, dann ist damit nicht gemeint, dass der Mensch Erfahrungen von Alter, Krankheit, Tod durch Transformation seines Daseins „bewältigen“ kann. Hermann Lübbe zufolge, der sich kritisch zur funktionalistischen Religionstheorie verhält, bezeichnet „Kontingenzbewältigung“ in erster Linie eine kognitive Leistung, die das bekennende Subjekt erbringt und infolgedessen als „Anerkennung der Unverfügbarkeiten unseres Daseins“ ausgelegt werden kann. Siehe Lübbe (2004), 167. 
wesens ${ }^{65}$ sein müsste, eine unglaublich destruktive Wirkung entfalten kann, die sich gegen die politisch-soziale Ordnung der Moderne richtet? Wie kann es sein, dass Menschen, die sich auf ,spekulative" Theologien berufen, sich derart ereifern können, den Tod für sich und für andere zu verlangen? Kann Wissenschaft den ungeheuren Entschluss, das eigene wie das Leben anderer durch eine extreme Geste zu negieren, es zu ,verschwenden“, überhaupt verstehen?

\section{Religiös motivierte Todesbereitschaft als Herausforderung der Wissenschaft}

Tatsächlich gibt es gute Gründe zur Annahme, dass die wissenschaftliche Auseinandersetzung mit Formen des religiösen Fanatismus spätestens seit dem Einsatz von Selbstmordattentaten schwieriger ist und weiter reicht als Debatten über Anspruch und Gültigkeit der Säkularisierungsthese in den Sozialwissenschaften vermuten lassen. Während sich nämlich zeigt, dass die religionssoziologische Forschung im Anschluss an Thomas Luckmann, Rodney Stark und Williams Sims Bainbridge, Peter L. Berger und José Casanova sehr wohl in der Lage ist, die webersche Formel der „Entzauberung der Welt" in Anbetracht des verstärkten Interesses an Spiritualität in technisch avancierten Gesellschaften ${ }^{7}$ einer umfassenden Neuinterpretation $^{8} \mathrm{zu}$ unterziehen, verhält es sich mit dem Phänomen religiös motivierter Gewalt, die menschliches Leben fordert, anders.

Die Radikalität religiösen Eifers stellt insbesondere für funktionalistische Religionstheorien eine besondere Herausforderung dar, weil die Bereitschaft militanter konfessioneller Gruppen, für ihre eschatologischen Vorstellungen und politischen Visionen bis in den Tod zu gehen, der Vorstellung einer „Logik des Sozialen“" so sehr

5 Kaufmann (1989), 80.

6 Weber (1988), 94-95.

7 In seiner Studie zur Spiritualität in Amerika in der Nachkriegszeit weist der amerikanische Soziologe Robert Wuthnow u.a. darauf hin, dass das Interesse an Wundern und Mysterien in den USA seit den späten 1980er- und frühen 1990er-Jahren dramatisch angestiegen ist: Umfragen zufolge glauben drei von vier Amerikaner(inne)n an Engel; ,,spirit guides, channeling, encounters with angels, and near-death experiences moved from tabloid journalism into mainstream culture." Wuthnow (1998), 115.

8 Und zwar ohne dabei deren wichtigste Prämisse - nämlich jene, dass die funktionale Differenzierung moderner Gesellschaften einen Wandel religiöser Lebensformen bewirke - aufzugeben.

9 Vgl. dazu Heinrichs (2005). 
widerspricht, ${ }^{10}$ dass es absurd wäre, Selbstmordanschläge als Funktion gesellschaftlicher Transformationsprozesse zu deuten. Eher als ein symmetrisches Verhältnis besteht wohl eine subtile Komplizenschaft zwischen den sozialwissenschaftlichen Diskursen, die soziales Leben unter dem Vorzeichen von Rationalität, Reflexivität und Operationalisierbarkeit auslegen, und jenen kollektiven Passionen, die sich nicht am Maßstab des immanent Realisierbaren orientieren - eine Komplizenschaft, die unmöglich zugunsten der einen oder der anderen Position entschieden werden kann. Geboten wäre daher, die Möglichkeit einer wechselseitigen, aber irreduziblen Verschränkung von Leben und Tod, von Immanenz und Transzendenz, von Selbsterhaltung und Selbstopferung zu denken, die Wissenschaft und soziales Handeln gleichermaßen provoziert. ${ }^{11}$

\section{Religiöser Eifer, kollektive Passionen, „reinigende“ Gewalt}

Vor dem Hintergrund dieser Problemstellung soll eine Annäherung an ein Motiv unternommen werden, das konfessionsübergreifend ein wesentlicher Bestandteil des militanten religiösen Eifers zu sein scheint und Rückschlüsse auf die Dynamik kollektiver Passionen sowie auf das wissenschaftliche Selbstverständnis von Religionstheorien zulassen könnte: Das Motiv, dem sich dieser Beitrag widmet, ist das der ,,reinigenden“ Gewalt - einer Form von Gewalt, die von militanten Gruppen wiederholt „,angerufen“ wird, um nach ritueller „Säuberung“ und einer neuen politisch-sozialen Ordnung zu verlangen, die mit den Vorstellungen der „unreinen“ politischen Moderne radikal zu brechen meint.

Im Mittelpunkt der Lektüre werden zwei Gottes-Reden stehen, die sich in ihrer Radikalität klar von institutionell anerkannten sowie von theologisch legitimen Auslegungen abheben und daher weder Anspruch auf Repräsentativität erheben können noch zur Charakterisierung religiöser Praxis dienen sollen. Aufgrund ihrer Bedeutung

10 In seiner Kritik am herrschenden kausalwissenschaftlichen Funktionalismus hat Niklas Luhmann unmissverständlich hervorgehoben, dass ,den Sozialwissenschaften das klar geschnittene empirische Problem des Todes fehlt“, sodass „das Problem des Fortbestandes eines Systems ins Unbestimmte“ verschwimmt. Siehe Luhmann (2005), 23.

11 Diese wechselseitige Verschränkung wird von Derrida bereits 1994 in den Mittelpunkt seines Nachdenkens über Religion gerückt und als „neue Grausamkeif“ bezeichnet, da sie „fortgeschrittene, wissenschaftstechnische Berechenbarkeit mit einer reaktiven Rohheit" verbindet. Siehe Derrida (2001), 88. 
für die gegenwärtige Politisierung von religiösen Gemeinschaften und für die Verschärfung von internationalen Konflikten können sie allerdings dazu beitragen, die besondere Faszination und Dynamik in den Blick zu nehmen, die von Formen religiösen Fanatismus ausgehen kann.

Nach einigen allgemeinen Vorbemerkungen zum Forschungsbereich der sakralen Soziologie soll auf ausgewählte Passagen aus den Reden des kürzlich verstorbenen baptistischen Pastors und Fernsehpredigers Jerry Falwell eingegangen werden. Im Anschluss daran sollen Deklarationen untersucht werden, die von militanten islamistischen Gruppen ins Internet gestellt worden sind, um die eigene Mission einem breiten Publikum zugänglich zu machen, Verantwortung für durchgeführte Aktionen zu übernehmen, neue Aktionen anzukündigen oder neue Schuhada, potentielle Blutzeugen, anzuheuern. Insbesondere wird auf Aussendungen von und auf Gesprächsausschnitten mit Mitgliedern des Al-Qaida-Netzwerks und nahe stehender Organisationen zurückgegriffen, die im Vergleich zu den Ansprachen Falwells weniger gesellschaftliche Anerkennung genießen dürften, jedoch für die Radikalisierung religiösen Eifers und für eine bestimmte Vorstellung von ,reinigender“ Gewalt symptomatisch sind.

\section{Sakrale Soziologie}

Trotz der aktuellen Bezugsmöglichkeiten kann das Thema der „Reinheit“ bzw. der „,reinigenden“ Gewalt im Bereich der Religionswissenschaft wohl kaum als neu bezeichnet werden. Genau genommen bildet es eine der zentralen erkenntnistheoretischen Achsen der frühen Religionssoziologie zur Bestimmung der ambivalenten Struktur des Sakralen bzw. des Heiligen. Nicht erst Émile Durkheim in Die elementaren Formen des religiösen Lebens, bereits Robertson Smith in Die Religion der Semiten ist zu verdanken, ,die Zweideutigkeit des Begriffs des Heiligen ins Licht gerückt zu haben". ${ }^{12}$

Galt das religionssoziologische Interesse zu Beginn des 20. Jahrhunderts ganz der Frage, inwiefern es sich bei dem Begriffspaar „rein/unrein“ um eine spezifisch mosaische Unterscheidung handle oder um ein strukturbildendes Moment ,archaischen“ religiösen Le- 
bens, sah es das Collège de Sociologie, das von 1933 bis 1963 als wissenschaftliches Projekt um Georges Bataille, Michel Leiris, Roger Caillois u.a. bestand, als seine besondere Aufgabe an, die politischen Implikationen der Ambivalenz des Sakralen in der Moderne herauszuarbeiten. ${ }^{13}$ Wiewohl Bataille bereits in seiner Frühschrift, die unter dem Titel „Die psychologische Struktur des Faschismus“ zwischen November 1933 und März 1934 in der Zeitschrift La Critique Social erschienen ist, mit Blick auf die politischen Entwicklungen in Italien, Deutschland und Spanien eindringlich gemahnt hat, dass nicht Militärmacht „Quelle der sozialen Autorität"14 sei, sondern Formen „einer religiösen Attraktion", ${ }^{15}$ wurde diesem Aspekt und Forschungsbereich in der Religionssoziologie höchst selten Beachtung geschenkt. Bis auf wenige Ausnahmen, zu denen das Werk des französischen Kulturanthropologen und Religionswissenschaftler René Girard gehört, haben sich Vertreter(innen) der Religionssoziologie in der Nachkriegszeit gänzlich anderen Fragen zugewandt als jener, ob es eine spezifische Dynamik kollektiver Passionen gibt, die mit Vorstellungen von Reinheit und Unreinheit arbeitet.

Berücksichtigt man allerdings den Umstand, dass sich die sakrale Soziologie in den 30er-Jahren des vergangenen Jahrhunderts unter dem Vorzeichen schwerwiegender politischer und sozialer Krisen entwickelt hat, wäre vorstellbar, dass diesem Forschungsbereich in nächster Zukunft verstärkt Aufmerksamkeit geschenkt werden wird. ${ }^{16}$ Einige Fragen und Forschungsperspektiven sollen unter Berücksichtigung von zwei aktuellen Bezugspunkten in diesem Beitrag vorab umrissen werden.

13 Vgl. dazu die außerordentlich genaue und lesenswerte Rekonstruktion der Religionstheorie des Collège de Sociologie von Marroquín (2005), 92-98.

14 Bataille (1997), 31.

15 Bataille (1997), 31.

16 Marroquín zufolge gibt es bereits erste Anzeichen, die in die Richtung eines erneuten Interesses an den Themen der sakralen Soziologie und an dem Collège de Sociologie verweisen. Nicht allein das Werk von Giorgio Agamben nimmt Spuren von Bataille auf, auch Forscher(innen)gruppen wie jene um das Collegio di Filosofia Sociale in Neapel und Rom haben zu einer „Wendung in der Forschung“ beigetragen. Siehe Marroquín (2005), 92. Zu erwähnen sind auch die Beiträge von Meddeb (2006) und Friedland (2004). 


\section{„Fundmentalistische“ Lektüren: Buchstabentreue oder diskursive Praxis?}

Der Name Falwell steht für die politisch erfolgreiche Strategie, über diverse pressure groups, insbesondere über die Bewegung Moral Majority, die von 1979 bis 1989 als größte konservative, aber konfessionsübergreifende Organisation bestanden hat, ${ }^{17}$ einen nachhaltigen Einfluss auf Institutionen und auf die öffentliche Meinung der USA zu nehmen. Deklariertes Ziel der Bewegung Moral Majority war, „a united front in the fight against wickedness" ${ }^{\text {"18 }} \mathrm{zu}$ bilden und Amerikaner(innen) an ihren Abfall vom moralisch rechten Weg zu erinnern. Falwells theologisch-politische Reden, die in den USA bis zu seinem Tod im Mai 2007 auf breite Zustimmung gestoßen sind, fordern von den Gläubigen „theological purity"19 und entzünden sich wiederholt an Vorstellungen, dass die Mehrheitsgesellschaft ,,wicked ways" 20 eingeschlagen habe.

Entgegen der Annahme, der man häufig in der religionswissenschaftlichen Fachliteratur zum Phänomen „Fundamentalismus“ begegnet, soll hier allerdings nicht die buchstabentreue Auslegung von offenbarten Texten für die Radikalität, das Charisma und die Militanz fanatischer evangelikaler Bewegungen verantwortlich gemacht werden. In seinem Beitrag mit dem Titel „Fundamentalism and Politics“ für das mehrbändige The Fundamentalism Project spricht John H. Garvey etwa von einer symptomatischen Insistenz, die seiner Meinung nach ein charakteristisches Merkmal dieser Bewegungen ist: "The symptom [...] is an emphasis on literalism in the interpretation of sacred texts. The insistence upon biblical literalism and inerrancy may be the most frequently remarked trait of American Protestant fundamentalists." 21 Eine solche Ausgangnahme greift nicht allein aus religionswissenschaftlicher Perspektive zu kurz, ${ }^{22}$ sie ist auch deshalb irreführend, weil sie suggeriert, dass es gar so etwas wie eine buchstäbliche Lektüre geben kann - als ob die einzelnen Wörter eine jeweils

17 Vgl. Liebman (1983), 54. Dies wurde Falwell von vielen anderen Predigern der religiösen Rechten wiederholt zum Vorwurf gemacht. Bob Jones III. ging sogar so weit, zu behaupten, dieses politisch-religiöse Projekt sei ,one of Satan's devices to build the world church of Antichrist.“ Zitiert nach Alitt (2003), 153.

18 Strober/Tomczak (1979), 173.

19 Falwell (1987), 361.

20 Falwell (1980), 243.

21 Garvey (1993), 15; siehe auch: Dollar (1973), XV.

22 Hood et al. (2005), 169. 
eigene, eine ursprüngliche und intime Bedeutung umschlössen, die erst im erweiterten Zusammenhang mehrdeutig wird und so einer historisch-kritischen interpretierenden Leistung bedarf.

Wie von Ferdinand de Saussure in Grundfragen der allgemeinen Sprachwissenschaft ausgearbeitet wurde, weisen aber weder Wörter noch einzelne Zeichen eine positive, d.h. in ihnen selbst begründete Bedeutung auf, denn „das Band, welches das Bezeichnete mit der Bezeichnung verknüpft, ist“, wie Saussure meint, „beliebig“. ${ }^{23}$ Auch wenn diese Beliebigkeit, im Französischen ist von l'arbitraire du signe die Rede, nicht mit Willkür oder Zufall verwechselt werden darf, bedeutet dies doch, dass keine ursprüngliche Eindeutigkeit angenommen werden darf, die erst mit Zunahme semantischer Komplexität mehrdeutig wird. Gelesen wird stets in einem semiotisch-semantischen Prozess, der sich an Interessen und Machtverhältnissen bricht und erst durch spezifische diskursive Praktiken Wirkung entfaltet.

Nimmt man diesen Einwand aus dem Bereich der strukturalistischen Linguistik ernst, so kann das nichts anderes bedeuten, als dass es sich bei der buchstäblichen Lektüre, die den evangelikalen wie islamistischen „Fundamentalismen“ zum Vorwurf gemacht wird, nicht um einen „Verstoß“ gegen die Prinzipien und Standards des interpretierenden Lesens handeln kann. Wohl eher ist anzunehmen, dass die Buchstabentreue eine Form der Interpretation ist, die sich an spezifischen politisch-religiösen Erwartungen ausrichtet - Falwell stützt seine Überlegungen auf die „reinigende“ Gewalt Gottes und auf die in Kürze erfolgende Wiederkunft von Jesus ${ }^{24}$-, eine besondere Auswahl von Passagen trifft - für seine Reden wählt Falwell vor allem Passagen aus den Büchern Nehemiah und Jeremiab ${ }^{25}$ - und sich bestimmter diskursiver Strategien bedient, um die Relevanz und „Wahrheit“" seiner Lektüre abzusichern ${ }^{26}$ - Katastrophen und politi-

23 Saussure (2001), 79.

24 Wie für viele andere radikale Evangelikale auch bedeutet die Gründung des Staates Israel für Falwell ,the single greatest sign indicating the imminent return of Jesus Christ.“ Zitiert nach Boyer (1999), 189.

25 Siehe Friend Harding (2000), 157-162.

26 Falwell selbst erzählt davon, dass das „richtige“ Lesen der Schrift das Erlernen einer eigenen diskursiven Praxis erfordert: „We memorized the five or six Scriptures that outlined the simple plan of salvation. [...] We practiced reading and quoting them to each other. [...] We turned back and forth between the verses until the pages almost fell into place and the passages leapt out at us. We paired into teams with one member pretending to know nothing of the faith and the other acting as the evangelist-teacher." Falwell (1987), 120. 
sche Ereignisse dienen Falwell als Beleg für die Stichhaltigkeit seiner theologischen Überlegungen; Reden, Bücher, Bibelstunden, Ferienlager für Kinder, TV-Shows etc. dienen deren Popularisierung.

\section{Semantisches Risiko}

Wenn es allerdings nicht die buchstäbliche Auslegung ist, die Falwells eifernden Gottes-Reden Suggestivkraft verleiht und für eine besondere Form der Radikalisierung verantwortlich ist, was ist es dann?

Wie Susan Friend Harding in ihrem Buch The Book of Jerry Falwell. Fundamentalist Language and Politics zu bedenken gibt, ist für die ekstatischen Predigten Falwells nicht das Motiv einer unverzerrten, texttreuen, mithin eindeutigen Auslegung von Bibelstellen ausschlaggebend, sondern ein semantisches Risiko, das in ein Feld von moralischen, biografischen, theologischen und politischen Ambivalenzen eingebettet wird. Mit Blick auf die Rituale der „born-again Christianity" 27 und auf die Erweckungswunder, die zentraler Bestandteil von Falwells Strategie waren, um die Gemeinde an sich zu binden, meint Friend Harding: "What counts as a miracle or a sign of election in these apostolic story cycles varies, but one thing all miracles have in common is semantic risk or ambiguity, some sort of excess or gap that demands interpretative attention and engagement, choices which place one inside or outside the faith at hand."28

Tatsächlich bieten die Reden von Falwell ebenso wie jene von anderen radikalen Baptisten und Fernsehpredigern wie Jimmy Swaggart, Jim und Tammy Faye Bakker oder Pat Robertson den Gläubigen und jenen, die gläubig werden sollen, keine Zuversicht im Namen Gottes. Der versammelten Gemeinde wird nicht die Frobe Botschaft verkündet, sondern das Bild einer lasterhaften und sündigen Welt, die Falwell in seiner Autobiografie Strength for the Journey mit folgenden Worten skizziert: "The modern list of sins grows longer with each night's evening news: rape, incest, child molestation, corporate theft, political perjury, arson, kidnap, drug dealing and drug abuse, divorce and violence in our homes, robbery and murder on the streets, terrorism and all-out bloody warfare between races and 
nations." 29 Die versammelte Gemeinde wird als verlorene und als potentiell verdammte angesprochen; und ihr wird ein Zugang zum herrlichen Reich Gottes in Aussicht gestellt, den sie nur durch ein äußerstes Wagnis gewinnen kann, durch die Bereitschaft, den Tod im Leben rituell zu vollziehen ${ }^{30}$ und ein neues Leben als wieder geborene(r) Christ(in) zu führen. Dieser Zugang allerdings unterliegt der Kontrolle einer charismatischen Führerpersönlichkeit, sodass sich die Gläubigen veranlasst sehen, ihr (bisheriges und zukünftiges) Leben in einem äußersten Wagnis in die Hände einer religiösen Autorität zu legen, die Einheit und Erfolg des Ritus garantieren soll.

Evangelikal eifernde Reden von Gott, wie sie für Falwell charakteristisch waren, werden somit in einem Feld von Ambiguitäten aufgespannt, das Risiko und Sicherheit auf strategische Weise miteinander verbindet. ${ }^{31}$ Der theologische Diskurs changiert zwischen den Extremen eines liederlichen und ausschweifenden Lebens, das in allen Details ausgemalt und vorausgesetzt wird, einerseits und einem Leben in gottgefälliger Sittlichkeit und apokalyptischer Erwartungshaltung andererseits. Im Rahmen einer solchen religiösen Strategie ist der Name Gottes jedenfalls nur dann aussprechbar, wenn er sich auf das „Unreine“ beziehen lässt, dem er gerade im Akt der rituellen „Reinigung“ notwendig verpflichtet bleibt.

\section{"Washed in the blood of Christ"}

Wenn Falwell sein Wort gegen die Metropolitan Community Churches richtet, in der vornehmlich lesbische und schwule Gläubige zusammenfinden, und in diesem Zusammenhang deren Zerstörung folgendermaßen ankündigt: "[T]hank God this vile and satanic system will one day be utterly annihilated and there'll be a celebration in heaven;"32 oder wenn er am 13. September 2001 in der Fernsehsen-

29 Falwell (1987), 6.

30 Friend Harding weist darauf hin, dass in diesen born-again-Veranstaltungen unterschiedliche rituelle Praktiken und psychologische Techniken zum Einsatz kommen, die ,social exclusion, dramatic enactments, bodily markings, physical stress or pain, fasting, interrogation, chanting, silence, immobility, and so on" umfassen, um eine neue kollektive Passion zu gewährleisten, die sich durch den Versuch, das „Unreine“ abzusondern, auszeichnet. Siehe Friend Harding (2000), 35.

31 Die zweistelligen Relationen Gott/Satan, gerettet/verdammt, abscheulich/rein sind die wichtigsten, aber nicht die einzigen Aspekte dieser Polarisierung.

32 Zitiert nach Linn (2004), 48. 
dung The 700 Club, die von seinem Freund und Mitstreiter Pat Robertson geleitet wird, den terroristischen Anschlag, der zwei Tage zuvor stattgefunden hat, mit den Worten kommentiert: "The abortionists have got to bear some burden for this because God will not be mocked. And when we destroy 40 million little innocent babies, we make God mad. I really believe that the pagans, and the abortionists, and the feminists, and the gays and lesbians who are actively trying to make that an alternative lifestyle, the ACLU, People for the American Way - all of them who have tried to secularize AmericaI point the finger in their face and say, 'You helped this happen", 33 dann zeichnet sich in diesen Kommentaren eine extreme Anspannung ab, die sich für die versammelten Personen kognitiv nicht auflösen lässt: Einerseits wird den Zuhörer(inne)n ein abscheuliches und „satanisches“ System der Lust und des Fleisches vor Augen geführt, ein System, dem sie selbst zugerechnet werden, andererseits wird ihnen eine triumphale Feier im Himmel angekündigt, an der sie sich beteiligen könnten - sofern sie sich den Wiedergeburtritualen hingeben.

Im Moment dieser äußersten Anspannung, die zugleich eine Verdichtung jener Anspannungen ist, die sich durch die Biografien von Swaggert, den Bakkers, von Robertson und insbesondere von Falwell ziehen, ${ }^{34}$ wird eine Entscheidung abverlangt, die als das Ende der semantischen und moralischen Zweideutigkeiten sowie der eigenen Zerrissenheit gepriesen wird. Durch die Einstimmung in den Chor der wiedergeborenen Christ(inn)en, durch die Erneuerung des ewigen Bundes (covenant) im Sinne der apokalyptischen Erwartung, dass der jüdische Antichrist ${ }^{5}$ kommen und dass das Reich Gottes wiederhergestellt werde, sollen sämtliche Klüfte, die die amerikanische Gesellschaft ebenso wie die Persönlichkeitsstruktur der anwesenden Gläubigen durchziehen, geschlossen und die absolute Einheit von Glaube und Praxis, von Kirche und Welt, von Öffentlichem und Privatem hergestellt werden. Friend Harding schreibt dazu: "It is a kind of inner rite of passage that is completed when sinners are saved, or born-again, regenerated, washed in the blood of Christ. Sal-

33 Zitiert nach Lincoln (2003), 108.

34 Falwells Vater war Atheist und Schmuggler und hat vermutlich seinen eigenen Bruder erschossen, bevor er sich selbst mit Alkohol zugrunde richtete. Vgl. Friend Harding (2000), 88.

35 Gow (1999). 
vation is experienced as a release from the bondage of sin and personal reconciliation with God. A new self, or the spiritual man, emerges and the supernatural imagination is cut loose as the newborn Christian accepts the meaning of the gospel and begins to speak the language of Christ." 36

Entscheidend ist, dass die rituelle Heilung nur dann ihren Zweck erfüllt, wenn sie relativ ist zu einem Rest an „Unreinem“, an wickedness, der nicht versöhnt werden darf. Denn nur solange eine radikale Polarität aufrechterhalten werden kann, nur solange es ein externalisiertes und identifizierbares Schattenbild gibt, einen „unreinen" Feind, der bekämpft werden muss, macht es Sinn, von Gott als Garanten eines „geheiligten Daseins“ zu sprechen. In diesem Sinne ist es auch kein Zufall, dass die Zunahme des Einflusses von radikalen evangelikalen Sekten eben nicht zu einer Deeskalation von sozialen Konflikten beigetragen hat, sondern genau zum Gegenteil, zu einer radikalen Eskalation, auf nationaler wie auf internationaler Ebene.

\section{Unheilige Allianz}

Als der Vorbeter Maulana Abdul Aziz am 14. September 2001 in einer Moschee in Islamabad vor versammelter Menge verkündete, dass Allah das Feuer und die Zerstörungskraft der beiden Flugzeuge verstärkt habe, um das World Trade Center zum Einsturz zu bringen, ${ }^{37}$ und als Osama bin Laden in einem Video, das am 7. Oktober 2001 von al-Jazeera ausgestrahlt wurde, das Ereignis mit den Worten "God is giving Americans what they deserve" 38 kommentierte, wurde ersichtlich, dass zwischen der Diktion der militanten christlichen und der militanten islamischen Bewegungen kein wesentlicher Unterschied besteht, wohl eher kann eine unterschwellige Allianz, zumindest eine „odd similarity“,39 wie Lee Griffith meint, angenommen werden. Eine Allianz, die sich auch darin andeutet, dass Falwell seinem Verbündeten Robertson gegenüber und in erstaunlicher Analogie zu Osama bin Ladens Kommentar meinte: "God continues to 
lift the curtain and allow the enemies of America to give us probably what we deserve." 40

Es besteht daher der dringende Verdacht, dass die Botschaften militanter islamistischer Bewegungen, die entweder ins Netz gestellt oder über die Fernsehsender al-Jazeera und al-Arabiya ausgestrahlt werden, nicht einfach eine Negation des „westlichen Lebensstils" und der amerikanisch-europäischen Nahost-Politik zum Ausdruck bringen - auch wenn das ihr deklariertes Ziel ist. ${ }^{41}$ Ihre politische und charismatische Legitimation erlangen diese Bewegungen primär nicht durch eine antithetische Haltung, sondern indem sie ihre Adressaten als vom amerikanisch-europäischen Imperialismus Gekeränkte, als Schwache, als Opfer ansprechen, als einen im Rahmen der ökonomischen Globalisierung nicht nutzbaren, nicht repräsentierbaren „Rest“. Dieser nicht repräsentierbare „Rest“ wird in der Rede eines eifernden und rächenden Gottes gesammelt, homogen verdichtet und einer Form „reinigender" Gewalt unterstellt, deren hauptsächliche Aufgabe darin besteht, einer kollektiven Passion gegen alles „Unreine“ Ausdruck zu verleihen.

Wenn die World Islamic Front in ihrem Statement Jihad Against Jews and Crusaders ${ }^{42}$ vom 23. Februar 1998 erlittene Demütigungen zum Ausgangspunkt des Kampfes gegen die „Gottlosen“ wählt und sich dabei auf die Sure $4.75^{43}$ beruft, um „Ausgestoßene“ anzusprechen und nach einem religiösen Führer zu rufen, folgt sie darin der Logik, die auch für den religiösen Eifer Falwells charakteristisch ist: Die eifernde Rede von Gott gründet sich auf eine besondere Bindung und Konzentration jener Kräfte, die die Grenze des dominanten sozialen Gefüges darstellen; sie richtet sich an Personen, die in ihrer Loslösung vom Bereich der ökonomischen Produktion absolute Bereitschaft zeigen sollen, im Namen Gottes, im Namen einer absoluten, einer „reinigenden“ Gewalt, ein neues Leben anzunehmen und - im Extremfall - sich und anderen den Tod zu geben.

40 Zitiert nach Lincoln (2003), 106.

41 Etwa in A Declaration of Jihad against the Americans Occupying the Land of the Two Holy Sanctuaries, in der sich Osama bin Laden gegen die „,blatant imperial arrogance of America, under the cover of the immoral United Nations" richtet. Zitiert nach Lawrence (2005), 25.

42 Lawrence (2005), 58-64.

43 "Why should you not fight in God's cause and for those oppressed men, women, and children who cry out: 'Lord, rescue us from this town whose people are oppressors! By your grace, give us a protector and a helper!'” Qu'ran 4.75, zitiert nach Lawrence (2005), 61. 


\section{Faszination des Heterogenen}

Der scheinbar „selbstlose“ und unerschrockene Einsatz des eigenen Lebens, der in den Abschiedsvideos von „Märtyrern“ inszeniert wird, ${ }^{44}$ die Bereitschaft, sich selbst und andere für den eigenen Glauben, im Namen Gottes in die Luft zu sprengen, lässt sich jedenfalls nicht ausschließlich darauf zurückführen, dass diesen Menschen eigentlich gar keine anderen Mittel zur Verfügung stehen, um sich gegen die fremde Besatzung zur Wehr zu setzen, ${ }^{45}$ oder darauf, dass sie ideologisch geblendet sind. ${ }^{46}$ Ideologie, Traumatisierung ${ }^{47}$, ethnisch begründete Solidarität und Mangel an militärischen Alternativen spielen sicher eine Rolle in diesem Zirkel der Gewalt und Gegengewalt. Angesichts eines militärisch-industriellen Komplexes, dessen produktive Logik es verbietet, das Leben der eigenen Soldatinnen und Soldaten $\mathrm{zu}$ riskieren, ${ }^{48}$ bezieht das religiös motivierte Selbstmordattentat seine besondere Faszination wohl aber auch von woanders.

Ein entscheidender Hinweis auf weitere Quellen mag der eingangs erwähnten Schrift Die psychologische Struktur des Faschismus entnommen werden, in der Bataille sich mit der ambivalenten Struktur souveräner Gewalt beschäftigt und ausführt, dass sich technisch avancierte Gesellschaften, die der kapitalistischen Produktion verpflichtet sind, notwendigerweise auf einen Ausschluss unnützer und nicht assimilierbarer Elemente gründen, dem Heterogenen. Für unsere

44 Siehe das Kapitel „Who becomes a Suicide Terrorist?“ in Pedahzur (2005), 118-154. Pedahzur gibt die Geschichte von Ghandour wieder, der am 25. April 1995 trotz der ablehnenden Haltung der Hisbollah einen Selbstmordanschlag gegen das israelische Militär verübt hat, um endlich einen ehrenhaften Tod als shabid zu sterben. Siehe Pedahzur (2005), 127.

45 Vgl. Ahmed (2005), 87-102.

46 Obwohl Pedahzur auch persönliche Krisen als Motiv anführt, argumentiert er hauptsächlich mit dem Aspekt der Ideologie. Pedahzur (2005), 26.

47 Der palästinensische Psychiater Iyad Saraj erinnert daran, dass “today's suicide attackers are the children who saw their parents humilated and struck by IDF soldiers during the first Intifada and they are ashamed that they did nothing to stop it. So they are impelled by a strong sense of revenge motivated by those personal scars." Zitiert nach Shay (2004), 61.

48 Laut Paul Virilio stellen nicht die beiden Golfkriege den letzten wichtigen Wendepunkt in der Geschichte der modernen Kriegsführung dar, sondern der Kosovo-Konflikt, der Tony Blair zufolge „a new kind of war not for a territory but for universal values" war. Virilio zieht aus dieser Aussage folgenden Schluss: "Unprecedently, during the Kosovo conflict, the two officially declared enemies were never to meet physically anywhere, thus marking the disappearance of a real battlefield of a kind which still existed, in a latent state, during the Falklands/Malvinas and Gulf conflicts." Zitiert nach Virilio (2002), 43. 
Untersuchung ist bedeutsam, dass Bataille in seiner Gegenüberstellung homogener (ökonomisch und gesellschaftlich verwertbarer) und heterogener (nicht verwertbarer) Lebensformen zum Schluss kommt, dass ritualisierte Gewalt sich meist dort konzentriert, wo sie „unterm imperativen Impuls [...] durch die Negation des undisziplinierten Charakters der Elemente, aus denen sie sich zusammensetzt, eine homogene Form“49 bildet.

Mit Blick auf den Islam, mit dem er sich in „Der verfemte Teil“ auseinandersetzt, meinte Bataille, dass sein Prinzip „perfekt [ist]. Es hatte nichts Zweideutiges oder Zwitterhaftes: das religiöse Oberhaupt war zugleich Gesetzgeber, Richter und Befehlshaber der Armee. Man kann sich keine strenger geeinte Gemeinschaft denken. Diese gesellschaftliche Bindung war allein durch den Willen geschaffen worden (der sie jedoch nicht wieder lösen konnte), und das hatte nicht nur den Vorteil, eine unerschütterliche moralische Einheit zu garantieren, sondern es prädestinierte den Islam auch für eine unbegrenzte Ausdehnung. "50 In abgewandelter Form besagt dies, dass die Komplexität und die besondere Faszination eifernder Gottes-Reden wohl auch darin bestehen mögen, die von der produktiven Mehrheitsgesellschaft ausgesonderten Anteile emotional wie sprachlich zu binden und über die Position einer religiösen Autoritätsfigur, die selbst ambivalent ist, auf eine potentiell tödliche Leidenschaft einzustimmen.

\section{„The love of death in the path of Allah“"}

Ein solcher Erklärungsansatz böte zumindest den Vorteil, Osama bin Ladens paradoxes Begehren, zu dem er sich 1997 in einem Interview bekannte, als extreme Konsequenz einer kollektiven Passion zu bezeichnen. Im Gespräch mit dem Fernsehjournalisten Peter Arnett wählte Osama bin Laden folgende Worte: "Being killed for Allah's cause is a great honor achieved by only those who are the elite of the nation. We love this kind of death for Allah's cause as much as you like to live. We have nothing to fear for. It is something we wish for." 51 Auf vergleichbare Weise gab Al-Zawahiri ein Jahr später bekannt, dass der Einsatz des eigenen Lebens die entschei-

49 Bataille (1997), 29.

50 Bataille (1985), 120-121.

51 Zitiert nach Hoffman (2006), 135. 
dende Waffe sei, um das empfindliche Nervenzentrum der hegemonialen Mächte zu treffen. Al-Zawahiri ging sogar so weit zu behaupten, dass sich die radikalislamistische Jugend in naher Zukunft im Wettstreit befinden werde, wer sich und anderen den Tod gebe. Denn: "it is the love of death in the path of Allah that is the weapon that will annihilate this evil empire of America by the permission of Allah. The mujahid youth will compete with each other to die in the path of Allah, to destroy the myth of 'great' America, by the permission of Allah."52 Sheik Abu Shukheudem wiederum hob hervor, dass der gewaltsame Tod den Weg zur Lust bereiten werde, da den Märtyrer(inne)n die Tore zu himmlischen Freuden offen stünden: "From the moment the first drop of blood is spilled the martyr does not feel the pains of his injury, and is absolved of all his bad deeds; he sees his seat in Paradise; he is saved from the torture of the grave; he is saved from the fear of the Day of Judgment; he marries seventytwo beautiful black-eyed women; he is an advocate for seventy of his relatives to reach Paradise; he earns the Crown of Glory, whose precious stone is better than all this world and everything in it." 53

Den eben zitierten Passagen haftet etwas Skandalöses an, das sich weder in der Radikalität des sprachlichen Ausdrucks noch in der Strategie der Propaganda, die sicherlich wesentlich ist, erschöpft: ${ }^{54}$ Bin Laden und Al-Zawahiri sprechen vom Märtyrertod nicht als einer politischen oder militärischen Notwendigkeit; sie erkennen darin nicht bloß ein Mittel zur Erreichung eines konkreten strategischen Zieles. Der gewaltsame Tod wird gewünscht, er wird geliebt. Er entfacht Begehren, das sich in der Erwartung festigt, man werde im Jenseits uneingeschränkt all jene Früchte genießen können, die von der Scharia bisher vorenthalten wurden. ${ }^{55}$ Die eigentliche Provokation dieser militanten Gottes-Reden besteht darin, dass in ihnen eine topologische Beziehung eröffnet wird, die sich für weite Bereiche einer konsumorientierten Gesellschaft, die der Vorstellung einer unbegrenzten,

52 Zitiert nach Hoffman (2006), 135.

53 Zitiert nach Hoffman (2006), 162.

54 Selbst wenn man diesen militant religiösen Gesprächauszügen unterstellte, dass die Radikalität ihrer Wortwahl allein der Anwerbung junger Kämpfer(innen) diente, müsste man erklären können, warum sich Menschen von dieser Strategie faszinieren lassen.

55 Laqueur (2003), 85-87. 
ewigen Produktivkraft verpflichtet ist, nicht anders als ungeheuerlich anmuten kann - jene zwischen Gott, Tod und Lust. ${ }^{56}$

\section{Passion und Logik}

Mit Rücksicht auf kulturkritische Studien, die sich aus anthropologischer, sozialphilosophischer und psychoanalytischer Perspektive mit dem Verhältnis von Tod, Körperlichkeit und Industrialisierung beschäftigen, scheint einiges dafür zu sprechen, dass der Tod in Bezug auf das kapitalistische Wirtschafts- und Gesellschaftssystem, das sich selbst reproduziert und repliziert, das nicht Assimilierbare ist - ein Gedanke, der besonders stark von Jean Baudrillard aufgenommen und herausgearbeitet wurde. ${ }^{57}$

In seiner Schrift Der Geist des Terrorismus kommt Baudrillard zum Schluss, dass die besondere Wirkungskraft, die von extremen Formen des Terrorismus, wie den Anschlägen des 11. September, ausgeht, nur dann angemessen beurteilt werden kann, wenn berücksichtigt wird, dass die Todesbereitschaft der „Logik des Sozialen“ bzw. den herrschenden Produktionsverhältnissen widerspricht. Nach Baudrillard besteht ,das grundlegende Ereignis [...] darin, dass die Terroristen aufgehört haben, völlig umsonst Selbstmord zu begehen, dass sie ihren eigenen Tod auf offensive und wirksame Weise ins Spiel bringen, gemäß einer strategischen Intuition, die schlicht und einfach die immense Fragilität des Gegners erkennt, die Fragilität eines Systems, das seine Beinahe-Perfektion erreicht hat und beim kleinsten Funken sofort verletzlich ist. Es ist ihnen gelungen, ihren eigenen Tod zu einer absoluten Waffe gegen ein System zu machen, das von der Ausschließung des Todes lebt, dessen Ideal die Parole

56 Besonders über das Verhältnis von sexueller Lust und religiös motivierter Gewalt wird in der gegenwärtigen Religionswissenschaft selten gesprochen, Roger Friedland zufolge handelt es sich hier aber um eine Beziehung, die man „erforschen und verstehen muß, wenn wir in dieser in immer größeren Schrecken versetzten Welt bestehen wollen. “ Friedland (2004), 36.

57 In Der symbolische Tausch und der Tod argumentiert Baudrillard, dass es ,heute nicht normal [ist], tot zu sein, und das ist neu. Tot zu sein, ist eine unvorstellbare Anomalie, alle anderen sind im Vergleich dazu harmlos. Der Tod ist ein Verbrechen, eine unheilbare Verirrung. Den Toten ist weder ein Ort noch ein Zeit/Raum zugewiesen, ihr Aufenthalt ist unauffindbar, sie sind in die radikale Utopie verstoßen - sie werden sogar noch mehr zusammengedrückt, so daß sie sich in Luft auflösen.“ Wenig später fügt er hinzu, dass ,wenn die große operationale Metropole die vollendete Form einer ganzen Kultur ist, so ist die unsere einfach eine Kultur des Todes.“ Baudrillard (1982), 198. 
,Null Tote“ ist. Jedes System mit ,null Toten` ist ein Nullsummenspiel. Alle Abschreckungs- und Vernichtungsmittel vermögen nichts gegen einen Feind, der den eigenen Tod bereits zu einer Waffe der Gegenoffensive gemacht hat. “58

Wenngleich Baudrillard in seiner Analyse von einem System dem westlichen - spricht und dabei Brüche und Spannungen vernachlässigt, die sich durch ebendieses System ziehen, bringt seine Kritik auf den Punkt, was die eingangs zitierte Polemik von Dawkins indirekt andeutet. Entflammte Gottes-Reden und Formen ,reinigender" Gewalt stellen nicht von ungefähr eine besondere Herausforderung, ja „Bedrohung“ für das wissenschaftliche Selbstverständnis und für funktionalistische Religionstheorien dar. Es ist, als ob sich in gegenwärtigen Gewaltszenarien der Wille abbildete, den herrschenden Wissens- und Produktionsverhältnissen die Potenz des diesen Verhältnissen innewohnenden Ausschlusses entgegenzuhalten. Und wenn es auch klare Divergenzen gibt, was die politischen und theologischen Ziele betrifft, die sich radikale Evangelikale in den USA setzen und die von militanten islamistischen Zellen verfolgt werden, so überschneiden sich ihre Reden und Strategien doch dort, wo sie versuchen, „Gott“ auf das Heterogene als Inbegriff des gesellschaftlich wie wissenschaftlich nicht Assimilierbaren zu beziehen.

Nimmt man die wechselseitige, aber irreduzible Verschränkung von kollektiver Passion und produktiver Logik ernst, kann dies wohl nur bedeuten, dass die Wissenschaft (als eine besondere Ökonomie der Zeichen) selbst Moment eines sie umfassenden Konflikts ist, den sie nicht wird lösen können, ohne zugleich ihren Bezug zum Religiösen zu überdenken. Anlässlich eines Gesprächs unter Freunden, das 1994 auf Capri stattgefunden hat und der „Rückkehr des Religiösen" gewidmet war, hat Jacques Derrida für diese Aufgabe eines zukünftigen Denkens des Religiösen folgende Worte gefunden: „Eine gewisse unterbrechende Ent-bindung ist nämlich die Bedingung des ,gesellschaftlichen Bandes' und macht die Atmung einer jeden ,Gemeinschaft ${ }^{\star}$ aus. Es handelt sich hier nicht um den Knoten eines gegenseitigen Sich-Bedingens, sondern eher um eine Möglichkeit, die sich der Entwirrung und Auflösung aller Knoten, dem Abbruch und der Unterbrechung aussetzt. Ort an dem der Sozius oder 
194 Religiöser Eifer und „reinigende“ Gewalt

das Verhältnis zum anderen sich öffnet - als Geheimnis der zeugnishaften Erfahrung und folglich eines bestimmten Glaubens. “59

\section{Literatur}

Ahmed, Hisham H. (2005): „Palestinian resistance and ,suicide bombing“. Causes and consequences", in: Bjørgo, Tore, Hg.: Root Causes of Terrorism. Myths, Reality and Ways Forward. Abingdon: Routledge, 87-102.

Allitt, Patrick (2005): Religion in America Since 1945. A History. New York: Columbia University Press.

Bataille, Georges (21985): „Der verfemte Teil“, in: Bataille, Georges: Die Aufhebung der Ökonomie. München: Matthes \& Seitz, 33-234.

Bataille, Georges (1997): Die psychologische Struktur des Faschismus. Die Sowveränität. München: Matthes \& Seitz.

Bataille, Georges (21985): „Der Begriff der Verausgabung“, in: Bataille, Georges: Die Aufhebung der Ökonomie. München: Matthes \& Seitz, 7-31.

Baudrillard, Jean (1982): Der symbolische Tausch und der Tod. München: Matthes \& Seitz.

Baudrillard, Jean (2002): „Der Geist des Terrorismus. Herausforderung des Systems durch die symbolische Gabes des Todes", in: Engelmann, Peter, Hg.: Der Geist des Terrorismus. Wien: Passagen.

Boyer, Paul S. (1999): When Time Shall be no more. Prophecy Belief in the Modern American Culture. Cambridge: Harvard University Press.

CNN (2001): „CNN Newsroom“, online unter: http://transcripts.cnn. com/TRANSCRIPTS/0110/08/nr.00.html (Zugriff am 30.11.2007).

Derrida, Jacques (2001): „Glaube und Wissen. Die beiden Quellen der ,Religion" an den Grenzen der bloßen Vernunft", in: Derrida, Jacques/Vattimo, Gianni, Hg.: Die Religion. Frankfurt/M.: Suhrkamp.

Dollar, George W. (1973): A History of Fundamentalism in America. Greenville: Bob Jones University Press.

Durkheim, Émile (21984): Die elementaren Formen des religiösen Lebens. Frankfurt/M.: Suhrkamp.

Fallwell, Jerry (1980): Listen America! New York: Doubleday.

Falwell, Jerry (1987): Strength for the Journey. New York: Simon \& Schuster.

Friedland, Roger (2004): „Religiöser Terror. Der Kampf gegen den Säkularismus und die Erotik der Ausnahmegewalt", in: Lettre International 65, 36-44.

Friend Harding, Susan (2000): The Book of Jerry Falwell. Fundamentalist Language and Politics. Princeton: Princeton University Press. 
Garvey, John H. (1993): „Introduction: Fundamentalism and Politics“, in: Marty, Martin E./Appleby, Scott R., Hg.: Fundamentalism and the State. Remaking Polities, Economies, and Militance. Chicago: The University of Chicago Press, 13-27.

Gow, Andrew (1999): „The Myth of the Jewish Antichrist. Falwell Stumbles

Badly“, online unter: http://www.h-net.org/ hns/articles/1999/ 021099a.html (Zugriff am 30.11.2007)

Griffith, Lee (2002): The War on Terrorism and the Terror of God. Grand Rapids: Wm. B. Eerdmans.

Heinrichs, Johannes (2005): Logik des Sozialen. Woraus Gesellschaft entsteht. Varna: Steno.

Hoffman, Bruce (2006): Inside Terrorism. New York: Columbia University Press.

Hood, Ralph W./Hill, Peter C./Williamson, Paul W. (2005): The Psychology of Religious Fundamentalism. New York: The Guilford Press.

Kaufmann, Franz-Xaver (1989): Religion und Modernität. Sozialwissenschaftliche Perspektiven. Tübingen: Mohr Siebeck.

Laqueur, Walter (2003): No End to War. Terrorism in the 21st Century. New York: The Continuum International Publishing.

Lawrence, Bruce, Hg. (2005): Messages to the World. The Statements of Osama bin Laden. London: Verso.

Liebman, Robert C. (1983): „Mobilizing the Moral Majority“, in: Liebman, Robert C./Wuthnow, Robert, Hg.: The New Christian Right. New York: Aldine, 49-73.

Lincoln, Bruce (2003): Holy Terrors. Thinking about Religion after September 11. Chicago: The University of Chicago Press.

Linn, Jan G. (2004): What's Wrong with the Christian Right? Boca Raton: BrownWalker Press.

Lübbe, Hermann (32004): Religion nach der Aufklärung. München: Wilhelm Fink.

Luhmann, Niklas (72005): Soziologische Aufklärung 1. Aufsätže zur Theorie sozialer Systeme. Wiesbaden: VS Verlage für Sozialwissenschaften.

Marroquín, Carlos (2005): Die Religionstheorie des Collège de Sociologie. Von den irrationalen Dimensionen der Moderne. Berlin: Parerga.

Meddeb, Abdelwahab (2006): „Das Heterogene. Tendiert der Islamismus zu einem vollkommenen Faschismus?", in: Lettre International 75, 22-23.

Pedahzur, Ami (2005): Suicide Terrorism. Cambridge: Polity Press.

Saussure, Ferdinand de (2001): Grundfragen der allgemeinen Sprachwissenschaft. Berlin: de Gruyter.

Shay, Shaul (2004): The Shabids. Islam and Suicide Attacks. With a foreword by Aharon Ze'evi Farkash. New Jersey: Transaction. Publishers.

Strober, Gerald/Tomczak, Ruth (1979): Jerry Falwell. Aflame for God. Nashville: Thomas Nelson.

Virilio, Paul (2002): Ground Zero. London, Verso. 
196 Religiöser Eifer und „,reinigende“ Gewalt

Weber, Max (1988): „Die protestantische Ethik und der Geist des Kapitalismus“, in: Weber, Max, Hg.: Gesammelte Aufsätž zur Religionssoziologie I. Tübingen: Mohr.

Wuthnow, Robert (1998): After Heaven. Spirituality in America since the 1950s. Berkeley-Los Angeles: University of California Press. 


\section{Das religiöse Denken und das Böse}

Werner W. Ernst

\section{Leben und Tod}

Wenn wir „Gewalt als Anfrage an monotheistische Religionen“ nicht bereits disziplinär eingrenzen wollen, wie etwa historisch, ethnologisch, soziologisch oder psychologisch, müssen wir unsere Ausgangnahme im Denken selber unter Anfrage stellen. Die Reflexion des „Anfangs“, die den Anfang ,anfänglicher“ denkt (Martin Heidegger), lässt „Gewalt" nicht erst mit „monotheistischen Religionen“ beginnen. Wir bedürfen zuallererst eines Begriffs von „Gewalt", der keineswegs von monotheistischen Religionen abzuleiten ist, sondern bloß in Form unserer Anfrage mit ihnen in Beziehung gesetzt wurde. "Gewalt" stammt vielmehr von einem „vorlaufenden Zusammenhang", dem Vorlauf nicht nur von Religionen, sondern von (menschlichen) Kulturen überhaupt.

Auch eine kulturwissenschaftliche Perspektive ist bereits eine disziplinäre Einschränkung. Sie nimmt eine (methodische) Trennung von „Natur" in Kauf, ohne sich weiter Gedanken darüber zu machen, was alles damit dem Umfang und dem Inhalt nach unberücksichtigt bleibt. Die Resultate solcher auf Trennung beruhenden Erkenntnisse sind dann auch mit eben demselben Makel fehlender Rücksichtnahme behaftet. Der Mangel der Resultate wird oftmals nicht mehr gesehen, weil der Fehler bereits in der „Trennungsgewalt" selber beschlossen liegt, welche unreflektiert bleibt oder aber ganz bewusst in Form „methodischer Abstraktion“ in Kauf genommen wird. - Dass die auf „Trennungsgewalt" beruhende Denkweise etwas mit der disziplinarwissenschaftlichen Herangehensweise und 
damit der ,westlichen Moderne“ zu tun hat, darauf wird noch zurückzukommen sein.

Mit „Trennungsgewalt“ nehmen wir einen Gewaltbegriff auf, der gar nicht erst Gefahr läuft, nach außen verlagert zu werden, weil er im methodischen Untersuchen selbst die Voraus-Setzung bildet. Unter Zuhilfenahme dieses Gewaltbegriffs würde sich in weiterer Folge Gewalt durch Gewalt (Gewalt im Denken, „Denkgewalt") erklären, eine Sichtweise, die uns Gewalt in keiner Weise erkennen lieBe. Angesichts dieser präkeren Situation müssen wir also noch hinter die „Denkgewalt“ zurückdenken, um womöglich an Denkspuren anschließen zu können, welche sich keiner Gewalt verdanken.

Wovon nehmen wir also Ausgang, wenn wir von „Gewalt" sprechen? Und welcher Begriff kommt für den Fall in Betracht, wo darum gerungen wird, ohne Gewalt sein Auslangen zu finden, an welchen Gewaltbegriff man dabei auch immer denken mag? - Wenn wir ,Gewalt“ mit dem „Bösen“ in Verbindung bringen, was wir mithin tun, dann können wir in Anbetracht Ausgang nehmenden Denkens von einer Triebkonzeption sprechen, welche nicht erst mit dem Menschen beginnt. Nach Sigmund Freud ist die Trieblehre „,sozusagen unsere Mythologie“. 1 „Die Triebe sind mythische Wesen, großartig in ihrer Unbestimmtheit." 2 Für den späteren Freud gibt es nur mehr zwei Grundtriebe. Die Triebe des Wachsens, des Aufbaus, der Verbindung und Vermehrung sind dem Lebenstrieb geschuldet, die diesen mindernden, spaltenden und (zer)störenden dem Todestrieb. Jede kleinste destruktive Wirkung führt zum Tod und ist deshalb nicht gut. Jeder kleinste Schritt zur Verbindung hin schafft in der Konsequenz (Weiter)leben und ist der Liebe gezollt und damit gut. $^{3}$ - Freud hat in Jenseits des Lustprinzips (1920) seiner Triebtheorie eine Art naturwissenschaftliche Grundlage zu geben versucht. Warum verweist er uns dann aber auch auf die „mythische“ Bedeutung der Triebe? Und um welche Mythen handelt es sich dabei?

Wir sind überzeugt, dass hier die jüdisch-religiösen Wurzeln Freuds eine große Rolle spielen. Als unbewusste Ausgangnahme wird wohl Freud bei Moses Anleihe genommen haben, der seinem Volk beschwörend ins (heilige) Stammbuch schreibt: „Siehe, ich lege dir heute Leben und Heil, Tod und Unheil vor!“ (Dtn 30.15) Und 
weiter: „Ich rufe heute wider euch Himmel und Erde zu Zeugen an: Vorgelegt habe ich dir Leben und Tod, Segen und Fluch! So wähle denn das Leben, damit du samt deinen Nachkommen am Leben bleibst!"“ (Dtn 30.19)

Dieser alttestamentarische Auftrag wird in unserer Kultur vielfach für selbstverständlich erachtet. Doch bereits die Eindringlichkeit und das Moment der Wiederholung sollten uns innehalten und die Gleichsetzung von Leben mit Heil und Segen, von Tod mit Unheil und Fluch überdenken lassen. Schließlich handelt es sich hier um ein Rätsel, das Rätsel des vorlaufenden Zusammenhangs von „Gut“ und „Böse“. Warum steht das Gute auf der Seite des Lebens - und im Unterschied dazu das Böse auf der Seite des Todes? Und weiters: Haben wir es bei diesem Unterschied von Gut und Böse, Leben und Tod, eher mit einer Ausnehmung am Zusammenhang zu tun, wobei der Zusammenhang gegenüber dem Unterschied die tragende Rolle spielt, oder aber verstehen wir den Unterschied schon mehr als Widerspruch, für den das Axiom des Gegensatzes die Ausgangnahme bildet? Kurz: Hat der Zusammenhang oder der Unterschied die grundlegendere Bedeutung? Oder aber spielen beide gleichwertig ineinander? - Wie steht es mit dem Verhältnis von Zusammenhang und Unterschied?

\section{Mythische Anschlusssuche}

Alle diese Fragen finden bei einer genauen Lektüre des biblischen Schrifttums eine Antwort! Dass damit auch die Gewaltfrage eine Erklärung erfährt, liegt auf der Hand. Gewalt = das Böse steht in unmittelbarem Zusammenhang mit der Frage nach dem Ausgang nehmenden Denken, wie es die Bibel lehrt. So gesehen braucht „Gewalt" gar nicht erst von außen an das jüdisch-christliche Denkerbe herangebracht werden, die Lehre von Gewalt = das Böse ist vielmehr selbst Bestandteil dieser monotheistischen Religionen.

Wenn Sigmund Freud etwa von der „Legierung“, dem Mischungsverhältnis, libidinöser und destruktiver Triebanteile spricht, dann stehen solche Überlegungen in der oben angeführten Tradition. Seine berühmte Theorie von der „Entlegierung“ erklärt uns in radikaler Weise das Symptom der Aufspaltung, Aufgespaltenheit des Bewusstseins, jene zum Bösen neigende Disposition des Menschen. 
Anhand der „Trennungsgewalt" wurde bereits das Böse im (methodischen) Denken der Moderne geortet. ${ }^{4}$ Dieses Denken findet jeweils auf der Ebene des „Logos“ statt. Freud ringt um eine Erklärung auf der Ebene biologisch-naturwissenschaftlicher Theoriebildung. Doch warum geht es ihm darüber hinaus um eine mythische Anschlusssuche?

Freud ist als Naturwissenschaftler hinsichtlich des Mythos anschlussfähig, weil er - wie bereits erwähnt - dem jüdischen Denktypus anhängt, welcher Abtrennung, Aufspaltung, Loslösung, Isolation für etwas Schlechtes (um nicht zu sagen Böses) und in der Praxis zu Unterlassendes hält. ${ }^{5}$ Je länger wir uns mit der Frage nach der Herkunft von Gewalt = das Böse beschäftigen, desto bewusster wird uns unser eigener Zusammenhang von Mythos und Logos, der nur um den Preis denkmäßiger Gewaltanwendung aufgetrennt werden kann. Von einer Ablösung des Mythos durch den Logos sprechen uns Historiker der Philosophie und Religion, als ob der Mythos durch das Hinzutreten des Logos seine Wirksamkeit verloren hätte!

Ist der Logos aus dem Mythos hervorgegangen, so hat er mit diesem etwas gemeinsam. Dieses Gemeinsame bleibt einer Betrachtungsweise der Teilung, welche den Logos jeweils getrennt vom Mythos und den Mythos jeweils getrennt vom Logos in Augenschein nimmt, unerkannt. Wenn wir uns hingegen am Gemeinsamen, dem Zusammenhang orientieren, können wir die historische Betrachtung der späteren Trennung vom Mythos derart relativieren, dass wir den Logos als vom Mythos noch zurück- bzw. einbehalten denken.

Bei diesem Umdenken sollten wir den Mythos selber zu Rate ziehen. Der erste Trennungsakt in der jüdisch-christlichen Überlieferung stammt von Gott. Dieses ,,von Gott her" müssen wir als Unterscheidungsmerkmal zu ,vom Menschen aus“ im Auge behalten. Was also hat - mythisch gesehen - Gott bereits geschaffen, als er einen Trennungsakt vornimmt? „Im Anfang schuf Gott den Himmel und die Erde. Die Erde war wüst und leer, Finsternis lag über der Urflut, und der Geist Gottes schwebte über den Wassern. Da sprach Gott: ,Es werde Licht!' Und es ward Licht. Gott sah, daß das Licht gut war." (Gen 1.1-4a)

\section{Hiezu bereits: Ernst (2004).}

5 Als eindrucksvolle Darstellung dieser zumeist auf die spätere, kabbalistische Literatur zurückgehenden Denkform: Scholem (1977). 
Wichtig ist anzumerken, dass dieses Handeln Gottes voll und ganz im Schöpfungshandeln besteht. Die Rede ist ausschließlich vom Heraustreten Gottes in sein Schöpfungswerk. Himmel, Erde, Wasser, Finsternis und selbst das Licht sind Kreatürliches und stehen somit bereits in Differenz zu Gottes Beschaffenheit, als dieser nur in sich ruhte und im Bei-sich-Sein eins war. Doch in diesem Einssein war Gott auch Liebe, wie Johannes sagt (1Joh 4.8). Wenn wir Liebe als Zeugin und Leben weitergebendes Leben verstehen, so erkennen wir in diesem Wesensmerkmal eine weitere Faltung Gottes, neben der der in sich ruhenden Wesenheit. Diese Faltungen hängen Gott also bereits vor seiner Schöpfung an, einer Schöpfung, die wir als Heraustreten Gottes in den Zustand seines Außer-sich-Seins verstehen wollen.

Gott ist mit sich eins, d.h., dass seine Wesenheiten, In-Ruhebei-sich-Sein und Liebe, zusammengehören. Der in und mit sich genug seiende Gott ist zugleich ein liebender Gott. Auch vor der Schöpfung schon bringt Gott ein Übermaß an Liebe in Fluss, Liebe, die allerdings noch nicht übergeflossen und damit auch nicht in ein anderes (= Schöpfung) übergegangen ist; Liebe, die bei allem Übermaß die Liebe noch bei sich hält. Wir müssen uns diesen in der Transzendenz bereits gefalteten Gott als ruhenden, beharrenden, bei sich seienden Gott vorstellen, dessen Liebe noch einbehalten bleibt, um in Form der Schöpfung dann die Transzendenz zu sprengen und überzufließen.

\section{Transzendenz}

Erst mit dem Schöpfungsbericht wird uns auch mitgeteilt, dass Gott ein Geistwesen ist. Als „Geist Gottes“ schwebte er „über den Wassern“. Wir können diesen Geist Gottes auch als weitere Faltung ansehen, welche Gottes Kraft hienieden mit der Geistigkeit Gottes in der Transzendenz verbindet. Liebe und Geistigkeit Gottes fließen also in Form der Schöpfung aus. Doch was passiert mit der ruhenden, beharrenden, an sich selbst haltenden Wesenheit Gottes? In der Immanenz von Schöpfung erscheint diese Wesenheit Gottes bestenfalls als „Nirwana- bzw. Konstanzprinzip“ (Sigmund Freud). Diesem Prinzip gemäß kehren alle Kräfte und Bewegungen wieder zum Ausgang der Bewegung zurück und münden in den Stillstand ein. Schlechterdings aber bedeutet die im Ausgang ruhende Wesenheit Gottes auf die Immanenz bezogen den „Todestrieb“, jenen Trieb al- 
so, welchen Sigmund Freud als der Liebe und dem Leben entgegengesetzt, d.h. diese störend und in der Konsequenz abtötend begreift.

Erweitern wir diese Lehre wieder um das Blickfeld der Transzendenz, so können wir erkennen, dass wir uns einer eindeutigen Häresie schuldig machen. Wenn Gewalt = das Böse $=$ Tod als immanenter Abkömmling der in der Transzendenz in sich ruhenden und bei sich seienden Wesenheit Gottes gedacht wird, ist Gott selber auch mit dem Bösen in Verbindung. In der Tradition der Kabbala hat Nathan von Gaza diesen Denkweg beschritten. ${ }^{6}$ Sigmund Freud muss sich dieser Position gar nicht erst stellen, weil er die Frage der Transzendenz von vornherein ausblendet. Nichtsdestoweniger stehen auch bei ihm Liebes- und Todestrieb gleichrangig nebeneinander. Da er als Atheist den Häresievorwurf nicht zu fürchten braucht, kann er Liebe $=$ Leben und Hass $=$ Tod als Mischungsverhältnis fassen, das keinem der beiden Grundtriebe einen Vorrang der Art einräumt, dass einer womöglich vom anderen ableitbar wäre. Auch der Liebes- und Lebenstrieb gilt also nicht als prioritär. - Die Annahme Freuds, dass Lebenstrieb und Todestrieb einander ausgleichen, wenn sich keine größeren Triebentmischungen ergeben, entspricht der Blickverengung einer um die Transzendenz verkürzten Immanenz. Für Freud ist es schlichtweg offen, wie sich Leben und Tod, die prähumane Natur inbegriffen, im Rahmen innerweltlicher Evolution noch weiterentwickeln.

Nun aber zurück zum „ersten Trennungsakt Gottes“. Wir haben über die ersten Schöpfungstaten Gottes gelesen - bis zur Lichtschaffung und Gutheißung des Lichtes. Es gibt zwar in der Genesis noch andere Gutheißungen, diese erste Gutheißung jedoch ist von besonderer Bedeutung. Sie leitet nämlich zum ersten Trennungsakt Gottes über. Wohlgemerkt, wir befinden uns innerhalb der Schöpfung, deren elementare Schaffung auch die Finsternis birgt. Nach der Gutheißung des Lichtes steht geschrieben: „Da trennte Gott Licht von Finsternis.“" (Gen 1.4b)

Im Rahmen einer die Transzendenz einbeziehenden Schöpfungstheorie kommt es nun darauf an, wie dieser in der Immanenz erfolgte Trennungsakt Gottes zu verstehen ist. Schließlich haben wir darauf hingewiesen, dass die trennende Denkgewalt des Menschen vom Bösen ist; muss nun der in der Welt erfolgte Trennungsakt 
Gottes nicht ebenso als böse interpretiert werden? - Wir ahnen es bereits, dieser häretische Gedanke ist nur möglich, wenn die Transzendenz im Denken entweder gar keine Berücksichtigung oder nicht die gebührliche findet. Die nicht gebührliche Berücksichtigung der Transzendenz bestünde darin, dass wir die Transzendenz in derselben Form einfacher Differenzbestimmung verstehen, wie wir Unterschiede innerweltlich festlegen! Die gebührliche Berücksichtigung der Transzendenz im Denken hingegen pocht auf den immer größeren Unterschied von Transzendenz und Immanenz im Verhältnis zu ihrem Zusammenhang.

Um am Mythos wieder anzuschließen: Da alles Kreatürliche von Gott stammt, ist zwar alles Kreatürliche auch göttlich, aber Gott ist niemals identisch mit dem Kreatürlichen, wie es pantheistische und esoterische Lehren verheißen. Nur das Heraustreten Gottes aus Liebe in sein Außer-sich-Sein ist mit der Schöpfung eins. Der an sich haltende, bei sich seiende, ruhende Gott hingegen, den wir uns nur als die Schöpfung noch zurückhaltenden („Gott vor der Schöpfung ${ }^{\circ}$ ), einbehaltenden Gott vorstellen können, ist die andere, fremde, unerforschliche Wesenheit Gottes, hinter die wir (denkmäßig) nicht gelangen können, weil uns eben die Transzendenz daran hindert.

Was also die Bestimmungen jenseits der Transzendenz anlangt, so ändern diese jeweils ihre Bedeutung und werden falsch, wenn wir an sie immanente Maßstäbe anlegen. Die Unterschiede hienieden wiederum, die sich auf dem Hintergrund ihres innerweltlichen (vorlaufenden) Zusammenhangs ausnehmen und beurteilen lassen, unterliegen einer Transformation, wenn sie auf die Transzendenz bezogen gedacht werden. Eine solche Bezogenheit auf die Transzendenz muss mitgedacht werden, wenn von Trennungsakten Gottes die Rede ist. So dürfen wir also gerade im Falle des ersten Trennungsaktes Gottes nicht allein die innerweltliche Teilung von Licht und Finsternis zur Ausgangnahme unseres Denkens machen. Wenn es nämlich der transzendente Gott ist, der Licht von Finsternis trennt, dann sind die Gründe dafür nicht nur innerweltlicher Art. Aus welchen transzendenten Gründen innerweltliche Trennungen stattfinden, können wir nicht wissen. Wir wissen nur, dass auch transzendente Gründe im Spiel sind. Trennung „von Gott her“, auch wenn diese innerhalb der Schöpfung erfolgt, bedeutet etwas ganz anderes als Trennung ,vom Menschen aus“. 


\section{Priorität des Guten}

Wenn der Schöpfer die Trennung vornimmt, dann bedeutet „Licht“ das „Gute“ und „Finsternis“ - an dieser Stelle noch ungesagt - das „Böse“. Eben diese Bestimmung von Licht und Leben, Finsternis und Tod ist damit in die Schöpfung eingegangen, zunächst als Zusammenhang, Legierung, und schließlich als Trennung. Alle Trennungen „vom Menschen aus“ hienieden sind von Übel. Die Trennung jedoch, welche ,,von Gott her“ zu denken ist, bedeutet etwas anderes. Sie ist der Wink in Richtung einer fundamentalen Trennung, der Trennung zwischen Transzendenz und Schöpfung. Diese Trennung, die wir göttliche Fundamentaltrennung nennen wollen, muss immer dann zum Ausgang genommen werden, wenn in der Heiligen Schrift von Gottes Trennungen (nicht von Trennungen durch den Menschen) die Rede ist. Aus der Fundamentaltrennung heraus, welche - wie wir gesagt haben - prioritär gegenüber dem Zusammenhang ist, schafft Gott die Trennung zwischen Licht und Finsternis, Gut und Böse.

Hier geht es eigens um die Bedingungen der Orientierung hienieden, welche nicht gegeben wäre, wenn von vornherein, vorlaufend, die Legierung die Ausgangnahme bildete. Wenn doch schon die der Immanenz näher liegenden Stufen des ebenso der Transzendenz zugehörigen Engelreichs von Gut und Böse durchsetzt sind, so sind es die Dinge dieser Welt erst recht. So darf es über alle Vermischtheit von Gut und Böse hinweg keine Unklarheit darüber geben, was Gut und Böse bedeuten. Deshalb ist es Gottes Entscheidung, die bereits für das Engelreich geltende Trennung von Licht und Finsternis für das Diesseits verbindlich zu machen. Alles Unglück dieser Welt stammt von der Unkenntnis bzw. der Leugnung von Licht und Finsternis, Leben (Liebe) und Tod, Heil und Unheil, Segen und Fluch, Gut und Böse. Und selbst die Anerkenntnis dieser Dinge durch den Erdenmenschen schützt nicht vor Irrtum und Sünde, weil in jeder neuen Situation, auf jedem neuen konkreten Feld das Verhältnis von Gut und Böse auch immer wieder neu bestimmt werden muss, um die richtige Wahl zu treffen. Das heißt, wir bedürfen einer Klarsicht darüber, was gut ist und was böse ist. In der Komplexität und Verschiebbarkeit dieser Bestimmungen (wie groß ist jeweils der Mangel an Gutem?) besteht das Rätsel, welches mythisch betrachtet bis auf den Fall Adams und Evas, ja noch weiter zurückliegend bis auf den Fall der Engel zurückgeht. Der Sündenfall der Menschheitskinder bildet bereits ein Wiederholungsgeschehen, 
das den Mangel des Menschen für seine fortlaufende Geschichte festschreibt. Den ersten Menschen war verboten, von den Früchten des Baumes der Erkenntnis von Gut und Böse zu essen. Diese Früchte waren ursprünglich Gott vorbehalten. Da die ersten Menschen wie Gott sein wollten, haben sie von den Früchten der Erkenntnis gegessen.

Nun sollten wir Menschen die Erkenntnis von Gut und Böse eigentlich haben. Da wir sie aber nur um den Preis der allergrößten Verbotsübertretung (wie Gott sein wollen!) erlangt haben, ist ebendieser Erkenntnis ein Makel eingeschrieben. Dieser Makel besagt: „Mit jeder neuen Entscheidung, oh Mensch, bist du unsicher darüber, ob du das Gute oder aber das Böse wählst, weil es deine Neigung selber ist, die gut oder böse ist. Nur als guter Mensch kannst du dich für das Gute entscheiden. Wenn du aber nicht gut bist, fehlt dir die Orientierung für deine Entscheidungen. Anhand der Orientierungslosigkeit aber magst du ermessen, inwieweit du kein Guter bist. Du kannst aber daran arbeiten, noch ein Guter zu werden!“

Gottes Schöpfungswerk der Trennung von Licht und Finsternis heißt also, dass wir uns angesichts dieser Wegweisung sehr wohl am Licht orientieren können und uns deshalb auch an ihm zu orientieren haben. Diese in der Ausgangnahme bereits schwer zu fassende, darüber hinaus mit einem Mangel behaftete Erkenntnis kann auch als Geheimnis oder - wie gesagt - Rätsel verstanden werden. Die Spitze dieses Geheimnisses ist freilich der gerade noch mögliche Blick auf die Transzendenz, in der Licht (Gott ist Liebe) und Finsternis (die sich selbst genügende Wesenheit Gottes) das einigende Band des Guten, des guten Gottes, bilden.

\section{Monotheistische Religionen - westliche Moderne}

Nach allem, was bisher über Gewalt und das Böse - in Differenz zu und im Zusammenhang mit Leben und dem Guten - gesagt worden ist, wird offenkundig, dass diese Thematik der jüdisch-christlichen Schriftreligion selber inhärent ist. Dies gilt auch für das theologische Denken, das den Koran zur Grundlage hat. Hier ist der transzendente Gott ungefaltet und die Fundamentaltrennung zwischen Transzendenz und Immanenz womöglich noch stärker konturiert, als es im biblischen Schrifttum der Fall ist. Da der Koran die Erbsünde nicht kennt, ist jeder Mensch für sich selbst in einer Weise verantwortlich, die ihn im Falle der Sünde die Schuld mit ihrer ganzen 
Wucht treffen lässt. Vielleicht kann man sagen, dass dieser stärkeren Schuldakzentuierung am Einzelmenschen ein desto verzeihenderer Gott entspricht. Jede Sure des Korans - nur Sure 9 bildet eine Ausnahme - erwähnt die hauptsächlichen Eigenschaften Allahs, Erbarmen zu haben und barmherzig zu sein.

In welchem anderen als dem genannten heiligen Schrifttum wird mehr über die Herkunft des Bösen (und der Gewalt) gesprochen? Sigmund Freud hat den Mythos in seine Überlegungen einbezogen, weil ohne eine Bestimmung des Zusammenhangs von Mythos und Logos das Gewaltproblem überhaupt nicht verstanden werden kann. Es ist gerade die westliche Moderne, die in Form disziplinarwissenschaftlichen Denkens einen voraus-gesetzten Gewaltbegriff verwendet, d.h. diesen aus dem ,vorlaufenden Zusammenhang" herausnimmt. Ein im Vorhinein definierter Gewaltbegriff wird dann mit Erscheinungsweisen z.B. monotheistischer Religionen verglichen und dort womöglich ,aufgefunden“ und damit auch noch zur Ursache erhoben. Solcherart „Aufgefundenwerden“ und „ZurUrsache-gemacht-Werden“ beruht auf Setzung. Ursachen, welche auf Ursachen-Setzung beruhen, haben nichts mit Begriffen wie „Anfang“, „Entstehung“, „Herkunft“, „Genesis“, „Entwicklung“, „Hervorbringung“ oder gar „Schöpfung“ zu tun. Ursachen-Setzung hat sich nicht der Mühe Ausgang nehmenden Denkens unterzogen. Gewalt und das Böse sind demnach eine Denkschwierigkeit westlicher Moderne. Diese Denkschwierigkeit kann durch den Denktypus westlicher Moderne auch gar nicht gelöst werden.

\section{Systemgewalt und religiöse Buhlschaft}

Zum Schluss unserer Überlegungen wollen wir noch ein endzeitliches Gewaltszenario nachzeichnen, das allein christlicher Überlieferung entstammt. Die Offenbarung des Johannes kündet an ihrem Ende, dem Ende von Endlichkeit, auch vom Ende der Gewaltbeziehung von Menschen. Die von der Genesis bis zur Apokalypse reichende Gewalt politischer wie religiöser Mächte findet ein Ende, indem sie in das von ihnen selber bereitete Inferno stürzen. Wir stützen uns in unserer Interpretation im Besonderen auf die Kapitel 13 und 17, wo der Kampf eines sich globalisierenden Staatsgebildes mit der religiösen Macht, die bis dahin mit der weltlichen gebuhlt hat, entschieden wird. Die innerweltlichen Mächte, welche die Monopolgewalt des Globus anstreben, werden durch das ,wilde Tier mit zehn Hörnern 
und sieben Köpfen“, die religiösen Institutionen der Endzeit durch die „Buhlerin von Babylon“ symbolisiert.

Die Globalisierung säkularer Gewalten, wie wir sie nennen wollen, geht in Richtung Einheitslogik, der Form des Setzens, in ihrer komplexesten Gestalt: der Zusammen-Setzung. Jede Art Zusammen-Setzung ist nur ein synthetisches Produkt des Menschen. Im Unterschied dazu gibt es den Zusammenhang, der ohne Widerspruch, Gegensatz, ohne Systemfremdes sein Auslangen findet. Und dieser Zusammenhang gilt von vornherein; er ist als „vorlaufend“ anzusehen. An ihm sind Ausnehmungen, Unterschiede, niemals etwas Fremdes; sie machen ihn vielmehr aus! Unterschiede bilden den Zusammenhang. Selbst der kleinste Unterschied würde, wenn er wegfiele, den Zusammenhang (auf)lösen. - Ganz anders bei der Zusammen-Setzung. Im Unterschied zum Zusammenhang fällt bei der Zusammen-Setzung immer etwas heraus. ZusammenSetzung heißt demnach: Zusammen-Setzung von allem, das sich zusammen-setzen lässt. Alles, was nicht zur Zusammen-Setzung fähig ist, muss ausgegrenzt, abgestoßen oder vernichtet werden. Das Gleiche gilt für die Globalisierung, welche eine Top-Form von Zusammen-Setzung ist. Auch hier heißt es: Was nicht globalisierungsfähig ist, ist nicht wert, mitgetragen zu werden!

Die globalisierenden Mächte des Bösen in der Apokalypse, welche nunmehr als Gesamtheit nach der einen Systemlogik herrschen, müssen also alles Zufällige, Partikulare, Sinnliche, Berauschende, Verräterische, (Be)trügerische, Labile, Irrationale, kurz: Unberechenbare, wie es das Prinzip der Buhlschaft darstellt, ausgrenzen. Teilung, Abspaltung, Ausgrenzung aber sind das Prinzip des Bösen. Das Szenario des Setzens und Ent-Setzens in der Apokalypse stellt also auf seinem Höhepunkt die globalisierte Macht des Bösen dar, welche auf der Fiktion monolithischer Systemlogik und ihrer Trennungsgewalt beruht. Diese Fiktion kalkulierender, rationaler Einheitslogik stößt sich an der Differenz des Unberechenbaren. Da die religiöse Buhlschaft dieses Unberechenbare repräsentiert, wird sie von den Mächten des weltlichen Systems der Dinge beargwöhnt. Dabei hilft ihr auch nicht, dass sie mit den säkularen Mächten paktiert. Der Charakter der Buhlschaft bringt es mit sich, nie ganz der Verfügung, Steuerung und Kontrolle rationaler Systemgewalt unterworfen zu sein.

So kann die korrupte, opportunistische Religionsmacht, selber Böses, zum Feind des Systembösen werden. Es gibt auf Dauer keine Übereinkunft des Bösen mit sich selber und mit anderen. Das Böse 
läuft im Grunde einer Einigung zuwider. Eine Einigung gelingt immer nur scheinbar, wenn es einen Feind (Sündenbock!) zu bekämpfen gibt. Doch das ist immer der Fall. Dieser Feind kann ein guter oder aber - wie im Falle der Buhlschaft - ein böser sein. Das Böse kämpft also gegen Gut wie Böse! - Das macht es so schwer, das Böse in der Auseinandersetzung mit Feinden zu erkennen. Sich nur mit dem Feind des Bösen zu solidarisieren, heißt also noch lange nicht, gegen das Böse zu sein. Auch wenn mit der Wahl des Feindes des Bösen das Gute getroffen würde, so wäre das Motiv einer solchen Wahl, die sich ausschließlich über die Feindschaft mit dem Bösen definierte, selber nicht gut. Die Orientierung muss daher (bei aller Legierung) mit dem Guten beginnen. So steht es auch das „Licht“ betreffend in Genesis, 1.1-4a, wovon wir Ausgang genommen haben. Das „Gute“ hat in der Vergangenheit - bei aller Schwierigkeit - auch immer Kontur gezeigt, in Form von Alternative oder Korrektur.

\section{Indifferenz}

In der Apokalypse nun verblasst diese Kontur zusehends. In Zeiten, wo falsche Propheten von wahren, Anti-Christusse von Christus nicht zu unterscheiden sind, ist auch die Orientierung an frommen Naturen nicht mehr möglich. Die Indifferenz ist so groß, dass die Menschen nicht mehr wahr von falsch, gut von böse unterscheiden können. Es herrscht nicht eine kumulative Vermischung (Haufen um Haufen) von Gut und Böse, sondern eine gleichsam stofflich ununterscheidbare, durchgehende. - In dieser dramatischen Situation von Ununterschiedenheit, am Höhepunkt der Apokalypse, stehen böse Mächte und scheinbar gute, die auch böse sind, gegeneinander. Der Argwohn der globalisierenden säkularen Gewalten gegenüber den korrupten, verräterischen und heuchlerischen Aktionen religiöser Institutionen steigert sich bis zum offenen Ausbruch. Das weltlich Böse vernichtet schließlich das religiös Böse, mit dem es in Konkubinat gelebt hat: „Und die zehn Hörner, die du sahst, und das Tier, sie werden die Buhlerin hassen, sie einsam und nackt werden lassen und ihr Fleisch fressen und sie im Feuer verbrennen." (Offb 17.16)

Die Bilder „einsam und nackt“ stehen wohl für die Strategie der Abspaltung des Eigenbösen, das nach außen projiziert wird, um hernach als Fremdes der Vernichtung preisgegeben zu werden (,im 
Feuer verbrennen“). Das „Fleisch der Buhlerin fressen“ bedeutet einerseits die Ambivalenz eines Eros, der sein Objekt, so wie er es liebt, auch verschlingt, andererseits die verkappte Eigenliebe, die das nach außen projizierte Fremde um den Preis der Vernichtung wieder in das Ich zurückholen darf.

Interessant ist nun der noch zum Höhepunkt der Apokalypse zählende kurze Augenblick nach Beseitigung der religiösen Buhlerin. Erstmals scheint eine säkulare Macht ohne Feind dazustehen. Es ist die aus vielen Weltmächten über die monolithische System- und Setzungslogik herbeigeführte, endgültig globalisierte Herrschaft, die nun meint, ganz für sich - uneingeschränkt und ungestört - regieren zu können. Der Gewalt eines Eigenbösen scheinen keine Grenzen gesetzt. - Doch hat die nunmehr globalisierte Systemmacht nicht die Rechnung ohne den Wirt gemacht? Ihr letzter Kampf war gegen Böses gerichtet. Dabei hat sie ständig versucht, sich den Anschein des „rational Guten“ zu geben.

\section{Lichter aus der Trübnis}

Das tatsächlich Gute hingegen war von den Ereignissen noch einbehalten. Dadurch ergibt sich eine Weiterführung des apokalyptischen Szenarios: Unter der Decke des Scheins einer weltumfassenden (globalisierten), alle säkularen Mächte vereinigenden Phalanx („das Tier mit den acht Köpfen“) regen sich geistige Kräfte, welche bisher eine unsichtbare Glaubensgemeinschaft bildeten. Diese „Lichter aus der Trübnis“, wie wir sie nennen wollen, haben sich genauso wie alle anderen Menschen in weltlichen Einrichtungen verdingen müssen. Hinzu kommt noch, dass sie ihre religiöse Sozialisierung in den mit den weltlichen Systemen paktierenden religiösen Institutionen erfahren haben. In dieser Zeit der Trübnis haben sie sich jedoch weder an der weltlichen noch an der Institution religiöser Machtausübung orientiert. Vielmehr haben sie erkannt, dass Bewährung aus all der Trübnis heraus zu erfolgen hat.

Geistige Lichter brennen überall dort, wo ein Ausweg aus der religiösen Buhlschaft mit den Systemmächten dieser Erde gefunden werden muss. Sie bilden untereinander ein weitläufiges, geistiges Band, das vor dem Fall der Buhlerin noch unsichtbar ist. Ihr Leuchten stammt von einer Geistigkeit, welche sich nicht von institutionalisierten Geistesmächten weltlicher oder religiöser Provenienz korrumpieren lässt. Diese Geistigkeit steht einer heuchlerischen gegen- 
über, welche nur mehr scheinhalber den Unterschied zur weltlichen Geistesmacht aufrechterhält.

Wo keine „Lichter aus der Trübnis“ leuchten, hat uns die Buhlerin, die ,auf vielen Wassern sitzt“ (Offb 17.1), den Blick dafür genommen, was an der weltlichen Systemmacht böse ist. Von der Systemmacht selber ist ein solches Eingeständnis schon gar nicht zu erwarten. Die Buhlerin hat sich derart mit dem „System dieser Dinge" eingelassen, dass sich die Menschen in ihrer Lebenspraxis, ob gläubig oder nicht, kaum noch voneinander unterscheiden. Dasselbe gilt für die Theorieebene, wo atheistische und auf Technik, ökonomischen Eigennutzen und Organisation reduzierte Denkweisen nicht mehr als Widerspruch zu Glaubenswahrheiten erlebt werden.

Das religiöse „Königreich“ der Buhlschaft entspricht den strukturellen Erfordernissen von Ausbeutung, Herrschaft und Unterdrückung genauso wie den Überzeugungen von Menschen, die keine religiösen Überhöhungen ihrer innerweltlichen Grundsätze brauchen. Die Diskursherrschaft über religiöse und glaubensmäßig verbürgte Wahrheit ist für die Buhlschaft bloß Vorteil, Luxus, Privileg, geistige Machtausübung, welche viele Menschen bei der Stange hält und die irdischen Gewalten gutheißen lässt. Die Denkherrschaft ist eine solche ideeller Abstraktion, welche von den materiellen Verhältnissen dieser Welt absieht. Die manifeste Trennung auf ideell-geistiger Ebene macht eine Buhlschaft auf materiell-weltlicher Basis erst möglich.

\section{Gemeinschaft der Heiligen}

Es ist nicht zufällig, dass die ,geheime“ Offenbarung selber noch von „Geheimnis“ spricht und „Verstand“, der „Weisheit“ (bzw. „Einsicht") besitzt, fordert (Offb 13.18, 17.9). Dabei kommt es auf das tatsächliche Unterscheidungs- und Urteilsvermögen aller Wahrheitssuchenden an, den Geist dieser Welt (das ,wilde Tier"), die buhlerischen religiösen Mächte der Welt und die ,wahre“ Geistesgemeinschaft („Gemeinschaft der Heiligen") auseinander zu halten. In der Apokalypse wird die Verstrickung aller Mächte, der religiösen mit den weltlich-geistigen (auf ideeller Ebene) und der religiösen mit den weltlichen (auf weltlich-materieller Ebene), in einem ungeahnten Ausmaß Wirklichkeit. Wer in dieser Situation nicht ,,wahrlich“ weise ist, kann nicht erkennen, wer die ,wahrhaft“ Geistgesinnten eigent- 
lich sind und wo die „Lichter“ leuchten. Wer ist „heilig“ („gut")? Und: Wo ist die „unsichtbare“ Gemeinschaft der Heiligen?

Solange die Buhlerin noch am Werk ist, ist die Desorientierung nahezu vollständig. Erst mit Auslöschung der Buhlerin durch die monolithische Herrschaftsphalanx bricht die von der Buhlerin symbolisierte Indifferenz von wahrhaft Geistgesinnten und Heuchlern auf. Die „wahrhaft Geistgesinnten“, die in den unterschiedlichsten Glaubensgemeinschaften „Lichter“ bilden, indem sie immer schon an den Machenschaften der Buhlerin Anstoß nahmen, erkennen nun einander als sichtbare Gemeinschaft. Auch sie tragen inzwischen ein Erkennungszeichen, das sie glasklar von der bösen Herrschaftsallianz dieser Welt unterscheidet. Erst in dieser Situation wird Wahrheit Bewegung, bewegte Wahrheit, die angekommen ist. Bis dahin ist es unsichere Wahrheit, welche im Dunkel dieser Welt, aber auch im Dunkel religiöser Heuchelei eingetrübt bleibt.

Freilich, die „Lichter“ gibt es immer schon. Sie werden jedoch von den Fesseln und Grenzen der eigenen Institution gefangen gehalten. Es ist aber geoffenbart, dass die globalisierten säkularen Mächte zum Instrument der Beseitigung der „Institution Buhlerin“" werden, womit auch die Grenzen der Institution für alle Geistgesinnten fallen. Schließlich wird das ,wilde Tier“ allein die Weltherrschaft antreten und den Unterschied zu den Geistgesinnten markieren. In dieser kurzen Zeit kann Licht zu Licht treten und das Königreich „des Lammes“ (Offb 17.14) sichtbar werden, das ein letztes Mal in der Rolle des Sündenbocks den Hass des „,wilden Tieres" auf sich zieht. - Die allerletzte Auseinandersetzung zwischen Tod und Leben eröffnet den Übergang in die Hervorbringung zurück ...

\section{Literatur}

Ernst, Werner (1998): „Psychoanalyse und Frieden“, in: Österreichisches Studienzentrum für Frieden und Konfliktlösung, Hg.: Über die Schönheit und Mächtigkeit des Kleinen. Die Leopold Kohr-Vorlesungen. Münster: Agenda Verlag.

Ernst, Werner (2004): „Wissenschaftspositivismus und Psychoanalyse“, in: Ernst, Werner/Walter, Hans Jörg, Hg.: Psychoanalyse an der Universität. Wien: LIT.

Freud, Sigmund (1969): „Neue Folge der Vorlesungen zur Einführung in die Psychoanalyse“, in: Freud, Sigmund: Studienausgabe. Band I: Vorle- 
212 Das religiöse Denken und das Böse

sungen zur Einfübrung in die Psychoanalyse und Neue Folge. Frankfurt/M.: Fischer.

Scholem, Gershom (1977): Von der mystischen Gestalt der Gottheit. Frankfurt/M.: Suhrkamp. 


\section{Allmacht und andere Mächte und Gewalten. Skizze eines systematisch-theologischen Projektes zum Verhältnis von Gott und politischem Diskurs in einer „postsäkularen“ Zeit}

Roman A. Siebenrock

In diesem kurzen Aufsatz möchte ich jenes Projekt skizzieren, das mich im Diskurs der Forschungen dieser Gruppe in den nächsten Jahren bewegen wird. Der Kern dieses Projektes beruht auf folgender Voraussetzung. Die Vorstellung von einer Säkularisierung unserer Gesellschaft beruht entscheidend auf der christlichen Tradition bzw. deren konkreten kirchlichen Ausprägungen (vor allem im Westen). Auch die europäische Religionskritik war faktisch Christentumskritik, näherhin Kirchenkritik. Wird ein so bestimmter Religions- und Säkularisierungsbegriff universalisiert, dann wird er entweder inhaltsleer oder imperialistisch - also außerstande, andere Kulturen auch nur angemessen wahrzunehmen. ${ }^{1}$ Er scheitert schon daran, dass es gerade auf dem Feld der "politischen Theologie“2 eine hohe Heterogenität zwischen den einzelnen christlichen Traditionen gibt. ${ }^{3}$

1 Während diese Einsicht sich in der These der Unangemessenheit eines universalisierten Religionsbegriffs schon durchgesetzt hat, ist die entsprechende Einsicht bei der analogen Fragestellung im Problembereich der Säkularisierung erst im Kommen.

2 Zur Orientierung siehe Siebenrock (2005a).

3 Die Konzepte des Staatskirchentums, der Trennung oder Kooperation von Kirche und Staat sowie der Ablehnung des Kirchenbegriffs in freien kleinen Gemeinschaften, deren Bedeutung für die neuzeitliche Entwicklung der Religions- und Gewaltfreiheit nachzugehen sein wird, können nicht unter einem übergeordneten Konzept zusammengefasst werden. Die Kriterien, die das Verhältnis von Glaubensgemeinschaft und Staat bzw. politischer Gemeinschaft nach katholischer Auffassung heute bestimmen, sind in der Erklärung des Zweiten Vatikanischen Konzils über die Religionsfreiheit zusammengefasst worden; siehe Siebenrock (2005b). In diese Erklärung fließen sowohl säkulare Rechtsvorstellungen wie Impulse der sogenannten Freikirchen des 15. und 16. Jahrhunderts ein. 
Auf der anderen Seite wurde nach der Aufklärung jene Leerstelle, die das traditionelle Christentum als ,gemeinsames Band“ der Gesellschaft zuvor eingenommen hatte, mit unterschiedlichen Höchstwerten gefüllt: Nation, Wissenschaft, klassenlose Gesellschaft, die Geschichte oder auch die eigene Maximierung der Handlungs- und Lustmöglichkeiten. In meinem Projekt erachte ich solche Letztorientierungen als „funktionale Götter"4 und gehe von der Auffassung aus, dass keine Gesellschaft ohne ein ,geheimes Band, das immer transzendenten Charakter" hat, auf Dauer bestehen kann. ${ }^{5}$ Meine Frage im Projekt lautet daher: Welcher Höchstwert, welcher „Gott" kann überhaupt mit guten Gründen beanspruchen, als Letztwert und Letztorientierung anerkannt zu werden? Was oder wer ist es wert, ein Gott genannt zu werden? Vielleicht, so könnte es sein, noch keiner von denen, die in unserer Geschichte bislang als mögliche Kandidaten für eine solche Position um Hilfe angegangen, gepriesen und angebetet wurden. Dies nenne ich die „suchende Messianologie“ der Politik, oder deren implizite Theologie. Damit setze ich den Diskurs der Aufklärung, wie Kant ihn verstanden hat, neu ins Recht, ${ }^{6}$ beschränke ihn aber nicht auf institutionalisierte Religionsformen, sondern erweitere ihn auf jeden möglichen Kandidaten, der beansprucht, Menschen für sich letztgültig in Anspruch zu nehmen.

Als Prüfungskriterium verwende ich eine doppelte Indizierung, die in folgenden Fragen ausgedrückt werden soll. Erstens: Was bedeutet Macht, und wie ist Allmacht zu verstehen? Von woher beziehen wir unsere Vorstellungen von Macht und wie können wir sie von anderen Formen menschlicher Wirkungsweisen, vor allem von Formen der Gewalt, unterscheiden oder abgrenzen? Diese Fragestellung ist ebenso elementar theologisch wie politisch. Lässt sich Gott überhaupt denken, ohne ihn als mächtig bzw. allmächtig zu denken? Und lässt sich über Politik ein Diskurs eröffnen, ohne zentral die

4 Damit greife ich auf den ältesten Gottesbegriff zurück: Mit dem Begriff „Gott“ in seinen unterschiedlichen Namensvarianten wurden die lebensbestimmenden Mächte des Menschen benannt. Gott lässt sich nur aus seinen Wirkungen erkennen und benennen.

5 Der Begriff „transzendent“ muss hier nicht ontologisch interpretiert werden. Er besagt, dass eine gemeinsame Übereinstimmung gestiftet werden muss, die den Einzelnen übersteigt. Diese „transzendente“ Gemeinsamkeit vermag aber Menschen zu motivieren, ihre Ganz-Hingabe in Anspruch zu nehmen - ja sie sind bereit, dafür ihr Leben einzusetzen (siehe unten: Leithypothese 3).

6 Siehe Kant (1968). 
Frage nach Macht und Gewalt zu stellen? Deshalb lautet auch der Titel des Projekts: „Allmacht und andere Mächte und Gewalten“. Das zweite Indiz stellt die Frage von der Konsequenz der Macht bzw. Allmacht für den Menschen: Welcher Wert ist berechtigt, unsere vollständige Hingabe zu fordern? Oder: Wofür ist die Lebenshingabe begründbar? Was oder wer darf das Leben kosten? Dieses Indiz stellt die Frage nach Leben und Tod, nach dem berechtigten Martyrium, aber auch nach dem Missbrauch der Hingabe- und Opferbereitschaft der Menschen. Dabei gehe ich von der Erfahrung aus, dass in einer endlichen Welt in Anbetracht der Unendlichkeit der menschlichen Sehnsucht und Begierde keine Politik ohne Verzicht und Opfer auskommen kann. ${ }^{7}$ Dieses Hauptinteresse ist nun in drei Leithypothesen etwas zu entfalten und von einem ersten theologischen Hintergrund her zu skizzieren. Auf diesem Hintergrund möchte ich mit den Personen und Ansätzen in unserer Arbeitsgruppe ins Gespräch kommen - prüfend, korrigierend, vertiefend.

\section{Leithypothese 1: Zum Verhältnis von ausdrücklichem und chiffriertem Gottesdiskurs}

Dem Theologen ist es aufgegeben, die Rede Gottes (von und über Gott) zu kultivieren. Im Gegensatz zur Tradition ist heute von einer doppelten „Verstellung“ der Gottesfrage auszugehen. Auf der einen Seite ist die Frage nach Gott implizit immer gegeben, auch wenn gerade heute deren Diskurs wieder aus der Öffentlichkeit ins Private zu verbannen gesucht wird. ${ }^{8}$ Aus anthropologischen Gründen ist die Frage nach Gott grundsätzlich nicht zu eliminieren. Sie ist daher immer auch öffentlich zu verantworten, und zwar im Kontext eines prinzipiellen Pluralismus und der ontologischen Strittigkeit Gottes. Die Strittigkeit Gottes in Europa, d.h. die Genese und Wirkung des neuzeitlichen Atheismus, sehe ich aber als Konsequenz der Friedensunfähigkeit der christlichen Konfessionen im 16. und 17. Jahr-

7 Dieses Moment zu missachten, scheint mir die gefährlichste Selbstlüge unserer Gesellschaft zu sein. Aus diesem Grunde sehe ich die Hauptaufgabe der Politik heute darin, die größten Katastrophen zu verhindern, und nicht darin, als Diensleistungsunternehmen das persönliche Glück aller zu garantieren. Wodurch aber können und werden Menschen motiviert, auf eigene Lebensmöglichkeiten zu verzichten?

8 Es könnte auch gefragt werden, welche Privatheit in einer medial strukturierten Öffentlichkeit - Big Brother lässt grüßen - es überhaupt noch geben kann? 
hundert an. Aus diesem Grund ist die heutige Debatte um Säkularisierung und Politik immer auf dem Hintergrund der realen kirchlichen Praxis dieser Zeit zu verstehen. Wenn also über Religion und Politik gesprochen wird, bleibt diese Frage so lange abstrakt, bis nicht die konkrete Frage nach den Ansprüchen und Handlungen der realen Repräsentanten und Institutionen, die „Religion“ in der Gegenwart wirksam werden lassen, aufgeworfen wird. Daher geht es letztlich nicht um Gott, sondern um Gruppen, die beanspruchen, im Namen Gottes zu sprechen und zu handeln? Deshalb stellt sich die Frage nach der entscheidenden, maßgeblichen und normativen Repräsentation Gottes in unserer Geschichte bzw. Gegenwart. Gibt es in der Geschichte ein „Maß Gottes“, und zwar ein letztgültiges, für das sich Gott selbst verbürgt?

\section{Erläuterung}

Der systematischen Theologie ist es aufgetragen, alles mit Rücksicht auf Gott, „,sub ratione dei“,, zu betrachten. Dabei ging die Theologie traditionell von einem schon bestimmten Gottesbegriff aus - einem Gottesbegriff, der durch die Philosophie, insbesondere durch die Tradition Platons und Aristoteles sowie die jüdisch-christliche, später islamische Tradition geprägt worden war. Diese Tradition umfasste sehr wohl im Neuplatonismus, den Mysterienreligionen und der antiken Gnosis auch das reichlich unübersichtliche religiöse Gesamtfeld mit einer Vielzahl an sehr unterschiedlichen gemeinschaftlichen Ausprägungen. Von einem solchen vorab bestimmten Gottesbegriff aber können wir heute nicht mehr ausgehen. Ich möchte für diese Unbestimmtheit, die aber immer noch auf Restbestände der religiösen und philosophischen Tradition vor allem in der Kritik zurückgreift, deshalb den Platzhalter „G.O.T.T.“ (sprich: „,tschi-ou-titi“) einführen. Dieser Platzhalter „G.O.T.T.“, vergleichbar mit einer neu einzuführenden Marke, kann jedoch ganz unterschiedlich ausge-

9 Diese klassische, auf Thomas von Aquin zurückgehende Definition der Theologie als Reflexion der Rede Gottes im doppelten Genetiv hat Wolfhart Pannenberg erneuert; siehe Pannenberg (1988), 15. Auch wenn diese Bestimmung der Theologie nicht von allen geteilt wird, ist für das hier entworfene Projekt diese Bestimmung deshalb bedeutsam, weil sie einerseits eine funktionale Vorgehensweise zulässt, andererseits aber unbedingt auf die Frage nach der realen Existenz Gottes beharren muss. Diese aber ist heute allein im Modus der Strittigkeit zu verhandeln. Deshalb wird das systematische Interesse nicht durch die Frage über Nutzen oder Schaden der Religion bewegt, sondern allein - ontologisch durch die Frage nach der Wirklichkeit Gottes. 
füllt werden. Dass diese Leerstelle innerhalb einer Gesellschaft und unter den normalen Bedingungen eines menschlichen Lebens nicht unausgefüllt bleiben kann, ist für mich eine Voraussetzung in der Suchbewegung meines Projektes. ${ }^{10}$ Wofür steht aber dieser Platzhalter? Formal gesprochen kann die Marke G.O.T.T. wie folgt eingeführt werden: Von G.O.T.T. spreche ich, wenn ich vom Ganzen meiner selbst und der Welt, und zwar in Verschränkung, spreche. Diese existentiell imprägnierte Frage nach G.O.T.T. wird aber in unserer menschlichen Geschichte nicht neutral gestellt, sondern immer im Kontext des Leides und des Todes. Daher bedarf es des Zusatzes: „,und zwar im Blick auf mögliches Heil angesichts der Erfahrung von Unheil und prinzipiellem Scheitern." Dieser Zusatz kann ausfallen und ist auch in manchen religionsgeschichtlichen Traditionen ausgefallen oder wenigstens sehr ins Hintertreffen geraten. Heute aber ist dieser Zusatz wegen der entfesselten Sehnsucht und einer fast schon als krank zu bezeichnenden Forderung nach Glück ${ }^{11}$ nicht unwichtig - insbesondere für den demokratischen Diskurs. Daher kann jetzt formuliert werden: „Von G.O.T.T. ist dann die Rede, wenn vom Ganzen meiner selbst und der Welt in Verschränkung die Rede ist; - und zwar im Kontext von Leid, prinzipiellem Scheitern und Tod im Blick auf mögliches Heil. Die politische Brisanz dieser Orientierung liegt darin, dass sich auch die persönlichste Fassung dieser Suche immer im historischen, gesellschaftlichen und politischen Raum entfaltet und daher die Erwartungen und Sehnsüchte, die darin zum Ausdruck kommen, als politische Mächte entfalten können.

Im Diskurs unserer Arbeitsgemeinschaft, der mit diesem Band eröffnet wird, scheint diese Fragestellung - vor allem mit ihrem on-

10 In hoher Disziplin, als Beispiel kann auf den frühen Buddhismus verwiesen werden, ist eine solche Zurückhaltung durchaus möglich. Gesamtkulturell aber ist eine solche Askese noch nie verwirklicht worden. Ist es nicht bezeichnend, dass der Buddhismus in Europa zunächst als ,atheistische Religion“ gepriesen worden ist?

11 Die Frage nach Glück ist gewiss eine der wichtigsten Grundvoraussetzungen, die Frage nach Gott angemessen zu stellen. Krankhaft scheint mir aber unsere Situation vor allem aus zwei Gründen zu sein: Erstens kann ich nicht sehen, wie es ein Recht oder einen Anspruch auf Glück im menschlichen Leben aufgrund unserer naturalen Gegebenheiten geben könnte. Von der Biologie aus und der Erfahrung der Geschichte her, sind - wie schon Hegel meinte - die Blätter des Glücks in der Geschichte leer. Pathologisch aber wird diese Forderung an Politik, Medizin und andere „Paradieses-Unternehmungen“, wenn das Glück als Leistung der Menschen eingefordert wird. Ist Glück machbar? Oder sollten wir nicht besser von Ablenkung, Kurzweil oder Vergnügen sprechen? - „Have fun!“ Deshalb stellt sich die Frage nach der Möglichkeit von Politik im Zeitalter der Apokalyptik. 
tologischen Gewicht - etwas abwegig zu sein. Geht es ja bei vielen politisch-gesellschaftlichen Fragen nicht primär um die Existenz Gottes, sondern um die Art der Wirksamkeit des Gottesgedankens für eine bestimmte Gemeinschaft, ihre Verfasstheit auf juristischer und gesellschaftlicher Ebene. Gewiss stellt sich heute diese Frage nach Gott nicht mehr auf eine Gruppe begrenzt, sondern immer im Horizont der globalen Menschheit, die durch ihre kulturelle Vielfalt grundsätzlich nicht auf die Optionen der westlichen Gesellschaft verpflichtet werden kann. ${ }^{12}$ Insofern gerät jede Vorstellung vom Ganzen der Welt und der Stellung des Menschen in ihr mit vielen anderen in Spannung, Dialog und/oder Konkurrenz. Damit wird immer implizit oder explizit die Frage nach Gott gestellt. Wenn die menschliche Vernunft aber immer die Frage nach dem Gesamt der Wirklichkeit stellen muss, dann ist auch die politisch-gesellschaftliche Wirklichkeit, insoweit sie vernünftig verantwortet werden soll, vor diese Frage nach dem Ganzen der Wirklichkeit gestellt. Sie hat diese Frage nicht ontologisch zu beantworten. Vielmehr stellt sich dem politischen Diskurs diese Frage in der Brechung der Macht: Mit welcher Wirklichkeit und der von ihr ausgehenden Macht haben wir zu rechnen? Mit welchen Einflüssen, Gesetzmäßigkeiten, Interdependenzen sowie direkten und indirekten Folgen unseres Handelns haben wir zu rechnen? Mit welcher Wirklichkeit und ihrer Macht als Einfluss und Konsequenz haben wir in unserem persönlichen und gemeinschaftlichen Leben zu rechnen? Und auf dieser Ebene stellt sich die Frage nach Gott allemal, weil auch heute Menschen - ob berechtigt oder nicht - Gott in Anspruch nehmen, sei es unter den Chiffren der Nation, der Geschichte, der Natur - oder auch nur unter dem Pseudonym der Verantwortung für kommende Generationen.

Damit aber steht der systematische Theologe in jenem Kontext, in dem die Christ(inn)en von Anfang an standen - im Kontext des dreifachen Gebrauchs des Wortes „Gott“: eines mythischen, eines

12 In seinem Gespräch mit Jürgen Habermas hält Joseph Ratzinger zunächst fest: "Was folgt aus alledem? Zunächst einmal, so scheint mir, die faktische Nichtuniversalität der beiden großen Kulturen des Westens, der Kultur des christlichen Glaubens wie derjenigen der säkularen Rationalität, so sehr sie beide in der ganzen Welt und in allen Kulturen auf je ihre Weise mitprägend sind“ (Joseph Ratzinger (2005) 54). Deshalb plädiert er für die Vorstellung einer ,polyphonen Korrelation“ der Weltkulturen (ebd., 57). 
politischen und eines physischen bzw. natürlichen. ${ }^{13}$ Der erste Typus der Gottesrede war das Metier der Dichter. Augustinus nannte diesen das „genus fabulosum“. Es diente schon damals der Unterhaltung und spielte sich vor allem auch auf dem Theater ab - und richtete sich daher nach den Erwartungen, dem Geschmack und den Unterhaltungsvorstellungen des Publikums. Dass dieser Typus der Gottesrede heute omnipräsent ist, muss nicht begründet werden. Der alte Satz des Thales gilt wenigstens in dieser Hinsicht heute: Die Welt ist voller Götter, die Medienwelt allemal. Der zweite Typus, das ,genus civile“, war jener Gebrauch der Gottesrede, der den Staatsmännern nützte, der also die politische Realität in all ihren Bereichen durchdrang. Beide zuerst genannten Typen gingen nach Augustinus ineinander über. Von beiden hielt der lateinische Kirchenvater nichts. Dem letzten Typus, dem natürlichen (physischen, griechisch: kata physin) räumte er allein Bedeutung ein. In dieser Gottesrede, die die Aufgabe der Philosophen war, ging es darum, nach der Natur, dem Wesen, der Wahrheit Gottes zu fragen. Sie war vom Leitsatz Platons geprägt: „Wie Gott ist seinem Wesen nach, so muss er auch immer dargestellt werden, mag einer im Epos von ihm dichten oder in Liedern oder in der Tragödie. So muss es sein. Nun ist doch Gott wesentlich gut und auch so darzustellen." ${ }^{14}$ Damit aber werden die anderen Typen mit einer inhaltlichen Bestimmung kritisiert. Die funktionalen Gottesreden haben daher ihr Maß an einem ontologischen Kriterium, das es auch heute noch einzuholen und zu bedenken gilt. Aus diesem Grund wird mein Projekt die funktionalen Gott-Reden mit substanziellen Fragestellungen belästigen. Dabei leitet mich die These: Auf Dauer ist die humane Funktion der Gottesrede allein auf der Basis der ontologischen Bestimmung der Wahrheit Gottes aufrechtzuerhalten. Jede Gottesrede kann daher an dieser sittlichen Bestimmung durch jeden Menschen, der seine Vernunft gebraucht, geprüft werden. Aber umgekehrt auch: Jede Letztorientierung ist in

13 Siehe Augustinus, De civitate Dei VI, 5-10. In dieser Passage wird uns die Unterteilung des Stoikers Varro aus dem ersten Jahrhundert nach Christus überliefert. - Und es wird sich im Folgenden zeigen, dass diese alte Orientierung bis heute sinnvoll und nützlich ist. Während Varro - wenigstens in der Tradition von Augustinus - diese Typen nicht nur zu unterscheiden versucht hat, sondern auch in ihrer Bedeutung zu trennen, werde ich zwar wie er die Bedeutung der natürlichen Theologie hervorheben, aber die beiden anderen Typen als Implikationen oder als mögliche Formen kontextuellen Gebrauchs bzw. Missbrauchs des Gottesbegriffs untersuchen.

14 Politeia (Der Staat) 379ab. 
gleicher Weise zu bemessen. Daher ist jeder chiffrierte Gottesdiskurs ausdrücklich substantiell zu messen. Dabei bleibt zu Beginn die Frage offen, ob es überhaupt möglich sein wird, eine funktionale Bestimmung Gottes zu überschreiten. Die Unausweichlichkeit der Gottesrede auf dem gesellschaftlichen und politischen Feld bezieht sich zunächst auf die funktionale Bestimmung. Nun die Frage: Kann der Eigendynamik dieses funktionalen Gottes- und Religionsbegriffs Einhalt geboten werden, ohne auf Gott selbst, den wahren Gott zu rekurrieren? Ich stelle die Hypothese auf: Den falschen und gefährlichen Gottesbildern kann nur mit kritischem Rekurs auf den wahren Gott Einhalt geboten werden. Im Prozess unserer Arbeitsgemeinschaft soll diese These an einer zentralen Eigenschaft Gottes verdeutlicht werden.

\section{Leithypothese 2}

Die vorzügliche Eigenschaft Gottes in unserem Diskursfeld ist die Macht bzw. die Allmacht Gottes. Ich frage, ob der gängige politische Machtbegriff nicht bereits untrennbar theologisch konnotiert ist. Dies ist auch dann gegeben, wenn auf eine säkulare Bestimmung der Macht und ihrer Begründung höchster Anspruch erhoben wird. In der theologischen Tradition interessiert mich dabei vor allem die interne Selbstkorrekturkraft. Außerdem stellt sich die Frage, ob eine politische Gemeinschaft (welcher Art auch immer) ohne religiöse Rahmenbedingungen konstituiert werden kann. Die Rede von der civil religion, die einige Autoren in diesem Band ansprechen, bestätigt diese Vermutung. Bislang leben wir immer noch von den Traditionen, deren bedeutendste vielleicht die Idee des „Leibes Christi“ und des „Reiches Gottes“ - auch in ihrer Ambivalenz - war.

\section{Erläuterung}

Die Verbindung von Gottesvorstellung und Politik ist älteste Tradition. Von der Verkörperung Gottes im König über das Gottesgnadentum bis zu messianischen Hoffnungen, mit denen wir bis heute politische Wenden, Führer oder „Leader“ erwartungsvoll umgeben, reicht die Palette. Auch wenn der Kern der Säkularisierung vielleicht in der nicht theistischen Begründung politischer Verantwortung liegt, sind Hoffnungen und Sehnsüchte der Menschen und Selbstwahrnehmungen der politischen Elite nicht immer identisch damit. Mit 
welchen theologischen Orientierungen in der Bestimmung der göttlichen Macht bzw. Allmacht trete ich aber in den Diskurs ein?

Dieser Diskurs ist durch die Komplexität der sich überlappenden Begriffsfelder, mit denen Macht bzw. Gewalt beschrieben werden, gekennzeichnet. Dabei ist auffallend, dass die Theologie heute eine deutliche Reserve gegenüber dem Allmachtsbegriff an den Tag legt. Der vielfältige Gebrauch der Begriffe zeigt sich auch in unserem Sprachgedächtnis. Insofern der politische und theologische Diskurs bis in die Neuzeit hinein zunächst griechisch, dann lateinisch und schließlich deutsch geführt wurde, durchdringen sich die Begriffsfelder. Es ist kaum möglich, für die verschiedenen Einzelbegriffe eine eindeutige Übersetzung zu geben. Im Griechischen werden Begriffe wichtig wie: ,arche“, „dynamis“, „exousia“; im Lateinischen: „dominium“ (Herrschaft/Eigentum), ,auctoritas“, „potentia“, „potestas“, „vis“; im Deutschen wiederum: „Herrschaft", „Gewalt", „Kraft“, „Können/Vermögen“ oder neudeutsch „Power““.15

In dieses semantische Minenfeld werde ich die theologische Tradition nicht allein einbringen - sie muss sich in solchen Untiefen bewähren. ${ }^{16}$ Die theologische Tradition spricht von Gott als dem

15 Siehe vor allem: „Macht/Gewalt“, in: Geschichtliche Grundbegriffe. Band 3 (1982), 817-935. Dieser umfangreiche Artikel nennt die religiösen Traditionen nur, wenn unausweichlich (vor allem im Mittelalter). Er favorisiert eine Säkularisierung des politischen Machtbegriffs im Rahmen der Entwicklung zum Verfassungsstaat, auch wenn dieser in seiner Verantwortung über die Menschen ausdrücklich hinausgreift. Dies entspricht sehr wohl einer geschichtlichen Entwicklung, die z.B. Mazohl-Wallnig für das Heilige Römische Reich bis 1806 nachzeichnet; siehe Mazohl-Wallnig (2005). Dabei stellt sie folgende, für mein Projekt höchst bedenkenswerte These im Blick auf die Selbstkrönung Napoleons und die Kaisererhebung Franz' II. auf: „Es hatte damit ein neues Zeitalter begonnen, ein Zeitalter, in welchem das Prinzip der Macht und die Durchsetzung politischer Eigeninteressen an die Stelle der alteuropäischen Rechtsordnung getreten waren, die - zumindest in der Theorie - das Recht über die Macht gestellt hatte“. Mazohl-Wallnig (2005), 254. Dass diese Formalisierung der Interessen bzw. ihre Wahrnehmung ausschließlich unter dem Aspekt der Durchsetzbarkeit nicht nur national, sondern auch individuell Konsequenzen zeitigte, macht sie an zwei kurzen Bestimmungen deutlich. So kann sie den Ersatzgott dieser Zeit, die Nation, als ,nationalen ,Dämon“" bezeichnen; siehe Mazohl-Wallnig (2005), 270. Und weiters: „Die neuen Eliten definierten sich nicht mehr durch Geburt, Recht und Amt, sondern durch Geld und (Steuer-)Leistung“. Mazohl-Wallnig (2005), 269.

$16 \mathrm{Mehr}$ orientierend als begründend und selbstkorrigierend heißt es im Katechismus der Katholischen Kirche Nr. 268: „Von den Attributen Gottes wird im Symbolum einzig die Allmacht angeführt; sie zu bekennen, ist für unser Leben von großer Bedeutung. Wir glauben, daß sie sich auf alles erstreckt, denn Gott, der alles erschaffen hat, lenkt alles und vermag alles. Wir glauben auch, daß sie liebend ist, denn Gott ist unser Vater; ferner, daß sie geheimnisvoll ist, denn einzig der Glaube vermag sie auch dann wahrzunehmen, wenn sie 
Allmächtigen, im Blick auf drei maßgebliche Kontexte: Schöpfung, Auferstehung Christi und Vollendung der Welt im Gericht. Von dieser Orientierung her stellt sich die Frage, ob nicht auch im politischen Bereich in ähnlichen Kontexten von Macht gesprochen wird. Aus diesem Grund wird die Allmacht Gottes zumeist theologisch mit zwei Bestimmungen charakterisiert: die Fähigkeit, alles zu können, was sie will, und die Eigengesetzlichkeit oder Freiheit. Für diese Tradition stand zunächst Johannes von Damaskus: Gottes Allmacht ist diesem zufolge ,eine Macht, die durch kein Maß erkannt, die nur durch den eigenen Willen gemessen wird. Denn sie kann alles, was sie will.“17 Augustinus hatte schon zuvor gesagt: „Er macht, was immer er will. Dies ist die Allmacht. Er macht, was immer er in guter Weise will, was er in gerechter Weise will. Was immer aber auf schlechte Weise geschieht, will er nicht. Niemand widersteht der Allmacht (vgl. Röm 19.9), so dass er (Gott) nicht machen könnte, was er will"“. ${ }^{18}$ Damit wird eine erste Einschränkung deutlich - die sittliche Bestimmtheit der platonischen Tradition: die Gutheit Gottes. Gott kann nichts Böses wollen, denn Gott ist das sich selbst verströmende Gute. ${ }^{19}$

Thomas schließlich verwendet den klassischen lateinischen Machtbegriff „potentia“, den er als reine Verwirklichung und Aktivität Gottes verstanden haben möchte: "esse principium activum, et nullo modo pati". ${ }^{20}$ Gott ist frei von jeglichem Leiden oder Passivität. Dabei fügt Thomas eine weitere Einschränkung ein, die entscheidend sein wird: die logische Möglichkeit: "[...] quod possit omnia possibilia, et ob hoc omnipotens dicatur". ${ }^{21}$ Mit solch formaler Vorstellung gibt sich jedoch Thomas nicht zufrieden. Er möchte vielmehr auch die Vollzugsweise der Allmacht Gottes beschreiben: “[...]

,ihre Kraft in der Schwachheit‘ erweist (2 Kor 12, 9). ,Alles, was ihm gefällt, das vollbringt er."“

17 De fide orthodoxa I, 8; mit Hinweis auf Ps 135.6.

18 De Symbolo ad Catechumenos I, 2.

19 Diese plotinische Bestimmung Gottes wird in der Tradition durch (Pseudo-)Dionysius Areopagita wirksam; siehe: De divinis nominibus 4,1.

20 Summa theologiae, I, q 25, a 1, corpus. Damit werden nur sprachlich äußerbare Möglichkeiten ausgeschlossen, wie die Schaffung eines „quadratischen Kreises“. Diese Möglichkeit ist deswegen unsinnig, weil sie nicht einmal als möglich gedacht werden kann. Im Gegensatz hierzu ist ein Einhorn als durchaus real möglich anzusehen.

21 STh, I, q 25, a 3, corpus: „Er kann alles, was möglich ist. Und deshalb wird Er allvermögend genannt". 
quod Dei omnipotentia ostenditur maxime in parcendo et miserando". 22

Am Ende des Mittelalters wird diese sittliche Bestimmtheit der göttlichen Allmacht aufgehoben. Es kommt zu einer Diskussion, die als Differenz von „potentia absoluta“ und „potentia ordinata“ die nachfolgende Tradition bestimmt. ,absoluta“ ist die Macht Gottes, weil sie an keine sittlichen Bestimmungen gebunden ist. Damit wäre die Kohärenz aller göttlichen Eigenschaften (z.B. Freiheit, Liebe, Gerechtigkeit und Barmherzigkeit) negiert. Meine Hypothese ist: Die Kritik an und der Ausschluss der Religion aus dem öffentlichen Diskurs begründen sich direkt oder indirekt mit dieser „Willkürvorstellung“ der göttlichen Allmacht. ${ }^{23}$ Bei Duns Scotus gewinnt dieser Gedanke seine Bedeutung mit der Auffassung, dass alle möglichen Ordnungen radikal kontingent seien. Den Folgen dieser These ist nachzugehen. Martin Luther schließlich zieht daraus die entscheidenden Konsequenzen: „Das gehört zu den Geheimnissen der göttlichen Majestät, in der seine Entscheidungen unbegreiflich sind. Und es ist nicht unsere Aufgabe, das wissen zu wollen, sondern vielmehr, diese Geheimnisse anzubeten [...] Es ist Gott, und für seinen Willen gibt es keine Ursache noch Grund, die ihm als Richtschnur und Maß vorgeschrieben werden könnte, da es nichts gibt, das ihm gleich oder über ihm ist. Sondern sein Wille ist Richtschnur für alle Dinge [...] Denn nicht deswegen, weil es ihm ziemt oder ziemte so zu wollen, ist richtig, was er will, sondern im Gegenteil: weil er selbst so will, deswegen muss recht sein, was geschieht."24 Ist Gottes Wille wirklich so? Bleibt die Allmacht im Kontext der Willkür?

Mich bewegt die Hypothese, dass die reale Geschichte ausgelebt und ausgelitten hat, was solches Denken als Möglichkeit und Bestimmung zuvor gedacht hat. Ich frage: Ist nicht die Formalisierung der Macht, d.h. ihre Loslösung von allen sittlichen (d.h. rechtlichen) Bestimmungen nicht eine Konsequenz von solchen Gedankenexperimenten? Gereicht es Gott wirklich zur Ehre, wenn er - faktisch als reine Willkürlichkeit erscheint. Ich räume hier gerne ein, dass ich

22 STh I, q 15, a 3, ad 3: „Gottes Allmacht zeigt sich am meisten im Schonen und Erbarmen“.

23 Wirksam vermittelt wurde diese These durch Blumenbergs monumentales Werk Die Legitimität der Neuzeit: Theologisch entscheidend ist in ihm die These, dass die Selbstbehauptung des Menschen als legitime Abkehr von einem unberechenbaren Gott und seiner Willkürmacht im Kontext des spätmittelalterlichen Nominalismus anzusehen sei.

24 De servo arbitrio, WA 18, 712. 
ein ,Thomist“ bin. ${ }^{25}$ Daher bleibt für mich eine wesentliche Aufgabe meines Projektes, einen Machtbegriff zu entwickeln, der nicht in die Aporien und die Fallen dieser Tradition gerät. Für diesen Machtbegriff gibt es drei erste Konkretionen: die logische Einschränkung, die ontologische Bestimmtheit und die sittliche Eindeutigkeit. Dieser Ansatz setzt voraus, dass alle Menschen, die im Besitz eines normalen und funktionstüchtigen Vernunftvermögens sind, darüber ihr Urteil fällen können.

Zum Unternehmen einer umsichtigen Fassung des Machtbegriffs gibt es einen entscheidenden Beitrag aus der Tradition, der hier - gerade wegen seiner Bedeutung - ausführlich zitiert werden darf. Er ist vom „,säkularen“ Diskurs um Macht noch kaum zur Kenntnis genommen worden:

„Die ganze Frage nach dem Verhältnis von Gottes Allmacht und Güte zum Bösen kann vielleicht (anstelle der Begriffsunterscheidung, daß Gott das Gute bewirkt und das Böse zuläßt) ganz schlicht folgendermaßen aufgelöst werden. Das Höchste, das überhaupt für ein Wesen getan werden kann, höher als alles, wozu einer es machen kann, ist dies: es frei zu machen. Eben dazu, dies tun zu können, gehört Allmacht. Dies scheint absonderlich, da Allmacht gerade abhängig machen müsste. Aber falls man Allmacht denken wird, wird man sehen, daß eben in ihr zugleich die Bestimmung liegen muss, sich selbst wieder solchermaßen in der Äußerung der Allmacht zurücknehmen zu können, daß eben deshalb das durch die Allmacht Entstandene unabhängig werden kann. Daher kommt es, daß ein Mensch den andern nicht ganz frei machen kann, weil der, welcher die Macht hat, selbst darin gefangen ist, daß er sie hat und deshalb ständig doch ein verkehrtes Verhältnis zu dem bekommt, den er freimachen will. Dazu kommt, daß in aller endlichen Macht, Begabung usw. eine endliche Selbstliebe ist. Allein die Allmacht kann sich zurücknehmen, indem sie sich hingibt, und dies Verhältnis ist ja eben die Unabhängigkeit des Empfangenden. Gottes Allmacht ist darum seine Güte. Denn Güte kann sich ganz hingeben, aber dergestalt, daß man, indem man allmächtig sich selbst zurücknimmt, den

25 Diese Frage durchzieht die Regensburger Rede von Papst Benedikt XVI. Auch wenn im Blick auf die persische Tradition ein aristotelisch-thomistischer Standpunkt eine tiefe Verbundenheit bedeutet hätte und der Papst also mit seinem Vorwurf der Willkür gerade an diese Tradition irrte, bleibt die grundsätzliche Thematik gerade für diese Arbeitsgemeinschaft entscheidend. 
Empfangenden unabhängig macht. Alle endliche Macht macht abhängig. Allmacht allein vermag unabhängig zu machen, aus dem Nichts hervorzubringen, was dadurch inneres Bestehen empfängt, dass die Allmacht sich ständig zurücknimmt. Die Allmacht ist nicht in einem Verhältnis zu andern gelegen, denn es gibt kein Anderes, zu dem sie sich verhält, nein, sie vermag zu geben, ohne doch das Mindeste von ihrer Macht preiszugeben, d.h., sie kann unabhängig machen. Das ist das Unbegreifliche, daß Allmacht nicht bloß vermag, das Allerimposanteste, das sichtbare Weltganze, hervorzubringen, sondern auch das Allergebrechlichste hervorzubringen vermag: ein der Allmacht gegenüber unabhängiges Wesen. Daß mithin die Allmacht, die mit ihrer gewaltigen Hand die Welt so hart anpacken kann, zugleich sich so leicht machen kann, daß das Entstandene Unabhängigkeit empfängt. Es ist nur eine ärmliche und weltliche Vorstellung von der Dialektik der Macht, daß sie immer größer wird je nach dem Maße, in dem sie zwingen und abhängig machen kann. Nein, da hat Sokrates es besser verstanden, daß der Macht Kunst es gerade ist, frei zu machen. Indes im Verhältnis zwischen Mensch und Mensch läßt sich dies niemals machen, wiewohl es immer wieder nötig sein mag, einzuschärfen, daß dies das Höchste ist; allein die Allmacht vermag es in Wahrheit. Wofern daher der Mensch Gott gegenüber auch nur das geringste selbständige Bestehen voraus hätte (in Richtung auf Materie), so könnte Gott ihn nicht frei machen. Die Schöpfung aus Nichts ist abermals der Ausdruck der Allmacht dafür, dass sie unabhängig machen kann. Der, welchem ich unbedingt alles schuldig bin, während er doch unbedingt alles behalten hat, er hat mich gerade unabhängig gemacht. Wofern Gott um der Erschaffung des Menschen willen selber ein wenig von seiner Macht verlöre, könnte er den Menschen eben nicht unabhängig machen. “26

In meinem Projekt ist die philosophische und politologische Diskussion um den Machtbegriff aufzugreifen und mit der theologischen Bestimmung zu diskutieren. Diese kann hier nicht vorweggenommen werden; - aber mir scheint, dass der theologische und der nicht-theologische Diskurs durchaus parallel verläuft. Daraus schlieBe ich die Hypothese: Was als Macht auf Erden verwirklicht wird, wird zuerst als göttliche Macht gedacht. 
Zwei Anmerkungen seien noch erlaubt. Mir scheint, dass die theologische Idee der freiheitsbestimmten Durchsetzungsfähigkeit Gottes den heutigen Machtbegriff stark bestimmt. Als Ahnherr sei hierfür Max Weber zitiert: „Unter ,Macht` sollen wir [...] ganz allgemein die Chance eines Menschen oder einer Mehrzahl solcher verstehen, den eigenen Willen in einem Gemeinschaftshandeln auch gegen den Widerstand anderer daran Beteiligten durchzusetzen. "27 Das Bild von Macht als Durchsetzungsfähigkeit bestimmt bis heute den Machtdiskurs zentral. ${ }^{28}$ Aus der Reihe tanzt vielleicht nur eine Bestimmung der Macht, die von Hannah Arendt. Nach ihr ist Macht die menschliche Fähigkeit, ,nicht nur zu handeln oder etwas zu tun, sondern sich mit anderen zusammenzuschließen und im Einvernehmen mit ihnen zu handeln. ${ }^{29}$

Was verstehe ich aber unter Macht? Mit welchem Vorbegriff trete ich in den Prozess ein? Als „Macht“ bezeichne ich die Fähigkeit, zu wirken - oder etwas zu bewirken (,,befähigen“). Macht haben bedeutet „befähigen“, Macht heißt „Sein-zu“, ja „Sein-für“. Macht ist eine notwendige Voraussetzung aller Seienden, insofern sie sind. Sie kann als „Seinsmächtigkeit“ bezeichnet werden. Macht ist basal, die Fähigkeit zu sein - oder vielleicht zutreffender: das Geschenk, zu sein und eine Geschichte haben zu dürfen..$^{30}$ Deshalb ist es sinnvoll, eine Wirkmacht von allem auf alles anzunehmen. Davon zu unterscheiden sind das Lebendige und jene Lebendigen, die handeln können. Macht ist die Voraussetzung für das Handeln.

Alle endlichen Seienden haben dieses Sein-zu (auch als Voraussetzung intentionalen Handelns) nicht aus sich selbst („Kontingenz"). Herkunft und Zukunft sind ihnen entzogen: Sie sind/werden befähigt zu sein (grundsätzlich und in ihrer konkreten Weise). Dies ist die Bestimmung der Kontingenz. Daher erfahren sie sich, insofern ihnen ihr ontologischer Status bewusst wird, als abhängig, aus-

27 Weber (2005), 678.

28 Hingewiesen sei auf: Dreyfus/Rabinow (1994), vor allem 241-261 und Foucault (1978) sowie Popitz (1992), Luhmann (1975) und Han (2005).

29 Arendt (2005), 45. Ob diese Bestimmung eine späte Wirkung ihrer Dissertation über den Liebesbegriff bei Augustinus sein könnte? Eine Übersicht über die Diskussion findet sich bei Eder (2007), Hoff (2007) und Veith (2005).

30 Allein bei Brugger (1979), 375 habe ich eine ähnliche Bestimmung gefunden: „Wo etwas bewirkt wird, durch Wirken wird und entsteht, da ist auch ein Bewirkendes und ein Vermögen, etwas zu bewirken, oder Macht“. Brugger versteht diese Macht als aktive Potenz, potentia operativa. 
gesetzt und daher immer auch als bedroht. Die prekäre Situation des Endlichen äußert sich in der Sorge und intensiver in einer ontologischen Furcht, die in je neuen Formen der Angst Gestalt annimmt und sich in Formen der Gewalt als vermeintliche Sicherung der bedrohten Existenz äußert. In diesem Kontext allein ist von der „Allmacht" Gottes zu sprechen. Deshalb wird Allmacht immer als ambivalent, wenn nicht als bedrohend erfahren. Gewalt und Macht oszillieren zwischen Bedeutungen, Bewertungen. Gewalt wird als die Macht erfahren, gegen den Willen anderer zu handeln. Darf in dieser Bedeutung die Allmacht Gottes als Superlativ solcher Macht expliziert werden? Ich sage: Nein! Die wahrhaft göttliche Allmacht ist kein Superlativ unserer infralapsarischen Machterfahrung, sondern steht zu dieser quer. Das bedeutet, dass wir in unserer Rede und Bestimmung der Eigenschaften Gottes die sündige Kontaminierung aller unserer Gottesvorstellungen radikal im Auge behalten müssen. Søren Kierkegaard ist in der Tradition vielleicht der Einzige, der Allmacht entschieden anders gedacht hat. ${ }^{31}$ „Allmacht“: Erschaffung und Befähigung anderer Freiheit zu ihrem Guten, zu ihrer Bestimmung. Haben wir nicht unzureichend von der Allmacht gedacht? Diese lässt sich nicht als Steigerungsform bedrohter Macht bestimmen. Wirkliche Macht zeigt sich ohne Angst um ihre eigene Stellung; sie kann sich entäußern. ${ }^{32}$ Daher ist Königtum eine vom Evangelium dekonstruierte Kategorie. Jesus kehrt die Verhältnisse um. Er wird zum Diener, Sklaven aller - ja die Allmacht Gottes erweist sich nach dem Evangelium des Johannes in der Ohnmacht seines Sohnes am Kreuz. Nichts wird mein Projekt mehr inspirieren als diese - nur scheinbare - Paradoxie, die in der Christologie zum Ausdruck kommt. Die Allmacht Gottes kommt allein in der Ohnmacht seines maßgeblichen Repräsentanten zum Ausdruck. Daher ist die ausdrückliche Rede von der Allmacht Gottes - theologisch gesprochen - ein Bittgebet: Gott möge sich erweisen als mächtiger als die Gewalten des Bösen und die Macht des Todes. 


\section{Leithypothese 3}

Was aber darf das Leben kosten? Das Leben kann nur kosten, was allen Menschen zum Heil gereicht. Die eigene Lebenshingabe ist nur möglich aus Liebe zu der Liebe, die mir zuerst geschenkt, erwiesen oder zuteil geworden ist. Streng genommen muss gesagt werden: Selbst Gott kann das Leben nicht fordern. Der Mensch kann nur in Freiheit den Ruf vernehmen, nicht für, sondern mit Gott, d.h. mit Christus, und auf ihn hin zu sterben. Für die theologische Analytik der Themenbereiche im Prozess der Arbeitsgemeinschaft ist eine Theologie des Martyriums essentiell.

\section{Erläuterung}

Die Rede vom Martyrium gehört zu den heikelsten Fragen im Verhältnis von Religion und Politik heute. Es ist nicht möglich, hier alle Aspekte zu diskutieren. ${ }^{33}$ Hier soll abschließend nur meine Ausgangsposition umrissen werden. In der Forderung an den Menschen erweist sich sowohl die Form der Politik als auch diejenige der Theologie. Lebenshingabe ist nur dann berechtigt, wenn dieses Opfer allen Menschen zugutekommt. Daher stellt sich die entscheidende theologische Frage in folgender Weise: Was ist das für ein Gott (höchste Wirklichkeit), der selbst in der Geschichte zum Opfer geworden ist? Die anthropologischen Kategorien des Martyriums, als Lebenshingabe, sind: Freiheit, Liebe, Vergebung und die Wahrung des Guten, das allen Menschen zuteil werden mag. Ich räume schon zu Beginn des Projektes ein, dass mich die Frage bewegt, ob der Gott des Gekreuzigten, die möglichen Bedingungen des Suchprojektes „G.O.T.T.“ erfüllen könnte. Das Kriterium Gottes aber ist der Mensch - dieser Mensch und die Lebensmöglichkeit aller Menschen, ja der gesamten Schöpfung. Daher stellt sich immer die Frage nach unserer Vorstellung von aller Wirklichkeit: Welches ist die letzte und alles bestimmende Macht, mit der wir in unserem Leben (und danach) zu rechnen haben?

Deshalb bin ich der Meinung, dass es für die wahre Gottesrede ein doppeltes $\mathrm{Ma}$ in unserer Geschichte gibt: (1) Das Bild der Ohnmacht der Allmacht oder das Kriterium des Kreuzes; (2) die unbedingte Freiheit und Anerkennung der Gewissen aller. Das Maß

33 An anderer Stelle hat der Autor eine elementare Theologie des Martyriums vorgelegt. Siehe hierzu Siebenrock (2007) und Siebenrock (2008). 
besteht in der Relation von Gewaltfreiheit, Annahme und Anerkennung prekärer Existenz. ${ }^{34}$

\section{Literatur}

Arendt, Hannah (152005): Macht und Gewalt. München: Piper.

Brugger, Walter (1979): Summe einer philosophischen Gotteslehre. München: Berchmans.

Eder, Sigrid (2007): „Machttheorien - Zwischen Freiheit und Zwang“, in: UNILEX 1-2, 40-45.

Foucault, Michel (1978): Dispositive der Macht. Über Sexualität, Wissen und Wabrheit. Berlin: Merve.

Dreyfus, Hubert L./Rabinow, Paul (21994): Michel Foucault. Jenseits von Strukturalismus und Hermeneutik. Weinheim: Beltz, Athenäum.

Han, Byung-Chul (2005): Was ist Macht? Stuttgart: Reclam.

Hoff, Gregor M., Hg. (2007): Macht und Obnmacht. Salzburger Hochschulwochen 2007. Innsbruck-Wien: Tyrolia.

Kant, Immanuel (1968): „Beantwortung der Frage: Was ist Aufklärung?“, in:

Kant, Immanuel: Gesammelte Schriften. Band 8. Berlin: de Gruyter, 35-42. Kierkegaard, Søren (1954): Reflexionen über Christentum und Naturwissenschaft. Düsseldorf-Köln: Eugen Diederichs.

Luhmann, Niklas (1975): Macht. Stuttgart: Enke.

Mazohl-Wallnig, Brigitte (2005): Zeitenwende 1806. Das Heilige Römische Reich und die Geburt des modernen Europas. Wien-Weimar: Böhlau.

Pannenberg, Wolfhart (1988): Systematische Theologie. Band 1. Göttingen: Vandenhoeck \& Ruprecht.

Popitz, Heinrich (21992): Phänomene der Macbt. Tübingen: Mohr.

Ratzinger, Joseph (2005): „Was die Welt zusammenhält. Vorpolitische moralische Grundlagen eines freiheitlichen Staates“, in: Habermas, Jürgen/Ratzinger, Joseph: Dialektik der Säkularisierung. Über Vernunft und Religion. Freiburg-Basel-Wien: Herder, 39-60.

Schwager, Raymund/Niewiadomski, Józef (2003): „Dramatische Theologie als Forschungsprogramm“, in: Schwager, Raymund/Niewiadomski, Józef, Hg.: Religion erzeugt Gewalt - Einspruch! Innsbrucker For-

34 Damit korrespondiert dieses $\mathrm{Maß}$ mit dem Kriterium des Friedens unter den Menschen, wie es die „Dramatische Theologie“ in ihrem Forschungsprogramm als zentrale Hypothese festgehalten hat; siehe Schwager/Niewiadomski (2003) 64: „(2-1)Ein tiefer, echter und dauerhafter Friede zwischen Menschen, der nicht auf Opferung Dritter aufgebaut ist und obne Polarisierung auf Feinde auskommt, ist sebr schwierig, ja übersteigt menschliche Kräfte. Wenn er dennoch Wirklichkeit wird, ist dies ein klares Zeichen, daß Gott selber (der Hl. Geist) in den Menschen am Wirken ist. Diese inkarnatorische Logik ist sowobl an der biblischen Botschaft als auch an den zablreichen ekeklesialen ,Zeichen der Zeit" in der menschlichen Geschichte ablesbar". 
schungsprojekt ,Religion - Gewalt - Kommunikation - Weltordnung'. Münster: LIT, 39-77.

Siebenrock, Roman A. (2005a): „Politische Theologie im Anschluss an Raymund Schwager SJ", in: Siebenrock, Roman A./Sandler, Willibald, Hg.: Kirche als universales Zeichen. In memoriam Raymund Schwager. Münster: LIT, 381-397.

Siebenrock, Roman A. (2005b): „Theologischer Kommentar zur Erklärung über die religiöse Freiheit Dignitatis humanae“, in: Hünermann, Peter/ Hilberath, Bernd J., Hg.: Herders Theologischer Kommentar zum Zweiten Vatikanischen Konzil. Band 4. Freiburg-Wien: Herder, 125-218.

Siebenrock, Roman A. (2007): „Nicht von dieser Welt. Franz Jägerstätters gelebtes Credo“, in: Scheuer, Manfred: Selig, die keine Gewalt anwenden. Das Zeugnis Fran₹ Jägerstätters. Innsbruck-Wien: Tyrolia, 168-181, 200205.

Siebenrock, Roman A. (2008): „Wer ist ein Märtyrer? Zur Archäologie eines verschütteten Ideals im Licht des Evangeliums Jesu Christi“, in: Regensburger, Dietmar/Larcher, Gerhard, Hg.: Paradise now!?: Politik Religion - Gewalt im Spiegel des Films. Marburg: Schüren Verlag.

Veith, Werner, Hg. (2005): Macht und Ohnmacht. Konzeptionelle und kontextuelle Erkundigungen. Münster: Aschendorff.

Wandinger, Nikolaus (2005): „Is Divine Omnipotence (Non-)Violent? Reflections from the Viewpoint of Dramatic Theology", in: JPJRS 8(1), $50-64$.

Weber, Max (2005): Wirtschaft und Gesellschaft. Grundriß der verstehenden Soziologie. Frankfurt/M.: Zweitausendeins. 


\section{Legitimiert das Gottesbild des Korans Gewaltanwendung?}

Karl Prenner

\section{Hinführung}

In der öffentlichen Diskussion und Meinungsbildung gibt es kaum ein Thema, dessen Meinungsspektrum so konträr diskutiert wird wie das vom Islam, ob dieser Friede und/oder Gewalt meine. Betroffen davon sind nicht nur das islamische Strafrecht und diverse kulturbedingte Praktiken, sondern auch der Umgang mit Angehörigen anderer Religionen - vor allem polytheistischer Religionssysteme -, die als „Ungläubige“ eingestuft werden. Und am „Unglauben“ hat nach islamischer Sicht auch das Christentum Anteil. „Es ist nicht zu leugnen“, schreibt Ömer Özsoy, „dass neben Juden und Polytheisten auch Christen im Koran in gewisser Hinsicht ausgegrenzt werden. Diese ausgrenzende Haltung ihnen gegenüber wurde dennoch in Folge späterer oft unfriedlicher Verhältnisse zwischen den beiden Religionsgemeinschaften sowohl von Muslimen als auch von Christen aus ihrem historischen Kontext gerissen und überinterpretiert, wodurch eine offensichtlich eingeschränkte und bedingte Ausgrenzung allmählich zu einer absoluten stilisiert wurde“. ${ }^{1}$

Für Gewaltanwendung und diverse Ausgrenzungsmechanismen wird in erster Linie das monotheistische Konzept des Korans verantwortlich gemacht, das quasi kompromisslose und ausgrenzende System des Eingottglaubens. Auf den ersten Blick scheinen dies viele Aussagen des Korans im Zusammenhang der Auseinandersetzungen 
des Propheten mit den polytheistischen Mekkanern, aber auch mit Juden und Christen zu bestätigen, denn davon ist auch das Gottesbild betroffen. Eine Gesamtsicht jener Haltungen, die diese Auseinandersetzungen im Koran reflektieren, erweist aber, dass wir hierbei sehr komplexe Vorgänge vor uns haben, die nicht so leicht auf einen Nenner zu bringen sind und daher auch von den späteren Rechtsgelehrten und Korankommentatoren in unterschiedlicher Weise beantwortet worden sind.

Ein Blick in das Arabien des 6. bzw. 7. Jahrhunderts zeigt, dass in diesem Raum unterschiedliche gesellschaftliche, aber auch religiöse Prozesse und Umorientierungen stattfanden. Was die spezifisch religiöse Situation anbelangt, war Arabien religionsplural geprägt. Neben den arabischen Juden und Christen gab es die polytheistischen bzw. animistischen Vorstellungen und weiters noch zoroastrische Einflüsse. Vor allem das christliche Spektrum der Halbinsel war in verschiedene heterodoxe Richtungen aufgespalten, zumindest aber in eine hellenistisch trinitarische und eine judenchristliche Richtung. Daraus resultieren die ambivalenten Aussagen des Korans über die Christen. Gesellschaftliche Umorientierungen wiederum hatten zur Folge, wie aus dem Koran hervorgeht, dass das alte Sozialsystem, die „Stammessolidarität“, sich aufzulösen begann. Dazu kommt noch, dass Arabien im Einflussgebiet zweier Großreiche, des Byzantinischen Reiches und des Persisch-Sasanidischen Reiches, stand, die um die Kontrolle der Handelswege zu See und zu Lande wetteiferten.

Grundsätzlich kann einmal angemerkt werden, dass, ob nun insgesamt eine Religion eher den Frieden fördert oder die Gewalt begünstigt, sich dies nicht einfach an deren Bezeichnung entscheidet, „,vielmehr an den grundlegenden Denkmustern und Verhaltensnormen, die diese Religion ihren Anhängern vermittelt, und an der historisch unter Umständen wandelbaren Art von deren Interpretation durch die Anhänger“.2 Ausschlaggebend sind demnach entsprechende hermeneutische Fragestellungen, die im Laufe der Zeit an die normativen Texte herangetragen werden und deren Beantwortung im entsprechenden Zeitkontext.

Insgesamt wurde und wird der Islam mit seinen überkommenen normativen Texten von den Muslimen und Musliminnen in den verschiedenen Kulturen und Gesellschaften bis heute sehr unterschied- 
lich gedeutet und gelebt. Wir haben es daher mit einer Pluralität von oft sehr kontroversen Deutungen zu tun, die sich alle auf normative Schriften berufen, oft aber diese komplexen und vielschichtigen Texte gesellschaftlich oder politisch funktionalisieren und in der Folge nur in selektiver Weise und dazu noch ohne Beachtung des historischen Kontextes wahrnehmen. Natürlich wirken sich auch die vielfältigen Globalisierungsprozesse, politische sowie soziale Konflikte und Krisenherde entscheidend auf diese Deutungen aus, indem solche Denk- und Handlungsmuster zum Zwecke der Überwindung von Krisen und Konflikten wieder aktiviert werden.

So führt etwa der ägyptische Literaturwissenschaftler Nasr Hamid Abu Zaid aus:

„Religion ist, was die Gläubigen aus ihren ursprünglichen Schriften machen. Schriften sprechen nicht von selbst; sie sprechen mit der Stimme der Gläubigen. Gott spricht durch den Menschen; sein göttlicher Diskurs ist damit letzten Endes menschengemacht. Die religiöse Bedeutung neigt entweder dazu zu stagnieren, oder sie kann fortentwickelt werden. Das hängt alles von den sozio-politischen und historischen Bedingungen $a b^{\text {". }}$.

Letztendlich verdichtet sich im Gottesbild auch die konkrete politische und gesellschaftliche Situation einer Gemeinschaft zu einer bestimmten Zeit und an einem bestimmten Ort. Die immanente Erfahrungsebene der Gläubigen wird so transzendiert und gewinnt insgesamt ein sinnstiftendes und damit identitätsstiftendes Element.

Im Koran werden die Auseinandersetzungen, auch die bewaffneten, zwischen den Muslimen (Gläubige) und Nichtmuslimen (Polytheisten, Juden und Christen) in mekkanischer und medinischer Zeit (622 Auswanderung von Mekka nach Medina) insofern reflektiert, als die damit verbundenen Haltungen Eingang gefunden haben. In diesen Haltungen werden aufgrund der unterschiedlichen gesellschaftlichen, religiösen, aber auch politischen Bedingungen von Mekka und Medina unterschiedliche Modelle des Zusammenlebens mit den Nichtmuslimen erkennbar; wir sprechen daher im Folgenden vom mekkanischen und vom medinischen Modell. Beide Modelle sowie die damit verbundenen Haltungen spiegeln sich auch im Gottesbild wider; dieses trägt Züge der ganz spezifischen Erfahrungen der muslimischen Gemeinde unter den spezifischen gesellschaft- 
lichen und politischen Bedingungen in Mekka und Medina. Daran schließt sich dann die Frage, ob diese Haltungen und ihre Verankerung im Gottesbild zeitunabhängig sind oder aber nur im jeweiligen Zeitkontext Gültigkeit haben, also die Frage nach einer Historisierung oder die nach einer Überzeitlichkeit; damit verbunden sind Fragen des Zusammenlebens zwischen Muslimen und Nichtmuslimen, Fragen der Akzeptanz oder Ausgrenzung anderer Religionen bzw. religiöser Systeme und damit Fragen nach einer religionspluralen Haltung.

\section{Mekkanisches und medinisches Modell}

Das grundsätzliche Selbstverständnis Muhammads als Gesandter und Prophet ist, Freudenbote (Verkünder der Frohbotschaft vom Schöpfergott und seiner Fürsorge) und Warner (vor dem Letzten Gericht) für sein Volk zu sein. Dies betonen sowohl mekkanische als auch medinische Suren. Ihm kommt nur die Verkündigung der Botschaft zu, was die Menschen mit dieser Botschaft machen, das liegt nicht mehr in seinem Verantwortungsbereich. Aus diesem Selbstverständnis des Propheten ergeben sich Haltungen, die auf einen friedlichen Umgang mit den Nichtmuslimen zielen bzw. ansatzweise auf eine mögliche Form von Religionspluralität.

„Ihr habt eure Religion, und ich habe meine Religion.“ (109.6)

„Wir haben unsere Werke, und ihr habt eure Werke (zu verantworten).“ (42.15, vgl. 6.135)

„Wenn sie sich aber abkehren, so obliegt dir nur die Ausrichtung (der Botschaft).“ (3.20, vgl. 5.99)

„Wir haben dich nicht als Hüter über sie gesandt." (4.80, vgl. 6.66)

„O mein Volk, handelt nach eurem Standpunkt. Ich werde auch so handeln. Dann werdet ihr wissen, wem die jenseitige Wohnstätte gehört." (6.135)

Aus der Prophetenbiographie Ibn Ishaqs ${ }^{4}$ und der entsprechenden Reflexion im Koran wissen wir, dass die Anhänger Muhammads im Laufe der Zeit verschiedensten Repressalien und Anfeindungen vonseiten der Mekkaner, d.h. der Polytheisten (muschrikun: gemeint sind damit jene, die dem einen Gott andere Wesen zur Seite stellen), 
ausgesetzt waren, Leiden und Ungemach zu erdulden hatten bis zur Vertreibung der gesamten Sippe der Haschim, der Muhammad entstammte, aus Mekka, einem Ereignis, das dann die Übersiedlung nach Medina notwendig machte.

„Geduldig sein“, „abwarten bis der Entscheid Gottes eintrifft“, „nachsichtig sein“, „vergeben“ umschreiben Haltungen, die grundsätzlich die mekkanische Zeit beherrschen (43.89, 15.85, 7.87, 11.93 u.a.).

„Sie bieten den Frieden an: ,Wir pflegten nichts Böses zu tun““, heißt es in 16.28. - „Doch, Gott weiß Bescheid über das, was ihr zu tun pflegtet."

Hier wird an ein Verhalten der Anhänger des Propheten appelliert, das seinen Lohn ausschließlich in Gott findet, bzw. wird eben das Urteil Gott überlassen. Denn, wie es oben geheißen hat, jeder hat seine Werke persönlich zu verantworten.

Die medinische Zeit wird dann davon beherrscht, dass diese erlittenen Aggressionen auf gleiche Weise erwidert werden dürfen. In diesem Stadium kommt dem Propheten auch eine gesellschaftliche und politische Rolle zu. Hier wird der Grundsatz „Gleiches ist mit Gleichem zu vergelten“ ausgesprochen. Daher wird in dieser Zeit die Erlaubnis zum Kampf gegeben (22.38), insgesamt zum „Dschihad auf dem Wege Allahs“, zum Einsatz für den Islam und die Gemeinde der Muslime, um ihre Existenz und ihr Überleben als Gemeinschaft zu gewährleisten. ${ }^{5}$ Die altarabische Praxis der „Razzien“ wird durch den religiös motivierten Einsatz und Kampf, nämlich den Dschihad, abgelöst.

„Die Erlaubnis [sich zu verteidigen] ist denen gegeben, die bekämpft werden, weil ihnen Unrecht geschah - und Gott hat wahrlich die Macht, ihnen zu helfen -, jenen, die schuldlos aus ihren Häusern vertrieben wurden, nur weil sie sagten: ,Unser Herr ist Gott'.“ (22.39)

Wer sich gegen euch vergeht, gegen den dürft ihr euch ähnlich vergehen, wie er sich gegen euch vergeht.“ (2.194)

Gleichzeitig wird jedoch der Vergeltung erfahrenen Unrechts auch eine Alternative entgegengehalten:

„Wer aber verzeiht und Besserung schafft, dessen Lohn obliegt Gott.“ (42.40) Ähnlich auch der folgende Vers: „Nicht gleich sind 
die gute und die schlechte Tat. Wehre mit einer Tat, die besser ist, da wird der, zwischen dem und dir eine Feindschaft besteht, so, als wäre er ein warmherziger Freund." (41.34)

Die Frage, warum in Mekka noch keine Erlaubnis zum Kampf gegeben wurde, wird durchwegs von der islamischen Tradition dahingehend beantwortet, dass die Anhänger des Propheten für eine solche Aktion noch zu schwach gewesen wären; anders dann die Situation in Medina, wo die Gemeindeordnung und die Verträge mit den Stämmen Medinas den nötigen Rückhalt boten. Ob dies tatsächlich eine authentische Erklärung liefert, muss dahingestellt bleiben; zumindest verweist der Koran auch auf eine Alternativhaltung.

Im Rahmen der Auseinandersetzungen und Kämpfe, die wohl in erster Linie politische und gesellschaftliche Hintergründe haben, verdichtet sich die Sicht, dass das Ziel des Kampfes erst dann erreicht wird und der Friede erst dann einkehren wird, wenn die „Ungläubigen", d.h. die Polytheisten, den Islam annehmen bzw. wenn der Islam den Sieg davonträgt (vgl. 9.33). Denn eine Bedrohung des Glaubens ist dann nicht mehr gegeben, wenn die Muslime, wie es in Sure 2 heißt, kämpfen, ,,bis es keine Verführung mehr gibt und bis die Religion gänzlich nur noch Gott gehört" (8.39, vgl. 2.193). Da aber die Polytheisten nicht aufhören, gegen die Gläubigen zu kämpfen, „bis sie euch von eurer Religion abbringen“, gilt bis dahin der totale Kampf:

„Und kämpft gegen die Polytheisten allesamt, wie sie gegen euch allesamt kämpfen." (9.36)

Auf diese Weise werden die Muslime die ihnen von ihren Feinden angetane Gewalt in gleicher Weise erwidern und die Bestrafung der Ungläubigen selbst vornehmen. Die entscheidende Frage hierbei wird aber dann sein: Sind nun die Polytheisten wegen ihrer Aggression oder aber wegen ihres falschen Glaubens zu bekämpfen? Denn an dieser Frage hängt die Akzeptanz anderer religiöser Bekenntnisse.

Für eine der Gesamtsicht des Korans entsprechende Beurteilung und Einordnung der Polytheisten ist zu bedenken, dass mitten unter jenen Versen, die zum Kampf auffordern, auch jene Verse stehen, die zum Frieden auffordern (4.90, 8.61 u.a.):

„Wenn sie sich von euch fernhalten und nicht gegen euch kämpfen und euch Frieden anbieten, dann erlaubt euch Gott nicht, gegen sie vorzugehen." (4.90)

„Und wenn sie sich dem Frieden zuneigen, dann neige auch du dich ihm zu und vertrau auf Gott.“ (8.61) 
„Sprich zu denen, die ungläubig sind: Wenn sie aufhören, wird ihnen vergeben, was vorher geschah." (8.38)

Von diesen Auseinandersetzungen waren auch die Juden Medinas betroffen. Gerade auf die Juden hatte der Prophet alle seine Hoffnungen gesetzt, dass sie Verständnis für seinen ProphetenAnspruch zeigen werden; jüdische Stämme bzw. Sippen finden wir auch in der Gemeindeordnung von Medina, allerdings werden hier die drei großen jüdischen Stämme nicht genannt. Daher war die Enttäuschung umso größer, als sich die Juden Medinas von ihm distanzierten. Die Vertreibung der drei großen jüdischen Stämme aus Medina bzw. die Hinrichtung der Männer eines Stammes war dann die Folge ihrer politischen Agitation gegen den Propheten, die auch der Grund dafür ist, dass den Juden im Koran vorgeworfen wird, sie seien vertragsbrüchig geworden.

Als die gesamte Halbinsel dem Islam unterworfen und damit die Bedrohung durch die Polytheisten beendet war, wurden auch die Christen, die die Oasensiedlungen Nord-Arabiens besiedelten, in diese Kämpfe verwickelt, weil sie sich politisch dem Byzantinischen Reich zugehörig fühlten; in diesem politischen Kontext wird ihnen nun auch vorgeworfen, dass sie auch ihren Eingottglauben nicht mehr rein bewahrt hätten. Angespielt wird hier auf die Trinitätslehre, die der Koran als Dreigötterlehre interpretiert; damit rückt für den Koran das Christentum in die Nähe des Polytheismus und hat Anteil am „Unglauben“ (vgl. 4.171, 5.72-73: „Ungläubig sind die, die sagen: ,Gott ist der dritte von dreien “" usw.). Von dieser politisch-religiösen Auseinandersetzung zeugt Sure 9.29-30, wo zum Kampf gegen die arabischen Juden und Christen aufgerufen wird („Gott bekämpfe sie“), bis sie als „Erniedrigte den Tribut entrichten“. Dieser Vers normiert eine juristische Praxis, die durch die Jahrhunderte weiter gepflegt wurde und Juden und Christen als Schriftbesitzer (abl alkitab) zu „Schutzbefohlenen“ (dhimmi) des islamischen Staates erklärt hat. Daher wurde die Aussage in Sure 2.256 „Es gibt keinen Zwang in der Religion" vor allem auf Juden und Christen angewandt; sie besagt, dass eben Juden und Christen, aber auch andere monotheistische Bekenner ihre Religion unter bestimmten Bedingungen beibehalten können. Insgesamt geht es hierbei in erster Linie um die Anerkennung des universellen Herrschaftsanspruches des Islam, nicht aber um eine generelle Bekehrung zum Islam.

Aus dem bisher Ausgeführten geht hervor, dass der mekkanischen und medinischen Zeit unterschiedliche gesellschaftliche und 
politische Situationen zugrunde liegen, die in der Folge auch ein unterschiedliches Handlungs- und Verhaltensmodell begründen.

\section{Zur Rolle und Funktion Gottes in beiden Modellen}

Von diesen politischen und religiösen Auseinandersetzungen in Mekka und Medina ist nun auch das Gottesbild betroffen. Dieses muss auf dem Hintergrund der Erfahrungen der Menschen in jenem bestimmten Zeitkontext, den wir soeben beschrieben haben, gesehen werden.

Entscheidend ist, dass sich mit dem Koran ein Konzept von Religiosität verbindet, das in einer umfassenden Weise alle Aspekte und Abläufe des geschöpflichen Daseins einschließt und sodann transzendiert. Diesem Religionsbegriff zufolge begreift der Koran die gesamte Situation des arabischen Volkes, die wirtschaftliche, politische und die soziale, als eine religiöse und beantwortet die entsprechenden Fragestellungen in der Folge auch von der Religion her. Dies bedeutet, dass das Gottesbild in den mekkanischen und medinischen Suren auch die spezifische Situation der Gläubigen spiegelt, denn diese suchen Antwort auf ihre Fragen und Nöte, suchen Hilfe und Schutz vor den Feinden und ihren Aggressionen. Gott ist direkt in dieses Geschehen involviert.

Diesem religiösen Konzept zufolge interpretiert der Koran die Menschheitsgeschichte als eine religiöse, nämlich die Geschichte der Propheten mit ihren jeweiligen Völkern. Auch die Sendung Muhammads zu den Arabern (später: zu allen Menschen) ordnet sich in diese Sichtweise ein. Durch die Vertreibung des Propheten und seiner Anhänger aus Mekka wurde ihnen jedoch Unrecht zugefügt; daher wird dann betont, dass dieser Gott, zu dem sich die Muslime bekennen und dessentwegen sie vertrieben wurden, auf ihrer Seite ist, als ihr Freund, Beschützer und Verteidiger (8.62). Die Muslime sollen daher auf ihn vertrauen. Die koranischen Prophetenerzählungen bzw. konkret die sogenannten „Straflegenden“ wollen durch ihre schematische Darstellung diesen Sachverhalt beispielhaft verdeutlichen als Ermahnung einerseits, aber auch als Zuversicht und Hoffnung andererseits: Der Prophet als Verkünder des Eingottglaubens und die an ihn Glaubenden werden gerettet, während jene, die seine Botschaft ablehnen, die (diesseitige und jenseitige) Strafe trifft. Es sind hier vor allem drei biblische Erzählungen, die auf diese Weise im Koran gedeutet werden: Mose und Pharao, der Auszug aus Ägyp- 
ten; Noah und die Sintflut; Lot, Sodom und Gomorra. Muhammads dichotomer Erfahrungshorizont im Laufe seiner Verkündigung, Ablehnung und Annahme seiner Botschaft spiegelt sich so bereits in den ihm vorausgehenden Gesandten und Ereignissen. Es ist daher nur logisch, wenn sämtliche Erfolge, auch die militärischen, Gottes Wirken und Handeln zugeschrieben werden.

„Gott verteidigt diejenigen, die glauben.“ (22.38, vgl. 59.6)

„O ihr, die ihr glaubt, wenn ihr Gott unterstützt, unterstützt Er euch und festigt eure Schritte. Was aber diejenigen betrifft, die ungläubig sind, so wehe ihnen." (47.7-8)

„Dies, weil Gott der Schutzherr derer ist, die glauben, und weil die Ungläubigen keinen Schutzherrn haben.“ (47.11)

„Gott weiß besser über eure Feinde Bescheid. Und Gott genügt als Freund, und Gott genügt als Helfer.“ (4.45)

Gerade das Kampfgeschehen bei der Wasserstelle von Badr (624), wo die Muslime zahlenmäßig den Mekkanern unterlegen waren, aber letztendlich doch siegten, wird beispielhaft für das muslimische Handeln ausgedeutet:

„Gott hat euch doch in Badr unterstützt, als ihr unterlegen waret. So fürchtet Gott, auf dass ihr dankbar werdet. Als du zu den Gläubigen sagtest: 'Genügt es euch denn nicht, dass euer Herr euch mit dreitausend herabgesandten Engeln beisteht? Ja, wenn ihr standhaft und gottesfürchtig seid und sie sogleich gegen euch vorrücken, steht euch euer Herr bei mit fünftausend gekennzeichneten Engeln. “ (3.122-125, vgl. 8.9-10, 8.17)

Die Erfahrungen bei Badr und bei anderen bewaffneten Auseinandersetzungen zwischen den Mekkanern und den Anhängern des Propheten verdichten sich in dem Grundsatz, dass, mit wem Gott ist, der letztendlich unbesiegbar ist:

„Wer sich Gott und seinen Gesandten und diejenigen, die glauben, zu Freunden nimmt (gehört zu ihnen): Die Partei Gottes sind die Obsiegenden.“ (5.56)

„Gott hat vorgeschrieben: ,Siegen werde Ich, Ich und meine Gesandten.' Gott ist stark und mächtig.“ (58.21, vgl. 61.9-11)

„Wenn Gott euch unterstützt, dann kann niemand euch besiegen. Und wenn Er euch im Stich lässt, wer ist es, der euch daraufhin unterstützen könnte? Auf Gott sollen also die Gläubigen vertrauen“ (3.160). Sure 9.25-26 spricht davon, dass „Gott euch an vielen Orten unterstützt hat [...] Und Er sandte Truppen, die ihr nicht sehen konntet, herab und peinigte diejenigen, die ungläubig waren." 
„Als ihr euren Herrn um Rettung batet, und Er euch erhörte: ,Ich werde euch mit tausend hintereinander reitenden Engeln beistehen.' [...] Der Sieg kommt ja nur von Gott. Gott ist mächtig und weise." (8.9-10, 8.17)

Die Erfahrung, dass Gott die Seinen niemals im Stich lässt, verdichtet sich sodann in diversen Grundsätzen, die den Gläubigen als Handlungsanleitung dienen sollen: „Wenn es unter euch auch nur zwanzig gibt, die standhaft sind, werden sie zweihundert besiegen. Und wenn es unter euch hundert gibt, werden sie tausend von denen, die ungläubig sind, besiegen“ (8.65).

Daher spricht der Koran auch vom Ränke schmiedenden Gott („Gott ist der Beste derer, die Ränke schmieden“ 8.30), seiner Strafe und Pein (59.2-4), die er gegenüber den Feinden der Gläubigen ins Treffen führt. Aber auch davon, dass ihm nichts verborgen bleibt:

„Wissen sie denn nicht, dass Gott über ihre Geheimnisse und ihre vertraulichen Gespräche Bescheid weiß, und dass Gott die unsichtbaren Dinge alle weiß?" (9.78)

Diese Stellen zeigen, dass sich ein dichotomisches Schema herausgebildet hat, von dem auch das Gottesbild geprägt ist: „Gläubige - Ungläubige“. In welchem Verhältnis stehen nun das mekkanische und medinische Modell und die diesen zugrunde liegenden Haltungen zueinander, in einem sich ausschließenden oder ergänzenden? Welche dieser Haltungen können als normgebend bezeichnet werden? Wie ist in diesem Kontext das dichotome Schema „Gläubige Ungläubige" zu interpretieren?

\section{Hermeneutische Fragestellungen}

Nach muslimischer Sicht gilt der Koran insgesamt als authentisches Wort Gottes, das den Zeitabläufen und ihren spezifischen Bedingungen enthoben ist. Trotzdem hat auch die traditionelle Koranexegese Methoden und Mittel entwickelt, die es erlauben, den Koran von unterschiedlichen Zeitkontexten her zu lesen.

Es sind insgesamt drei Kriterien:

- Die Offenbarungsperiode wird, wie bereits obiger Darstellung zugrunde liegt, traditionell in zwei große Perioden eingeteilt, die mekkanische und die medinische (daher mekkanische und medinische Suren). Mit beiden Örtlichkeiten verbinden sich nicht nur spezifische geographische, gesellschaftliche, politische und kulturelle Voraussetzungen, sondern auch unterschiedliche Of- 
fenbarungsinhalte, die darauf Bezug nehmen; verbunden damit sind unterschiedliche Wahrnehmungen der Nichtmuslime und entsprechende Haltungen ihnen gegenüber, denn in medinischer Zeit geht es auch um die soziale und politische Ordnung des neu entstehenden Gemeinwesens.

- Die islamische Tradition spricht konsequenterweise auch von „Offenbarungsanlässen“ (asbab an-nu₹ul) und nimmt somit diese situationsbedingten Elemente auf. Die Herabsendung einer Offenbarung setzt eine bestimmte zeitgeschichtliche Situation voraus, die eine bestimmte Verordnung oder Direktive notwendig macht. Für die Koranexegeten stellt sich hier allerdings die Frage nach der Generalisierung solcher oft zeitbedingter Direktiven und Entscheide, d.h. der Anspruch auf zeitlose Gültigkeit, wobei dann, wenn generalisiert wird - und das geschieht in der Regel -, der konkrete zeitbedingte Kontext verloren geht.

- Weiters arbeitet die Koranexegese auch mit der Abrogation, d.h., früher Geoffenbartes wird durch später Geoffenbartes aufgehoben (al-nasich wa-l-mansuch), ein Prinzip, das von den einzelnen Gelehrten unterschiedlich gehandhabt wird. „Im großen und ganzen steht man auf dem Standpunkt, daß nur normative Bestimmungen des Qur'an, die in einen bestimmten historischen Zusammenhang eingebunden sind, Gegenstand der Abrogierung sein dürfen“. ${ }^{6}$ Dieses Prinzip resultiert aus der Notwendigkeit, dass unterschiedliche Situationen auch unterschiedliche Direktiven erforderlich machen. Mit diesem Prinzip sollen gegensätzliche Aussagen des Korans erklärt werden.

Es gibt heute eine Vielzahl von Muslimen und Musliminnen, die nicht den Terminus „historische Kritik“ verwenden, denn man kann das Wort Gottes nicht kritisieren, wohl aber versuchen, dieses Wort Gottes aus dem zeitgeschichtlichen Kontext der damaligen Hörer und Hörerinnen in jenen der heutigen durch eine entsprechende hermeneutische Methodologie zu transportieren und dadurch verständlich zu machen. Viele sprechen daher von einer „Historisierung“ des Korans, indem sie ihn in den Kontext der Zeit des 7. Jahrhunderts stellen. 
So kommt etwa Ömer Özsoy zu folgendem Ergebnis:

„Es ist sowohl aus wissenschaftlicher als auch aus islamischer Sicht eine ethische Verpflichtung, den Koran historisch-hermeneutisch zu lesen und so zu behandeln. Dies gilt als eine wissenschaftliche Pflicht, denn ein übergeschichtliches Lesen des Korans verursacht nicht nur Ablehnung der historischen Tatsächlichkeiten, in denen er herabgesandt worden ist, sondern auch Verfälschung der ursprünglichen Bedeutung seines Wortlautes. Das ist offensichtlich auch eine islamische Pflicht, weil erst dadurch möglich ist, die universelle Botschaft des Korans in der Moderne zu aktualisieren und wieder lebendig zu machen".

Er geht also davon aus, dass sich die Adressaten der koranischen Botschaft verändert haben. Gegenüber den Erstadressaten bleiben den heutigen viele Ausdrücke des Korans verschlossen, denn Sprache transportiert immer auch die Kultur eines Volkes zu einer bestimmten Zeit, in unserem Fall jene Arabiens des 6. und 7. Jahrhunderts.

Was nun insgesamt das mekkanische und medinische Modell anbelangt, kann man nach dieser Sicht unter Beachtung der entsprechenden zeitgeschichtlichen Umstände und Hintergründe davon ausgehen, dass in den mekkanischen Offenbarungen ein die Zeiten überdauerndes gültiges Modell formuliert worden ist, in den medinischen Suren - ab dem Bruch mit der Judenschaft Medinas (624) dagegen wurde dieses Modell unter ganz spezifischen Zeitbedingungen angewandt, was dann bedeutet, dass diese Praxis in Medina zeitund umstandsbedingte Elemente enthielt. Daher gilt es zu unterscheiden zwischen zeitlos gültigen Aussagen und solchen, die zeitund kontextgebunden sind, also den sich verändernden Bedingungen von Ort und Zeit angepasst sind.

Eine Vielzahl von Reformern, wie Fazlur Rahman', Abu Zaid', Abdolkarim Sorusch u.a., plädieren für eine zeit- und umstandsbedingte Differenzierung in den unterschiedlichen Haltungen und Aussagen des Korans, also für eine Hermeneutik des Wortes Gottes und damit für die „Anpassung religiös begründeter Werte und Verhaltensnormen an wechselnde zeit- und ortsgebundene Umstän- 
de“. ${ }^{10}$ Für Abu Zaid ist der Koran als Wort Gottes unantastbar. Aber seine Botschaft ist ausgedrückt im Code der arabischen Sprache. Sprache ist jedoch das Resultat einer bestimmten Zeit mit ihren spezifischen soziokulturellen Bedingungen. Die sprachliche Formulierung der Botschaft Gottes ist folglich abhängig von ihrem Kontext, und diesen Kontext gilt es zu begreifen. Um den Koran zu verstehen, ist es daher notwendig, an ihn mit den herkömmlichen Methoden der Textinterpretation heranzugehen. ${ }^{11}$ Sorusch wiederum bezeichnet es als „ein weit verbreitetes Missverständnis, wenn religiöses Wissen - also bestimmte Doktrinen, eine bestimmte Lehre von Gott und seinen Attributen oder konkrete Auslegungen göttlicher Gebote - mit der göttlichen Wahrheit selbst verwechselt werde“".12

Aber bereits die traditionelle Koranexegese geht von einer Historisierung jener Koranpassagen aus, die von den Auseinandersetzungen und Kämpfen mit den Polytheisten, mit Juden und Christen sprechen; demnach handelt es sich um zeitgebundene Bestimmungen, die von der damaligen Politik bestimmt waren. Damit wird auch eine grundsätzliche Antwort auf die Frage gegeben, ob nun die Polytheisten wegen ihres aggressiven Vorgehens oder wegen ihres „Unglaubens“ zu bekämpfen seien. Nach dieser Sicht gelten viele Verse aus Sure 9 (vorletzte oder letzte Sure, die geoffenbart wurde in dieser Sure konzentriert sich das letzte Stadium der Auseinandersetzung mit den Polytheisten) nur für arabische Polytheisten, d.h., sie haben für nichtarabische Polytheisten keine Geltung. Es handelt sich um eine ,zeitgebundene Bestimmung, welche das Ziel hatte, die Kaaba von den Anzeichen des Schirk (Polytheismus) zu reinigen und die Streitkraft der Götzendiener auf der arabischen Halbinsel zu zerschlagen“. Wenn sich die Polytheisten friedlich verhalten, können mit ihnen auch Schutzverträge (dhimma) abgeschlossen werden, sind sie also wie Juden und Christen zu behandeln. ${ }^{13}$ Daher wurde es nach einigen Rechtsgelehrten (hanafitische Rechtsschule) später möglich, mit den Hindus und Buddhisten auch dhimma-Verträge abzuschließen. Allerdings gibt es diesbezüglich bis heute unter den Gelehrten unterschiedliche Auffassungen. 
In diesem Kontext spielt nun das Prinzip Abrogation eine entscheidende Rolle; die Frage, welche Stellen als abrogiert gelten können, wird von den jeweiligen Gelehrten unterschiedlich beantwortet. Bei einigen Vertretern des politischen Islam wird sogar das gesamte mekkanische Modell als abrogiert bezeichnet. Diese Gelehrten gehen davon aus, dass der Schwertvers in 9.5 (,Wenn die heiligen Monate abgelaufen sind, dann tötet die Polytheisten, wo immer ihr sie findet, greift sie, belagert sie und lauert ihnen auf jedem Weg auf"), der Bekämpfungsvers in 9,29 („Kämpft gegen diejenigen, die nicht an Gott und nicht an den Jüngsten Tag glauben [... “") oder Sure 47.4 („Wenn ihr auf die, die ungläubig sind, trefft, dann schlagt (ihnen) auf die Nacken. Wenn ihr sie schließlich schwer niedergekämpft habt, dann schnürt (ihnen) die Fesseln fest. Danach gilt es, sie aus

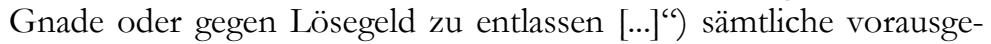
hende Stellen in den mekkanischen und medinischen Suren, die für ein friedliches Zusammenleben plädieren, außer Kraft setzen; davon sind etwa 114 Stellen betroffen (z.B. 2.139, 3.20, 4.80-81, 5.13, 5.99, $6.108,6.112,6.135,6.158)$.

Entscheidend für diese Sicht ist, dass, wie es Sayyid Qutb oder Abd as-Salam Faradsch, zwei wichtige Leitgestalten für den politischen Islam, ausdrücken, die mekkanische Periode „die Periode der Entstehung des Aufrufes (zum Islam)“ ist; Sure 5.3 („Heute habe Ich euch eure Religion vollendet ${ }^{(*)}$ abrogiert die Idee, „dass wir uns in der mekkanischen Periode befinden. Wir sind nicht am Beginn von etwas wie der Prophet, sondern wir haben die Offenbarung in ihrer endgültigen Form anzunehmen". .14

Nach der Meinung anderer Gelehrter (z.B. Ibn al-Dschauzi, 12. Jahrhundert) besitzen jedoch auch all jene Stellen in den mekkanischen Suren, die sich für ein friedliches Zusammenleben aussprechen, Rechtsgültigkeit: „Der Schwertvers und Bekämpfungsvers abrogieren keinen einzigen Vers aus dem Koran - gleich ob es sich um Verse handelt, die den Umgang mit den Nichtmuslimen bestimmen, oder ob es sich um Verse handelt, die mit der Erlaubnis [...] zu tun haben, die Nichtmuslime aus Selbstverteidigungsgründen zu bekämpfen, oder ob es sich um andersartige Verse handelt [...]." ${ }^{\prime 15}$ Als Begründung wird angegeben, dass nicht der Glaube ent- 
scheidend ist, sondern ob sich Nichtmuslime gegenüber Muslimen friedlich oder feindlich verhalten.

„Die große Mehrheit [...] der Rechtsgelehrten der malikitischen, hanafitischen und hanbalitischen Rechtsschulen sagt, dass der Beweggrund für den Kampf die Bekriegung, Bekämpfung und Übertretung von Seiten der Nichtmuslime ist - und nicht deren Ablehnung des Islam. Niemand wird allein wegen seiner Ablehnung des Islam getötet, sondern aufgrund seines Angriffs gegen den Islam. Es ist nicht erlaubt, diejenigen zu bekämpfen, die nicht den Islam bzw. die Muslime angreifen. Mit diesen Menschen sollen die Muslime auf friedliche Weise umgehen."16

Dies wird auch an einigen Stellen des Korans klar ausgesprochen:

„Gott verbietet euch nicht, gegen diejenigen pietätvoll und gerecht zu sein, die nicht der Religion wegen gegen euch gekämpft, und die euch nicht aus euren Wohnungen vertrieben haben." (60.8; vgl. 9.4, 9.7, 9.12)

Der aus Indien stammende muslimische Gelehrte Syed Zainul Abedin (1928-1993) geht davon aus, dass es legitim ist, zwischen der Rolle, die der Prophet in Mekka hatte, und derjenigen, die er in Medina hatte, zu unterscheiden: „Die späteren Generationen können Mekka als moralische Kategorie nicht ausklammern. Medina ist dagegen eine Option, die ihnen begegnen mag oder nicht [...] Mekka ist dagegen eine Notwendigkeit. Es gibt keine Alternative dazu. Die Botschaft Muhammads ist universal. An dieser Tatsache führt kein Weg vorbei. Ebenso gibt es kein Ausklammern des ursprünglichen Kontextes dieser Botschaft, d.h., wenn jemand in unseren Tagen Muslim wird, kann er nicht um Mekka herumkommen. Mekka ist primär nicht eine physische Kategorie. Es ist mehr. Es ist auch eine moralische Kategorie. Man kann sogar sagen, dass es für spätere Generationen primär eine moralische Kategorie ist". Er meint, dass Muslime dazu neigen, ,eine scheinbar kleine Tatsache zu übersehen, die jedoch von unglaublicher Tragweite ist: das erste, ursprüngliche Medina wurde nicht durch militärische Eroberung gewonnen. Der Prophet wurde eingeladen nach Yathrib/Medina von seinen Bewohnern."17 
Den beiden Örtlichkeiten Mekka und Medina im Arabien des 7. Jahrhunderts kommen unterschiedliche geographische, soziokulturelle und politische Bedeutungen zu. Jedoch: die spezifische zeitgeschichtliche Situation in Medina hat u.a. auch zu Handlungsmustern geführt, die sich wegen ihres konkreten historischen Kontextes einer gewissen Generalisierung entziehen, ein Faktum, das von den Rechtsgelehrten durchaus auch beachtet wird. Medina kann nur schwerlich eine Norm sein, diese Rolle kommt Mekka zu. Das heißt, dass auch das Gottesbild diesem historischen Kontext unterworfen ist, indem es eine der jeweiligen historischen Situation adäquate Haltung transzendiert.

\section{Die Frage nach einer Religionspluralität}

In Sure 22.17 werden unter die Schriftbesitzer auch die Polytheisten (muschrikun) eingereiht:

„Diejenigen, die glauben, und diejenigen, die Juden sind, und die Sabier und die Christen und die Magier und diejenigen, die Polytheisten sind - siehe, Gott wird am Tag der Auferstehung zwischen ihnen entscheiden. Gott ist ja Zeuge über alle Dinge."

Yusuf Ali, ein indischer Muslim, schreibt in seinem Kommentar: „Es überrascht ein wenig, dass auch die Polytheisten mit aufgezählt werden, aber das Argument ist, dass alle Glaubensrichtungen, die aufrichtig sind, Angelegenheiten sind, in die Menschen sich nicht einmischen können. Unsere Pflicht ist Toleranz innerhalb der angemessenen Grenzen, d.h., solange dadurch nicht Unterdrückung, Ungerechtigkeit und Verfolgung entstehen. Wo wir ein offensichtliches Unrecht verhindern können, ist es unsere Pflicht, dies zu tun. Es wäre jedoch unsererseits falsch, uns ohne jede Grundlage zu ereifern, nur weil andere Menschen unseren Standpunkt nicht teilen" “. ${ }^{18}$

In diesem Zusammenhang wäre demnach die Frage aufzugreifen, ob nicht im mekkanischen Modell der Ansatz für eine religionsplurale Haltung gegeben ist; von einer solchen spricht auch Sure 5.48, allerdings ist hier nur von Juden, Christen und Muslimen die Rede:

„Für jeden von euch haben Wir eine Richtung und einen Weg festgelegt. Und wenn Gott gewollt hätte, hätte Er euch zu einer einzigen Gemeinschaft gemacht. Doch will Er euch prüfen in dem, was

18 Die Bedeutung des Korans (1996/97), Band 1 (1997). 
Er euch hat zukommen lassen. So eilt zu den guten Dingen um die Wette. Zu Gott werdet ihr allesamt zurückkehren, dann wird Er euch kundtun, worüber ihr uneins waret."

Wenn auch die Polytheisten mit ihrem ,falschen Glauben" fehlgeleitet sind, wie aus dem Koran hervorgeht (nach Sure 4.48 kann die Sünde der „Beigesellung“ nicht vergeben werden), so kommt diese Beurteilung, wie ebenfalls aus dem Koran hervorgeht, letztendlich Gott zu und nicht den Menschen. Wenn es also nicht der „falsche Glaube“ der Polytheisten ist, sondern ihr aggressiv feindliches Verhalten, das zu einer entsprechenden Antwort herausfordert, wäre dies ein gewisser Ansatz für ein friedliches Nebeneinander und damit ein Ansatz für eine bedingte religionsplurale Gesellschaft bzw. für Toleranz, denn auch mit den Polytheisten könnten zumindest nach einem Teil der Rechtsgelehrten - dhimma-Verträge geschlossen werden. Nach der Meinung anderer Rechtsgelehrter haben sie freilich ihr Recht auf Existenz verloren. Abgesehen davon bleibt dann immer noch die Frage, ob dieser dhimma-Status der Nichtmuslime einer religionsplural ausgerichteten Gesellschaftsordnung entspricht. Von muslimischer Seite wird dieser Toleranzstatus von Juden und Christen als „Schutzbefohlenen“ des islamischen Gemeinwesens generell als Akzeptanz von Judentum und Christentum interpretiert und damit als religionsplurale Haltung. Vergessen wird aber hierbei, dass der Koran etwa das Christentum dahin gehend kritisiert und korrigiert, dass es durch die Trinitätslehre den Eingottglauben verfälscht habe, wodurch das Christentum keinen Heilsanspruch mehr stellen könne. ${ }^{19}$ Dazu kommt noch, dass die Angehörigen eines solchen „Schutzvertrages“ nicht mit den Muslimen gleichgestellt sind, sondern Bürger zweiter Klasse sind. Daher:

„Wer eine andere Religion als den Islam sucht, von dem wird es nicht angenommen werden. Und im Jenseits gehört er zu den Verlierern" (3.85, vgl. 3.19). Aus der Gesamtsicht des Korans, so müssen wir folgern, hat sich demnach eine religionsplurale Haltung, worauf etwa die Suren 5.48 und 22.17 hinweisen, nicht durchgesetzt.

„Es wäre ein wichtiger Schritt“, schreibt Özsoy weiter, „für die Muslime auf dem Wege des koranischen Ideals von der Einigkeit der Menschen in Bezug auf gemeinsame universale Werte, wenn sowohl bei der künftigen Koranforschung als auch in den Dialogbemühun- 
gen in Betracht gezogen würde, dass kufr nicht ,Unglaube،, sondern ,Undankbarkeit' ${ }^{6}$ - eine religiös-ethische Einstellung, die manche Muslime auch einschließen könnte - und islam nicht nur ,MuslimSein', sondern auch ,Ergebenheit Gott gegenüber' - eine religiösethische Einstellung, die manche Nichtmuslime auch einschließen könnte - bedeuten." 20

\section{Literatur}

Abu Zaid, Nasir Hamid (1996): Islam und Politik. Kritike des religiösen Diskurses. Frankfurt/M.: Dipa Verlag.

Abu Zaid, Nasir Hamid (2001): „Ich bin es leid, den Islam zu verteidigen“. Gott spricht durch die Menschen: Das Problem des Fundamentalismus besteht darin, dass er das Geschichtliche zum Ewigen erklärt", in: Süddeutsche Zeitung Nr. 283, 8./9. Dezember 2001, VII.

Ibn al-Dschauzi, Al-Hafidh Dschamaluddin (1982): Nawasib al-Koran. Beirut: Dar al-Kutub al-'ilmijja.

Balic, Smail (2001): Islam für Europa: neue Perspektiven einer alten Religion. KölnWien: Böhlau.

Die Bedeutung des Qur'ans (1996-1997): 5 Bände. München: SKD Bavaria Verlag.

Faradsch, Abd as-Salam (1991): ,al-Faridah al-gha'bah“, in: Rifaat, Ahmad Sayed: An-Nabi al-musallah (1): Al-Rafidun. London: Riad El-Rayyes Books Ltd, 127-149.

Goldziher, Ignaz (1970): Die Richtungen der Islamischen Koranauslegung. Leiden: E. J. Brill.

Hildebrandt, Thomas (2006): „Nasr Hamid Abu Zaid: Interpretation - die andere Seite des Textes“, in: Amirpur, Katajun/Ammann, Ludwig, Hg.: Der Islam am Wendepunkt. Freiburg/B: Herder, 127-135.

Ibn Ishaq, Muhammad (1961): Sirat rasul Allah, hg. v. Wüstenfeld, F., 3 Bände, Neudruck. Göttingen.

Jansen, Johannes J.G. (1996): The Neglected Duty. London: Macmillan Publishing Company, 159-234.

Kallfelz, Wolfgang (1995): Nichtmuslimische Untertanen im Islam. Wiesbaden: Harrassowitz.

Khoury, Adel Th. (1987): Der Koran. Gütersloh: Gütersloher Verlagshaus Gerd Mohn.

Krämer, Gudrun (1992): „Kritik und Selbstkritik: Reformistisches Denken im Islam", in: Lüders, Michael, Hg.: Der Islam im Aufbruch? München: Piper, 209-227. 
Madjid, Nurcholish (1994): „Religiöser und gesellschaftlicher Pluralismus. Eine islamische Sicht im Kontext indonesischer Erfahrung", in: Bsteh, Andreas, Hg.: Friede für die Menschbeit. Grundlagen, Probleme und Zukunftsperspektiven aus islamischer und cbristlicher Sicht. Mödling: St. Gabriel, 219232; 233-249 (Gesprächsbeiträge im Plenum).

Özsoy, Ömer (2007): „,Leute der Schrift' oder Ungläubige?“, in: Schmid, Hansjörg/Renz, Andreas/Sperber, Jutta/Terzi, Duran, Hg.: Identität durch Differenz? Wechselseitige Abgrenzungen in Christentum und Islam. Regensburg: Friedrich Pustet, 107-118.

Özsoy, Ömer (2006): „Darf der Koran historisch-hermeneutisch gelesen werden?"“, in: Altermatt, Urs/Delgado, Mariano/Vergauwen, Guido (Hg.): Der Islam in Europa. Zwischen Weltpolitik und Alltag. Stuttgart: W. Kohlhammer, 153-159.

Maulawi, Feisal (2006): Die Schariagrundlagen für das Verbältnis zwischen Muslimen und Nichtmuslimen. Karlsruhe: Deutscher Informationsdienst über den Islam e.V.

Moussalli, Ahmad (1992): Radical Fundamentalism: The Ideological and Political Discourse of Sayyid Qutb. Beirut: American University of Beirut.

Prenner, Karl (2005): „Islamischer Fundamentalismus und Koraninterpretation", in: Salamun, Kurt, Hg.: Fundamentalismus ,interdisziplinär". Wien: LIT, 117-151.

Qutb, Sayyid (1982): Ma'alim fi t-Tariq. Kairo: Dar al-Schuruq.

Rahman, Fazlur (1982): Islam and Modernity. Chicago: University of Chicago Press.

Seidel, Roman (2006): „Abdolkarim Sorusch: Viele Wege zur Wahrheit“, in: Amirpur, Katajun/Ammann, Ludwig, Hg.: Der Islam am Wendepunkt. Freiburg/B: Herder, 82-89.

Troll, Christian (1991): „Der Blick des Koran auf andere Religionen“, in: Kerber, Walter, Hg.: Wie tolerant ist der Islam? München: Kindt, 47-69.

Wielandt, Rotraud (2004): „Islam und Gewalt“, in: Waldenfels, Hans/ Oberreuter, Heinrich, Hg.: Der Islam - Religion und Politik. Paderborn: Ferdinand Schöningh, 37-48.

Wielandt, Rotraud (1996): „Wurzeln der Schwierigkeit innerislamischen Gesprächs über neue hermeneutische Zugänge zum Korantext", in: Wild, Stefan, Hg.: The Qur'an as text. Leiden: E.J. Brill, 257-282.

az-Zuhaili, Wahbat (O.J.): Athar al-harb fil fiqh al-islami (Der Krieg und das islamische Recht). Damaskus: Dar ul fikr. 



\section{Problemfelder der Praxis}





\section{Voraussetzungen und Stolpersteine für den interreligiösen Dialog. Eine Praxisbeobachtung aus christlicher Sicht in Österreich}

Elisabeth Dörler

Die westliche Moderne versteht sich relativ unreflektiert als eine aufgeklärte Moderne, in der Religionsfreiheit herrscht, die Demokratie aber wichtiger als Religion ist. Dies ist für mich eine Art Essenz aus den Medien.

Doch wenn es um Konflikte zwischen Angehörigen verschiedener Gruppen mit unterschiedlichen religiösen Wurzeln geht, entsteht allzu rasch eine Rivalität: westliche Moderne versus Islam. Dabei werden neben der religiösen Ebene auch schnell andere Ebenen herangezogen und vermischt, die zwar irgendwie miteinander zu tun haben, aber eben nicht dieselben sind.

Ein Beispiel ist für mich die Islamkonferenz im November 2005 in Wien, die vom österreichischen Außenministerium veranstaltet wurde. Es war „klar“, dass die Sprecher(innen) aus muslimisch geprägten Ländern im Namen des Islams sprachen, die Mitteleuropäer(innen) aber als Mitteleuropäer(innen), die teilweise auch Christ(inn)en waren.

Auf der regionalen Ebene zeigt sich die Dynamik eilfertiger Polarisierung z.B. in einem Konflikt wie jenem mit türkischstämmigen Jugendlichen, die sich für ihre Mutprobe eine katholische Kirche aussuchten. Daraus wurde in den Medien ein Religionskrieg zwischen Christ(inn)en und Muslim(inn)en, obwohl die ganze Sache den Eltern bzw. Familien dieser Jugendlichen sehr peinlich war, weil es im Islam gerade durch die Reinheitsregeln nicht zum guten Ton gehört, Gebetsräume zu verschmutzen. 
Internationale Konflikte der islamischen Welt oder für uns schwierige bis falsch interpretierte Wertesysteme von Muslim(inn)en irgendwo auf der Welt werden auf muslimische Migrant(inn)en in der Region angewendet:

So soll sich der Vorarlberger Textilarbeiter Ahmed, dessen Großeltern aus der Türkei kamen, für die terroristischen Taten von Al Kaida in einer Diskussion rechtfertigen. Oder die bosnische Nicht-Kopftuchträgerin Enisa, die als Flüchtling in Vorarlberg lebt, soll auf einmal die Theologie, die hinter dem Bedeckungsgebot des Korans steht, bzw. die Frauenbeschneidung im Sudan erklären.

Damit ist nicht verwunderlich, dass sich viele Muslime und Musliminnen aus dem praktischen Dialog zurückziehen. Es ist vielen $\mathrm{zu}$ anstrengend, andauernd gegen äußerst aggressive Angriffe der christlich geprägten Mehrheitsgesellschaft zu argumentieren.

Spitzen, die in meinen Augen für das gewaltfreie Zusammenleben, also das friedliche Zusammenleben, von Christ(inn)en und Muslim(inn)en in Österreich störend sind, tauchen regelmäßig auf:

- Muslimische Migrant(inn)en werden für den weltweiten Terrorismus im Namen des Islams in einer Art Sippenhaft verantwortlich gemacht.

- Weil es auch bei uns zu beobachtende islamistische - aber nicht gewalttätige - Gruppierungen gibt, werden alle Muslime und Musliminnen diesen Gruppen zugeordnet.

- Während der Westen sonst meist auf fachlich qualifizierte Referent(inn)en in Fachgesprächen besteht, sollen in diesem sensiblen Bereich gläubige Menschen ohne theologische, soziologische, politologische o.ä. Fachausbildung hoch reflektiert zum Gespräch beitragen.

- $\quad$ Es wird vielfach sehr undifferenziert von „dem Islam“ gesprochen, obwohl wir selber auf einer Differenzierung der christlichen Welt, gerade im Hinblick auf fundamentalistische Strömungen im Christentum, bestehen.

- Aus der Beobachtung, dass in den Industriegebieten viele der muslimischen Migrant(inn)en aus einer patriarchalen, bäuerlichen, nicht nach westlichen Grundsätzen gebildeten Welt (orale Traditionen, Analphabetentum) kommen und sich hier darum nicht leicht integrieren können, wird das Prinzip abgeleitet, dass Muslime und Musliminnen generell nicht integrierbar sind. 
- Das Fehlverhalten entwurzelter Jugendlicher, die weder die Wertevorstellung ihrer islamischen Herkunftskultur noch die der westlichen Welt internalisiert haben und damit in beiden Gesellschaften sozial höchst auffällig werden, wird schnell als islamische Arroganz oder Aggression gedeutet.

- Migrationsprobleme werden in den gängigen Diskussionen vorschnell monokausal auf den Islam zurückgeführt, obwohl es aus der Soziologie bekannt ist, dass es ein Diasporaverhalten gibt, für das Angehörige aller Religionen anfällig sind.

Ich will hier klar aussprechen, dass ich die echten Probleme - die auch angesprochen werden müssen - nicht verniedlichen will, aber sie sollen dort angegangen werden, wo sie ihren Ort haben, und nicht bei zufälligen Vertreter(inne)n des Islams, die sich selber zwar als Muslime und Musliminnen, aber nicht als Repräsentant(inn)en der islamischen Welt fühlen.

Dies alles ist in der Dialogarbeit in der Praxis zu spüren. Denn Muslime wollen von der Mehrheitsgesellschaft mit Recht weder überfordert noch „,bemuttert“ werden. - Unter „Bemuttern“ verstehe ich in diesem Fall, dass alles entschuldigt wird, weil man ja mit den armen Muslimen ,lieb“ sein muss, anstatt ein Problem ernst zu nehmen. In beiden Rollen fühlen sich berechtigterweise viele Muslime nicht ernst genommen oder in eine Ecke gedrängt und werden somit für Aggressionen anfällig.

Es ist derzeit sicher eine große Herausforderung, mit Muslimen partnerschaftlich kommunizieren zu lernen und nicht nur über sie. Aber wenn wir nicht wollen, dass Frustration oder Ungerechtigkeit in Aggression gegen die vermeintlichen Urheber kippt, müssen wir als derzeit durchschnittlich Stärkere (an Bildung, Sprachvermögen, Gesetzeskenntnis, Sozialressourcen, im Einschätzenkönnen der gesellschaftspolitischen Realität usw.) daran mitwirken, dass der mit migrantischen Problemen belastete Islam bei uns die Chance hat, zu einem dialogfähigen Partner - und dies nicht nur auf der obersten Funktionärsebene - zu werden.

Dies kann in einem konkreten Prozess durch die Einbindung von Muslim(inn)en in Entscheidungen, das Klären von Vorgängen, die nachvollziehbare Begründung von Werten bzw. Wünschen der Mehrheitsgesellschaft oder einfach auch durch Geduld und Zeit zum Nachvollziehen der von der Mehrheit vertrauten Handlungsweise erreicht werden. 
Aber es bedarf auch auf der Seite der Christ(inn)en der Chance, diesen Wandel von einer christlich geprägten Gesellschaft in eine jetzt nicht nur theoretisch verfasste, sondern auch praktisch gelebte pluralistische Gesellschaft zu verstehen und akzeptieren zu lernen, ohne die eigene christliche Identität zu verlieren. Meine Erfahrung zeigt mir, dass dies wichtig für die Annahme ist. Wenn Angehörige der christlich geprägten Gesellschaft, die in ihrer Schulzeit selten dieses relativ junge Phänomen reflektiert kennen lernen konnten, nicht die Möglichkeit haben, sich mit dieser neuen Wirklichkeit des Islams nicht nur auf der universitären, theologischen, sondern auch auf der Ebene des praktischen Lebensvollzugs auseinanderzusetzen, fühlen auch sie sich betrogen und werden ebenfalls für Aggressionen bzw. Manipulationen anfällig, wie es viele islamophobe Leserbriefe und Reaktionen auf Internetmeldungen der Medien zeigen. 


\section{Gewalterfahrungen muslimischer Kinder und Stellung der Gewalt im islamischen Religionsunterricht (IRU)}

Ednan Aslan

Für Muslime ist es eine neue Erfahrung, als Minderheit in einer pluralistischen Gesellschaft zu leben, sich darin als Teil zu identifizieren und daran zu partizipieren.

Der Islam kennt in seiner Geschichte verschiedene Gesellschaftsmodelle, in denen unterschiedliche Kulturen und Religionen unter den islamisch legitimierten Regeln zusammenlebten. Es existierten auch theologische Konzepte, die den vorübergehenden Aufenthalt der Muslime in einer nicht islamisch geprägten Gesellschaft regelten. Dass die Muslime in einer pluralistisch-christlich geprägten Gesellschaft auf Dauer bleiben und daraus eine Heimat unter diesen Verhältnissen entsteht, ist für die islamische Theologie neu. Die klassische Jurisprudenz sah dabei immer eine Assimilationsgefahr für die Zukunft der Muslime und empfahl die Auswanderung in das Haus des Friedens „Darul Islam- Darussalam“.

Der sich einstellende innere Frieden wäre nach dieser Theorie nur mit einer islamischen Lebensweise möglich, die das Gewissen nicht durch allzu viele Kompromisse belastet, und eine solche Lebensweise könnte nur eine rein islamische Gesellschaft ermöglichen. Nun leben wir in einer Gesellschaft, die größtenteils ihre Inspiration und ihren Einfluss und dementsprechend auch ihre Regeln nicht mehr aus dem Glauben bezieht. Erfreulich ist jedoch die dadurch entstandene Offenheit, die einer Vielfalt von Glaubensüberzeugungen ermöglicht, so friedlich nebeneinander zu leben. Ein Garant dafür ist ganz zweifelsohne die gesetzliche Garantie der Religionsfreiheit, wie sie sich im Sinne einer demokratisch-säkularistischen Ge- 
sellschaft definiert. Man kann sagen, dass sich derartige Erfolge selten in der Geschichte finden.

Es war in der islamischen Geschichte nicht immer selbstverständlich, dass die Muslime eine Lebensweise nach ihren religiösen Vorstellungen führen durften. Darüber hinaus war es auch nicht selbstverständlich, sich der staatlich verordneten Religiosität zu widersetzen.

\section{Muslime in Österreich}

Die größte Gruppe unter den 339.000 in Österreich lebenden Muslimen ist jene mit türkischer Staatsbürgerschaft (123.000), gefolgt von den Österreichern, Bosniern (64.628), Jugoslawen (21.594), Mazedoniern (10.969) und Iranern (3.774). Die meisten arabischen Muslime kommen aus Ägypten (3.541) und Tunesien (1.065).

Mehr als ein Drittel der Muslime in Österreich lebt in Wien. Dort beträgt ihr Anteil 7,8\%. Laut Zentralinstitut Islam-Archiv ist anzunehmen, dass Österreich nach Frankreich mit 4,2\% den zweithöchsten Anteil an muslimischen Einwohnern in der EU hat. 1971 betrug der Wert noch 0,3\%. Etwas mehr als 95.000 der Muslime in Österreich sind auch hier geboren.

Österreichweit liegen Muslime mit 4,2\% noch knapp hinter den Protestanten (4,7\%).

In Österreich wurde im Schuljahr 2003/04 an 1.716 Pflichtschulen für 31.890 Schüler(innen) und an 191 mittleren und höheren Schulen für 4.400 Schüler(innen) ein islamischer RU angeboten. An den Pflichtschulen unterrichteten 279 islamische Religionslehrer(innen) (RL), an den mittleren und höheren Schulen 52. Die Zahl der Schüler(innen) stieg im Jahr 2004/2005 auf insgesamt ca. 40.000 an, die Standorte wurden ausgeweitet.

Die Aufsicht wird durch das Schulamt der Islamischen Glaubensgemeinschaft in Österreich (IGGiÖ) und mit ihren neun Schulinspektoren gewährleistet.

\section{Die Gewalterfahrungen}

Nach dieser Einführung komme ich zu meinem eigentlichen Thema, nämlich welche „Gewalterfahrungen“ die muslimischen Kinder in dieser Gesellschaft machen und wie die Stellung der Gewalt im islamischen Religionsunterricht ist. 
Mit Gewalt meine ich, dass die Schüler(innen) wiederholt und über eine längere Zeit den negativen Handlungen einer oder mehrerer Personen oder Institutionen ausgesetzt sind. Die negativen Handlungen sind nicht immer absichtlich, in meinem Beitrag werden die Folgen unqualifizierter Handlungen, ob absichtlich oder unabsichtlich, als Gewalt aufgefasst.

Wenn ich hier von den Gewalterfahrungen muslimischer Schüler(innen) spreche, meine ich nicht, dass die nichtmuslimischen Kinder solche Erfahrungen nicht machen. Es ist durchaus möglich, dass auch die nichtmuslimischen Schüler(innen) ähnliche Erfahrungen machen. Gewalt an den Schulen ist ein gesamtgesellschaftliches Phänomen in Europa. Die Gewaltforscher sprechen zwar von religiösem Fundamentalismus, Radikalismus, mir ist jedoch eine speziell islamisch begründete Gewalt an den Schulen nicht bekannt.

Nach den letzten Studien der Gewaltforschung sind die Differenzen zwischen muslimischen und nichtmuslimischen Schüler(inne)n in der Gewaltbereitschaft oder Gewaltausübung sehr gering. Diese geringe Differenz wird mit situativen und sozialen Faktoren, die auf der Seite der Muslime zum Tragen kommen, begründet. ${ }^{1}$ Ich habe mir auch nicht zum Ziel gesetzt, die Hintergründe der Gewalt unter den muslimischen Jugendlichen zu analysieren, sondern die Gewalterfahrungen der muslimischen Jungendlichen, die als Hindernis vor gesellschaftlicher Integration und Partizipation stehen, zu klären und den islamisch-religionspädagogischen Standpunkt zu verdeutlichen.

Muslimische Schüler wachsen in einem gesellschaftlichen Umfeld auf, das durch zahlreiche negative Erfahrungen der Menschen gekennzeichnet ist. In Bezug auf dieses Umfeld spricht man von Arbeitslosigkeit, Rassismus, Diskriminierung, Stigmatisierung, Nationalismus, Benachteiligung usw. In einem solchen Milieu wird die Wärme, Menschlichkeit, Freundlichkeit und Hilfsbereitschaft der Mehrheitsgesellschaft stark vermisst. ${ }^{2}$ Und somit auch die Anerkennung der kulturellen und religiösen Eigenschaften der Minderheiten.

1. Unter diesen Verhältnissen wachsen die muslimischen Kinder in einer kulturell- religiösen Isolation auf, sodass die Mehrheitsgesellschaft als eine gewisse Bedrohung für die eigene kulturelle 
und religiöse Identität betrachtet wird. Die muslimischen Schüler(innen) leben in einem Spannungsfeld, das ihnen eine vorurteilsfreie Begegnung mit der Gesellschaft erschwert. Jede Art der Erfahrung, die den Erfahrungen der Eltern widerspricht, kann als Gefahr der Entwurzelung verstanden werden. Hier entsteht eine spezifisch geprägte Gewalt in einem kulturellen Überzeugungssystem. In diesem System gilt eine aktive Teilhabe an der Gesellschaft als Verrat an der eigenen Kultur. Damit ist der Konfliktstoff für eine innermuslimische Spannung viel höher als in anderen Familien. Trotz ihres guten emotionalen Verhältnisses zu ihren Eltern verschärfen sich die Konflikte der muslimischen Schüler(innen) - mit wachsenden Alter - vor allem mit den Vätern. ${ }^{3}$ Kleidung/Aussehen, schulische Leistungen, längeres Ausgehen am Abend, finanzielle Angelegenheiten, religiöses Leben und Rückkehrandrohung sowie weitere Auseinandersetzungen sind Themen des familiären Streites.

2. Muslimische Jugendliche, die mit der in ihrer familiären Situation begründeten Unsicherheit und Angst der Gesellschaft begegnen, sind in der Gesellschaft neben der unmittelbaren Diskriminierung durch Personen zusätzlich noch verschiedenen Formen der institutionalisierten Diskriminierungen ausgesetzt. Ältere Schüler(innen) berichten mehr über ihre öffentlichen Diskriminierungserfahrungen als die jüngeren. Die von ihren Eltern zur kulturellen Distanz erzogenen jungen Menschen werden in der Öffentlichkeit in ihrem Gefühl des „AndersSeins“ bestärkt. Die öffentlichen Diskriminierungserfahrungen vertiefen die Identitätskluft der muslimischen Schüler(innen). Damit sind die Kinder einer starken Spannung zwischen Elternhaus und Schule ausgesetzt. ${ }^{4}$ Das führt dazu, dass die Schüler(innen) zu Gewalttätigkeiten oder zur Übernahme von extrem-religiösen, nationalistischen Orientierungen neigen. Dadurch gewinnen diese Menschen subjektive Sicherheiten und Gewissheiten. Sie haben dann zwar eine Orientierung, aber sie leben unter einer großen Spannung.

3. Die islamischen Organisationen und Vereine, die sehr stark an den Traditionen ihrer Herkunftsländer orientiert sind, sehen ih- 
re Chance in diesem Konfliktfeld, in dem sie den Jugendlichen eine kollektive Identität vermitteln. Die existenziellen Fragen „Wer bin ich?“, „Wozu gehöre ich?“ und „Was soll ich tun?“ finden ihre Antwort in dieser kollektiven Identität des AlsMoslem-anders-Seins. Als Moslem anders zu sein vermittelt auch ein Überlegenheitsgefühl, das den jungen Menschen eine Selbstdefinition ermöglicht, die wiederum auf dem schwankenden Boden der Unsicherheit und Angst steht.

4. Die größten Gewalterfahrungen machen die muslimischen Kinder an den öffentlichen Schulen. In dieser ersten ernsthaften Begegnung erfahren sie, dass ihre kulturellen und sprachlichen Fähigkeiten keine oder wenig Anerkennung finden. Sogar ihre Namen werden eine Last für den Alltag. Die Lehrer(innen), die diesen Namen nicht gut aussprechen, suchen für diese Kinder Spitznamen, die man, so die Lehrer(innen), leichter aussprechen könne. Die Schüler(innen) müssen des Weiteren die bittere Erfahrung machen, dass ihre Eltern hier mit Rat und Tat versagen. Plötzlich hat man einen Vater, der nicht sprechen kann. Eine Mutter, die einen nicht mehr versteht. Diese Situation verstärkt die Unsicherheit und Angst unter den muslimischen Schüler(inne)n.

5. Das Gefühl der Verlassenheit, der Defekt der Andersartigkeit führt zu einer Benachteiligungskrise. Die konkreten Erfahrungen mit Angelegenheiten wie Schwimmunterricht, Schulausflug, Elternabenden, Bekleidung, Essgewohnheiten verhindern im neuen Kontext der Schule ein Fuß fassen. Diese Schüler(innen) brauchen viel mehr Energie, Ausdauer, geistige Möglichkeiten und emotionelle Unterstützung, um die unterschiedlichen Erfahrungswelten von Elternhaus und Schule so miteinander zu vereinbaren, dass es zu einer geistigen Entspannung kommt.

\section{Islamischer Religionsunterricht}

Nun komme ich zur Rolle des IRU. Der RU steht als Pflichtgegenstand inmitten dieser Entwicklungen. Was aber kann der IRU wirklich leisten?

Kein Unterrichtsfach ist mit so hohen Erwartungen verbunden wie der islamische Religionsunterricht an europäischen Schulen. Im deutschsprachigen Raum wiederum sind die Erwartungen noch höher als in anderen Teilen Europas. 
Gesellschaft, Politik und Wirtschaft artikulieren ihre Erwartungen aus ihren Perspektiven: Islamischer Religionsunterricht soll die Identität stärken, Integration fördern, Terror verhindern, christlichen Religionsunterricht stabilisieren, die Koranschulen ersetzen, auch vielleicht den Liberalismus fördern.

Auch auf muslimischer Seite sind die Erwartungen mit hohen Idealen verbunden. Ein Gegenwartsautor vergleicht die Rolle muslimischer Lehrer und Lehrerinnen mit der Rolle des Propheten. Nach ihm sind die islamischen Lehrpersonen Erben der Propheten, folgen sie den Anweisungen Gottes, sind im Leben enthaltsam, begehen keine üblen Tätigkeiten, sollten regelmäßig den Koran rezitieren, ihre schlechten Angewohnheiten aufgeben; und in der weiterführenden klassischen Literatur kommen nochmals hohe Qualitätsansprüche auf die Religionslehrerinnen und -lehrer zu.

Die Eltern erwarten auch vom Religionsunterricht, dass ihre Kinder dort zu gehorsamen, anständigen und praktizierenden Muslimen erzogen oder überspitzt gesagt zu Heiligen gemacht werden.

Islamischer RU kennt die Spannung zwischen muslimischen Kindern und der Gesellschaft und versucht in einer friedlichen Atmosphäre dafür zu sorgen, dass eine islamische Identität in einer demokratischen Gesellschaft möglich ist. Diese Identität braucht eine Atmosphäre der Entspannung und des Friedens.

Dafür ist es notwendig, dass der RU die Gewaltdefinition der klassischen Theologie in der Gegenwart neu definiert (die klassische Theologie: hier vermeide ich ganz bewusst den Islam zu erwähnen, weil der Islam in seiner Geschichte immer wieder verschieden verstanden worden ist und wieder neu verstanden werden muss). Eine große und neue Herausforderung an die islamische Religionspädagogik ist, dass die koranischen Begriffe im europäischen Kontext neu definiert werden müssen.

\section{Gewalt im Islam}

Gewalt wird im geläufigen Islam-Verständnis nicht grundsätzlich abgelehnt. Der Islam war sehr früh in seiner Geschichte mit Gewalt konfrontiert und zur Abwehr gezwungen. In der weiteren Geschichte des Islam wurde die Gewalt immer wieder zur Verteidigung des Islam legitimiert. Frieden herrschte in den islamischen Ländern dann, wenn die Muslime sich von dieser Abwehr- und Opferrolle befreien konnten. Kolonialismus und darauf folgende Diktaturen in den isla- 
mischen Ländern waren wichtige Hindernisse für die verschiedenen Reformbewegungen in den islamischen Ländern, die die neue Stellung des Islam in der Gegenwart zu definieren versuchten.

Die islamische Präsenz in Europa bietet uns die historische Chance, die Stellung des Islam in einer demokratischen Gesellschaft frei von historischen Belastungen neu zu verstehen.

\section{Islamische Religionspädagogik}

Wichtigste Herausforderung an die islamische Religionspädagogik und Theologie ist, die jungen Menschen aus dieser Opfer- und Abwehrrolle zu befreien und in die Lage zu versetzen, mit einem neuen Religionsverständnis eine eigene Identität zu begründen und an der Gesellschaft zu partizipieren. In diesem Prozess brauchen die Muslime eine Atmosphäre der Freiheit und Gleichberechtigung, um dem Staat gegenüber ein neues Selbstverständnis als Bürger mit einer kritischen Loyalität entwickeln zu können. Der Islam soll dabei die Fragen beantworten, die er aus seiner Geschichte nicht kennt oder welche immer nur peripher behandelt wurden, damit diese nun ins Zentrum der theologisch-pädagogischen Diskussionen rücken.

Das schwierige Verhältnis zwischen Theologie und Religionspädagogik verursacht immer wieder heftige Diskussionen unter den beteiligten Akteuren des Vorhabens. Da wären zum einen die Theologen, die Religionspädagogik und Didaktik zu untergeordneten Disziplinen degradieren, und zum anderen die Pädagogen, die die Theologie zu ersetzen versuchen. Zu Beginn der Bemühungen um eine Vermittlung zwischen Theologie und Pädagogik bestand unser Hauptproblem, das der Religionspädagogen, darin, den Theologen zu erklären, was eigentlich Pädagogik leisten könnte. Ein solcher Prozess braucht einen langen Atem. Vor allem Wissenschaftler, die die Wissenschaftskultur der Gegenwart nicht kennen, finden wenig Sinn in dieser neuen Zusammenarbeit.

Die islamische Theologie wird in der Praxis herausgefordert, nicht nur die Fragen der jungen Menschen zu verstehen, sondern auch in Zusammenarbeit mit der Religionspädagogik im Kontext vertretbare und vereinbare Konzepte zur Erziehung muslimischer Kinder zu entwickeln. Meine Erfahrungen belegen die unglaubliche Dynamik der islamischen Fachwissenschaften, die sehr schnell aus eigener Tradition heraus auf den Kontext reagieren können. Der Islam verfügt über ausreichende theoretische Grundlagen. Hier ge- 
winnt die institutionelle Integration der islamischen Gemeinschaft an Bedeutung, die für diesen Diskurs die Infrastruktur vorbereitet.

\section{Gewalt in der Curriculum-Entwicklung des IRU}

Gewalt umfasst ein breites Spektrum von Angriffen und Übergriffen auf die körperliche, psychische, soziale, religiös-kulturelle und persönliche Würde eines Menschen. Diese Gewalt äußert sich nicht immer offen und nicht immer greifbar. IRU versucht die Schüler(innen) für das breite Spektrum der Gewalt zu sensibilisieren.

1. Der neue Curriculumsentwurf der IGGiÖ für die Grundschule thematisiert die Gewalt in ihren verschiedenen Ausdrucksformen in sechs Unterrichtseinheiten ${ }^{5}$ direkt und in den weiteren zehn Einheiten wird sie indirekt angesprochen. Für die weiterführenden Schulen kann ich noch nichts sagen, weil wir die Arbeit noch nicht angesprochen haben. Die aktuellen Lehrpläne (LP) sprechen zwar die moralischen Eigenschaften der Muslime, die für Frieden in der Gesellschaft von großer Relevanz sind, an, aber dieser LP leidet noch zu sehr unter diesem Verteidigungssyndrom.

Ab der ersten Klasse werden die Kinder auf die unterschiedlichen Formen der Gewalt in der Familie aufmerksam gemacht. Hier geht es nicht nur um Opfer-Bilder in der Gewalt, sondern auch die kulturell-religiös legitimierte Gewalt wird nicht verschwiegen. Viele Formen traditionell hingenommener Gewalt werden aus der Dunkelheit des Tabus herausgeholt und enttabuisiert. Dieser Ansatz stößt oft auf innerislamische, theologisch und traditionell begründete Widerstände, die in einem neuen innerislamischen Diskurs heftig ausdiskutiert werden.

2. Der Umgang mit struktureller Gewalt in der Gesellschaft ist keine einfache Aufgabe für den RU in Österreich. RU soll die Identität mit der Gesellschaft fördern und gleichzeitig die Kinder zu einer konstruktiven Auseinandersetzung mit der strukturellen Gewalt, die sich mit verschiedenen Facetten gegen den Islam richtet, motivieren. Hierbei geht es darum, eigenes Gewaltpotenzial zu klären und Gewalt gegen die Muslime zu ver-

5 „Ich bin ein Wunder“ (1. Klasse), „Wir sind nicht allein“ (2. Klasse), „Viele Religionen in meiner Schule“ (4. Klasse), „Islam ruft zum Frieden“ (4. Klasse), „Ich möchte ehrlich sein“ (4. Klasse), „Österreich ist meine Heimat“ (4. Klasse). 
sachlichen. Die Tradition der Gewalt gegen den Islam wird als eine Quelle der Abwehrkraft verstanden, um sich in dieser Opferrolle bestätigen zu können. Daraus ist sogar eine eigene Theologie entstanden, die den geistigen Widerstand der Muslime als Minderheit manifestiert.

Es wäre ein falsches Signal, dieses Gesellschaftsproblem zu pädagogisieren und auf eine Aufgabe für den RU bzw. für die Schule zu reduzieren. Dem Problem kann nur mit einem Gesellschaftskonsens begegnet werden, wenn die Integration der Muslime zum Vorteil aller Beteiligten gelingen soll.

Ich kenne die Auseinandersetzung um die Unterrichtseinheit „Österreich ist mein Heimatland" ${ }^{\circ}$, die heftige innermuslimische Diskussionen verursacht hat. Aus diesen Diskussionen konnte ich entnehmen, dass die Gewalterfahrungen der Muslime nicht aus ihrem religiösen Alltag stammen, sondern sich von ihrer gesellschaftlichen Stellung her schreiben. Die institutionelle Integration der Muslime ist meiner Meinung nach die wichtigste Voraussetzung für eine gesellschaftliche Integration. Eine institutionelle Integration bietet die Chance, dass man die strukturelle Gewalt besser lokalisieren und überwinden kann.

3. Die Schulen sind mit der hohen muslimischen Präsenz überfordert. Gewalt wird als eine kulturelle Eigenschaft der Muslime hingenommen und mit islamischer Tradition begründet. ${ }^{7}$ Eine Hauptschuldirektorin sagte mir, dass die Bezirksschulinspektoren Gewalt als Gewalt nur akzeptieren, wenn Blut fließt. Blaue Flecken, Drohungen, Beschimpfungen gelten als normaler Schulalltag. Eine Schlägerei mit über 20 Beteiligten in einer Schule in Wien wurde als Selbstverständlichkeit unter den jungen Türken verharmlost.

6 Unterrichtseinheit in der 4. Klasse nach dem LP des IRU für die Volksschulen. Intention: Die in Österreich geborenen Generationen von Muslimen brauchen eine islamische Identität, die sie von der Unsicherheit des Fremdseins befreit und ihnen die Fähigkeit verleiht, sich in Österreich heimisch zu fühlen. Der Glaube kann die Lebenssituation der Muslime in Österreich deuten und bewältigen helfen. Der islamische RU soll zur Entwicklung einer solchen Identität in einer nichtmuslimischen Gesellschaft beitragen, sodass ein friedliches Zusammenleben zwischen Muslimen und der Mehrheitsgesellschaft in Gleichberechtigung und gegenseitiger Zuwendung gelingt.

7 „Jungen lehnen die Lehrerinnen ab", „Weil wir keine Muslime sind“, „Weil wir nicht schlagen dürfen“, „Die Väter hetzen die Kinder gegen uns“ sind einige Beispiele. 
IRU versucht unter diesen schwierigen Verhältnissen, sich mit anderen Unterrichtsfächern zu vernetzen. Dialog und Vernetzung sind Standardgrundlagen des IRU. Darüber hinaus werden mit islamischen Werten, wie Versöhnung, Verzeihung, Dankbarkeit, Gleichheit und Würde, die eigenen Standpunkte geklärt, um sich glaubwürdig für die Überwindung der Gewalt einsetzen zu können. „Wie legitimiere ich Gewalt?“, „Wo erlebe ich Gewalt?“, „Warum erlebe ich Gewalt?“, „Wer sind die Friedenshelden meiner Geschichte?" - dies sind nur einige Fragen, die der IRU zu klären versucht.

Die soziale Lage und Schulsituation muslimischer Schüler(innen), die sie zu einer Hoffnungslosigkeit führen, werden vom IRU mit großer Aufmerksamkeit wahrgenommen, sodass wir immer einen Grund zum Hoffen haben. IRU kann einen wichtigen Beitrag für den Frieden in der Gesellschaft leisten und leistet diesen schon gegenwärtig. Nur dürfen wir das Fach in dieser Hinsicht nicht überstrapazieren. Um Gewalt als Gesellschaftsphänomen überwinden zu können, brauchen wir ein Konzept, das Frieden als Bildungsauftrag ernst nimmt und die gemeinsamen ethischen Werte aller Religionen als ernstzunehmende Kompetenzen in alle Schulfächer integriert.

\section{Literatur}

Alacacioglu, Hasan (2000): Deutsche Heimat Islam. München: Waxmann.

Fuchs, Marek (21999): „Ausländische Schüler und Gewalt an Schulen. Ergebnisse einer Lehrer- und Schülerbefragung“", in: Holtappels, Heinz Günter/Heitmeyer, Wilhelm/Melzer, Wolfgang/Tillman, KlausJürgen, Hg.: Schulische Gewaltforschung. Stand und Perspektiven. WeinheimMünchen: Juventa, 119-136.

Gapp, Patrizia (2007): „Konflikte zwischen den Generationen? Familiäre Beziehungen in Migrantenfamilien“, in: Weiss, Hilde, Hg.: Leben in zwei Welten. Zur sozialen Integration ausländischer Jugendlicher der zweiten Generation. Wiesbaden: Verlag für Sozialwissenschaften.

Heitmeyer, Wilhelm/Müller, Joachim/Schröder, Helmut (1997): Verlockender Fundamentalismus. Türkische Jugendliche in Deutschland. Frankfurt/M.: Suhrkamp. 


\section{Welchen Frieden schafft der Religionsunterricht? Schulische Gewalt und Friedensfähigkeit als Herausforderung des katholischen Religionsunterrichts an öffentlichen Schulen}

Matthias Scharer

Der von den christlichen Konfessionen bzw. von den anerkannten Religionen inhaltlich verantwortete und bestimmte Religionsunterricht an öffentlichen Schulen in Österreich stellt ein klassisches Beispiel dafür dar, wie sich die "westliche Moderne" sowohl als Anspruch als auch als Dilemma zeigt. Österreich hat durch die rechtliche Anerkennung des islamischen Religionsunterrichts und seine Gleichstellung mit dem konfessionell verantworteten christlichen Religionsunterricht insofern eine modellhafte Situation in Europa geschaffen, als sich an der rechtlich abgesicherten inhaltlichen Bindung eines schulischen Unterrichtsfaches an die Kirchen und Religionsgemeinschaften, wie sie der Rechtslage in Österreich entspricht, ${ }^{1}$ ein typischer Konflikt zwischen liberalen Bildungsvorstellungen und der jeweiligen Religion bzw. Konfession entzünden kann. Angesichts der spätmodernen Entwicklungen der schulischen Bildung wird auch „die Religion“ in der Schule herausgefordert, ihr Verhältnis zur Bildung in der Gestalt des schulischen Religionsunterrichts kritisch zu bedenken. ${ }^{2}$ Gleichzeitig stellt aber auch der Religionsunterricht keine geschichtslose Konstante im Schulsystem dar; seine konzeptionelle Entwicklung korreliert mit der Schulentwicklung und mit den Veränderungen in den gesellschaftlichen Vorstellungen von Bildung.

Im Ringen des katholischen Religionsunterrichts um seine konzeptionelle Gestalt nach dem Zweiten Vatikanischen Konzil werden 
Konfliktbereiche sichtbar, in denen sich der islamische und der katholische Religionsunterricht in ihrer jeweiligen Situation innerhalb des schulischen Bildungssystems sowohl berühren als auch unterscheiden. An der Ungleichzeitigkeit im Hinblick auf die jeweilige konzeptionelle Gestalt des islamischen bzw. des katholischen Religionsunterrichts können wiederum Fragen um die Religion an der Schule verdeutlicht werden, die ohne die jeweils andere Religion oder Konfession ausgeblendet blieben. So zeigt sich die Triade von westlicher Moderne, Christentum und Islam im schulischen Kontext als spezielle Herausforderung, welche die Gewalt-/Friedensproblematik auf der systemischen Ebene berührt.

Spitzt man die grundsätzlichen Fragen um den Zusammenhang von schulischer Bildung und Religion in der Gestalt des islamischen bzw. des katholischen Religionsunterrichts auf die Frage zu, welchen Beitrag der Religionsunterricht - in diesem Fall der katholische Religionsunterricht - in der jeweiligen konzeptionellen Gestalt für Gewaltprävention und Friedensfähigkeit im Schulsystem leisten bzw. nicht leisten kann, dann zeigen sich in der Verbindung von systemischer Präsenz von Religionen bzw. Konfessionen an der spätmodernen Schule und ihren konzeptionell-thematischen Ansprüchen Herausforderungen, die eine ähnlich intensive Zusammenarbeit der Religionen in der religionspädagogischen Forschung nahelegen, wie sie bereits zwischen den Konfessionen besteht. Auf diesem Hintergrund erfolgt zunächst ein kurzer, akzentuierter und daher keineswegs erschöpfend ausgewogener Blick auf die ambivalente Situation „der Religion“ im Kontext der Bildung an der spätmodernen Schule.

\section{Die Ambivalenz von Religion im Kontext der spätmodernen Schule}

Bildung und Unterricht sind keine überzeitlichen Größen. Als gesellschaftliche Phänomene sind sie vom gesellschaftlichen Wandel zutiefst berührt. Hier soll in aller Kürze auf einige mögliche Folgen des Wandels hin zu einer ,erfolgreichen“, globalen Markt- und Kommunikations(medien)gesellschaft aufmerksam gemacht werden, inso- 
fern diese die grundsätzliche Orientierung schulischer Bildung berühren. ${ }^{3}$

Ausgelöst durch Entwicklungen, die den globalen (wirtschaftlichen) Erfolg durch „,totale“ Kommunikation zum zentralen Kriterium für die Lebensqualität von Mensch und Gesellschaft hochstilisieren $^{4}$ und „Exzellenz“ „als Ergebnis von Leistung“ zum Bildungsziel auf allen Ebenen erklären, ${ }^{5}$ kommt auch die Schule zunehmend unter Druck, ein möglichst perfektes Management von (wirtschaftlich) anerkannten Qualifikationen zu gewährleisten, die zu Höchstleistungen des Schulsystems und der einzelnen Schülerinnen und Schüler führen. Diese Wandlung von Bildungsverständnis ${ }^{6}$ und Schule zeigt sich nicht zuletzt an der Etablierung neuer Begriffe wie „Bildungsstandards“, „Humankapital“, „Qalitätsmanagement“, „Wissensmanagement ${ }^{\text {"'7 }}$ usw., wie sie neuerdings in das Bildungssystem Einzug halten. So werden, der wirtschaftlichen Logik entsprechend, Schülerinnen und Schüler zu Kundinnen und Kunden und damit zu Konsumentinnen und Konsumenten in einem Wissenstransfersystem, das ein möglichst reichhaltiges Angebot von Wissensgütern mit einer guten Werbestrategie, die sich nicht selten unter dem Begriff „Didaktik“ verbirgt, ,,verkaufen“" soll. Wie ein Supermarkt mit dem Angebot einer Unzahl von Konsumartikeln, aus denen man beliebig wählen kann, funktioniert zunehmend auch Schule als „Markt", in dem man sich beliebig bedienen kann. Damit wird jene alte Bildungsauffassung über Bord geworfen, der gemäß sich Lernen als „Inter-esse“ vollzieht; als jenes relativ zweckfreie Kommunikationsgeschehen also, das zwischen den beteiligten Personen und den bildungs-, weil lebensrelevanten Lerngegenständen eröffnet wird, ${ }^{8}$ um mehr Leben im Sinne von Lernprozessen in Freiheit und Verantwortung zu erschließen. Obwohl gerade in den Reformvorschlägen der Expertinnen- und Expertenkommission für eine Neue Mittelschule

3 Damit ist nicht gesagt, dass Schule überall in der aufgezeigten Weise „funktioniert“; gerade die hauptverantwortlichen Akteure im Schulsystem, die Lehrerinnen und Lehrer, versuchen sich vielfach dem öffentlichen Druck zu widersetzen, unter dem Schule vielfach steht.

4 Vgl. den Slogan: „Geht's der Wirtschaft gut, geht's uns allen gut“.

5 Dzierbicka/Schirlbauer (2006), 115.

6 Vgl. Scharer (1999).

7 Vgl. Dzierbicka/Schirlbauer (2006).

8 Vgl. Scharer (1995). 
in Österreich ${ }^{9}$ die Tendenz in Richtung Öffnung des Unterrichts auf individualisiertes Lernen und fächerübergreifende Unterrichtsformen sowie in Richtung einer stärkeren Beachtung von Theater, Musik und Kunst in der Schule, einer mobileren Zeitstruktur usw. zu würdigen ist, bleibt die Ursprungsbedeutung des Wortes „Bildung“, die ihm sein „Erfinder“, der mittelalterliche Mystiker und Theologe Meister Eckhart gab, grundsätzlich verschlossen: Dass der Mensch im Laufe seines Lebens in das „eingebildet“ werde, was er im Lichte christlichen Glaubens immer schon ist: Ebenbild Gottes und Schwester und Bruder Jesu Christi, der Ikone des unsichtbaren Gottes in der Welt. ${ }^{10}$ Es geht an dieser Stelle nicht darum, ein Schreckensszenario spätmoderner Bildung zu zeichnen, um diesem die „Religion“ umso glänzender gegenüberzustellen; vielmehr geraten Theologie und Religionspädagogik selbst zunehmend mehr in die „Wozu-Falle“ von - auch religiöser - Bildung. ${ }^{11}$

Diese kurzen schulkritischen Überlegungen sollen bewusst im Dialog mit meinem muslimischen Kollegen angeschnitten werden, der die Möglichkeit zum islamischen Religionsunterricht an den österreichischen Schulen als besondere Chance in diesem Land vorfinden wird. Gemeinsam müssen wir allerdings auch darauf verweisen, dass der Religionsunterricht an öffentlichen Schulen, wie es ihn flächendeckend in Österreich gibt, kein Privileg darstellt, das der Staat den Religionsgemeinschaften einräumt. Auseinandersetzung mit Religion im öffentlichen Bildungssystem ist ein gesellschaftliches Erfordernis, das nicht zuletzt angesichts der zunehmenden interreligiösen und interkulturellen Herausforderungen und Konflikte, die es gerade auch in Österreich gibt, seine Nützlichkeit klar aufweisen kann; jenseits aller Nützlichkeitserwägungen von Religion in der Schule begründet sich der religiöse Aspekt von Bildung aber in jener anthropologischen Grundbefindlichkeit jedes Menschen, die ihn als immer schon „Gesuchten“ kennzeichnet. ${ }^{12}$ „Die Gottesfrage ist die [...] tiefste Frage des Menschen nach sich selbst, nach Sinn und Be-

9 Vgl. den ersten Zwischenbericht der EXPERTINNENKOMMISSION ZUKUNFT DER SCHULE vom 14.11.2007.

10 Vgl. Menze (1970), 134-135.

11 Vgl. Scharer (2003).

12 Vgl. Gruber (2003), 27. 
deutung seines Lebens" ${ }^{\prime 13}$ jene Frage(n) also, die in der Bildung erschlossen wird/werden.

Der islamische Religionsunterricht teilt mit dem katholischen Religionsunterricht das Schicksal, dass die Schule der westlichen Moderne bis in ihre Organisation und Didaktik hinein ein Handlungsfeld darstellt, in dem Religion immer mehr zu einem Fremdkörper wird, wenn sie sich nicht jenen Funktionen anpasst, die ihr die Gesellschaft etwa im Bereich von Kontingenzbewältigung, Motivation zu ethischem Handeln, der Vermittlung von Sinnangeboten oder der Bewältigung von Konflikten, die sich möglicherweise aus der zunehmenden Multikulturalität und Multireligiosität der Gesellschaft ergeben, zuweist. Gegenüber einer solchen auf „Frieden" durch funktionelle Einpassung in das System Schule basierenden Religion, kann Religionsunterricht gerade dort bedeutsam werden, wo die prophetische Seite der Religion ins Spiel kommt; dort also, wo die gesellschaftlichen Erwartungen an sie, wie an die Schule insgesamt, nicht einfach widerstandslos erfüllt werden.

Der unter dem Verdacht eines ,imperialen Gestus“"14 der Kirchen und Religionen stehende Religionsunterricht in der westlichen Moderne stellt also für beide Seiten ein Risiko dar: Die Kirchen und Religionen kommen mit dem Religionsunterricht in das Dilemma, möglicherweise ihren prophetischen Auftrag zugunsten einer reibungslosen Integration in die Erwartungen des ökonomisierten Schulsystems zu verraten; die Schule steht in Gefahr, sich mit dem konfessionellen und an die inhaltliche Verantwortung der Religionsgemeinschaften gebundenen Religionsunterricht ein Unterrichtsfach in die Schule zu holen, das mit seinem außengesteuerten Anspruch die gesellschaftlich zugewiesenen Grenzen funktionaler Religion überschreiten und zu einer grundsätzlich systemkritischen Instanz werden könnte. Weil die befürchtete Außensteuerung des islamischen Religionsunterrichts durch die eigene Religionsgemeinschaft der säkularen Öffentlichkeit besonders suspekt erscheint, mehren sich die Stimmen liberaler (!) Kreise, nicht zuletzt auch einiger Wissenschaftler, ${ }^{15}$ aus dem konfessionell bzw. von einer Religion verantworteten Religionsunterricht eine neutrale Religionskunde oder einen Ethikunterricht für alle zu machen.

13 Gruber (2003), 27.

14 Vgl. den Beitrag von Otto Kallscheuer in diesem Buch.

15 Vgl. das Interview mit Thomas Schmidinger in Zimmermann (2007). 


\section{Die Schule - ein Ort der Gewalt und des Friedens}

Die Ambivalenz von Religion an der Schule spitzt sich unter dem Fokus von Gewalt und Frieden nochmals zu. Zumindest seit den großen Lehrplanreformen in den 1970/80er-Jahren, die durch die Curriculumreform ausgelöst wurden, ist im schulischen Bildungsbereich bekannt, dass Gewalt ein zunehmendes Problem in der Gesellschaft und in der Schule darstellt. Die Antwort auf diese Herausforderung besteht einerseits darin, dass „die Grundwerte des menschlichen Zusammenlebens“ als ein Kernproblem von schulischer Bildung erkannt werden und dass andererseits das Unterrichtsprinzip „Friedenserziehung“ für alle Fächer vorgeschlagen wird. Im revidierten Lehrplan von Schleswig-Holstein aus den 1990er-Jahren klingt das dann wie folgt:

„Friedenserziehung lässt sich als der Versuch begreifen, die verschiedenen Formen der Gewalt und Friedlosigkeit im internationalen und innergesellschaftlichen Bereich zu erfassen, ihre Ursachen zu analysieren, ihre wechselseitigen Abhängigkeiten zu erkennen sowie zu einem Abbau von Gewalt beizutragen." 16

Es steht also außer Streit, dass die Schule ein Ort der Bildung ist, der es in mehrfacher Hinsicht mit Gewalt zu tun hat, der aber auch Gewalt minimierend und friedensstiftend wirken kann. Ob die Gewalt an/in der Schule speziell im deutschsprachigen Raum zunimmt, ist umstritten. Der mediale Eindruck über die Zunahme von Gewalt im Kontext von Schule muss in Anbetracht der öffentlichen Sensations- und Unterhaltungslust kritisch betrachtet werden. Im Kontext schulischer Gewalt muss grundsätzlich zwischen der Gewalt an/in der Schule, der Gewalt durch die Schule und der Gewalt, in die die Schule hineingezogen wird (vor allem durch die Gewalt in den Familien), unterschieden werden.

\subsection{Gewalt in der Schule}

Wenn wir von Gewalt in der Schule sprechen, dann meinen wir alle physischen und psychischen Gewaltphänomene, die zwischen einzelnen Schüler(inne)n und Schüler(innen)-Gruppen, zwischen Lehrer(inne)n und Schüler(inne)n und mitunter auch zwischen Eltern und Schüler(inne)n bzw. Lehrer(inne)n in der Schule auftreten. 
Eines der bekanntesten Gewaltphänomene in diesem Bereich ist das sogenannte Bullying, eine Art von Mobbing, das sich in Schulklassen relativ häufig ereignet. Man kann aktives Bullying als aggressive Angriffe gegen Mitschüler(innen) (Täterperspektive) von passivem Bullying oder Viktimisierung als dem Erfahren aggressiver Angriffe durch Mitschüler(innen) (Opferperspektive) unterscheiden. Axel Bödefeld erklärt Bullying - in Rückgriff auf die Theorie René Girards - in einer umfassenden Studie aus dem SündenbockMechanismus heraus. ${ }^{17}$ Bullying äußert sich zunächst primär als psychische Gewalt, indem ein oder mehrere Schüler(innen) Opfer einzelner oder mehrerer Schüler(innen) werden, wobei es aktive Täter, Mitbeteiligte, Zuschauer und Unbeteiligte gibt. Cyber-Bullying ist eine intermediale Form, ,bei der Schüler(innen) peinliche Fotos oder Videos von Lehrer(inne)n und Mitschüler(inne)n ins Internet stellen. Es ist nicht nur gegen Lehrer(innen) gerichtet, sondern auch Mitschüler(innen) werden auf diese Art von anderen gequält, indem mit Handy-Kameras Videos auf Toiletten oder in Umkleideräumen gemacht und dann im Internet veröffentlicht werden."18

\subsection{Gewalt durch die Schule}

Eine weite und höchst kontroversiell geführte Debatte bezieht sich auf das Problem, ob und inwiefern das Schulsystem selbst, einschließlich der darin praktizierten Lehr-/Lernformen, einen Ort von (struktureller) Gewalt darstellt. Schul- und erziehungskritische Theorien wie die der „Antipädagogik“, aber auch so bekannte Schulkritiken wie die von Hartmut von Hentig ${ }^{19}$, von Paulo Freire ${ }^{20}$ oder von Ivan Illich ${ }^{21}$ haben, in einer jeweils sehr unterschiedlichen Ausrichtung, nicht zuletzt die Problematisierung struktureller Gewalt durch die Schule bzw. durch bestimmte Lehr-/Lernformen zum Ziel. Tatsache ist, dass schulische Bildung immer durch den Zwang gesetzlich verordneter Anwesenheit, verordneter Lehrpläne und Medien mitbestimmt ist. Wieweit bereits diese Vorgegebenheit oder konkrete Zwänge, die im Kontext schulischer Lehr- und Lernansätze Gestalt

\section{Bödefeld (2006).}

18 http://arbeitsblaetter.stangl-taller.at/KOMMUNIKATION/Bullying.shtml (Zugriff vom 13.6.2007)

19 Vgl. Hentig (2003).

20 Vgl. Freire (1971); Freiere/Betto (1986).

21 Illich (2003). 
gewinnen, als strukturell gewaltsam empfunden bzw. bezeichnet werden können, hängt von der jeweiligen Perspektive ab, unter der einerseits Schule und Lernen und andererseits strukturelle Gewalt gesehen werden.

\subsection{Gewalt, die in die Schule hineingetragen wird}

Wie wir bereits gesehen haben, steht die Schule zunehmend unter dem Anspruch, gesellschaftliche Probleme, die sie nicht selber erzeugt, zu lösen. Dazu gehört auf jeden Fall die Frage der Gewalt in der Familie, im kindlichen und jugendlichen Freizeitbereich und an jugendlichen Migrant(inn)en in und außerhalb der Schule. Wie immer die Schule zu den von der Gesellschaft aufgebürdeten oder durch sie bedingten Aufgaben steht, sie kann die Tatsache nicht verdrängen, dass in jeder Schulklasse Opfer von familiärer und außerschulischer Gewalt sitzen können, ja vermutlich sitzen. Im Hinblick auf solche in die Schule hineingetragene Gewaltproblematik kann die Schule dazu beitragen, dass

- die gesellschaftliche Tabuisierung der Gewaltthematik vor allem im familiären oder auch im Migrationszusammenhang aufgebrochen wird,

- $\quad$ sich ein zukünftiges Opfer möglicherweise selbst besser helfen kann,

- $\quad$ sich Schüler(innen), die Opfer sind, vielleicht jemandem anvertrauen,

- Schüler(innen), die von Opfern ins Vertrauen gezogen werden, Wege der Hilfe kennen,

- Schüler(innen) mit Zivilcourage auf Verdachtsfälle reagieren (Vertrauenslehrer(innen), Beratungseinrichtungen usw.).

Ein eindrucksvolles Beispiel von Gewalt, die in die Schule hineingetragen wird, findet sich im Buch von Inger Hermann „Halt's Maul, jetzt kommt der Segen'22: Die Klagen einer Schülerin, die den Religionslehrer außerhalb der Unterrichtszeit anruft und ihm ihr ganzes Elend mit den gewalttätigen Stiefeltern und mit der eigenen gewalt- 
bereiten Mutter schildert, spitzen sich in der Aussage zu: „Wenn ich von meinem Bruder schwanger werde, dann schlägt sie mich tot.“23

\section{Religionsunterricht an einer gewalttangierten und friedensengagierten (öffentlichen) Schule}

Da Religionsunterricht in Österreich von der ersten Klasse der Grundschule bis zur letzten Gymnasialstufe ordentliches Schulfach ist, ${ }^{24}$ ist er Teil des Systems einer gewalttangierten und friedensengagierten Schule. Wie einige Beispiele in diesem Abschnitt zeigen werden, ist der Religionsunterricht mit der Gewalt im Kontext von Schule nicht selten in einer besonderen Weise konfrontiert. In diesem Zusammenhang soll nach der speziellen Herausforderung des Religionsunterrichts im Hinblick auf Gewalt in der Schule gefragt werden. Da diese Frage aber nicht generell, sondern nur im Kontext der jeweiligen konzeptionellen Entwürfe von Religionsunterricht diskutierbar ist, werden grundsätzliche Ansätze des Religionsunterrichts nach dem 2. Vatikanischen Konzil mit der Gewalt-/Friedensproblematik im Religionsunterricht in Zusammenhang gebracht. Dabei erweist sich die Neubegründung des Religionsunterrichts im Kontext der Synode der Bistümer Deutschlands auch für die konzeptionelle Entwicklung des katholischen Religionsunterrichts in Österreich als prägend.

\subsection{Begründung des konfessionellen Religionsunterrichts}

Fragt man nach der Konzeption und Begründung des Religionsunterrichts an der öffentlichen Schule nach dem 2. Vatikanischen Konzil, dann stößt man unwillkürlich auf den Text der Gemeinsamen Synode der Bistümer Deutschlands zum Religionsunterricht. ${ }^{25}$ Dieser Text ist nicht zuletzt auch in wichtigen Teilen in das Katecheti-

23 Hermann (2000), 66-68.

24 Von dem sich die Schüler(innen) in den ersten zehn Unterrichtstagen eines Schuljahres ab dem 14. Lebensjahr abmelden können; vorher obliegt die Abmeldemöglichkeit den Eltern. Für Schüler(innen), die nicht am Religionsunterricht teilnehmen, wurde in Österreich an manchen Schulen ein Ethikunterricht als Schulversuch eingerichtet. In den meisten Bundesländern Deutschlands gibt es den Ethikunterricht für die vom Religionsunterricht abgemeldeten oder nicht zum (konfessionellen) Religionsunterricht zugelassenen Schüler(innen) flächendeckend.

25 Gemeinsame Synode der Bistümer in der Bundesrepublik Deutschland (1979), 123-152. 
sche Direktorium für die Weltkirche ${ }^{26}$ eingegangen; damit wird in einem weltkirchlichen Dokument erstmals zwischen der Katechese (in der Gemeinde) und dem Religionsunterricht in der Schule klar unterschieden. ${ }^{27}$

\subsubsection{Die Begründung der Wür々̧burger Synode für den Religionsunterricht}

Um die umfangreichen Begründungen des konfessionellen Religionsunterrichts an öffentlichen Schulen im Text der Würzburger Synode zu verstehen, muss man auf die gesellschaftliche Situation am Beginn der 1970er-Jahre verweisen: Der konfessionelle Religionsunterricht an öffentlichen Schulen war plötzlich nicht mehr selbstverständlich. In dieser Hinsicht unterscheidet sich der gesellschaftliche Kontext des Synodentextes wesentlich von der gesellschaftlichen Situation, in der sich der islamische Religionsunterricht in Österreich heute vorfindet: Während der islamische Religionsunterricht als logische Folge des Rechts einer anerkannten Religion auf Religionsunterricht gesehen und gesellschaftlich im Hinblick auf eine mögliche integrierende Wirkung auf die Kinder und Jugendlichen öffentlich eher begrüßt wurde, kamen die christlichen Kirchen im Gefolge der sogenannten 68er-Bewegung unter einen enormen gesellschaftlichen Druck, den konfessionellen Religionsunterricht an der öffentlichen Schule zu legitimieren: Warum sollte nur Religionsgemeinschaften und nicht auch Weltanschauungen wie dem Marxismus ein Schulfach offen stehen? Wenn aber Letzteren keines zugestanden wird, warum dann den christlichen Kirchen?

Der Synodentext spiegelt den Legitimierungsdruck des Religionsunterrichts in einer offenen, pluralen Gesellschaft wider. Er begründet den katholischen Religionsunterricht - über seine rechtliche Verankerung im Konkordat hinaus - durch folgende Argumentationsstränge:

- Pädagogisch im Hinblick auf die europäische Kulturtradition, ihr Menschenbild, das die Religion einschließt und die gesell-

26 Allgemeines Direktorium für die Katechese (1997), 80-84.

27 Allerdings wurde der Synodentext im weltkirchlichen Direktorium auch verändert. Speziell im Hinblick auf die Nennung der verschiedenen „Typen“ von Schüler(inne)n im Religionsunterricht, der sich als gläubig verstehenden, der im Glauben angefochtenen und der sich im Moment als ungläubig verstehenden Schüler(innen), will die Synode den Letztgenannten zu einem begründeten Urteil verhelfen, während das katechetische Direktorium sie missionieren will. 
schaftliche Verankerung des Christentums trotz Säkularisierung als Realität zeigt.

- Theologisch, indem eine ,anthropologisch gewendete, gesellschaftsbezogene Theologie“ als fachwissenschaftliche Grundlage des Religionsunterrichts seinen Angebotscharakter für alle Schüler(innen) legitimiert.

\subsubsection{In weiteren kirchlichen Dokumenten binzukommende Tendenzen und Begründungen}

In weiteren kirchlichen Dokumenten wird vor allem der Dienstcharakter des Religionsunterrichts (diakonische Begründung) verstärkt: Religionsunterricht wird nicht mehr primär aus der Verkündigungsfunktion (Martyria) der Kirche heraus verstanden, sondern als Diakonie an allen Kindern und Jugendlichen, ganz gleich auf welchem Niveau der Glaubensüberzeugung sie sich befinden. Im Positionspapier der Deutschen Bischofskonferenz von $1996^{28}$ wird allerdings auch - gegenüber vielfachen Forderungen nach einem ökumenisch verantworteten Unterricht - die Konfessionalität des katholischen Religionsunterrichtes neuerlich unterstrichen. Die konfessionelle Eindeutigkeit bezieht sich nicht mehr auf die Schüler(innen), die vielfach kein Bewusstsein für die eigenen Konfession mehr haben; sie bezieht sich auf die eindeutige Beheimatung der Religionslehrer(innen) in einer konkreten Glaubensgemeinschaft mit ihren spezifischen Überzeugungen. Erst aus einer klaren Position heraus wäre ein echter Dialog mit anderen Überzeugungen möglich.

Gerade die konfessionelle bzw. religionsspezifische Eindeutigkeit wird angesichts der Gewaltproblematik der Schule und ihrer Möglichkeiten, gewaltpräventiv und Frieden fördernd $\mathrm{zu}$ handeln, vielfach angefragt. Wäre nicht ein überkonfessioneller oder gar interreligiöser Religionsunterricht geradezu dazu prädestiniert, die kaum noch bewussten Konflikte zwischen den Konfessionen und - mehr noch - die zwischen den Religionen und Kulturen konstruktiv, d.h. gewaltpräventiv und friedensstiftend zu bearbeiten? Um zu sehen, welche Möglichkeiten und Grenzen der katholische - also konfessionsgebundene - Religionsunterricht diesbezüglich hatte und hat, werden nun die wichtigsten Konzepte mit der Gewalt-/Friedensproblematik in Verbindung gebracht. 


\subsection{Konzepte des Religionsunterrichts an einer gewalttangierten Schule und deren Offenheit im Hinblick auf Gewaltminimierung und Friedenserziehung}

Die Entwicklung der Konzepte des katholischen Religionsunterrichts wird in der Religionspädagogik unterschiedlich gesehen und beschrieben. Ich akzentuiere hier zentrale Konzepte ${ }^{29}$ im Zusammenhang mit der Gewalt-/Friedensproblematik.

\subsection{1 „Friss Vogel, oder stirb!“- Das katechetische Konzept}

Das katechetische Konzept des Religionsunterrichts unterscheidet nicht zwischen dem Religionsunterricht an der Schule und der Katechese in der Gemeinde. Es rechnet mit gläubigen oder zumindest kirchennahen Kindern, Jugendlichen und Eltern. Aufgabe des Religionsunterrichts ist die methodisch-didaktisch möglichst lebendige und eindringliche Vermittlung des katholischen Glaubensgutes, das als ein über die Zeiten hin feststehender Wissensbestand betrachtet wird. Dazu gehören neben dem Glaubensbekenntnis, den Sakramenten und dem Dekalog Erzählungen aus dem Alten und Neuen Testament, welche die Glaubenswahrheiten deuten und illustrieren. Ziel dieses Religionsunterrichts ist die Kenntnis der katholischen Glaubenslehre und wenn möglich die Identifikation mit ihr. Der Fundamentaltheologe Jürgen Werbick spricht im Zusammenhang mit dem katechetischen Konzept des Religionsunterrichts von einer „Friss-Vogel-oder-stirb-Katechese“, der das Wichtigste in der Glaubenserschließung fehle, nämlich die „Leerstellen“, in die sich die Schüler(innen) in ihrem eigenen religiösen Suchprozess „hineinbuchstabieren" können. ${ }^{30}$ In der Diskussion mit Ednan Aslan auf der Klausurtagung der Forschungsplattform zeigten sich Parallelen in der Entwicklung des islamischen Religionsunterrichts mit dem katechetischen Konzept, insofern als - bei aller Vorsicht im Hinblick auf die grundsätzliche Vergleichbarkeit der beiden Religionen - der islamische Unterricht an der Moschee mit seiner Konzentration auf das Erlernen des Korans mit einem katechetischen Konzept in Verbindung gebracht werden könnte.

29 Die Konzepte sind nicht scharf voneinander abtrennbar; jede einzelne Religionsstunde ist derart komplex, dass sie in der Regel nicht auf ein einziges Konzept rückführbar ist. Eine Konzeptbeschreibung unterliegt demnach immer der Gefahr von Generalisierungen, die den empirisch feststellbaren Ablauf nur ungenügend „einfangen“ können.

30 Werbick (1989). 
Fragt man danach, wo im katechetischen Konzept ein möglicher Ort für die Gewalt-/Friedensthematik sein kann, dann wird man in die sogenannte „Sittenlehre“ verwiesen. Vor allem im Kontext des Tötungsverbots des Dekalogs werden die entsprechenden Fragen - klassisch im Frage-Antwort-Spiel des Merksatzkatechismus - abgehandelt. Die Vermittlungsfrage im Religionsunterricht ist in diesem Konzept noch völlig von der Inhaltsfrage getrennt: Autoritäre oder ideologisierende Vermittlungszusammenhänge werden nicht in ihrer theologischen Problematik erkannt. Insofern wird auch die geschlossene Form des Frage-Antwort-Spiels der Katechismusstruktur nicht kritisch aufgebrochen.

\subsection{2 „Dann haben sie ibn verkauft"-Das biblisch-kerygmatische Konzept}

Das biblisch-kerygmatische Konzept des Religionsunterrichts ersetzt die aus der neuscholastischen Systematik kommende Glaubenslehre durch das biblisch bezeugte Kerygma als Grundbotschaft des Glaubens. Insbesondere in der durch Albert Höfer und seine Schule begründeten Verbindung von biblisch-kerygmatischer und gestaltorientierter Katechese, wie sie über einige Jahrzehnte den österreichischen Religionsunterricht bestimmte, ${ }^{31}$ wird die Identifikation mit den biblischen Gestalten sehr wichtig. Im Zusammenhang mit Gewalt und Frieden sind gerade jene Gestalten aus dem Alten Testament von Bedeutung, die den Kindern die Identifikation mit widerstandsbereiten, aber nicht mit brutaler Gewalt handelnden biblischen Personen ermöglichen. Es fragt sich allerdings, inwieweit die - noch immer katechetisch verwendeten - biblischen Gestalten einer historischkritischen Exegese standhalten. Die Freundschaft zwischen David und Jonathan wird zu einer echten Bubenfreundschaft; die Auseinandersetzung zwischen Saul und David lässt David als jungen Helden erscheinen, der für die Sache Gottes und seines Volkes einen gerechten Kampf kämpft.

Inger Hermann berichtet in diesem Zusammenhang von Fabio, einem gewaltanfälligen Jungen, der ihn derart provoziert, dass er kurz davor steht, ihn zu schlagen. ${ }^{32}$ Am nächsten Tag fehlt Fabio.

31 Vgl. u.a. Höfer (1979).

32 „Trotzig, fast hasserfüllt, schaut er mich an. Einige Sekunden lang sind wir Feinde. ,Gott ist mit uns am Abend und am Morgen', denke ich. Höre in mir Fabios Frage: ,Stimmt das auch?' ,Ja', hatte ich geantwortet. ,Oh Gott', denke ich, ,dann sei auch jetzt hier. Ich bin kurz davor, ihn zu schlagen. Oder ich muss rauslaufen."“ Hermann (2000), 60. 
Die Nachfrage des Religionslehrers ergibt, dass ihn sein arbeitsloser Vater auf den Strich geschickt hat und er deshalb in ein Heim muss. Zum Abschluss seines Berichtes schreibt Inger Hermann: „Sein Heft liegt immer noch auf meinem Schreibtisch. Der letzte Satz darin: ,Joseph wurde verkauft. Das war sehr schlimm für ihn ..."“.33 Der Hefteintrag ist eindrucksvolles Beispiel einer biblischen Gestaltarbeit, die ihre berührende Dramatik in der Identifikation des vom Vater auf den Strich geschickten Buben mit dem ägyptischen Joseph gewinnt.

\subsubsection{Gewalt „unter der Bank", während das Friedenscurriculum läuft - Das curriculare Konzept}

Das biblisch-kerygmatische und gestaltorientierte Konzept wird zumindest in Österreich ${ }^{34}$ - in der Regel vom curricularen Religionsunterricht abgelöst. Das curriculare Konzept bedeutet einen völligen Bruch mit den katechetischen und biblisch-kerygmatischen Traditionen des Religionsunterrichts, die ihren primären Bezug in der Theologie haben. Die angloamerikanische Curriculumstheorie, die sich zunächst auf die Lehrplanentwicklung bezog, in der Folge aber alle Ebenen der Unterrichtsplanung und -durchführung mit einschloss, war ausschließlich erziehungswissenschaftlich-didaktisch ausgerichtet. Sie wurde terminologisch vom bereits erwähnten Text der Würzburger Synode rezipiert und damit - trotz ihrer nichttheologischen Herkunft - kirchenoffiziell. Erstmals konzentrierten sich Lehr- und Unterrichtspläne nicht mehr vorrangig auf die Inhalte des Religionsunterrichts, ob katechetisch oder biblisch-kerygmatisch begründet. Zum zentralen Leitbegriff wurde die Zielbestimmung. Alle möglichen Zielhierarchien, angefangen bei den Globalzielen bis zu den Feinzielen, die jeden einzelnen Unterrichtsschritt zielorientiert bestimmten, sollten den Religionsunterricht mit den anderen Unterrichtsfächern vergleichbar und vor allem evaluierbar machen. Im Idealfall eines geschlossenen Curriculums sollte es vor den individuellen Einflüssen des Lehrers „sichere“ Lernprogramme geben. Die Lernziele, die für jeden einzelnen Unterrichtsschritt, für die Unter-

33 Hermann (2000), 61.

34 Das religionskundlich-hermeneutische Konzept von Hubertus Halbfas, das in Deutschland weite Verbreitung fand, wurde in Österreich nur als Schulversuch durchgeführt. Die Schulbücher von Hubertus Halbfas kamen in Österreich nicht auf die reguläre Schulbuchliste. 
richtseinheit insgesamt, für einen Jahresplan, ja für den ganzen Bildungsplan zu formulieren und zu begründen waren, steuerten die durch den Unterricht erreichbaren Qualifikationen der Schüler(innen). Solche Lernzielhierarchien entstanden aus dem „curricularen Strang“, der die in umfangreichen Studien erhobene „Adressat(inn)ensituation", die gesellschaftliche Wirklichkeit und die neuesten Erkenntnissen der Fachwissenschaft Theologie miteinander zu vernetzen suchte.

Gewaltprävention und Friedenserziehung konnten im Religionsunterricht in spezifischen Lernprogrammen angezielt werden. Trotz ihrer klaren Zielorientierung sind insbesondere geschlossene Curricula in der Regel unfähig, auf die aktuellen Störungen des Unterrichts angemessen einzugehen, in denen sich die Konflikt- und Gewaltproblematik besonders häufig zeigt. Aus diesem Grund bildete sich bereits innerhalb der Curriculumstheorie der Begriff des hidden Curriculums heraus, der das - mitunter gewalttätige - Tun zwischen Schüler(inne)n ,unter der Bank“ ans Licht brachte; jenes gewaltsame Handeln, das sich möglicherweise gerade während einer Unterrichtseinheit abspielt, die Gewaltprävention und Friedenserziehung zum Ziel hat.

Durch die Vernetzung von jeweils aktuellen fachwissenschaftlichen Einsichten, der empirisch erhobenen Adressat(inn)ensituation und der gesellschaftlichen Wirklichkeit im curricularen Strang, könnten z.B. Einsichten der mimetischen Theorie oder der dramatischen Theologie mit der Gewaltsituation der Schüler(innen) heute und der gewaltanfälligen gesellschaftlichen Wirklichkeit so miteinander vernetzt werden, dass daraus entsprechende Lernziele formuliert und Lernprogramme entwickelt werden könnten. Gleichzeitig würde aber die interaktionell-kommunikative Blindheit des curricularen Unterrichts zeigen, wie wirkungslos ein solch zielorientiertes Handeln bleiben kann, ja wie es sich vom Lerneffekt her trotz edler Ziele geradezu ins Gegenteil verkehren kann, wenn das „versteckte“ Curriculum unbearbeitet bleibt.

Obwohl das curriculare Konzept bis heute auf weite Strecken den Unterricht in der Schule und inzwischen auch an der Universität dominiert und derzeit über die Festlegung von Bildungsstandards noch stringenter und klarer evaluierbar gemacht wird, gab und gibt es im Bereich des katholischen Religionsunterrichts immer mehr Bedenken gegenüber geschlossenen Lernzielkonzepten. Ein Bonmot, das Kardinal Döpfner zugeschrieben wird, gibt gut die kirchliche 
Skepsis gegenüber einem bis ins Detail plan- und evaluierbaren Unterrichtskonzept wieder, das noch dazu stark von angloamerikanischen Begriffen durchsetzt war. Döpfner soll bei einem Besuch im Deutschen Katechetenverein auf dem Höhepunkt der curricularen Euphorie einmal gesagt haben: „Immer wenn ich in den DKV komme und das Wort Curriculum höre, möchte ich eine Kniebeuge machen“. Das drückt mit leiser Ironie die Fremdheit gegenüber einem didaktischen Ansatz aus, der ausschließlich aus der Erziehungswissenschaft gekommen war und die didaktische Relevanz des christlichen Glaubens im Hinblick auf seine ihm eingeschriebene Kommunikationsgestalt außer Acht ließ.

\subsubsection{Wenn Leben und Glauben in Korrelation geraten}

Vor allem dem geschlossenen Curriculum gegenüber setzten sich in der Folge und bis heute wieder stärker aus der Theologie heraus begründete Konzepte des Religionsunterrichts durch, denen immer deutlicher die Bedeutung der Vermittlungswege und -formen für die inhaltliche Glaubwürdigkeit des schulischen Bildungsgeschehens bewusst wird. Das Problem der radikalen Freisetzung von Inhalt und Form im curricularen Unterricht wurde erkannt.

Das heute gängige Konzept des Religionsunterrichts, auf dem auch alle Lehrpläne seit den 1990er-Jahren basieren, kann mit dem Begriff eines korrelativen und symbolorientierten Konzeptes benannt werden. Anthropologisch gewendete Theologien wie die von Paul Tillich, Edward Schillebeeckx, Karl Rahner u.a., welche die menschliche Erfahrung ${ }^{35}$ als Brücke über den ,garstigen Graben“ zwischen der Offenbarungs- und Glaubenstradition einerseits und der Situation des Menschen andererseits ansahen, ${ }^{36}$ wurden auch für die Didaktik des Religionsunterrichtes maßgeblich. Das Symbol, letztlich das zentrale christliche Glaubenssymbol als Inkarnation Gottes in Jesus Christus, wurde als die zentrale Gestalt des Religionsunterrichts erkannt, an der man die untrennbare Zusammengehörigkeit von Botschaft und Situation, von Inhalt und Form erkennen kann. Was aber geschah und geschieht, wenn die Seite der Lebenserfahrungen der Schüler(innen) so sehr in der systemischen Gewalt gefangen ist, dass diese quasi alle Lebensbereiche bestimmt? 
Die Grenze des korrelativen Konzeptes scheint dort erreicht zu sein, wo es zwischen der Lebenssituation der Schüler(innen) und den biblischen und kirchlichen Erfahrungen, auf denen die christliche Botschaft beruht, nichts mehr zu korrelieren gibt. Wo, wie der bereits mehrmals zitierte Religionslehrer Inger Hermann berichtet, „das Aufschlitzen“ einem Jugendlichen den einzigen Spass bringt, den er haben kann.

\subsection{5 „Aufschlitzen, das bringt Spaß“- Das differenzhermeneutisch- kommunikative Konzept}

Wenn es scheinbar nichts mehr zu korrelieren gibt, weil das Leben derart durch Gewalt deformiert ist, dann ist die radikale Differenz zwischen Botschaft und Situation bittere Realität. Der/die Schüler(in) bleibt einer religiösen, ethischen bzw. aus dem Glauben geprägten Erfahrung gegenüber fremd. Korrelationsbedachten Religionslehrer(inne)n fällt es oft schwer, diese grundsätzliche Fremdheit zwischen den in den biblischen Texten und der christlichen Tradition verschrifteten Erfahrungen und den Erfahrungen mancher Kinder und Jugendlichen auch tatsächlich gelten zu lassen. Zu sehr sind sie auf das Gelingen des Vermittlungsgeschehens ausgerichtet. Doch diese wechselseitige Fremdheit, welche die Differenz und Fremdheit auf die anderen Menschen hin, ja sich selbst und seiner eigenen gewaltzerstörten Lebensgeschichte gegenüber inmitten eines zerstörten gesellschaftlichen Kontextes mit einschließt, zeigt sich in vielfachen symbolisch-dramatischen Formen eines scheinbar alles bestimmenden Lebensskripts, in dem es nur Unheil zu geben scheint. Die Massivität der Unheilserfahrung kann sich auf die Religionslehrer(innen) übertragen und ruft mitunter das eigene Bedürfnis hervor, Gewalt anzuwenden: ,'Oh Gott', denke ich, ,dann sei jetzt auch hier. Ich bin kurz davor, ihn zu schlagen. Oder ich muss rauslaufen" , 37 schreibt Inger Hermann in einem inneren Dialog.

Es bedarf wohl aller Glaubenskraft daran, dass Gott auch auf krummen Zeilen gerade schreiben kann und dass selbst in einem scheinbar nur von Unheil strotzenden Lebenstext eine andere Melodie mitspielen kann, die freilich im Moment der Gewalt wie abgetötet erscheint. Erst das körperliche Gespür für die radikale Andersheit und Fremdheit des Anderen im unmittelbaren Körperkontakt mit 
Ingo, dem Aufschlitzen den einzigen Spaß bereitet, eröffnet eine neue Erfahrung: Das täglich praktizierte Ritual des Lehrers, dem behäbigen Ingo die Hände aus den Hosentaschen zu nehmen, verändert die Situation zwischen den beiden. Dem gewaltanfälligen Schüler, der sich völlig gleichgültig gegenüber verbalen Ermahnungen zeigte, eigenhändig die Hände aus den Hosentaschen zu nehmen, erwies sich gerade deshalb als wirksam, weil es weder ein Patentrezept für ähnliche Situationen noch eine besondere didaktische Maßnahme darstellte. Vielmehr zeigt sich darin die authentische Differenzerfahrung einer sich selbst eingestandenen Hilflosigkeit und Ohnmacht des Religionslehrers. Die spontane Reaktion in der Ohnmacht wird für Ingo, ja für beide, für einen Moment zum Heilszeichen. Die kurze Heilserfahrung in der Interaktion mit dem Religionslehrer löscht die lange Gewalterfahrung nicht aus: Ingo „,jagt“ zwei alte Omas vor sich her und schlitzt mit sichtlichem Vergnügen dem Teddy eines kleinen Kindes den Bauch auf, nach dem Muster, wie sein geliebter Hase vom Vater massakriert und ihm als Essen vorgesetzt worden ist. Der Kreislauf solcher Gewalt darf nicht unbeachtet oder ängstlich übergangen werden. Grenzen, Abgrenzungen sind angezeigt. Es kommt zur Konfrontation, die nicht mehr pädagogisch gesteuert ist: „Du kannst deine Hände in den Taschen lassen. Es ist mir völlig egal. Wenn du sie dauernd zum Quälen brauchst ...". Eine gewagte, aber menschlich sehr verständliche Intervention des Religionslehrers; sie könnte zum Abbruch der Beziehung zu Ingo führen, aber auch einen neuen Kontakt an der Grenze ermöglichen. Friedensarbeit ist Arbeit an der Grenze, an einer Grenze, die heiß und gefährlich ist, insbesondere im geregelten schulischen Kontext. Liebe und Zuneigung sind an der konfliktiven Grenze zwischen Menschen ebenso zu Hause wie kalte Ablehnung. Wer sich an die Grenze heranwagt, wird verändert, so oder so. Im Beispiel von Ingo durch die finstere Trauer hindurch auf ein kleines Stück mehr Leben hin.

Damit wurde an einem konkreten Beispiel ein Konzept von Religionsunterricht deutlich, das theoretisch-generell schwer beschreibbar ist. Ein solches sowohl die Fremdheit und Andersheit von Schüler(inne)n und den Kontakt an klaren Grenzen annehmendes, gleichzeitig aber auch auf die Hoffnungsdimension des Glaubens hin offenes Kommunikationsgeschehen regrediert weder in das alte katechetische Konzept, das manche kirchlich Verantwortliche aus Frustration über die scheinbar nicht mehr gelingende Korrelation 
immer lauter fordern, noch verschweigt es verschämt die Glaubensdimension des Religionsunterrichts, die sich in Gewaltsituationen vor allem fruchtbar für eine konfliktoffene Kommunikation an der Grenze zeigt.

\section{Gewaltminderung und Friedensfähigkeit „lernen“ oder/und sich schenken lassen? - Eine abschließende Kriteriologie zu den Möglichkeiten und Grenzen des Religionsunterrichts an der Schule}

Wenn man mit erfahrenen Religionslehrer(inne)n über die Frage spricht, welchen Frieden der Religionsunterricht in der Schule schaffen könnte, dann kommt oft eine Dimension ins Spiel, die dem curricularen Konzept eines lernzielbestimmten Unterrichts oder auch dem Bemühen um Bildungsstandards für den Religionsunterricht völlig fremd ist: die Dimension des Geschenkes, die Dimension der Gnade. „Manchmal gibt es solche Situationen, wo du eigentlich nicht recht weißt wieso eigentlich, aber es stellt sich ein Friede in einer Klasse ein, der voller Leben ist", sagte mir unlängst ein Religionslehrer. Diese Aussage erinnert an die Kernhypothese dramatischer Theologie. „Ein tiefer, echter und dauerhafter Friede zwischen Menschen, der nicht auf Opferung Dritter aufgebaut ist und ohne Polarisierung auf Feinde auskommt, ist sehr schwer erreichbar, ja übersteigt menschliche Kräfte. Wenn er dennoch Wirklichkeit wird, ist dies ein klares Zeichen, dass Gott selber (der Hl. Geist) in den Menschen am Wirken ist." 38

Religionsunterricht, der für das Geschenk des Friedens offen ist, vollzieht sich im Tun und Lassen. Mit aller Vorsicht können im Anschluss an Karl E. Nipkow einige „Maßnahmen“ benannt werden, die friedensstiftend wirken können:

- Ganzheitlich wirkende Lernumgebung, Friedens(lern)-Kulturen, systematische Aufklärung der Kriegs-/Friedenszusammenhänge.

- „Menschliche Nähe als Risiko und Chance - das Gesicht des Anderen und kommunikative Kompetenzen“.39 
- Interkulturelles (und interreligiöses) Verstehen als „,verschärfende Anforderung der Friedenspädagogik“"40

Solche Aspekte und Maßnahmen sind mögliche günstige Bedingungen dafür, dass der Geist Gottes selbst in der Schule der westlichen Moderne und in deren Religionsunterricht gewaltpräventiv und friedensstiftend wirken kann.

Die besondere Herausforderung, die speziell die Rolle von (Religions)lehrer(inne)n in einer effizienzorientierten Schule tangiert, besteht aber im „Lassen“. Es hat im Gewalt- und Friedenskontext u.a. mit dem zu tun, was in der kommunikativen Theologie als „Dableiben, auch wenn nichts mehr geht" bezeichnet wird. Damit verbunden ist immer auch die Offenheit „für das, was geht", obwohl es nicht didaktisch herstellbar ist. Der katholische Religionsunterricht „schafft" also jenen Frieden in der Schule und um die Schule herum, den sich Religionslehrer(innen) und Schüler(innen) in gewaltpräventiven und friedensstiftenden Handlungen auch dann noch schenken lassen, wenn scheinbar oder tatsächlich nichts mehr geht.

\section{Literatur}

Bödefeld, Axel (2006): „... und du bist weg!“ Bullying in Schulklassen als Sündenbock-Mechanismus. Wien: LIT.

Dzierzbicka, Agnieszka/Schirlbauer, Anton, Hg. (2006): Pädagogisches Glossar der Gegenwart. Von Autonomie bis Wissensmanagement. Wien: Erhard Löcker GesmbH.

Freire, Paulo/Betto, Frei (1986): Schule, die Leben heißt. München: Kösel.

Freire, Paulo (1971): pädagogik der unterdrückten. bildung als praxis der freiheit. Stuttgart: Kreuz Verlag.

Gemeinsame Synode der Bistümer in der Bundesrepublik Deutschland (1979): Beschlüsse der Vollversammlung. Offizielle Gesamtausgabe I. FreiburgBasel-Wien: Herder, 123-152.

Gruber, Franz (2003): Das entzauberte Geschöpf. Konturen des christlichen Menschenbildes. Kevelaer: Verlagsgemeinschaft Topos plus.

Hentig, Hartmut von (2003): Die Schule neu denken. Eine Übung in praktischer Vernunft. München-Wien: Carl Hanser.

Hermann, Inger (2000): „Halt's Maul, jetzt kommt der Segen ... “. Kinder auf der Schattenseite des Lebens fragen nach Gott. Stuttgart: Calwer Verlag.

40 Nipkow (2007), 396. 
Höfer, Albert (1979): Die neuen Glaubensbücher, Einführung in die integrative Religionspädagogik 5.-8. Schulstufe. Graz-Wien: Styria.

Illich, Ivan (52003): Entschulung der Gesellschaft. Eine Streitschrift. München: C.H.Beck Verlag.

Kongregation für den Klerus (1997): Allgemeines Direktorium für die Katechese. Vatikanstadt: Liberia Editrice Vaticana.

Menze, Clemens (1970): „Bildung“, in: Speck, Josef/Wehle, Gerhard, Hg.: Handbuch pädagogischer Grundbegriffe. Band 1. München: Kösel, 134-184.

Nipkow, Karl Ernst (2007): Der schwere Weg zum Frieden. Geschichte und Theorie der Friedenspädagogik von Erasmus bis zur Gegenwart. Gütersloh: Gütersloher Verlagshaus.

Scharer, Matthias (1995): Begegnungen Raum geben. Kommunikatives Lernen in Gemeinde, Schule und Erwachsenenbildung. Mainz: Matthias Grünewald Verlag.

Scharer, Matthias (1997): „Wieviel Religion braucht die Schule? Zur gesellschaftlichen Plausibilität von Religions- und Ethikunterricht", in: ThPQ 145, 376-383.

Scharer, Matthias (1999): „Wie wird kirchliche Bildung marktgerecht oder: Welche Bildung macht den Markt gerecht? Communiotheologische Überlegungen zum kirchlichen Bildungsgeschehen", in: Hilberath, Bernd Jochen, Hg.: Communio - Ideal oder Zerrbild von Kommunikation, Freiburg-Basel-Wien: Herder, 235-242.

Schillebeeckx, Edward (1980): „Erfahrung und Glaube“, in: Böckle, Franz/Kaufmann, Franz Xaver/Rahner, Karl/Welte, Bernhard, Hg.: Christlicher Glaube in moderner Gesellschaft 25, Freiburg-Basel-Wien: Herder, 73-116.

Schwager, Raymund/Niewiadomski, Józef (2003): „Dramatische Theologie als Forschungsprogramm“, in: Schwager, Raymund/Niewiadomski, Józef, Hg.: Religion erzeugt Gewalt - Einspruch! Innsbrucker Forschungsprojekt, Religion - Gewalt - Kommunikation - Weltordnung'. Münster: LIT, 39-77.

Sekretariat der deutschen Bischofskonferent, Hg. (1996): Die bildende Kraft des Religionsunterrichts. Zur Konfessionalität des katholischen Religionsunterrichts.

Tillich, Paul (1987): Systematische Theologie. Band 1. Frankfurt/M.: de Gruyter, 9-80.

Werbick, Jürgen (1989): Glaubenlernen aus Erfahrung. Grundbegriffe einer Didaktike des Glaubens. München: Kösel.

Zimmermann, Maria (2007): „Österreich ist ein Rückzugsraum. Viele, denen es in Deutschland zu eng werde, kämen nach Österreich, sagt Islam-Experte Schmidinger. Interview mit Thomas Schmidinger", in: Salzburger Nachrichten, 18. September 2007, 3. 



\section{Die Autorinnen und Autoren}

Arnold Angenendt, Professor emeritus am Institut für Frühmittelalterforschung der Universität Münster; seit 2000 Mitglied des interdisziplinären DFG-Sonderforschungsbereiches „Symbolische Kommunikation und gesellschaftliche Wertsysteme vom Mittelalter bis zur französischen Revolution" an der Universität Münster und Leiter des darin angesiedelten Projektes „Liturgie im Mittelalter“. Forschungsschwerpunkte: Toleranz und Gewalt im Christentum, Liturgie und Frömmigkeit im Mittelalter.

Ednan Aslan, seit 2006 Professor für Islamische Religionspädagogik an der Fakultät für Philosophie und Bildungswissenschaft der Universität Wien; seit 2005 Arbeit als Fachinspektor für den islamischen Religionsunterricht an den Pflichtschulen in Wien. Forschungsschwerpunkte: Theorie der islamischen Erziehung in Europa, Islam in Europa, Migrantenkinder an den öffentlichen Schulen, Gewalt in der Erziehung.

Sibylle Auer, Studium der Politikwisssenschaft, 2007 Dissertation über „,Heiliges Land Tirol'? Enteignung, Zerstörung und Transformation von alten Stein-, Baum- und Quellkulten“. Mitarbeiterin der interfakultären Forschungsplattform „Weltordnung - Religion Gewalt" an der Universität Innsbruck. Forschungsschwerpunkt: Matriarchatsforschung.

Elisabeth Dörler, Leiterin des Werkes der Frohbotschaft Batschuns und Islambeauftragte der Diözese Feldkirch. Studium der Theologie, 2003 Dissertation über „Verständigung leben und lernen. Am Beispiel von türkischen Muslimen und Vorarlberger Christen“. Langjährige Aufenthalte in der Türkei, von 1996-2004 Gemeindeleiterin der christlichen St. Georgs-Gemeinde in Istanbul.

Werner W. Ernst, seit 1987 Professor für Politikwissenschaft an der Universität Innsbruck; seit 1997 Psychotherapeut und Psychoanalytiker in freier Praxis. Gründungsmitglied der Gesellschaft für Psychoanalyse und des Instituts für P.A. (Innsbruck). Mitarbeiter der interfakultären Forschungsplattform „Weltordnung - Religion - Gewalt" an der Universität Innsbruck. Forschungsschwerpunkte: sozialwissenschaftliche Theorien und politische Ideengeschichte, Religi- 
onspolitologie, Positivismus- und Systemkritik, (Denk-)Gewaltforschung, Setzungsanalyse und psychoanalytische Theoriebildung.

Hanna-Barbara Gerl-Falkovitz, seit 1993 Professorin für Religionsphilosophie und vergleichende Religionswissenschaft an der Technischen Universität Dresden. Vizepräsidentin der Edith-SteinGesellschaft Deutschland, Vizepräsidentin der Gertrud-von-Le-FortGesellschaft zur Förderung christlicher Literatur. Forschungsschwerpunkte: Religionsphilosophie des 19. und 20. Jahrhunderts, Religionsphilosophische Anthropologie der Geschlechter, Theologische Grundlegung der Neuzeit, Ethik der Weltreligionen.

Otto Kallscheuer, freier Politikwissenschaftler und Philosoph. Zahlreiche Gastdozenturen, u.a. an der Freien Universität Berlin, am Institute for Advanced Study der Princeton University, am Istituto Universitario Orientale in Neapel und am Institut für die Wissenschaften vom Menschen in Wien. Neben der wissenschaftlichen Tätigkeit auch als freier Publizist (u.a. bei der Frankfurter Allgemeinen Zeitung) und als Buchautor tätig.

Jürgen Manemann, seit 2004 Professor für Christliche Weltanschauung, Religions- und Kulturtheorie an der Katholisch-Theologischen Fakultät der Universität Erfurt. Mitglied im internationalen Komitee „Road to Responsibility in the Age of Shoah“ und Mitbegründer und Organisator des Ahauser Forums Politische Theologie. Forschungsschwerpunkte: Politische Theologie, Geschichte und Gedächtnis, Religion und Terror.

Andreas Oberprantacher, seit 2005 wissenschaftlicher Mitarbeiter am Institut für Philosophie der Universität Innsbruck. 2006 Dissertation über „Spiegel-Zeichen. Noten zum Denken des Selbstseins am Leitfaden des Mythos von Narziss." Mitarbeiter der interfakultären Forschungsplattform „Weltordnung - Religion - Gewalt“ an der Universität Innsbruck. Forschungsschwerpunkte: Sozialphilosophie, Politische Theorie, Friedens- und Konfliktforschung.

Wolfgang Palaver, seit 2002 Professor für Christliche Gesellschaftslehre am Institut für Systematische Theologie der Universität Innsbruck; seit 2006 Leiter der Arbeitsgemeinschaft „Politik - Religion - Gewalt" bei der Österreichischen Forschungsgemeinschaft; seit 2007 Leiter der interfakultären Forschungsplattform „Weltord- 
nung - Religion - Gewalt“ an der Universität Innsbruck sowie Präsident der internationalen wissenschaftlichen Gesellschaft „Colloquium on Violence and Religion“. Forschungsschwerpunkte: die mimetische Theorie René Girards, Thomas Hobbes, Carl Schmitt, Friedens- und Konfliktforschung.

Karl Prenner, seit 1997 Professor für Islamwissenschaft mit Schwerpunkt Koranforschung am Institut für Religionswissenschaft der Universität Graz; seit 2001 Vizepräsident der Österreichischen Gesellschaft für Religionswissenschaft. Forschungsschwerpunkte: Modernediskurs in den islamischen Gesellschaften, Europa und Islam, vergleichende Aspekte der drei monotheistischen Religionen.

Matthias Scharer, seit 1996 Professor für Katechetik und Religionspädagogik am Institut für Praktische Theologie der Universität Innsbruck; seit 1993 Lehrbefähigung in der Themenzentrierten Interaktion. Leiter der Forschungsgruppe „Kommunikative Theolo-

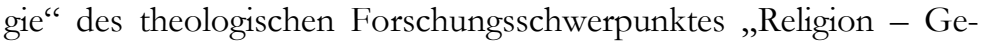
walt - Kommunikation - Weltordnung“ und Mitarbeiter der interfakultären Forschungsplattform „Weltordnung - Religion - Gewalt“ an der Universität Innsbruck. Forschungsschwerpunkte: Themenzentrierte Interaktion nach Ruth Cohn, Kommunikative Theologie.

Thomas Scheffler, seit 2007 DAAD-Langzeit-Gastprofessor am Institut für Politikwissenschaft der Université Saint-Joseph in Beirut; seit 2000 Forschungsmitarbeiter am Institut für Politikwissenschaft der Universität Berlin. Forschungsschwerpunkte: Studien zum Nahen und Mittleren Osten, Terrorismusforschung, Einfluss der Religion auf Gewalt- und Friedensdynamiken (speziell Christentum und Islam).

Roman A. Siebenrock, seit 2006 Professor für Dogmatik am Institut für Systematische Theologie der Universität Innsbruck; seit 2006 auch Leiter des theologischen Forschungsschwerpunktes „Religion Gewalt - Kommunikation - Weltordnung“ und Mitarbeiter der interfakultären Forschungsplattform „Weltordnung - Religion - Gewalt" an der Universität Innsbruck. Forschungsschwerpunkte: John Henry Newman, Karl Rahner, Zweites Vatikanisches Konzil, Theologie des Martyriums. 



Die Publikationsreihe Edition Weltordnung - Religion - Gewalt ist der interdisziplinären Auseinandersetzung mit der politisch wichtigen Frage des Verhältnisses von Religion und Gewalt angesichts einer sich globalisierenden Welt verpflichtet. Die Autor(inn)en teilen einerseits den Anspruch, Stellung zu den drängenden sozialen und politischen Problematiken der Gegenwart zu beziehen, insbesondere zu der Frage nach einem friedlichen Zusammenleben in einem religiös und weltanschaulich pluralen Europa, und versuchen andererseits diese Fragen in ihrem historischen Entstehungskontext zu verstehen.

Band 1 versammelt Analysen und Kontroversen zum Thema Religion und Gewalt in Hinblick auf die Herausforderungen, die durch technologische Entwicklungen, wirtschaftliche Globalisierung und zivilisatorischen Wandel entstehen. Mit Beiträgen von Aleida Assmann, Jörg Becker, Mariano Delgado, Wolfgang Dietrich, Jean-Pierre Dupuy, Andreas Exenberger, Wilhelm Guggenberger, Simon Hartmann, Hartmann Hinterhuber, Rüdiger Lohlker, Wolfgang Palaver, Robert Rebitsch, Willibald Sandler, Raymund Schwa-

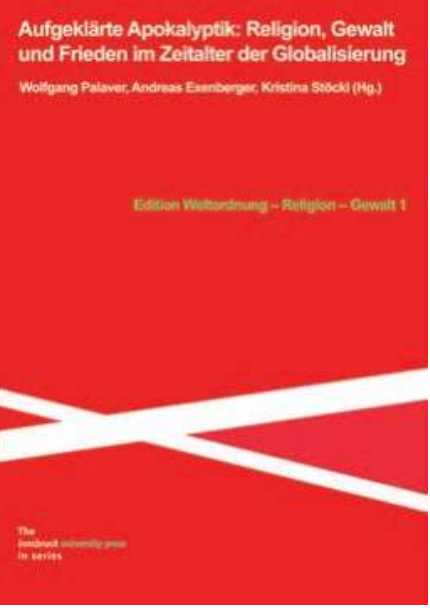
ger, Roman Siebenrock, Petra Steinmair-Pösel, Kristina Stöckl und Claudia von Werlhof. 
